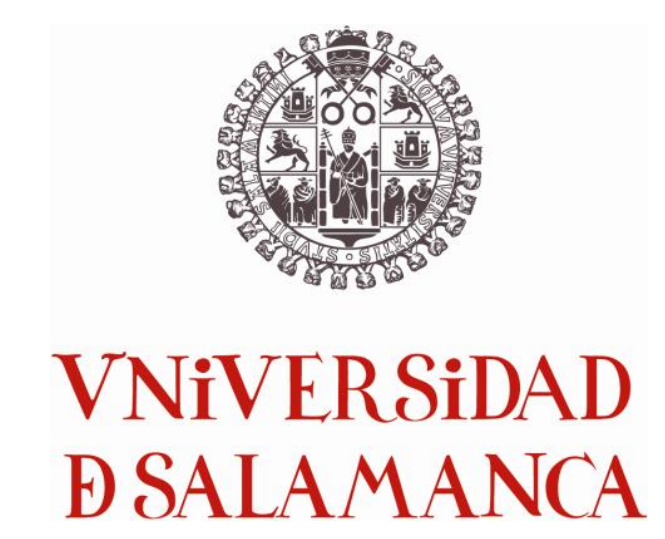

FACULTAD DE FARMACIA

DEPARTAMENTO DE QUÍMICA ANALÍTICA, NUTRICIÓN Y BROMATOLOGÍA

\title{
ÁCIDO LINOLEICO CONJUGADO EN LECHE DE OVEJA Y PRODUCTOS DERIVADOS: PRESENCIA E INFLUENCIA DEL PROCESO TECNOLÓGICO
}

José Luis Rodríguez Castañedas 



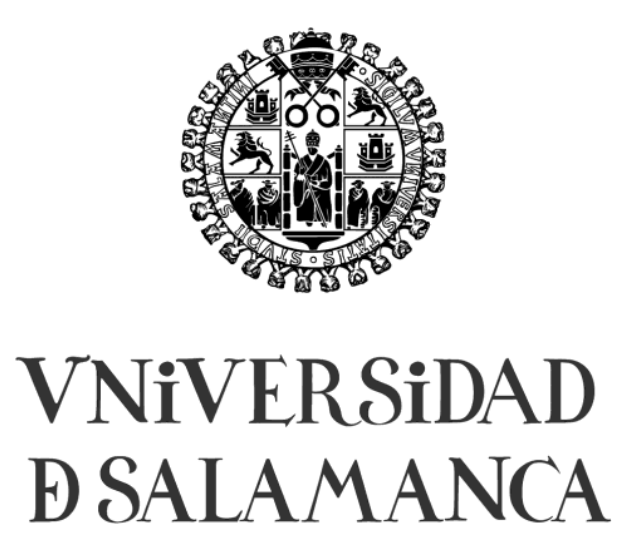

FACULTAD DE FARMACIA

DEPARTAMENTO DE QUÍMICA ANALÍTICA, NUTRICIÓN Y BROMATOLOGÍA

\author{
ÁCIDO LINOLEICO CONJUGADO EN LECHE DE \\ OVEJA Y PRODUCTOS DERIVADOS: PRESENCIA E \\ INFLUENCIA DEL PROCESO TECNOLÓGICO
}

TESIS DOCTORAL

MEMORIA PRESENTADA POR JOSÉ LUIS RODRÍGUEZ CASTAÑEDAS PARA OPTAR AL TÍTULO DE DOCTOR

BAJO LA DIRECCIÓN DE LAS DOCTORAS

MARÍA CONCEPCIÓN GARCÍA MORENO Y MARÍA JESÚS PEÑA EGIDO 

M. ${ }^{a}$ Concepción García Moreno y M. ${ }^{a}$ Jesús Peña Egido, Profesoras Titulares de Nutrición y Bromatología de la Universidad de Salamanca y directoras del trabajo “Ácido Linoleico Conjugado en Leche de Oveja y Productos Derivados: Presencia e Influencia del Proceso Tecnológico", realizado por José Luis Rodríguez Castañedas para optar al título de Doctor,

\section{AUTORIZAN}

La presentación del mismo, al considerar que se han alcanzado los objetivos inicialmente previstos. 

Para la realización de este trabajo, se ha contado con los siguientes apoyos institucionales:

- Beca de Tercer Ciclo y Doctorado del Grupo Santander - Universidad de Salamanca (Período 2005 - 2008).

- Proyecto de Investigación de la Junta de Castilla y León: “Ácido Linoleico Conjugado: Método de Análisis de los Diferentes Isómeros. Presencia en Leche de Oveja y Productos Derivados" (Ref. SA099A07).

- Leche Gaza, S.L. (Zamora) ha colaborado suministrando las muestras y con asesoramiento técnico. 

Cuando vayan mal las cosas, como a veces suelen ir; Cuando tenga tu camino solo cuestas que subir; Cuando tengas poco haber, pero mucho que pagar Y precises sonreir, aun teniendo que llorar. Cuando el dolor te agobie y no puedas ya sufrir, Descansar acaso debas... ;Pero nunca desistir!

Tras las sombras de la duda, ya planteada, ya sombría; Puede estar quizás el triunfo, no el fracaso que temías,

$Y$ no es dable a tu ignorancia figurarte cuan cercano Puede estar el bien que anhelas y que juzgas tan lejano.

Lucha pues por más que tengas en la brega que sufrir, Cuando este peor todo, ¡más debemos insistir! Anónimo 

A mi madre,

A mis hermanos y sobrinos,

Y en especial a ti Edu 



\section{AGRADECIMIENTOS}

Me parece increíble que ya haya llegado este momento, pero a pesar de los obstáculos encontrados y del tiempo invertido en este trabajo, tengo una gran satisfacción por haber culminado esta etapa. Ya no quiero mirar atrás, más bien quiero que este logro me motive a seguir adelante, con nuevos proyectos y nuevos objetivos.

Nada en este mundo llega a tus manos de manera fácil, o al menos, en mi caso, muchas veces así ha sido; aunque me siento afortunado, porque siempre he tenido buenas personas a mi lado, todas ellas dispuestas a hacer todo lo que estuviera a su alcance para guiarme por el sendero correcto. Es de bien nacido ser agradecido, y por eso, este pequeño espacio lo he querido reservar para agradecer a todos aquellos que, directa o indirectamente, han mostrado su apoyo incondicional durante el desarrollo y culminación de este trabajo:

A Dios, por guiarme por el buen camino y por darme la oportunidad de conocer a todas aquellas personas que de una u otra forma contribuyeron en mi esfuerzo por llevar a feliz término este trabajo. Por darme la paciencia necesaria cuando más la necesité, por darme la moral y la fuerza de voluntad para seguir adelante sin flaquear, por proteger a los míos desde el "otro lado del charco" durante esta larga ausencia y por ser el que ha llevado la rienda de mi camino y mi felicidad a un buen término.

A las Dras. Concepción García Moreno y María Jesús Peña Egido, Profesoras Titulares de la Universidad de Salamanca, por guiarme de forma ejemplar durante la realización de este trabajo, ya que gracias a su esmero, interés, disponibilidad y buenos consejos, ha sido posible culminarlo con éxito. Os agradezco de todo corazón el interés y toda la ayuda incondicional que día a día mostrasteis para que pudiera llevar por buen camino este trabajo. A ti Mariaje, por aportar a la tesis tu amplio y envidiable conocimiento sobre el CLA, y por tener la paciencia de corregir con acertado criterio este trabajo. Y a ti Concha, porque creíste en mi y porque no me abandonaste en ningún momento, a pesar de los obstáculos y los contratiempos que nos fuimos encontrando. Siempre estuviste dispuesta a sacar esto adelante. ;Y siempre con una sonrisa y buen talante! Me aportaste mucho como directora y como persona, por eso me siento afortunado de haberte tenido como directora de mi tesis. Gracias y mil veces gracias, siempre te tendré presente en mis pensamientos.

A LECHE GAZA y a su Director Gerente Don José Luis Calvo Rosón, por el suministro de muestras y por el asesoramiento técnico y tecnológico necesario. También agradecer a aquellas personas de la empresa que pusieron de su parte para hacernos llegar las muestras, desde María Jesús Devesa hasta los repartidores y mensajeros. Agradezco también toda la colaboración relacionada con la estadística, prestada por parte del Profesor Francisco Javier Martín Vallejo.

A todos los profesores que forman parte del Departamento de Química Analítica, Nutrición y Bromatología de la Universidad de Salamanca. A los profesores: Pilar Aparicio, Milagros Delgado, Maite Escribano, César García, Rafael García, Alfonso Gómez, Ana González, Yolanda Gutiérrez, Julián Rivas y Celestino Santos. Gracias por sus constantes ánimos, buenos consejos, amabilidad, interés y disposición cuando lo necesité.

A María José Sierra Cuadrado, pues para mi fuiste más que una administrativa del departamento, has sido y eres el hombro a quien todos terminamos llorando nuestras penas. ¡Y poco te lo agradecemos! Me siento agradecido por tus ánimos y preocupación en algunos momentos de flaqueza, y por tu disposición durante la edición de este trabajo. A ti también José Joaquín, ya que en más de una vez me sacaste de varios apuros en las cuestiones relacionadas con el laboratorio. También deseo que te recuperes pronto de esas lesiones que, por fortuna, quedó en un susto. 
A los que permanecen en el departamento (Cristina y David, José Miguel, Laura, Mati, Montse, Nacho, Natalia, Raúl, Rebeca, Susana); a los que han pasado o siguen pasando por él (Ana Lucya, Andrea, Enrique, Farid, Felipe, Francesco, Giulia, Glenda, Hugo, Ivania, Jorge, José Miguel, Juanjo, Katrin, Leticia, María García, María Vilani, María José, Quique, Romina, Simone, Valentina...) y a alguno más que se me pueda escapar. Gracias a todos por todo vuestro cariño, por cada instante de conversación, por hacer que mi estancia en el Departamento fuera cada día más agradable. Un especial agradecimiento a mi compañera y amiga Mati, pues no sólo fuiste la que me llevó de la mano en mis inicios en el laboratorio, sino también porque en los últimos meses fuiste de gran ayuda durante la edición de este trabajo.

A todos mis buenos amigos en España, son tantos que no cabrían en pocas líneas... pero si en mi corazón, ya que cada día os preocupáis por mí y por mi bienestar en este país que tanto quiero. A Alejandro, Alessandro, Ana, Ángela, Antonio, Arturo y José María, Carmen y Julián, Carmen y Roberto, Carmencita, Cris G., Darío, David G., David y Olli, Elena, Fátima y Nacho, Isabel, Jorge, Lola y Jesús, Mamen, Manolo, Mar, María y Sergio, Marta, Pamela, Paulo, Ramón, Ricardo, Tere y Vane... Y alguno más, seguro... También quiero agradecer a todos los que no han dudado en acompañarme durante la defensa de este trabajo, muchas gracias por vuestro cariño y ánimo en un día tan importante.

A todos los compañeros de pachanga en los partidillos semanales de "fumbol sala" en Salas Bajas, espero que sigamos prolongando en el tiempo estos momentos de esparcimiento, sin importar que haga frío, calor, o que alguno por ahí diga "voy si no llueve".

A mis padres, Bernardina y José Ángel, porque su amor atraviesa los océanos y la distancia para inspirarme a seguir adelante. A mis hermanos: Eniseth, René, María Isabel, Benigno, Héctor y Florencio. A mis abuelos, tíos, primos y a todos mis sobrinos: Yasimar, Lewis, Aiskel, Raiza, Armani, Yamal, Ameth, Ernesto, Jeremy... ¡y a los que vengan después!

A mis amigos de Panamá... Gracias a todos, por estar pendientes de mí día a día y por enviar desde tan lejos todo el cariño y los buenos deseos para esta nueva etapa de mi vida aquí en España. A Digmar, Mayumi, Dayana y Tomás, Carlos, Gerardo, Sixta, Iván, Ricky, Rocko, Ruth, Anay y Olmedo, Dayán, Segundo.

A ti, querido Eduardo, pues eres el que has vivido en primera persona todas mis tristezas y alegrías. El que me anima cuando me ves sin ganas, el que llora de alegría por mis logros, el que ríe mis payasadas, el que soporta mis necedades... el que me da fuerzas para seguir adelante. Gracias por estar conmigo en los momentos buenos y no tan buenos; por animarme cuando me veías sin ganas, por “aguantar” todos estos años nuestro sacrificio, por darme fuerzas para seguir adelante. Por ser más que un compañero sentimental. Por transmitirme seguridad y tranquilidad siempre... Se que cada paso que has dado en tu vida, lo has hecho teniendo presente a este negrito que te quiere iy te querrá siempre!

A todos vosotros... Y a ti que te has interesado en leerlo...; GRACIAS! 


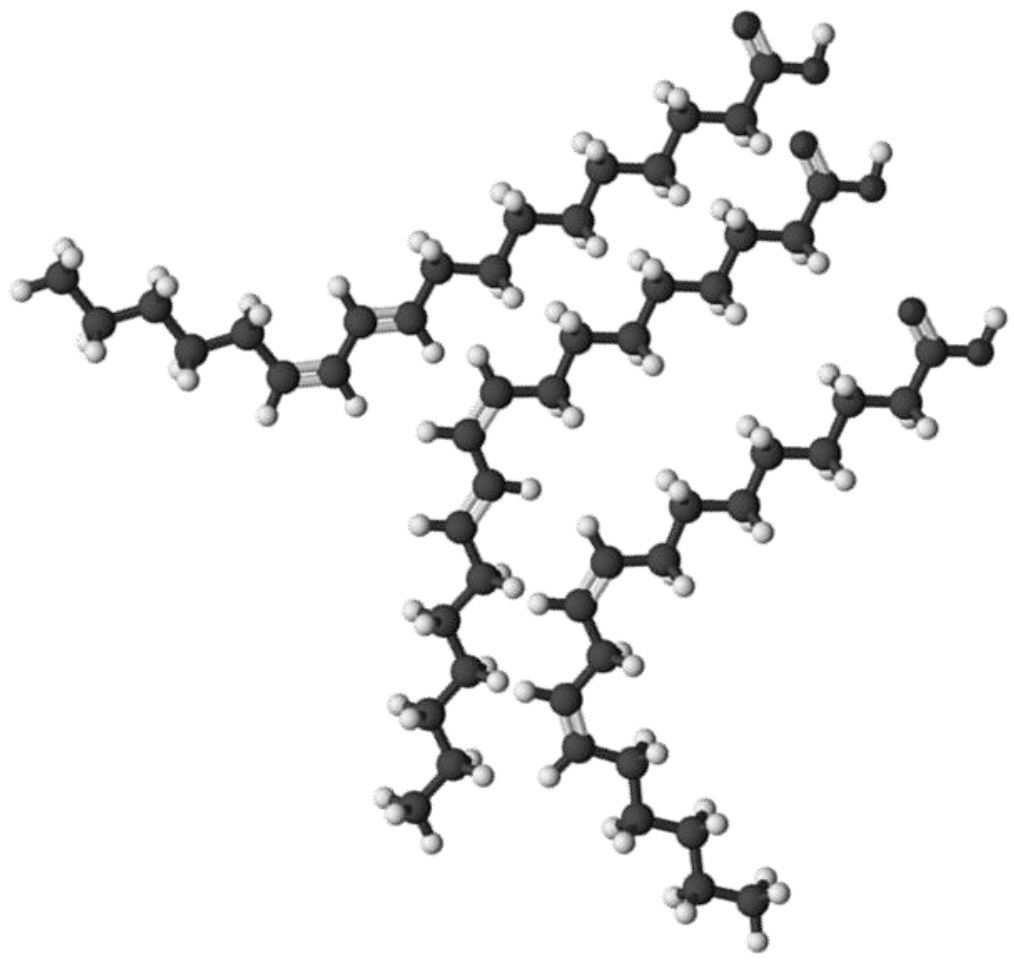

ÍNDICE Y ABREVIATURAS 



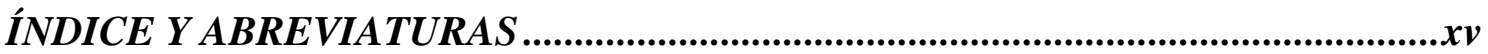

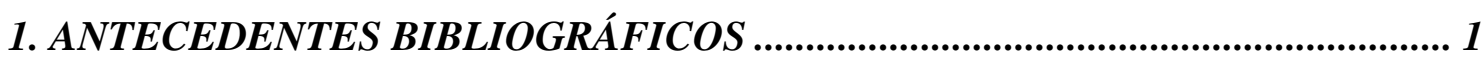

1.1. Aspectos generales y nutricionales sobre la leche de oveja ............................................ 3

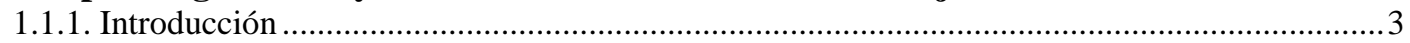

1.1.2. Composición y propiedades de la leche de oveja .......................................................................

1.1.2.1. Importancia de las proteínas en la leche de oveja ........................................................5

1.1.2.2. Valor nutricional de la grasa láctea ................................................................................ 7

1.1.2.3. Interés nutricional de otros componentes presentes en la leche de oveja .........................9

1.1.3. Factores que condicionan la composición de la leche de oveja ............................................... 12

1.1.3.1. Factores relacionados con el animal ......................................................................... 12

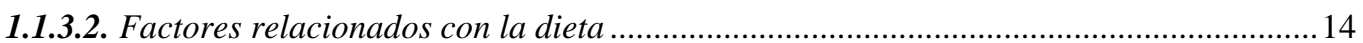

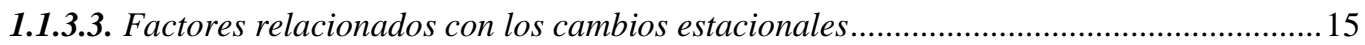

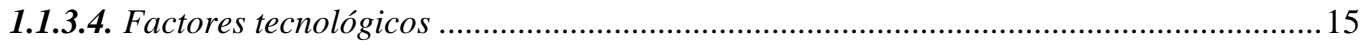

1.2. Ácido Linoleico Conjugado (CLA) ......................................................................16

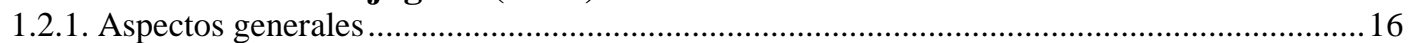

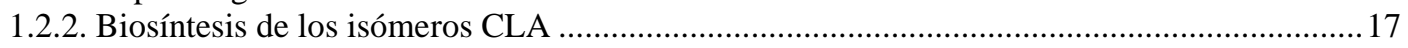

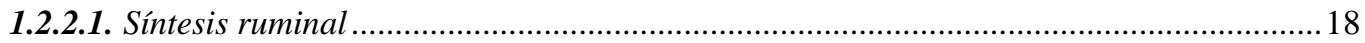

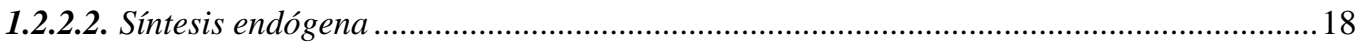

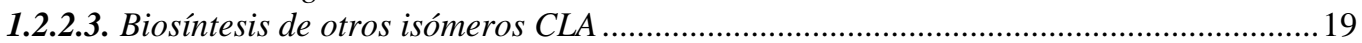

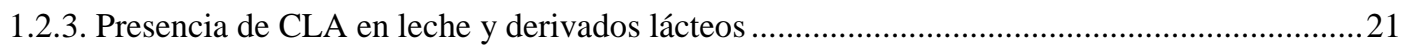

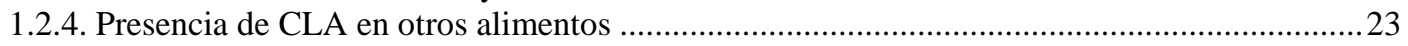

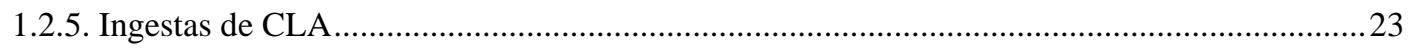

1.3. Factores que condicionan el contenido de CLA en la leche y derivados lácteos ...... 25

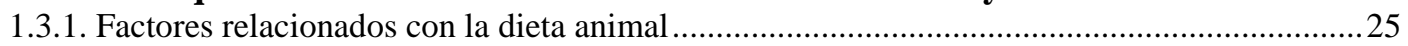

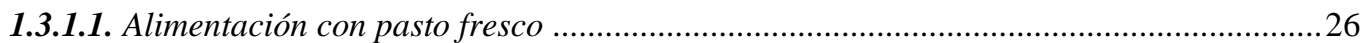

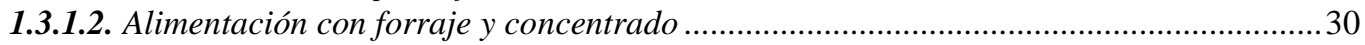

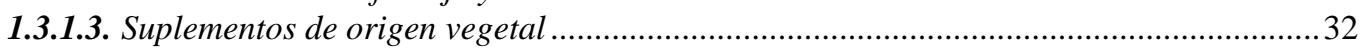

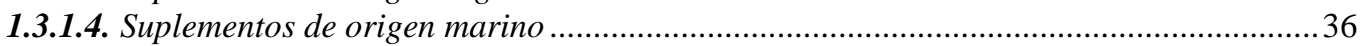

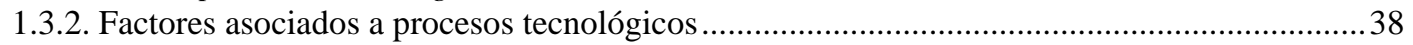

1.3.3. Otros factores relacionados con el propio animal .................................................................42

1.4. Aspectos funcionales del CLA..............................................................................4 44

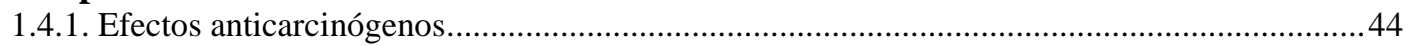

1.4.2. Efectos en el peso y la composición corporal ....................................................................4

1.4.3. Efectos sobre los factores relacionados con el desarrollo de diabetes tipo 2 y enfermedades

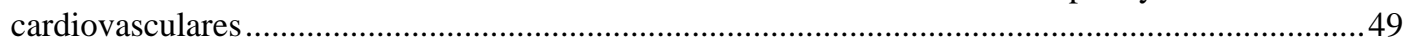

1.4.3.1. Efectos sobre la sensibilidad a la insulina y homeostasis de glucosa .............................50

1.4.3.2. Efectos en lípidos plasmáticos .....................................................................................51

1.4.3.3. Efectos sobre la peroxidación lipídica ……………………………………….............51

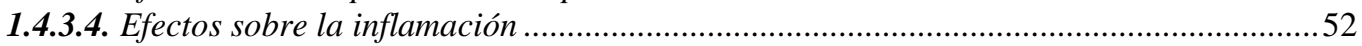

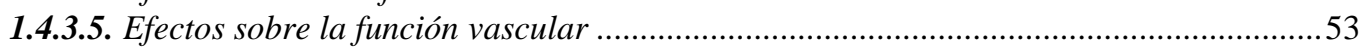

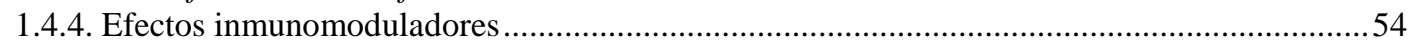

1.5. Análisis de CLA en lácteos ...................................................................................................... 57

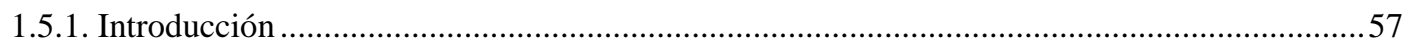

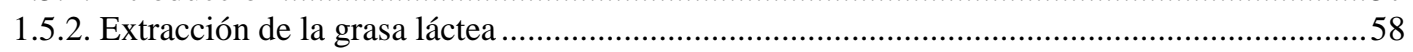

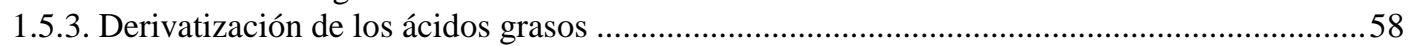

1.5.4. Técnicas de fraccionamiento para el análisis de CLA ...........................................................61

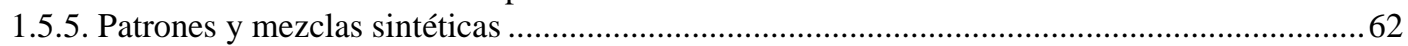

1.5.6. $\mathrm{Ag}^{+}$-HPLC: Aplicación a la determinación de CLA en lácteos ..............................................62

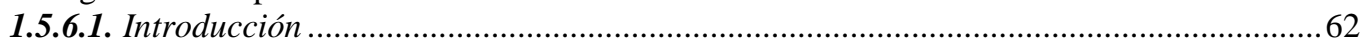

1.5.6.2. Condiciones analíticas utilizadas en la cromatografía $\mathrm{Ag}^{+}-H P L C$...........................................

1.5.6.3. Orden de elución de los isómeros CLA por $\mathrm{Ag}^{+}$-HPLC ..............................................65

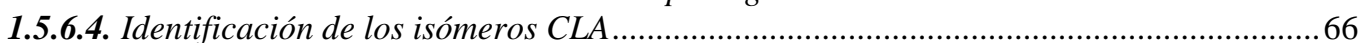

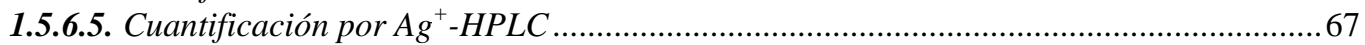

1.5.6.6. $\mathrm{Ag}^{+}$-HPLC como técnica complementaria de la cromatografía de gases .........................68 


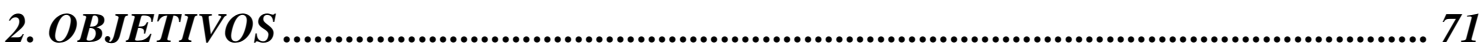

3. PUESTA A PUNTO Y VALIDACIÓN DEL MÉTODO DE ANÁLISIS ................ 77

3.1. Método de análisis................................................................................................................. 79

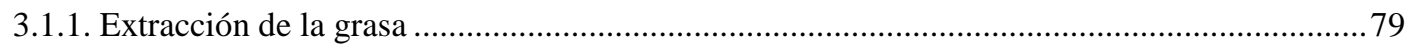

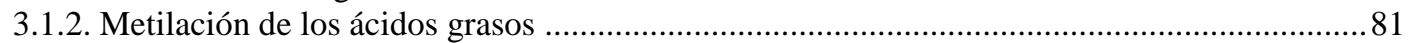

3.1.3. Determinación de CLA por $\mathrm{Ag}^{+}-\mathrm{HPLC}$ con detector de diodos .............................................82

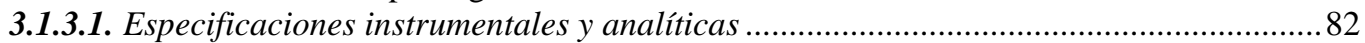

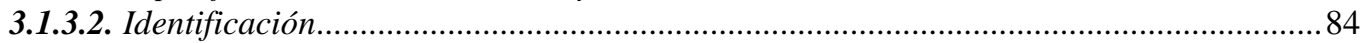

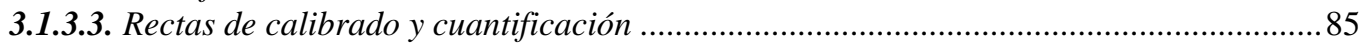

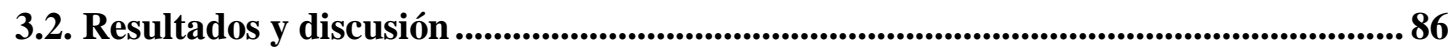

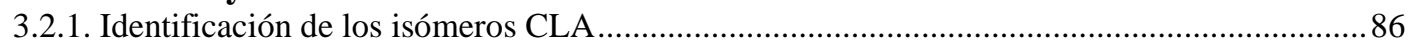

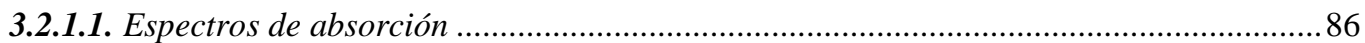

3.2.1.2. Identificación mediante la co-inyección de una mezcla sintética de CLA........................88 88

3.2.1.3. Identificación a través de los volúmenes de retención relativos $(R R V)$..........................90

3.2.1.4. Comentarios respecto a la resolución cromatográfica de los isómeros CLA ...................91

3.2.1.5. Observaciones sobre los cromatogramas registrados a 205 y $268 \mathrm{~nm}$............................99

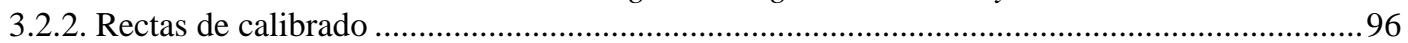

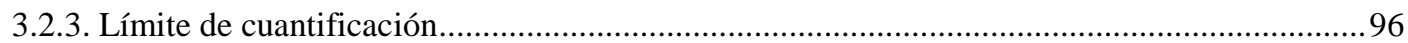

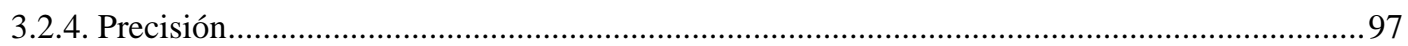

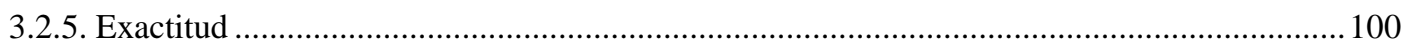

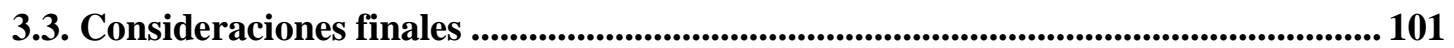

4. ISÓMEROS CLA EN LECHE DE OVEJA PARCIALMENTE DESNATADA Y

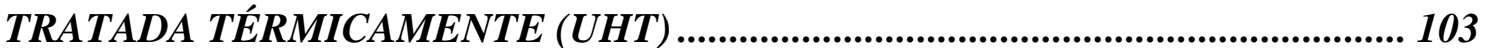

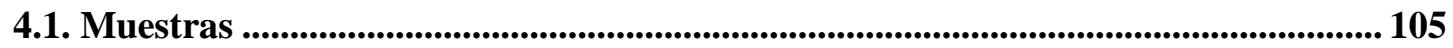

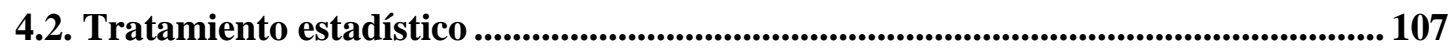

4.3. Resultados y discusión ..................................................................................................107

4.3.1. Influencia del procesado y del almacenamiento .............................................................. 110

4.3.1.1. Efecto del procesado y el almacenamiento en el contenido de CLA total .....................111

4.3.1.2. Efecto del procesado y el almacenamiento en los isómeros individuales ......................112

4.3.2. Contenido de CLA total y variación estacional ...............................................................114

4.3.3. Contenido individual de los isómeros CLA y variación estacional ..........................................119

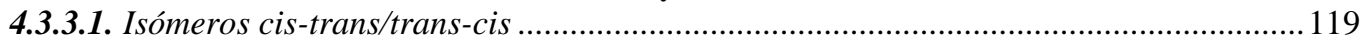

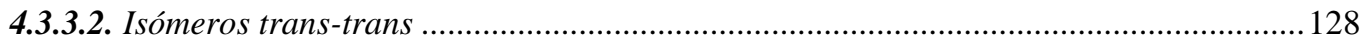

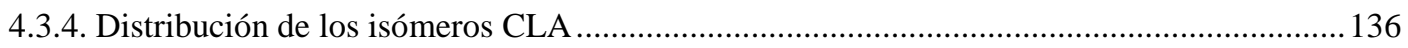

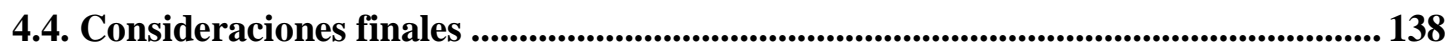

5. ISÓMEROS CLA EN CUAJADAS Y YOGURES ELABORADOS CON LECHE

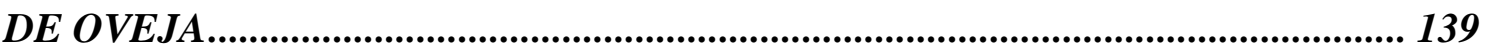

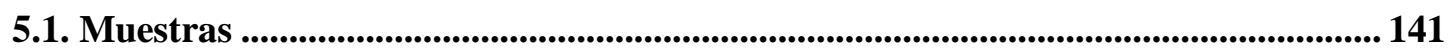

5.2. Tratamiento estadístico ......................................................................................................... 142

5.3. Resultados y discusión .............................................................................................................. 142

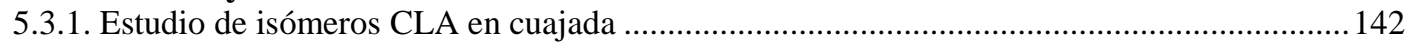

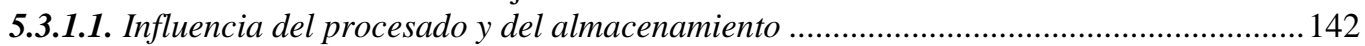

5.3.1.2. Contenido y variación estacional del CLA total e isómeros individuales .......................146

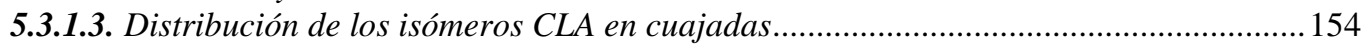

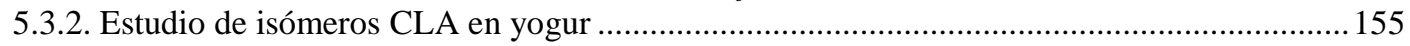

5.3.2.1. Contenido y variación del CLA total e isómeros individuales ........................................156

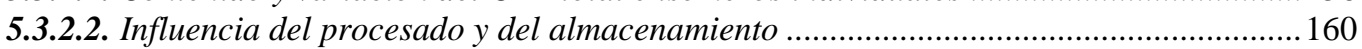

5.3.2.3. Distribución de los isómeros CLA en yogures ........................................................... 162

5.4. Consideraciones finales ................................................................................................. 163 


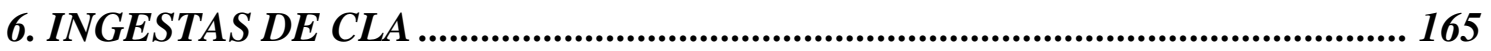

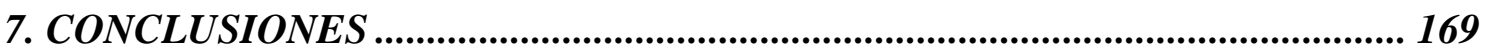

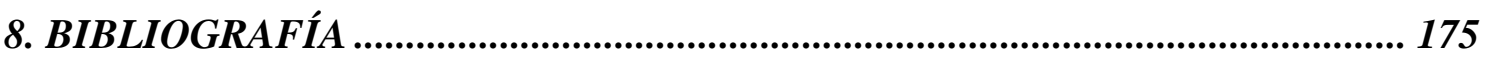

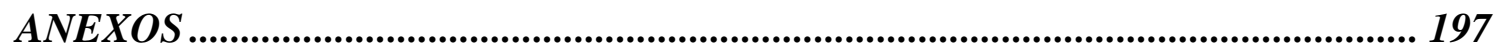

Anexo 1: Cálculo de factores de conversión de unidades ................................................... 199

Anexo 2: Familia, nombre científico y nombre común de algunas plantas utilizadas como pasto en la alimentación animal ................................................................................ 203

Anexo 3: Publicaciones......................................................................................................................... 204 

AG: Ácido (s) graso (s).

$\mathbf{A g}^{+}$-HPLC: Cromatografía líquida de alta resolución con intercambiador de iones plata.

$\mathbf{A g}^{+}$-TLC: Cromatografía en capa fina con intercambiador de iones plata.

$\mathbf{A g}^{+}$-SPE: Extracción en fase sólida con intercambiador de iones plata.

AOAC: Association of Analytical Communities.

APCI: Ionización química a presión atmosférica.

APPI: Fotoionización a presión atmosférica.

BCR-163: Material de referencia (grasa de carne porcina).

CDR: Cantidad diaria recomendada.

CI-MS/MS: Espectrometría de masas en tándem con ionización química.

CLA: Ácido linoleico conjugado.

DAD: Detector de diodos.

DC: Dieta control (ver también TMR).

DHA: Ácido docosahexaenoico.

DMOX: Dimetiloxazolina y derivados.

DR: Registro dietético.

EFSA: European Food Safety Authority.

EPA: Ácido eicosapentaenoico.

FAME: Éster metílico de ácido graso.

FAO: Organización de las Naciones Unidas para la Agricultura y la Alimentación.

FAOSTAT: Base de datos estadísticos de la FAO.

FD: Dieta duplicada.

FDA: Food and Drug Administration.

FFQ: Cuestionario de frecuencia de alimentos.

FID: Detector de ionización de llama.

FTIR: Espectroscopía infrarroja con transformada de Fourier.

FT-Raman: Espectroscopía Raman con transformada de Fourier.

GAZA: Ganaderos de Zamora.

GC: Cromatografía de gases.

GRAS: Sustancia "Generalmente Reconocida como Segura".

HDL: Lipoproteínas de alta densidad.

HOMA-IR: Homeostatic Model Assessment - Insulin Resistance.

HORRAT: "Horwitz ratio" o relación entre desviaciones estándar relativas.

HTST: Pasteurización a alta temperatura y corto tiempo.

ICAM: Molécula de adhesión intercelular.

ICP-AES: Espectrometría de Emisión Atómica con Plasma Acoplado Inductivamente.

IDF: Federación Internacional de Lechería.

IG-(A, E, M): Inmunoglobulina (A, E, M). 
IL-(1ß, 6, 10): Interleucina $(1 \beta, 6,10)$.

ISO: Organización Internacional para la Estandarización.

LDL: Lipoproteínas de baja densidad.

LOQ: Límite de cuantificación.

MS: Espectrometría de masas.

MTAD: 4-metil-1,2,4-triazolina-3,5-diona y derivados.

NAS: National Academy of Sciences.

NDA: Panel de Alergias, Nutrición y Productos Dietéticos.

OMS: Organización Mundial de la Salud.

PCR: Proteína C Reactiva.

PUFA: Ácido graso poliinsaturado.

RA: Ácido ruménico (cis-9,trans-11 $\mathrm{C}_{18: 2}$ ).

RMN ( ${ }^{1} \mathbf{H}-,{ }^{13} \mathbf{C}$-): Resonancia magnética nuclear (protónica, carbono 13).

RP-HPLC: Cromatografía líquida de alta resolución en fase reversa.

RRV: Volumen de retención relativo.

RV: Volumen de retención.

RSD: Desviación estándar relativa.

SD: Desviación estándar.

TAG: Triglicérido.

TMR: Ración integral o dieta básica (del inglés "total mixed rations). Ver también DC.

TNF- $\alpha$ : Factor de necrosis tumoral (alfa).

TVA: Ácido vacénico (trans-11 $\left.\mathrm{C}_{18: 1}\right)$.

UHT: Ultra-High-Temperature (Temperatura ultra alta).

UV: Ultravioleta.

VCAM: Molécula de adhesión vascular. 


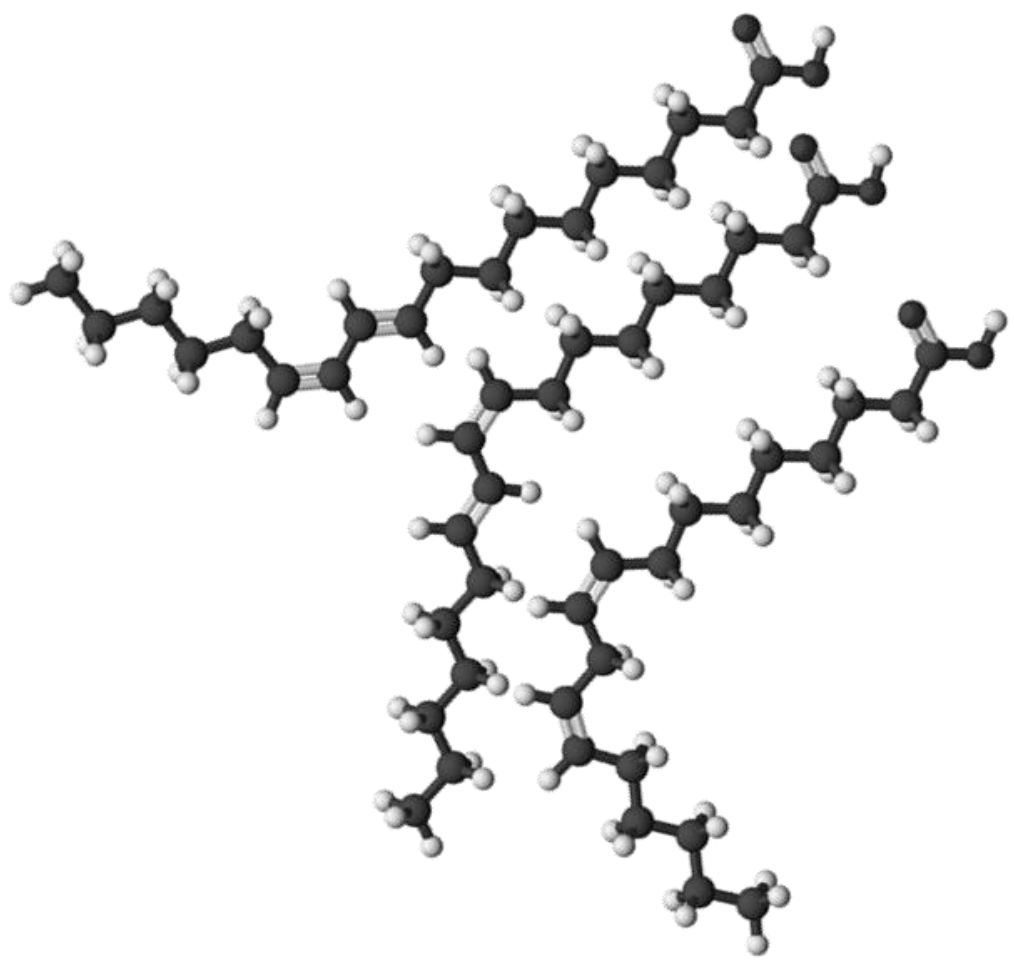

1. ANTECEDENTES BIBLIOGRÁFICOS 



\section{ANTECEDENTES BIBLIOGRÁFICOS}

\subsection{ASPECTOS GENERALES Y NUTRICIONALES SOBRE LA LECHE DE OVEJA}

\subsubsection{Introducción}

La leche es un alimento básico con un alto valor biológico, sobre todo en los primeros meses de vida de los mamíferos. Su composición y su valor nutricional la hace apta no sólo para la especie que la produce, sino también para otras especies animales. Es rica en proteínas, lípidos, carbohidratos, minerales y vitaminas. Incluso algunos de sus componentes han mostrado tener cierta capacidad funcional, como determinados ácidos grasos poliinsaturados (PUFA).

Tradicionalmente, la leche de vaca es la de mayor consumo, bien sea como tal o en forma de derivados lácteos. Sin embargo, la producción láctea de otras especies, como la leche de oveja, puede llegar a tener mayor relevancia en la economía nacional de algunos países mediterráneos y de Oriente Medio. Según estimaciones de la FAO, la producción de leche de oveja a nivel mundial alcanzó los 9,25 millones de toneladas; es decir, sólo el 1,32 \% de la producción láctea total. La Unión Europea contribuye con el $32 \%$ de toda la producción mundial de leche de oveja. Sus principales productores son: Grecia, Rumanía, Italia, España y Francia (FAOSTAT, 2009). Cerca de un 17\% de la producción de leche ovina en la Europa Comunitaria la aporta España, siendo Castilla y León, con casi un 70\%, la región española que produce más leche de oveja (GómezCortés, 2010).

La leche de oveja se destina principalmente para la elaboración de quesos, ya que presenta mejores propiedades de coagulación. También se utiliza para fabricar otros derivados lácteos, como yogures, cuajadas, dulce de leche y requesón. Incluso desde hace pocos años, la empresa zamorana GAZA, S.L., la está comercializando como leche líquida para consumo directo. Comparada con la leche de vaca, la calidad nutricional de la leche de oveja puede llegar a ser muy superior, ya que posee un mayor contenido de proteínas, lípidos y calcio, que se traduciría en un mayor aporte a la dieta de dichos nutrientes. 


\subsubsection{Composición y propiedades de la leche de oveja}

La leche de oveja es un sistema complejo de sustancias que se encuentran distribuidas en distintas fases (Tabla 1.1). Se diferencia de la leche de vaca en algunas características, unas directamente observables (como su color blanco opalescente) y otras relacionadas con sus propiedades fisicoquímicas (Park et al., 2007). Comparada con la leche de vaca, posee una mayor densidad y es más viscosa. El sabor intenso que la caracteriza se debe a su contenido de ácidos grasos de cadena corta, que además contribuyen a que tenga un $\mathrm{pH}$ ligeramente ácido $(\mathrm{pH}$ 6,65). Su punto de solidificación (el cual se aproxima a $-0,58^{\circ} \mathrm{C}$ ) es útil cuando se quieren detectar adulteraciones, principalmente por adición de agua (Pulina y Nudda, 2004; Park et al., 2007).

Tabla 1.1. Composición global de la leche de oveja según sus fases

\begin{tabular}{ll}
\hline FASE & COMPONENTES \\
\hline Solución o fase acuosa & Carbohidratos (lactosa), minerales, compuestos nitrogenados no \\
& proteicos y vitaminas hidrosolubles \\
\hline Suspensión o fase micelar & Proteínas, sales minerales enlazadas a micelas de caseína \\
\hline Emulsión o fase globular & Grasas y vitaminas liposolubles \\
\hline
\end{tabular}

Pulina y Nudda (2004).

A diferencia de lo que sucede con la leche de vaca, existen pocos estudios que pongan de manifiesto las propiedades nutritivas de la leche de oveja (Park et al., 2007). Sin embargo, tanto la leche de oveja como sus productos lácteos derivados, son alimentos con un alto valor nutricional para el ser humano. Comparada con la leche de vaca, la leche de oveja es más rica en nutrientes (Tabla 1.2). Además, su aporte energético es mucho mayor, ya que contiene una mayor cantidad de grasas y proteínas. El contenido en lactosa es bastante semejante en ambas especies, mientras que su contenido en minerales, y sobre todo en calcio, es mayor en la leche de oveja. 
Tabla 1.2. Composición nutricional de la leche de oveja y la leche de vaca

\begin{tabular}{c|c|c|c|c}
\hline \multirow{2}{*}{ COMPONENTE } & \multicolumn{2}{|c|}{ LECHE DE OVEJA } & \multicolumn{2}{c}{ LECHE DE VACA } \\
\cline { 2 - 5 } & Valor medio & Intervalo & Valor medio & Intervalo \\
\hline Agua (\%) & 82,1 & $80,7-82,5$ & 86,6 & $85,4-88,0$ \\
Sólidos totales (\%) & 18,1 & $14,4-20,7$ & 12,5 & $12,0-12,5$ \\
Sólidos no grasos (\%) & 12,0 & $9,00-11,4$ & 9,00 & --- \\
Grasas (\%) & $\mathbf{6 , 8 2}$ & $\mathbf{3 , 6 0}-\mathbf{9 , 9 7}$ & $\mathbf{4 , 1 0}, \mathbf{5 , 1 0}$ \\
Colesterol (mg/100g) & 11,0 & ---- & 14,0 & ---- \\
Proteína Total (\%) & $\mathbf{5 , 5 9}$ & $\mathbf{4 , 7 5}-\mathbf{7 , 2 0}$ & $\mathbf{3 , 6 0}$ & $\mathbf{3 , 1 0}-\mathbf{3 , 9 0}$ \\
Caseína (\%) & 4,50 & $3,72-5,01$ & 2,60 & $-3,00$ \\
Proteína sérica (\%) & 1,00 & $0,80-1,00$ & 0,60 & $0,50-0,70$ \\
Nitrógeno no proteico (\%) & 0,80 & ---- & 0,20 & --- \\
Lactosa (\%) & $\mathbf{4 , 8 8}$ & $\mathbf{4 , 1 1}-\mathbf{5 , 5 1}$ & $\mathbf{4 , 7 0}$ & $\mathbf{4 , 6 6 - 5 , 0 0}$ \\
Minerales (cenizas) (\%) & $\mathbf{0 , 9 2}$ & $\mathbf{0 , 8 0}-\mathbf{0 , 9 6}$ & $\mathbf{0 , 7 2}$ & $\mathbf{0 , 6 8}-\mathbf{0 , 7 4}$ \\
Calcio (mg/100g) & $\mathbf{1 9 3}$ & $\mathbf{1 8 3}-\mathbf{2 3 9}$ & $\mathbf{1 1 9}$ & $\mathbf{1 1 0}-\mathbf{1 2 2}$ \\
Fósforo (mg/100g) & 145 & $135-158$ & 93 & $86-100$ \\
Energía (kcal/100g) & 100 & $94-108$ & 64 & $61-70$ \\
Energía (kJ/100g) & 418 & $393-451$ & 268 & $257-293$ \\
\hline
\end{tabular}

Hampel et al. (2004); Pulina y Nudda (2004); Haenlein (2006); Park et al. (2007); Palma et al. (2008); Raynal-Ljutovac et al. (2008); Mataix Verdú et al. (2009); Swaisgood (2010).

\subsubsection{Importancia de las proteínas en la leche de oveja}

El alto contenido de proteínas en la leche de oveja, hace que sea la más apta para la elaboración de productos como quesos y requesón. Las distintas fracciones proteínicas presentes en la leche se clasifican en dos grandes grupos: caseínas y proteínas séricas.

La leche de oveja, comparada con la leche de vaca (Tabla 1.2) aporta a la dieta una mayor cantidad de proteínas, y por tanto, su aporte en aminoácidos también será mayor (Tabla 1.3). Para evaluar la calidad de las proteínas de un alimento puede recurrirse a diferentes métodos, entre ellos, uno de los más utilizados consiste en comparar la cantidad de aminoácidos esenciales con el contenido de los mismos en una proteína de referencia. El resultado de dicha comparación se expresa como índice químico o cómputo proteico referido al aminoácido limitante. Se pueden utilizar diferentes combinaciones como proteína patrón: la propuesta por la FAO-OMS, la del National Academy of Sciences (NAS, USA), o incluso las ingestas recomendadas de aminoácidos esenciales para niños de dos a cinco años. 
El índice químico de la leche de oveja es del 91\%, tomando como referencia la combinación-tipo de la FAO-OMS (Cervera et al., 2004), mientras que a la leche de vaca le correspondería un $97 \%$ si se utilizara el contenido de metionina recogido por Haenlein (2006) (Tabla 1.3). Hay que aclarar que en la mayoría de los textos de nutrición se recoge un contenido medio de metionina en leche de vaca de $33 \mathrm{mg} / \mathrm{g}$ de proteína y con esta cantidad el índice químico correspondiente sería del 94\%. Dicho índice sería del 100\% para ambas especies, si se calcula con la proteína de referencia propuesta por la NAS, o con respecto a las necesidades de niños de 2 a 5 años.

En definitiva, que la calidad biológica de la leche de oveja es comparable a la de la leche de vaca, pero hay que resaltar que, a igual cantidad de leche ingerida, el contenido de aminoácidos esenciales que aporta la leche de oveja es mayor. Se estima que un consumo diario de $500 \mathrm{~mL}$ de leche de oveja podría cubrir entre el 52 y el $68 \%$ de la ingesta recomendada de proteínas para un adulto, mientras que la misma cantidad de leche de vaca aportaría entre el 28 y el $36 \%$.

Además de su interés nutricional, las proteínas lácteas también poseen cierto interés funcional, ya que pueden ser precursoras de diversos componentes biológicamente activos, conocidos como péptidos bioactivos. Estos péptidos, generalmente compuestos de 2 a 20 aminoácidos, son fragmentos proteínicos que se forman mediante hidrólisis enzimática de las proteínas lácteas durante la digestión gastrointestinal y/o durante el procesado de ciertos productos lácteos.

Tabla 1.3. Contenido en aminoácidos esenciales de la leche de oveja y de vaca

\begin{tabular}{|c|c|c|c|c|c|c|c|}
\hline \multirow{3}{*}{ Aminoácido } & \multirow{2}{*}{\multicolumn{2}{|c|}{$\begin{array}{l}\text { Leche de oveja }^{1} \\
(5,98 \% \text { proteínas })\end{array}$}} & \multirow{2}{*}{\multicolumn{2}{|c|}{$\begin{array}{l}\text { Leche de vaca }^{1} \\
(3,29 \% \text { proteínas })\end{array}$}} & \multicolumn{3}{|c|}{$\begin{array}{l}\text { Proteínas de referencia utilizadas } \\
\text { para determinar el índice químico }\end{array}$} \\
\hline & & & & & FAO-OMS $^{2}$ & NAS $^{3}$ & $\begin{array}{c}\text { Niños } \\
(2-5 \text { años })^{4} \\
\end{array}$ \\
\hline & $\mathrm{g} / 100 \mathrm{~g}_{\text {LECHE }}$ & $\mathrm{mg} / \mathrm{g}_{\text {PROT }}$ & $\mathrm{g} / 100 \mathrm{~g}_{\text {LECHE }}$ & $\mathrm{mg} / \mathrm{g}_{\text {PROT }}$ & \multicolumn{3}{|c|}{$\mathrm{mg} / \mathrm{g}_{\text {PROT }}$} \\
\hline Isoleucina & 0,338 & 57 & 0,199 & 61 & 40 & 25 & 28 \\
\hline Leucina & 0,587 & 98 & 0,322 & 98 & 70 & 55 & 66 \\
\hline Lisina & 0,513 & 86 & 0,261 & 79 & 55 & 51 & 58 \\
\hline Metionina+cisteína & 0,190 & 32 & 0,113 & $34 / 33^{*}$ & 35 & 25 & 25 \\
\hline Fenilalanina+tirosina & 0,565 & 94 & 0,318 & 96 & 60 & 47 & 63 \\
\hline Treonina & 0,268 & 45 & 0,149 & 45 & 40 & 27 & 34 \\
\hline Triptófano & 0,084 & 14 & 0,046 & 14 & 10 & 7 & 11 \\
\hline Valina & 0,448 & 75 & 0,220 & 67 & 50 & 32 & 35 \\
\hline Histidina & 0,167 & 28 & 0,089 & 27 & 0 & 18 & 19 \\
\hline
\end{tabular}

${ }^{(\mathbf{1})}$ Haenlein (2006). ${ }^{(2)(*)}$ Cervera et al. (2004). ${ }^{(3)}$ Suárez López et al. (2006). ${ }^{(4)}$ Bos et al. (2000). 


\subsubsection{Valor nutricional de la grasa láctea}

En la leche de oveja, la fracción lipídica o grasa láctea es el constituyente cuantitativamente más importante (Tabla 1.2), la cual está formada mayoritariamente por los triglicéridos (TAG) y por una menor proporción de otros componentes liposolubles (Tabla 1.4).

Tabla 1.4. Composición media de la grasa de leche de oveja y de vaca

\begin{tabular}{l|ccc|ccc}
\hline \multirow{2}{*}{ Componente } & \multicolumn{3}{|c|}{ Oveja (g/100g de grasa) } & \multicolumn{3}{c}{ Vaca (g/100g de grasa) } \\
\cline { 2 - 7 } & Media & Mín. & Máx. & Media & Mín. & Máx. \\
\hline Triglicéridos & 96,9 & 96 & 98 & 95,8 & 95 & 98 \\
Colesterol & 0,288 & 0,270 & 0,350 & 0,300 & 0,200 & 0,460 \\
Fosfolípidos & 0,8 & --- & --- & --- & 0,6 & 1,1 \\
Otros & 2,0 & 0,5 & 2,9 & 2,4 & 0,6 & 4,0 \\
\hline
\end{tabular}

Juárez (1999); Haenlein (2001); Jensen (2002); Goudjil et al. (2003); Stanton et al. (2003); Fontecha et al. (2005); Swaisgood (2010).

En la grasa láctea ovina se han llegado a identificar hasta 134 tipos de triglicéridos, de los cuales más de la mitad (51\%) contienen tres ácidos grasos saturados, un tercio aproximadamente (31\%) corresponden a TAG con al menos un ácido graso monoinsaturado y el resto de triglicéridos (18\%) contienen algún ácido graso poliinsaturado (Fontecha et al., 2005).

Del total de ácidos grasos presentes en la leche de oveja (Tabla 1.5), cerca del $75 \%$ corresponden a la suma del contenido de los ácidos palmítico, oleico, esteárico, mirístico y cáprico. $\mathrm{El}$ contenido de los ácidos caproico $\left(\mathrm{C}_{6: 0}\right)$, caprílico $\left(\mathrm{C}_{8: 0}\right)$ y cáprico $\left(\mathrm{C}_{10: 0}\right)$ en la leche de oveja es mayor que en la leche de vaca y se les asocia con las características organolépticas propias de la leche de ovino. La relación $\mathrm{C}_{12} / \mathrm{C}_{10}$ se usa como criterio de autenticidad para distinguir la leche de vaca de la leche de oveja. Esta relación debe ser mucho más baja en la leche de oveja (entre 0,56 y 0,58) que en la leche de vaca (entre 1,1 y 1,2) (Goudjil et al., 2004). 
Tabla 1.5. Contenido de ácidos grasos presentes en la leche ovina y bovina

\begin{tabular}{|c|c|c|}
\hline \multirow[t]{2}{*}{ Ácidos Grasos } & \multicolumn{2}{|c|}{$\begin{array}{c}\text { Intervalo de variación } \\
\text { (\% sobre el total de ácidos grasos) }\end{array}$} \\
\hline & Ovejas & Vacas \\
\hline \multicolumn{3}{|l|}{ Saturados } \\
\hline $\mathrm{C}_{4: 0}$ (butírico) & $3,07-4,20$ & $1,64-4,50$ \\
\hline $\mathrm{C}_{6: 0}$ (caproico) & $2,68-3,79$ & $1,55-2,96$ \\
\hline $\mathrm{C}_{8: 0}$ (caprílico) & $1,68-3,77$ & $0,94-1,61$ \\
\hline $\mathrm{C}_{10: 0}$ (cáprico) & $5,54-11,94$ & $1,69-3,52$ \\
\hline $\mathrm{C}_{5: 0-11: 0}$ (impares) & $0,10-0,30$ & $0,10-0,39$ \\
\hline $\mathrm{C}_{12: 0}$ (láurico) & $3,44-6,59$ & $1,87-4,41$ \\
\hline $\mathrm{C}_{13: 0}$ & $0,12-0,23$ & $0,07-0,20$ \\
\hline $\mathrm{C}_{14: 0}$ (mirístico) & $8,57-12,35$ & $7,91-13,54$ \\
\hline $\mathrm{C}_{15: 0}$ & $0,76-1,11$ & $0,75-1,50$ \\
\hline $\mathrm{C}_{16: 0}$ (palmítico) & $20,86-35,39$ & $23,17-34,41$ \\
\hline $\mathrm{C}_{17: 0}($ margárico $)$ & $0,58-0,70$ & $0,44-0,79$ \\
\hline $\mathrm{C}_{18: 0}$ (esteárico) & $4,86-15,62$ & $9,42-14,20$ \\
\hline $\mathrm{C}_{20: 0-24: 0}$ & $0,28-1,06$ & $0,31-0,44$ \\
\hline Ramificados $\left(\mathrm{C}_{14: 0-17: 0}\right)$ & $1,42-2,38$ & $1,72-2,83$ \\
\hline \multicolumn{3}{|l|}{ Insaturados } \\
\hline $\mathrm{C}_{10: 1-14: 1}$ & $0,45-0,86$ & $1,25-1,44$ \\
\hline $\mathrm{C}_{16: 1}$ (palmitoleico) & $0,74-1,80$ & $1,07-2,57$ \\
\hline $\mathrm{C}_{17: 1}$ & $0,15-0,39$ & $0,14-0,39$ \\
\hline $\mathrm{C}_{18: 1}$ (total) & $16,68-31,58$ & $17,52-30,36$ \\
\hline $\mathrm{C}_{18: 1}($ trans-11, vacénico) & $0,87-3,40$ & $0,58-3,82$ \\
\hline $\mathrm{C}_{18: 2}$ (total) & $2,98-6,85$ & $2,17-5,05$ \\
\hline $\mathrm{C}_{18: 2}($ cis-9,cis-12) & $1,93-4,63$ & $1,55-3,62$ \\
\hline $\mathrm{C}_{18: 2}$ (conjugado, total) & $0,56-2,20$ & $0,40-1,41$ \\
\hline $\mathrm{C}_{18: 3}$ (total) & $0,42-2,10$ & $0,24-0,99$ \\
\hline $\mathrm{C}_{20}-\mathrm{C}_{22}$ (insaturados) & $0,08-0,30$ & $0,20-1,03$ \\
\hline $\mathrm{C}_{20: 5}(\mathrm{EPA})$ & Trazas $-0,10$ & Trazas $-0,10$ \\
\hline $\mathrm{C}_{22: 6}(\mathrm{DHA})$ & Trazas $-0,06$ & Trazas $-0,14$ \\
\hline
\end{tabular}

De la Fuente y Juárez (2004); Goudjil et al. (2004); Luna et al. (2005b); Nudda et al. (2005); Park et al. (2007).

Para ambos tipos de leche, el ácido palmítico $\left(\mathrm{C}_{16: 0}\right)$ es el más abundante de los ácidos grasos saturados, mientras que el oleico $\left(\mathrm{C}_{18: 1}\right)$ es el mayoritario de los ácidos grasos insaturados. Dentro de los insaturados, hay que destacar los ácidos grasos trans. En la leche, su contenido representa entre el 2,5 y el 5\% (del total de ácidos grasos). El principal constituyente trans de la leche es el trans-11 $\mathbf{C}_{\mathbf{1 8 : 1}}$ (conocido como ácido vacénico, TVA), que es el precursor, por síntesis endógena, del cis-9,trans-11 C 18:2 $_{1}$ (ácido ruménico), isómero mayoritario del ácido linoleico conjugado (Goudjil et al. 2004; Park et al., 2007). Los aspectos relacionados con el ácido linoleico conjugado 
(CLA) se expondrán más adelante (apartados 1.2, 1.3 y 1.4). Otros ácidos grasos importantes son el docosahexaenoico (DHA) y el eicosapentaenoico (EPA). Sin embargo, los contenidos en leche apenas alcanzan el $0,1 \%$, por lo que su contribución para cubrir las necesidades nutricionales será poco significativa.

\subsubsection{Interés nutricional de otros componentes presentes en la leche de oveja}

Del resto de los componentes encontrados en la leche de ovino, podemos destacar la lactosa como carbohidrato principal, los minerales y las vitaminas. La presencia de estos dos últimos componentes es minoritaria; sin embargo, pueden tener una función nutricional muy importante, como ocurre con el calcio.

Lactosa: De los carbohidratos presentes en la leche, la lactosa es el único que se encuentra en una proporción importante. La función fundamental de la lactosa es energética, aunque también puede facilitar la absorción intestinal de minerales como el calcio, magnesio y fósforo (Park et al., 2007). Es un disacárido formado por glucosa y galactosa que está disuelto en la fase acuosa de la leche, junto con cantidades muy pequeñas de los dos monosacáridos constituyentes. El contenido medio de lactosa en la leche de oveja es semejante al de la leche de la vaca (Tabla 1.2). Sin embargo, respecto al contenido de materia no acuosa (o extracto seco), la lactosa constituye una fracción menor en leche de oveja (entre 22 y $27 \%$ ) que en la leche de vaca $(33-40 \%)$.

Calcio y otros minerales: Los minerales constituyen una pequeña parte de los componentes de la leche, pero tienen un papel importante tanto en el aspecto nutritivo como en el tecnológico. El contenido total de minerales en la leche de ovino es ligeramente más alto que el de la leche de vaca (Tabla 1.2). Además, conviene destacar que la leche de oveja posee niveles más altos de calcio, fósforo, magnesio y cinc (Tabla 1.6).

Es importante señalar que la principal fuente de calcio en la dieta son los productos lácteos. Al comparar los niveles de calcio encontrados en ambos tipos de leche, es evidente que el mayor aporte dietético de este mineral se logra con el consumo de leche de oveja, cuyo contenido medio es hasta 1,6 veces superior al que se ha encontrado en leche de vaca. En un estudio independiente de los objetivos de este trabajo, hemos valorado el contenido de calcio en 6 muestras de leche de oveja 
semidesnatada, tratada térmicamente, utilizando para su determinación la espectrometría de emisión atómica con plasma acoplado inductivamente (ICP-AES, $\lambda=422,673 \mathrm{~nm}$ ). Se encontró que el contenido medio de calcio en las mismas era de $170 \pm 4,3 \mathbf{~ m g ~ C a ~ / ~}$ $100 \mathbf{m L}_{\text {Leche, }}$ un valor que, a pesar de ser ligeramente más bajo del que se recoge en la bibliografía, es superior al de la leche de vaca. Incluso la leche de oveja contiene más calcio que la leche de vaca enriquecida (160 mg Ca / 100mL Leche, Mataix Verdú et al., 2009). Todo ello corrobora la importancia de la leche de oveja como fuente de calcio natural.

Tabla 1.6. Contenido mineral en la leche de oveja y de vaca

\begin{tabular}{l|cc|cc}
\hline \multirow{2}{*}{ Elemento (mg/100g) } & \multicolumn{2}{|c|}{ Leche de oveja } & \multicolumn{2}{c}{ Leche de vaca } \\
\cline { 2 - 5 } & Mín. & Máx. & Mín. & Máx. \\
\hline Calcio (Ca) & 183 & 239 & 110 & 122 \\
Fósforo (P) & 124 & 158 & 86 & 119 \\
Magnesio (Mg) & 15 & 21 & 10 & 13 \\
Potasio (K) & 136 & 155 & 148 & 152 \\
Sodio (Na) & 40 & 58 & 45 & 58 \\
Cobre (Cu) & 0,030 & 0,068 & 0,022 & 0,060 \\
Hierro (Fe) & 0,050 & 0,122 & 0,050 & 0,100 \\
Yodo (I) & Trazas & 0,052 & 0,003 & 0,090 \\
Manganeso (Mn) & 0,005 & 0,009 & Trazas & 0,020 \\
Selenio (Se) & 0,001 & 0,014 & 0,001 & 0,003 \\
Zinc (Zn) & 0,500 & 0,856 & 0,380 & 0,550 \\
Cloro (Cl) & 82 & 160 & --- & 100 \\
Azufre (S) & --- & 29 & --- & 32 \\
Aluminio (Al) & 0,05 & 0,18 & n.d. & n.d. \\
\hline
\end{tabular}

Datos tomados de: Hampel et al. (2004); Park et al. (2007); Palma et al. (2008); Raynal-Ljutovac et al. (2008); Mataix Verdú et al. (2009); Moreiras et al. (2009).

El consumo de un vaso $(250 \mathrm{~mL})$ de leche de oveja cubriría el $50 \%$ de la ingesta recomendada de calcio en España para la población infantil y adulta y el $43 \%$ de la correspondiente a los adolescentes; la misma cantidad de leche de vaca aportaría el 38 y el 30\%, respectivamente, para los mismos grupos de población (ver Figura 1.1).

La importancia del calcio radica en que es un constituyente fundamental del hueso; el crecimiento del esqueleto óseo requiere un balance de calcio positivo hasta que se alcanza la masa ósea máxima. Pero después de cierta edad, los seres humanos, en especial las mujeres, empiezan a experimentar pérdidas lentas de masa ósea; ello da lugar a una disminución gradual de la resistencia ósea y a un aumento del riesgo de 
fracturas. Con la ingesta de calcio, esta pérdida de masa ósea podría prevenirse en cierta medida, aunque en la actualidad se admite que no toda la pérdida de hueso puede prevenirse con calcio dietético adicional. En todo caso, la intervención nutricional más prometedora para reducir el riesgo de osteoporosis, sobre todo en las etapas más avanzadas de la vida, es garantizar durante los años de crecimiento, un aporte de calcio que permita obtener la masa ósea máxima.

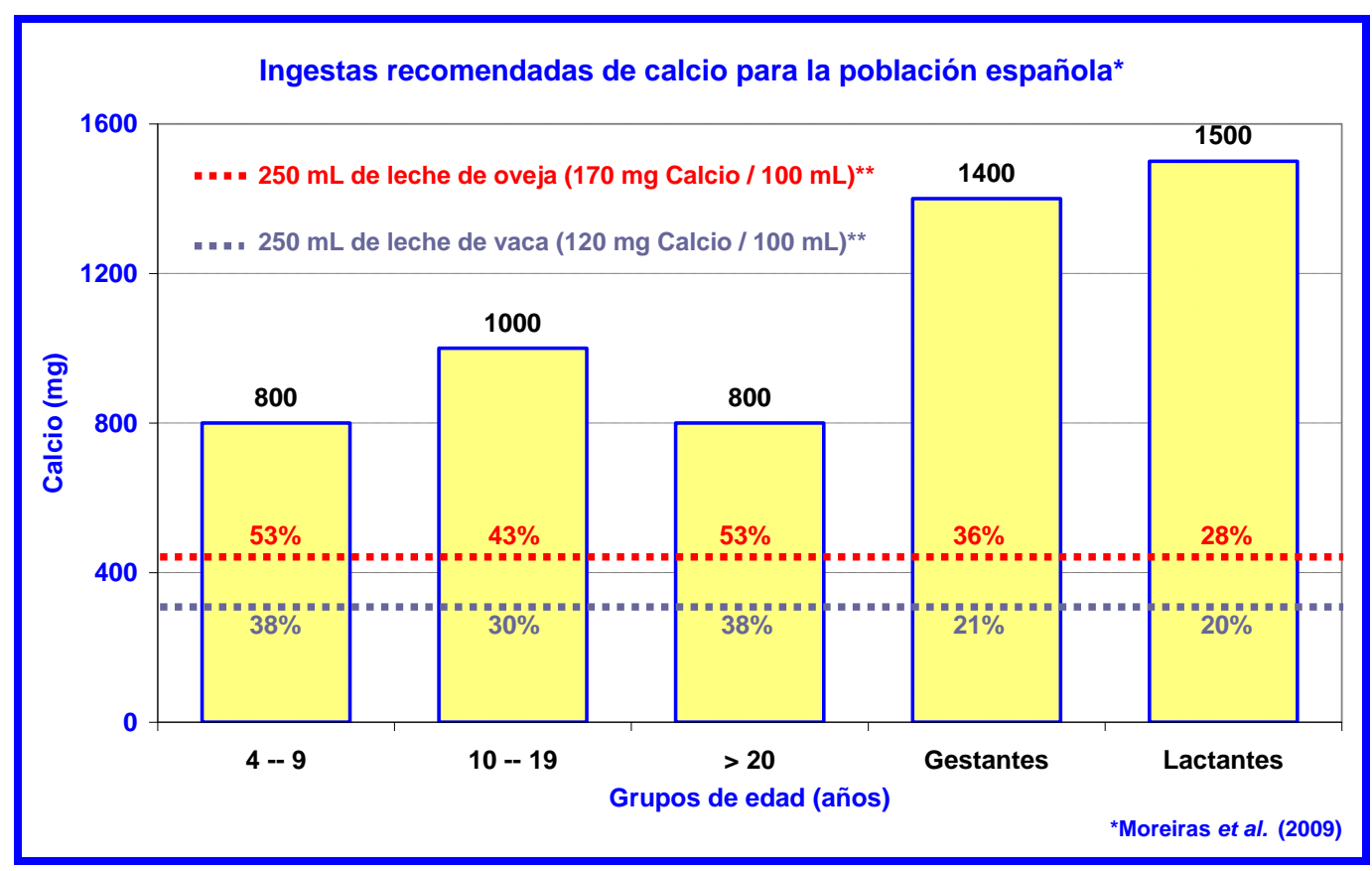

Figura 1.1. Porcentaje de la ingesta recomendada de calcio que cubrirían $250 \mathrm{~mL}$ de leche. **Para la leche de oveja, se consideró el contenido de calcio determinado en las muestras de leche de oveja que hemos analizado; mientras que para la leche de vaca, se utilizó el valor medio de las Tablas de Composición de Alimentos de Mataix Verdú et al. (2009) y Moreiras et al. (2009).

Vitaminas: La leche contiene vitaminas hidrosolubles y liposolubles, destacando entre las primeras, tiamina $\left(\mathrm{B}_{1}\right)$, riboflavina $\left(\mathrm{B}_{2}\right)$, niacina $\left(\mathrm{B}_{3}\right)$ y entre las segundas, la vitamina A y la E. Aunque se cuenta con poca información bibliográfica acerca del contenido vitamínico de la leche de oveja, se puede admitir que, en general, la concentración de las mismas es ligeramente más alta que en la leche de vaca (Tabla $1.7)$. 
Tabla 1.7. Contenido de vitaminas en la leche de oveja y vaca

\begin{tabular}{l|cc|cc}
\hline \multirow{2}{*}{ Vitamina ( $\boldsymbol{\mu g} / \mathbf{1 0 0 g})$} & \multicolumn{2}{|c|}{ Leche de oveja } & \multicolumn{2}{c}{ Leche de vaca } \\
\cline { 2 - 5 } & Mín. & Máx. & Mín. & Máx. \\
\hline A (retinol) & 44,0 & 83,0 & 30,0 & 60,0 \\
D (colecalciferol) & Trazas & 0,18 & 0,01 & 0,08 \\
E (tocoferol) & Trazas & 110 & 70,0 & 110 \\
B $_{1}$ (tiamina) & 50,0 & 80,0 & 30,0 & 50,0 \\
B $_{2}$ (riboflavina) & 230 & 376 & 150 & 210 \\
B $_{3}$ (niacina) & 416 & 450 & 80,0 & 270 \\
B $_{5}$ (ácido pantoténico) & 407 & 450 & 314 & 350 \\
B $_{6}$ & Trazas & 80,0 & 20,0 & 60,0 \\
B $_{8}$ (biotina) & Trazas & 0,93 & Trazas & 2,0 \\
B $_{9}$ (ácido fólico) & Trazas & 5,00 & 3,00 & 6,00 \\
B $_{12}$ & 0,50 & 0,71 & 0,25 & 0,40 \\
C (ácido ascórbico) & 4000 & 5000 & 940 & 2400 \\
\hline
\end{tabular}

Muñoz y Bienzobas (2003); Farran et al. (2004); Badui (2006); Haenlein (2006); Park et al. (2007); Palma et al. (2008); Raynal-Ljutovac et al. (2008); Mataix Verdú et al. (2009); Moreiras et al. (2009).

\subsubsection{Factores que condicionan la composición de la leche de oveja}

La cantidad, calidad y composición de la leche de oveja puede variar en función de numerosos factores. Es difícil valorar la influencia individual de cada uno de ellos, debido a sus posibles interrelaciones. Por ejemplo, la climatología condiciona el tipo de alimentación del animal, que a su vez determinará algunas características nutricionales de la leche. La cría y mantenimiento de una raza concreta en una zona depende de su adaptación a las condiciones ambientales de la región. Los factores que parecen tener menor influencia son los relacionados con el procesado de la leche, ya que una vez ordeñada y conservada adecuadamente, los cambios que se producen durante su tratamiento son mínimos. En los siguientes apartados, se exponen estos factores y los efectos que causan sobre el contenido en nutrientes de la leche de oveja.

\subsubsection{Factores relacionados con el animal}

Entre estos factores se pueden mencionar: la raza, la edad del animal, tipo/número de partos y el período de lactación (Tabla 1.8). Las variaciones en el contenido de lactosa, proteínas y grasa pueden ser muy significativas según la raza del animal, observándose un mayor contenido de grasa en ovejas Manchegas y un mayor contenido proteínico en ovejas Churras (Nudda et al., 2002; Pulina y Nudda, 2004; Jaeggi et al., 2005). Respecto a la edad del animal, cuantos más años tengan, parece 
que el contenido de grasa y proteína en la leche es más alto (Othmane et al., 2002). Según lo observado por De la Fuente et al., (2009), un incremento en la edad de la oveja repercute en: (1) un incremento del contenido de ácidos grasos de cadena corta y media; (2) un descenso del contenido de ácidos grasos mono- y poliinsaturados y (3) una disminución en el contenido de ácidos grasos pertenecientes a la familia $\mathrm{C}_{18}\left(\mathrm{C}_{18: 0}, \mathrm{C}_{18: 1}\right.$, $\left.\mathrm{C}_{18: 2}, \mathrm{CLA}, \mathrm{C}_{18: 3}\right)$.

Tabla 1.8. Factores que influyen en el contenido de nutrientes en la leche de oveja

\begin{tabular}{|c|c|c|c|}
\hline FACTOR & Grasa $(\%)$ & Proteína (\%) & Lactosa $(\%)$ \\
\hline \multicolumn{4}{|l|}{ Raza } \\
\hline Awassi & $6,50-7,50$ & $5,20-6,10$ & $4,80-5,10$ \\
\hline Comisana & $6,40-10,6$ & $5,90-10,4$ & $4,00-5,20$ \\
\hline Lacaune & 7,20 & 5,90 & --- \\
\hline Manchega & 9,10 & 5,40 & --- \\
\hline Merino & $7,70-8,50$ & $4,90-6,40$ & $4,70-4,90$ \\
\hline Sarda & $6,50-6,70$ & $5,40-6,00$ & $4,80-4,90$ \\
\hline Churra & $6,80-7,10$ & $6,00-6,30$ & 4,30 \\
\hline Lacha & $6,50-7,90$ & --- & --- \\
\hline \multicolumn{4}{|l|}{ Edad } \\
\hline 1,5 años & 6,26 & 5,63 & 4,44 \\
\hline 2,5 años & 6,36 & 5,79 & 4,33 \\
\hline 3,5 años & 6,56 & 5,87 & 4,37 \\
\hline$>4$ años & 6,78 & 5,83 & 4,41 \\
\hline \multicolumn{4}{|l|}{ Tipo de partos } \\
\hline Parto simple & 6,82 & 6,31 & --- \\
\hline Parto múltiple & 6,71 & 6,26 & --- \\
\hline \multicolumn{4}{|l|}{ Número de partos } \\
\hline Primero & 6,65 & 6,27 & --- \\
\hline Sucesivos & 6,88 & 6,30 & --- \\
\hline \multicolumn{4}{|l|}{ Período de lactación } \\
\hline 45 días & 5,96 & 5,69 & $4,22-4,70$ \\
\hline 75 días & 5,99 & 5,87 & $3,83-4,32$ \\
\hline 105 días & 6,51 & 6,32 & --- \\
\hline 135 días & 7,23 & 6,70 & --- \\
\hline 150 días & 8,20 & 6,85 & --- \\
\hline
\end{tabular}

Nudda et al. (2002); Othmane et al. (2002); Pulina y Nudda (2004); Sevi et al. (2004); Jaeggi et al. (2005).

Respecto al tipo y número de partos, algunos señalan que, a medida que aumenta el número de partos, lo hace también el contenido de grasa (Othmane et al., 2002). Del período de lactación o de lactancia (que en la oveja es de sólo seis meses), se ha observado que a medida que avanza la lactación, aumenta ligeramente el 
contenido en grasa y proteínas en la leche, disminuyendo el de lactosa (Sevi et al., 2004; Jaramillo et al., 2008). Sin embargo, las variaciones encontradas, debido a la influencia de dichos factores, no son muy significativas.

\subsubsection{Factores relacionados con la dieta}

La alimentación proporcionada a los animales tiene mucha influencia en la composición de la leche, especialmente en el contenido de grasa. Producir una leche con más o menos grasa dependerá en gran medida del contenido y tipo de lípidos, así como de la cantidad de proteínas de la dieta (Nudda et al., 2004; Sevi et al., 2004). En España, es bastante común que el ganado ovino tenga una alimentación basada en un sistema semiextensivo; es decir, se aprovecha la disponibilidad de pasto fresco para su alimentación y, cuando es necesario, se combina con dietas a base de forrajes y concentrados. En todo caso, es importante considerar que los cambios realizados en la dieta animal deben hacerse lentamente, para que así el animal pueda readaptar su sistema digestivo a dichos cambios (Gómez-Cortés, 2010).

Una dieta rica en un ácido graso determinado se traduce en un aumento de su contenido en la leche, sin embargo, un exceso del mismo en la dieta puede provocar una disminución del contenido graso total (De la Fuente y Juárez, 2004). Suplementos dietéticos con aceite de oliva, ricos en ácido oleico (cis-9 $\mathrm{C}_{18: 1}$ ), aumentan el contenido de este ácido graso, aunque con la posibilidad de provocar un descenso del contenido de ácidos grasos de cadena corta y media. Una alimentación con grandes cantidades de hidratos de carbono fácilmente fermentables (almidón o azúcares) provoca también una disminución en el contenido de grasa láctea (Nudda et al., 2004). También se piensa que una dieta rica en energía, particularmente en forma de carbohidratos solubles, puede aumentar el contenido de proteínas en la leche de oveja. Cuando la dieta es deficitaria en proteínas, es posible que el contenido proteínico en la leche también disminuya. No se ha encontrado un efecto significativo del tipo de alimentación sobre la cantidad de macroelementos ( $\mathrm{Ca}, \mathrm{P}, \mathrm{Mg}, \mathrm{K}, \mathrm{Na}, \mathrm{Cl}$ y S). Sin embargo, la concentración de algunos microelementos en la leche (tales como Mn, Co, Al, F, I, Mo y Se) puede verse afectada por el contenido de los mismos en la dieta. 


\subsubsection{Factores relacionados con los cambios estacionales}

Los cambios estacionales tienen un impacto significativo en la composición de la leche, ya que están estrechamente relacionados con el tipo de alimentación proporcionada al animal y con el período de lactación. En algunas publicaciones se recoge que, el contenido de grasa y proteína en leche de oveja se incrementa en la época primaveral y veraniega, sin embargo, en otoño es cuando se empieza a observar una disminución del contenido de estos nutrientes, que llegan a ser más bajos en la época invernal. Se han observado variaciones estacionales significativas en los ácidos grasos poliinsaturados (entre los que se encuentran el ácido $\alpha$-linolénico y los isómeros CLA). El efecto estacional observado en el contenido de ácidos grasos poliinsaturados es inverso al del contenido de ácidos grasos de cadena corta y media (De la Fuente et al., 2009).

\subsubsection{Factores tecnológicos}

En general, no se producen efectos importantes en la composición láctea por los factores tecnológicos. Los tratamientos térmicos (calor y/o frío) a los que se somete la leche para garantizar su seguridad y/o conservación, influyen más sobre sus propiedades físicas y su estabilidad que sobre las características nutritivas de la misma. El rendimiento de leche y algunos componentes de la misma pueden verse relativamente afectados según la frecuencia de ordeño, pero tampoco es una influencia significativa (Nudda et al., 2002). 


\section{2. ÁCIDO LINOLEICO CONJUGADO (CLA)}

\subsubsection{Aspectos generales}

Se denomina ácido linoleico conjugado (conjugated linoleic acid, CLA) a la mezcla de isómeros posicionales y geométricos del ácido linoleico (cis-9,cis-12 $\mathrm{C}_{18: 2}$ ), con un sistema de dobles enlaces conjugados y una de las siguientes configuraciones geométricas: cis-cis, cis-trans, trans-cis, trans-trans.

Si tenemos en cuenta que los dobles enlaces conjugados pueden aparecer entre las posiciones 6-8 y 13-15, teóricamente deberían existir por lo menos 32 isómeros CLA posibles (Cruz-Hernández et al., 2004; Delmonte et al., 2004a). Sin embargo, en el rumen y en la grasa de la leche sólo se han identificado 17 de los 32 isómeros, cuantificándose, según la técnica analítica empleada, entre 12 y 14 isómeros (Luna et al., 2005a, 2005c).

Tabla 1.9. Contenido porcentual de isómeros CLA presentes en la leche ovina y bovina

\begin{tabular}{|c|c|c|}
\hline \multirow[t]{2}{*}{ Isómero CLA } & \multicolumn{2}{|c|}{$\begin{array}{l}\text { Intervalo de variación } \\
\text { (\% sobre el CLA total) }\end{array}$} \\
\hline & Ovejas & Vacas \\
\hline \multicolumn{3}{|l|}{ trans-trans } \\
\hline trans-12,trans -14 & $1,03-3,47$ & $0,49-2,25$ \\
\hline trans -11, trans -13 & $1,04-5,08$ & $0,88-4,77$ \\
\hline trans -10, trans -12 & $0,68-1,77$ & $0,52-1,68$ \\
\hline trans -9, trans -11 & $0,81-1,99$ & $0,71-2,21$ \\
\hline trans -8, trans -10 & $0,53-1,62$ & $0,15-1,29$ \\
\hline trans-7,trans-9 & $0,29-1,13$ & $0,37-1,46$ \\
\hline trans -6, trans -8 & $0,37-0,45$ & $0,46-0,53$ \\
\hline \multicolumn{3}{|l|}{ cis-trans + trans-cis } \\
\hline 12,14 cis-trans/trans-cis & $0,52-1,83$ & $0,18-1,76$ \\
\hline 11,13 cis-trans/trans-cis & $0,76-4,23$ & $0,47-4,78$ \\
\hline 10,12 cis-trans/trans-cis & $0,28-0,77$ & $0,10-0,64$ \\
\hline 9,11 cis-trans/trans-cis & $67,2-85,5$ & $76,5-84,3$ \\
\hline 8,10 cis-trans/trans-cis & $0,11-0,71$ & $0,30-1,00$ \\
\hline 7,9 cis-trans/trans-cis & $3,31-15,8$ & $2,87-10,2$ \\
\hline
\end{tabular}

Luna et al. (2005a, 2005b, 2005c y 2007); Martins et al. (2007); Park et al. (2007); Partidario et al. (2008); Rodríguez-Alcalá et al. (2009).

De todos los isómeros CLA presentes en la grasa de la leche de oveja (Tabla 1.9), el cis-9,trans-11 $\mathrm{C}_{18: 2}$ (comúnmente llamado ácido ruménico) es el más abundante, ya que representa más del $65 \%$ del contenido total de CLA. El segundo 
isómero más abundante en la leche suele ser el trans-7,cis-9 $\mathrm{C}_{18: 2}$ (entre 3 y 16\%). El resto de isómeros aparecen en proporciones más bajas y no superan el 3\%, salvo en muestras de leche obtenidas de animales alimentados con ciertos tipos de suplementos (ver apartado 1.3.1), en las que algunos isómeros minoritarios llegan a alcanzar niveles de concentración relativamente mayores (Collomb et al., 2004). El contenido natural del trans-10,cis-12 $\mathrm{C}_{18: 2}$ en la leche no llega al $1 \%$ del total de isómeros. En lo que respecta a los isómeros trans-trans, estos pueden alcanzar hasta un 10\% del CLA total, mientras que los isómeros cis-cis habitualmente no se determinan por encontrarse en la leche en cantidades muy bajas.

La importancia de los isómeros CLA, en concreto el cis-9,trans-11 y el trans10,cis-12 (Figura 1.2), radica en que se les atribuyen ciertas propiedades funcionales. En el apartado 1.4 se tratan estos posibles efectos funcionales.
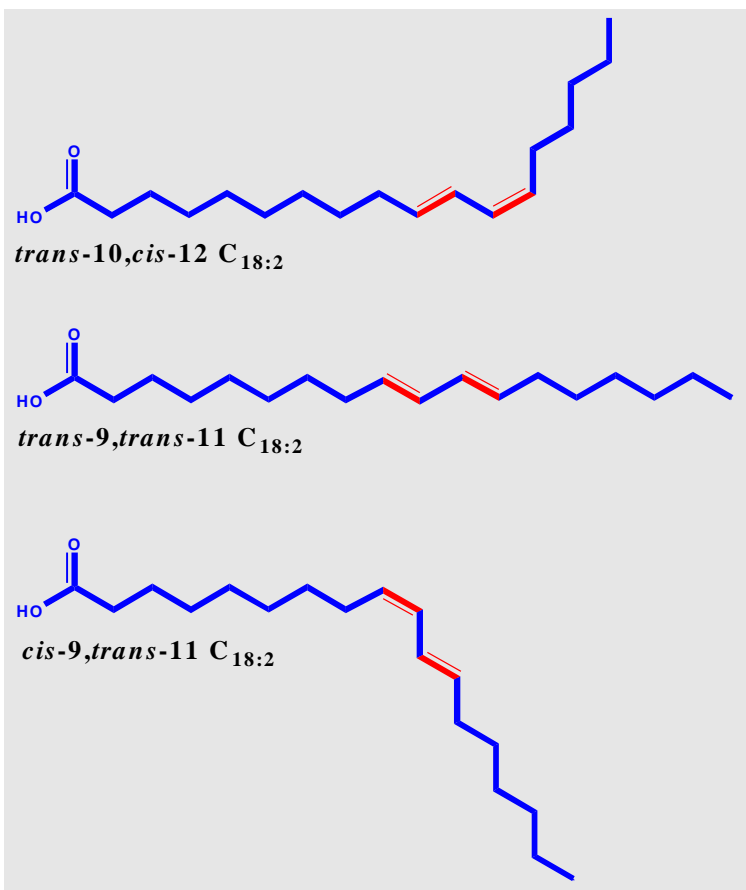

Figura 1.2. Estructura de algunos isómeros CLA.
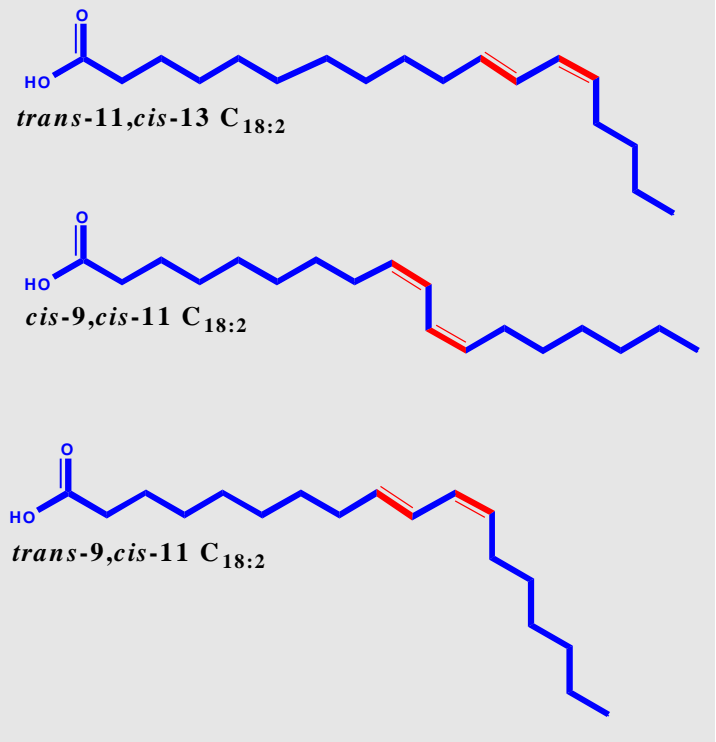

\subsubsection{Biosíntesis de los isómeros CLA}

La biosíntesis de CLA en rumiantes puede tener dos orígenes: uno en el rumen (síntesis ruminal) y otro en la glándula mamaria (síntesis endógena). 


\subsubsection{Sintesis ruminal}

En el rumen, los ácidos grasos poliinsaturados pueden llegar a sufrir una biohidrogenación incompleta, promovida por enzimas de distintos microorganismos anaerobios (entre ellos, Butyrivibrio fibrisolvens). Con el ácido linoleico (cis-9,cis-12 $\mathrm{C}_{18: 2}$ ) como sustrato, los intermediarios insaturados que se originan son el ácido ruménico (cis-9,trans-11) y el ácido vacénico (TVA, trans-11 $\mathrm{C}_{18: 1}$ ). En la biohidrogenación de sustratos como el ácido $\boldsymbol{\alpha}$-linolénico (cis-9,cis-12,cis-15 $\mathrm{C}_{18: 3}$ ), se forman otros intermediarios distintos al ácido ruménico (cis-9,trans-11,cis-15 $\mathrm{C}_{18: 3}$ y trans-11,cis-15 $\mathrm{C}_{18: 2}$ ), los cuales son convertidos rápidamente en TVA (Khanal y Dhiman, 2004; Loor et al., 2004).

La Figura 1.3 representa el mecanismo de síntesis de CLA en el rumen. Esta ruta biosintética sugiere como primer paso la isomerización del doble enlace "cis" en posición 12 del sustrato (ácido linoleico o $\alpha$-linolénico), pasando a tener configuración "trans" en el carbono 11. En la siguiente etapa, el doble enlace "cis-9" experimenta una hidrogenación rápida, formándose el ácido vacénico. Si la biohidrogenación fuese completa, el producto final sería el ácido esteárico $\left(\mathrm{C}_{18: 0}\right)$, pero la conversión de TVA a esteárico la realizarían otros microorganismos diferentes a B. fibrisolvens (Jenkins et al., 2008). Además, esta conversión se ve impedida por la gran estabilidad del doble enlace trans-11 (Kraft et al., 2003). Esto explicaría la acumulación de ácido vacénico, y por tanto, el alto contenido de este ácido graso en lácteos de rumiantes (Haro et al., 2006; Luna, 2006; Gómez-Cortés et al., 2008a; Hervás et al., 2008a; Bodas et al., 2010). Durante la biohidrogenación, el pH ruminal juega un papel muy importante. En cultivos ruminales, trabajar a $\mathrm{pH} \geq 6,0$ ejerce un efecto positivo sobre los contenidos de TVA y CLA (Luna, 2006; Gómez-Cortés, 2010).

\subsubsection{Síntesis endógena}

Hoy en día se sabe que sólo una parte del ácido ruménico presente en la grasa láctea tiene origen en el rumen, ya que el resto se genera en la glándula mamaria (síntesis endógena). Diversos estudios han demostrado que la mayor parte del contenido de ácido ruménico presente en la grasa láctea (entre un 64 y un 98\%) se sintetiza a través de esta ruta (Bauman et al., 1999; Griinari y Bauman, 1999). Como se muestra en la Figura 1.3, el ácido vacénico que se produce en el rumen sufre una desaturación en la 
glándula mamaria, debido a la acción de la enzima $\boldsymbol{\Delta}^{\mathbf{9}}$-desaturasa, convirtiéndose en ácido ruménico.

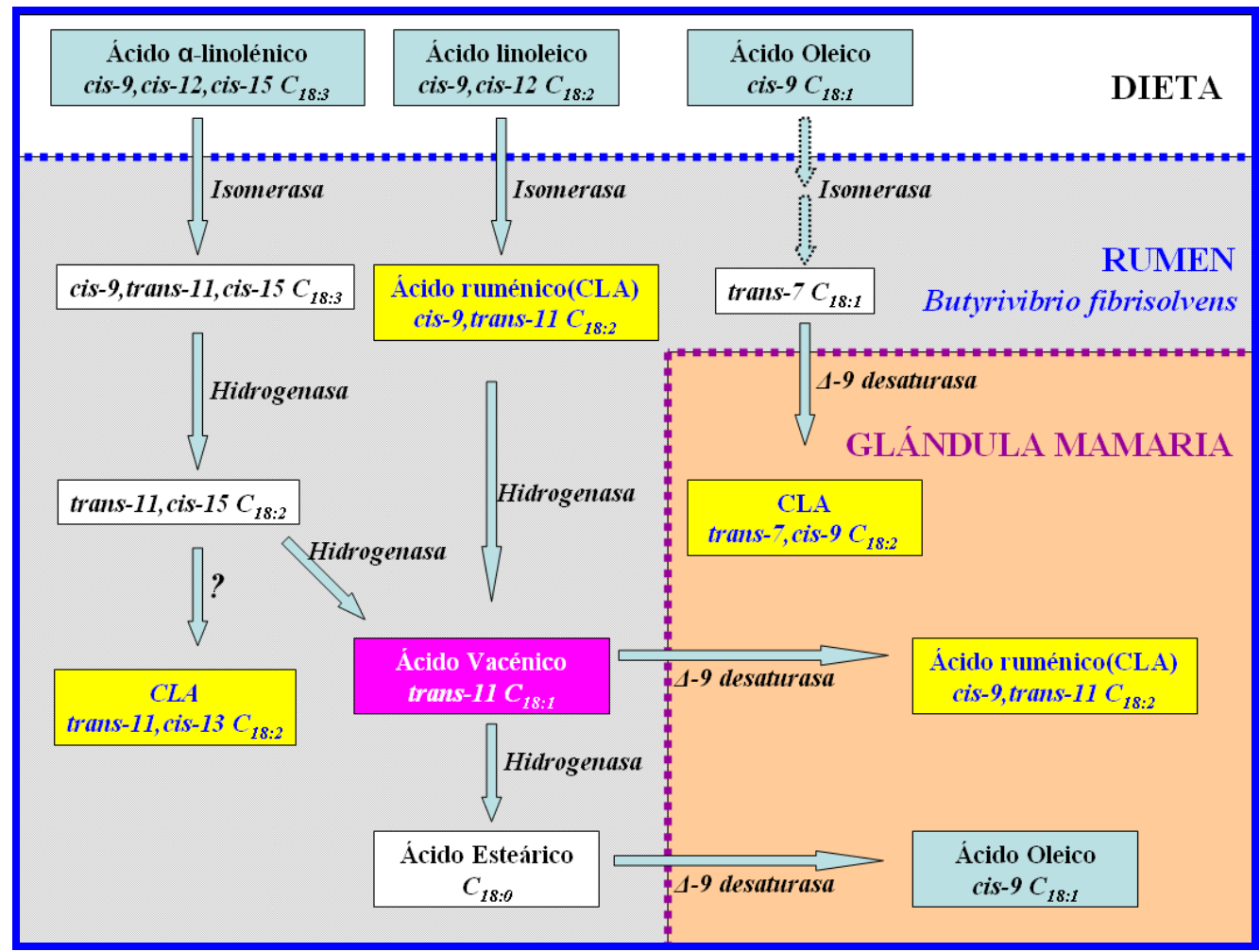

Figura 1.3. Principales rutas de formación de ácido ruménico (cis-9,trans-11) en el rumen y en la glándula mamaria. Adaptada de Collomb et al. (2006); Luna (2006); Gómez-Cortés (2010).

Hay que resaltar que, independientemente de la ruta biosintética, existe una estrecha relación entre los contenidos de ácido vacénico y ácido ruménico. Esta afirmación ha sido demostrada por numerosos estudios llevados a cabo en productos lácteos de origen bovino, la cual también se ha hecho extensiva a los productos lácteos de origen ovino (Cabiddu et al., 2005; Luna et al., 2005b; Luna, 2006).

\subsubsection{Biosíntesis de otros isómeros CLA}

Son muchas las publicaciones relacionadas con la biosíntesis del ácido ruménico, sin embargo apenas existen estudios que detallen la posibilidad de formación endógena de otros isómeros de CLA. Este hecho puede deberse a dos razones: primero, a que muchos de estos isómeros no se encuentran en cantidades significativas en la grasa de la leche; y segundo, a que la funcionalidad de muchos de ellos no ha sido establecida (Luna, 2006; Gómez-Cortés, 2010). 
Se cree, por ejemplo, que la síntesis del isómero trans-10,cis-12, (minoritario en la leche pero con cierta importancia funcional), también podría llevarse a cabo a través de cualquiera de las dos formas de síntesis propuestas anteriormente: por biohidrogenación, mediante la acción de la cis-9,trans-10 isomerasa bacteriana o por síntesis endógena, a partir del trans-10 $\mathrm{C}_{18: 1}$. Lo que sí parece estar claro es que el ácido $\alpha$-linolénico no es precursor de este isómero CLA en el rumen (Luna, 2006; GómezCortés, 2010). Griinari y Bauman (1999) proponen una ruta alternativa para la biosíntesis de trans-10,cis-12, la cual se representa en la Figura 1.4 y que posiblemente se lleve a cabo con microorganismos distintos a B. fibrisolvens, como la Megasphoera elsdenii (Kim et al., 2002; Klieve et al., 2003; Jenkins et al., 2008).

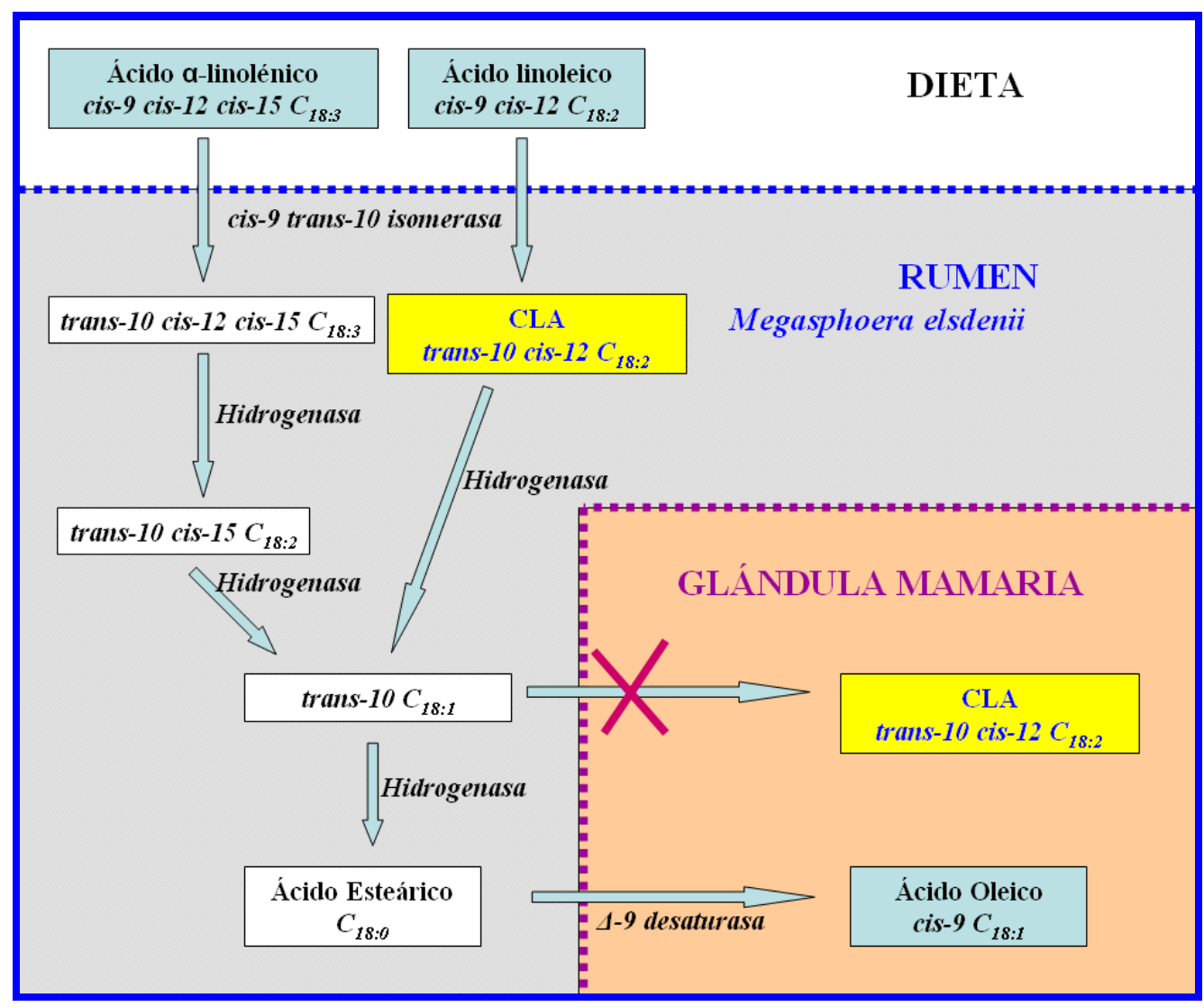

Figura 1.4. Rutas alternativas de la biohidrogenación del ácido linoleico y $\alpha$-linolénico en el rumen, según el mecanismo propuesto por Griinari y Bauman (1999). Adaptada de Luna (2006) y Gómez-Cortés (2010).

Respecto al trans-7,cis-9, parece que se sintetiza casi exclusivamente por vía endógena (ver Figura 1.3), a partir del trans-7 $\mathrm{C}_{18: 1}$, un intermediario del ácido oleico (cis-9 C $18: 1$ ) (Corl et al., 2002; Piperova et al., 2002). Del resto de isómeros CLA no 
existe información acerca de su biosíntesis, aunque se cree que pueden originarse a partir de otras moléculas trans- $\mathrm{C}_{18: 1}$ presentes en el líquido ruminal (Luna, 2006).

Por lo tanto, sería de gran interés que se llevaran a cabo más estudios sobre los mecanismos de formación de los isómeros CLA, ya que nos ayudarían a entender la complejidad de las rutas bioquímicas implicadas en la síntesis de estos isómeros presentes en la leche. De esta manera, se podrían buscar estrategias que permitirían incrementar el contenido de CLA en la leche y productos lácteos (De la Fuente y Juárez, 2004). En los últimos años, dichas estrategias ya se han ido implementando con bastante éxito. Muchas de ellas están enfocadas hacia la modificación de la dieta de los animales, a los que se les suministran suplementos grasos con un alto contenido en ácido linoleico y $\alpha$-linolénico (para más detalles al respecto, ver el apartado 1.3.1).

\subsubsection{Presencia de CLA en leche y derivados lácteos}

De manera natural, las principales fuentes alimentarias de CLA son los productos procedentes de animales rumiantes (lácteos y cárnicos). La leche y sus derivados son los que, de forma natural, aportan a la dieta la mayor cantidad de CLA, y según la especie animal, se cree que la grasa de la leche de oveja posee un mayor contenido de CLA que la grasa láctea de vaca y de cabra (Park et al., 2007).

En la Tabla 1.10 se recogen los contenidos de CLA total en diferentes productos lácteos. El intervalo de variación representa los valores máximos y mínimos de CLA encontrados en la bibliografía para cada producto. Estos valores están expresados en miligramos por gramo de grasa (mg/g $\mathbf{g}_{\mathrm{Grasa}}$ ), aunque es más frecuente que se expresen en base al porcentaje total de ácidos grasos (libres o esterificados). En esta tabla se observa una amplia variación del contenido de CLA en productos lácteos, atribuida principalmente al tipo de alimentación proporcionada al animal, a los procesos tecnológicos y a otros factores relacionados con la genética y fisiología del animal. La influencia de dichos factores, se discutirá más adelante (apartado 1.3). 
Tabla 1.10. Contenido total de ácido linoleico conjugado (CLA) en leche y derivados lácteos

\begin{tabular}{|c|c|c|c|}
\hline \multirow[t]{2}{*}{ Alimento } & \multicolumn{2}{|c|}{$\begin{array}{c}\text { Intervalo de variación } \\
\left(\mathrm{mg} / \mathrm{g}_{\text {Grasa }}\right)\end{array}$} & \multirow[t]{2}{*}{ Referencias } \\
\hline & Mín. & Máx. & \\
\hline Leche de oveja entera, pasteurizada & 5,70 & 6,50 & Luna et al., 2007 \\
\hline Leche de vaca entera, pasteurizada & 2,00 & 11,41 & Mushtaq et al., 2010; Pestana et al., 2009 \\
\hline Leche de vaca entera, UHT & 5,08 & 7,63 & Jones et al., 2005; Fritsche y Steinh., 1998a \\
\hline Leche de vaca baja en grasa & 2,10 & 9,20 & Mushtaq et al., 2010; Guler et al., 2010 \\
\hline Leche de cabra & 4,10 & 9,40 & Alonso et al., 1999 \\
\hline Mantequilla & 2,50 & 9,67 & Mushtaq et al., 2010; Ledoux et al., 2005 \\
\hline Yogur de leche de vaca & 2,07 & 11,20 & Akalin et al., 2007; Espírito S. et al., 2010 \\
\hline Yogur probiótico (leche de vaca) & 3,28 & 11,01 & Akalin et al., 2007; Espírito S. et al., 2010 \\
\hline Yogur (leche de oveja) & --- & 6,92 & Prandini et al., 2007 \\
\hline Leche fermentada de vaca & 4,70 & 6,15 & Prandini et al., 2007 \\
\hline Cuajada (leche vaca) & 4,89 & 7,44 & Prandini et al., 2009 \\
\hline Cuajada (leche oveja) & --- & 5,85 & Herzallah et al., 2005 \\
\hline Queso bovino varios & 1,90 & 11,93 & Mushtaq et al., 2010; Laloux et al., 2007 \\
\hline Queso ovino varios & 3,96 & 10,11 & Abilleira et al., 2009 \\
\hline Queso caprino varios & 2,70 & 6,94 & Martins et al., 2007; Prandini et al., 2011 \\
\hline Queso mozzarella & 4,30 & 9,80 & Khanal y Olson, 2004; Parodi, 2003 \\
\hline Nata & 3,70 & 7,49 & Mushtaq et al., 2010; Laloux et al., 2007 \\
\hline
\end{tabular}

Por otra parte, hay que mencionar los productos sintéticos con CLA que se utilizan en complementos alimenticios y para su adición a alimentos. Se emplean preparaciones con una riqueza aproximada del $80 \%$ en CLA total $\left(\right.$ Clarinol $^{\circledR}$ y Tonalín $^{\circledR}$ ) y están compuestas por mezclas de los isómeros cis-9,trans-11 y trans10,cis-12 en proporción 1:1 y bajos porcentajes de otros isómeros de CLA (del orden del 4\%). El resto de componentes de la mezcla representa, aproximadamente, un $7 \%$ de ácidos grasos saturados (palmítico y esteárico), un 12\% de ácido oleico y pequeñas cantidades de ácido linoleico $(<2 \%)$.

Actualmente en España, existen en el mercado leche y yogures con CLA añadido $\left(\right.$ Tonalín $^{\circledR}$ ) cuya concentración es del $0,6 \%$ y 1,5\%, respectivamente, en el producto final. En sus etiquetados recogen la recomendación diaria máxima de consumo (3g de CLA aportados por dos raciones). A pesar de ello, hasta el momento no se ha adoptado ninguna decisión legal sobre su autorización como nuevo ingrediente alimentario, según el Reglamento (CE) $\mathbf{N}^{\mathbf{0}} \mathbf{2 5 8 / 9 7}$, aunque sí se han publicado dos opiniones científicas acerca de su seguridad (EFSA, 2010a y 2010b) (ver apartado 1.4.3). 


\subsubsection{Presencia de CLA en otros alimentos}

Después de la leche y sus derivados, los alimentos que presentan mayor contenido de CLA son los productos cárnicos de rumiantes, sobre todo los de origen ovino. Las carnes y derivados de animales no rumiantes (como las aves y el cerdo) contienen niveles mucho más bajos de CLA, como cabría esperar si se tienen en cuenta sus principales rutas biosintéticas. También está presente en algunos alimentos de origen vegetal y marino, en concentraciones pequeñas (Tabla 1.11).

Tabla 1.11. Contenido total de ácido linoleico conjugado (CLA) en distintos alimentos

\begin{tabular}{l|cc|c}
\hline \multirow{2}{*}{ Alimento } & \multicolumn{2}{|c|}{$\begin{array}{c}\text { Intervalo de variación } \\
\text { (mg/gasa) }\end{array}$} & Referencias \\
\cline { 2 - 3 } & \multicolumn{2}{|c|}{ Mín. } & Máx. \\
\hline Cárnicos (vacuno) & 1,20 & 10,0 & Schmid et al., 2006 \\
\hline Cárnicos Ovino & 4,30 & 19,0 & Schmid et al., 2006 \\
\hline Otros cárnicos (cerdo) & 0,60 & 1,90 & Chin et al., 1992 \\
\hline Otros cárnicos (aves) & 0,13 & 2,50 & Mushtaq et al., 2010; Chin et al., 1992 \\
\hline Huevos & 0,30 & 0,60 & Khanal y Olson, 2004; Chin et al., 1992 \\
\hline Productos marinos & 0,30 & 0,60 & Chin et al., 1992 \\
\hline Aceites vegetales & 0,10 & 0,70 & Chin et al., 1992 \\
\hline
\end{tabular}

\subsubsection{Ingestas de CLA}

Los valores correspondientes a las ingestas de CLA estimadas en algunos países se muestran en la Tabla 1.12. La variabilidad observada entre las distintas poblaciones puede deberse a las diferencias en sus hábitos alimentarios y tipos concretos de alimentos consumidos, a los métodos de estimación del consumo alimentario y a las concentraciones de CLA en los alimentos. En cuanto a los niveles de CLA la información es incompleta, el intervalo de variación amplio, y cuando se hace referencia al CLA total no siempre se consideran los mismos isómeros. Todo ello dificulta en gran medida la determinación de la ingesta real de CLA.

En el caso de España, el único dato disponible procede del trabajo de Wolff y Precht (2002), que estimaron la ingesta del isómero cis-9,trans-11 en quince países de la Unión Europea, basada únicamente en el consumo de leche. En los países del sur de Europa los valores eran más bajos (España 140 mg/día, Grecia y Portugal 150 mg/día), mientras que en Suecia, Finlandia e Irlanda, la ingesta oscilaba entre 330 y 380 mg/día. 
Si consideramos los estudios recientes, se observa que la menor ingesta de cis9,trans-11 (56 mg/día) corresponde a Portugal, siendo bastante próxima a la ingesta media calculada para la población catalana ( $72 \mathrm{mg} / \mathrm{día})$, en la que no existen grandes diferencias entre ambos sexos, al contrario de lo que ocurre en el Reino Unido, donde la ingesta es de aproximadamente el doble en hombres (127 mg/día). Los valores determinados en Francia son muy superiores, debido probablemente al mayor consumo de mantequilla y quesos, que contribuyen de manera significativa a la ingesta total. En general, se considera que el mayor aporte de CLA procede de la leche y los productos lácteos, mientras que el consumo de carnes y derivados contribuye con el 25 - 30\% a la ingesta total de CLA (Schmid et al., 2006).

Por otra parte, se ha demostrado que entre un 20 - 25\% del ácido vacénico de la dieta puede convertirse en el isómero cis-9,trans-11 en humanos. Por ello, y teniendo en cuenta la ingesta de ácido vacénico, se ha propuesto que la disponibilidad total del CLA en el organismo podría estimarse multiplicando su ingesta por un factor de 1,4 o 1,5 (Jutzeler y Colombani, 2010).

Tabla 1.12. Ingesta de CLA

\begin{tabular}{|c|c|c|c|c|}
\hline \multirow{2}{*}{ País/Región } & \multirow{2}{*}{ Referencia } & \multirow{2}{*}{ Método de estimación } & \multicolumn{2}{|c|}{ Ingesta CLA (mg/día)* } \\
\hline & & & Hombres & Mujeres \\
\hline $\begin{array}{c}\text { Unión Europea } \\
\text { (15 países) }\end{array}$ & Wolff y Precht (2002) & Consumo de leche & \multicolumn{2}{|c|}{ 140* - 380* (mín. y máx.) } \\
\hline \multirow{3}{*}{ Alemania } & Fritsche y Steinh. (1998b) & Encuesta Nacional & 430* & $350 *$ \\
\hline & \multirow{2}{*}{ Fremann et al. (2002) } & FFQ & $-\cdots$ & $246^{*}$ \\
\hline & & DR, 7días & --- & 323* \\
\hline \multirow{2}{*}{$\begin{array}{c}\text { España } \\
\text { Cataluña (ESP) }\end{array}$} & Wolff y Precht (2002) & Consumo de leche & \multicolumn{2}{|c|}{$140 *$} \\
\hline & Mayneris -P. et al. (2010) & FFQ & 79* & $67 *$ \\
\hline Francia & Laloux et al. (2007) & DR, 7días & 213 & 178 \\
\hline Portugal & Martins et al. (2007) & Encuesta Nacional & \multicolumn{2}{|c|}{$74(56 *)$} \\
\hline \multirow{2}{*}{ Reino Unido } & Rosell et al. (2005) & FFQ & 370 & -- \\
\hline & Mushtaq et al. (2010) & DR, 7 días & 127 & 68 \\
\hline Suecia & Jiang et al. (1999) & DR, 7días & $160 *$ & 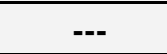 \\
\hline Brasil & Nunes y Torres (2010) & Consumo de lácteos & \multicolumn{2}{|c|}{36} \\
\hline \multirow{2}{*}{ Canadá } & \multirow{2}{*}{ Ens et al. (2001) } & DR, 7días & \multicolumn{2}{|c|}{$95 *$} \\
\hline & & Encuesta Nacional & 332* & $295^{*}$ \\
\hline \multirow{3}{*}{ Estados Unidos } & \multirow{3}{*}{ Ritzenthaler et al. (2001) } & DR, 3días & $176(133 *)$ & $104(79 *)$ \\
\hline & & FFQ & $197(151 *)$ & $93(72 *)$ \\
\hline & & FD, 3 días & $212(193 *)$ & $151(140 *)$ \\
\hline
\end{tabular}

Los valores señalados con asterisco (*) representan la ingesta del isómero cis-9,trans-11, el resto de valores representan la ingesta de CLA total. DR = Registro dietético; $\mathbf{F D}=$ Dieta duplicada; $\mathbf{F F Q}=$ Cuestionario de frecuencia de consumo alimentario. 


\subsection{FACTORES QUE CONDICIONAN EL CONTENIDO DE CLA EN LA LECHE Y DERIVADOS LÁCTEOS}

\subsubsection{Factores relacionados con la dieta animal}

El factor que más influencia tiene sobre el contenido de CLA en la leche es el tipo de alimentación proporcionada al animal, ya que a través de una dieta controlada, es posible llevar a cabo estrategias que permitan aumentar el contenido de CLA en la leche y productos lácteos. Con la utilización de pasto fresco en la dieta, es posible aumentar de forma natural los niveles de CLA en leche, ya que contienen altas cantidades de ácido $\alpha$-linolénico (Collomb et al., 2006; Dewhurst et al., 2006; Kalac y Samková, 2010). Sin embargo, en determinadas épocas del año no es posible disponer de pasto fresco, por lo que en su lugar se suelen suministrar raciones integrales (TMR, "total mixed rations") a base de forrajes y concentrados en distintas proporciones (Chilliard et al., 2007). En general, este tipo de dietas no contribuye de forma significativa a aumentar el contenido de CLA en leche, ya que no aportan las cantidades suficientes de ácido linoleico y/o $\alpha$-linolénico, ambos precursores de CLA en el rumen. Los menores contenidos de estos ácidos grasos en dichas raciones integrales se suelen incrementar añadiendo determinados suplementos lipídicos, como son las semillas y aceites de oleaginosas, los aceites de pescado y algas marinas, entre otros.

En la actualidad, muchas de las investigaciones relacionadas con el CLA se enfocan hacia el estudio de los efectos que ocasionan los distintos tipos de alimentación animal, ya que la cantidad y forma en la que se adicionan los lípidos a la dieta, la composición de la dieta básica y el período de tiempo en que se proporcionan dichas dietas, tienen un efecto importante sobre los cambios en la concentración de CLA en la grasa de la leche (Dewhurst et al., 2006). La mayor parte de estos estudios se han llevado a cabo en leche y productos lácteos de origen bovino (Collomb et al., 2006; Dewhurst et al., 2006; Chilliard et al., 2007; Kalac y Samková, 2010). Sin embargo, en los últimos años ha ido creciendo el interés por demostrar el efecto de estos suplementos alimenticios cuando se quiere aumentar el contenido de isómeros CLA en la leche de oveja y sus derivados (Cabiddu et al., 2005; Luna et al., 2005b; Nudda et al., 2005; Pulina et al., 2006; Hervás et al., 2008a y 2008b). 
A continuación, se describirán los diferentes tipos de dietas suministradas a los animales y sus posibles efectos sobre los niveles de CLA en leche de oveja. Para ello, además se considerarán los niveles de ácidos grasos precursores en la dieta. Las unidades en las que se suelen expresar dichos contenidos no son uniformes, por lo que, para fines comparativos, se optó por utilizar el miligramo por gramo de grasa $\left(\mathrm{mg} / \mathrm{g}_{\text {Grasa }}\right)$ como unidad común. Aquellos valores que no estaban expresados así, fueron transformados en $\mathrm{mg} / \mathrm{g}_{\text {Grasa }}$ empleando factores de conversión previamente calculados. Dichos cálculos aparecen adjuntos al final de esta memoria (ver Anexo 1).

\subsubsection{Alimentación con pasto fresco}

Los distintos tipos de pasto fresco empleados en la dieta de rumiantes contienen un porcentaje muy bajo de ácidos grasos (entre un 1 y un $3 \%$, expresado en materia seca), sin embargo, cerca del 50 - 75\% están presentes como ácido $\alpha$-linolénico (Chilliard et al. 2007). En la Tabla 1.13 se muestran las distintas proporciones de ácidos grasos presentes en algunos pastos frescos.

Tabla 1.13. Composición de ácidos grasos presentes en algunos pastos frescos

\begin{tabular}{|c|c|c|c|c|c|c|c|}
\hline \multirow{2}{*}{ Familia y nombre científico* } & \multicolumn{5}{|c|}{ Gramos de ácido graso/kg de pasto } & \multicolumn{2}{|c|}{$\begin{array}{l}\text { \% del total de } \\
\text { ácidos grasos }\end{array}$} \\
\hline & $\begin{array}{l}\text { Palmítico } \\
\text { C16:0 }\end{array}$ & $\begin{array}{c}\text { Esteárico } \\
\text { C18:0 }\end{array}$ & $\begin{array}{l}\text { Oleico } \\
\text { C18:1 } \\
\end{array}$ & $\begin{array}{c}\text { Linoleico } \\
\text { C18:2 }\end{array}$ & $\begin{array}{c}\alpha \text {-Linolénico } \\
\text { C18:3 }\end{array}$ & $\begin{array}{c}\text { Linoleico } \\
\text { C18:2 }\end{array}$ & $\begin{array}{c}\alpha \text {-Linolénico } \\
\text { C18:3 }\end{array}$ \\
\hline \multicolumn{8}{|l|}{ Gramineae (Gramíneas) } \\
\hline Lolium multiflorium Lam. & 3,05 & 0,94 & 0,84 & 2,26 & 6,94 & 15,42 & 47,34 \\
\hline Lolium perenne $\mathrm{L}$. & 4,30 & 1,01 & 1,24 & 2,90 & 11,42 & 13,29 & 52,34 \\
\hline Lolium rigidium Gaudin & 2,38 & 0,37 & 0,87 & 2,07 & 16,41 & 9,56 & 68,68 \\
\hline Dactylius glomerata L. & 3,91 & 0,92 & 0,45 & 2,85 & 10,56 & 14,49 & 53,69 \\
\hline Festuca arundinaceae Schreb. & 4,21 & 1,06 & 0,96 & 2,55 & 11,98 & 11,78 & 55,33 \\
\hline Festuca pratensis Huds. & 4,09 & 0,99 & 1,04 & 2,74 & 10,95 & 13,29 & 53,13 \\
\hline Phleum pratense $\mathrm{L}$. & 4,05 & 1,05 & 1,05 & 3,18 & 10,43 & 15,31 & 50,22 \\
\hline \multicolumn{8}{|c|}{ Leguminosae o Fabaceae (Leguminosas) } \\
\hline Trifolium pratense $\mathrm{L}$ & 4,17 & 0,62 & 0,79 & 5,21 & 17,70 & 17,72 & 60,20 \\
\hline Trifolium repens $\mathrm{L}$. & 4,56 & 0,63 & 0,93 & 5,43 & 16,40 & 18,85 & 56,94 \\
\hline Trifolium subterraneum L. & 2,29 & 0,55 & 0,40 & 3,59 & 18,89 & 13,95 & 73,23 \\
\hline Medicago sativa $\mathrm{L}$. & 5,66 & 0,74 & 0,71 & 6,22 & 24,79 & 16,03 & 63,91 \\
\hline Medicago polymorpha L. & 2,96 & 1,61 & 0,38 & 4,46 & 21,29 & 15,00 & 71,57 \\
\hline Hedysarum coronarium $\mathrm{L}$. & 2,18 & 0,56 & 1,10 & 1,68 & 11,86 & 9,40 & 62,43 \\
\hline \multicolumn{8}{|c|}{ Compositae o Asteraceae (Compuestas) } \\
\hline Chrysanthemum coronarium $\mathrm{L}$. & 2,74 & 0,50 & 0,66 & 5,97 & 16,30 & 22,75 & 62,69 \\
\hline
\end{tabular}

Cabiddu et al. (2005); Dewhurst et al. (2006); Van Ranst et al. (2009); Dierking et al. (2010); Kalac y Samková (2010).

(*) Los nombres comunes correspondientes se recogen en el Anexo 2. 
El suministro de pasto fresco en la dieta de los animales rumiantes es la forma más natural y más eficaz de aumentar en su leche los niveles de ácidos grasos poliinsaturados, particularmente los de CLA (Stanton et al., 2003; De la Fuente y Juárez, 2004). Las ovejas que se alimentan con pasto fresco pueden proporcionar una leche cuyo contenido de CLA es bastante superior a la que se obtiene de ovejas alimentadas con dietas secas (Pulina et al., 2006; Biondi et al., 2008; Gómez-Cortés et al., 2009a), llegándose incluso a triplicar los niveles encontrados en dietas control (Cabiddu et al., 2005; Atti et al., 2006; Pulina et al., 2006; Ostrovsky et al., 2009). En la Figura 1.5 se representan algunos de los resultados obtenidos en leche de oveja.

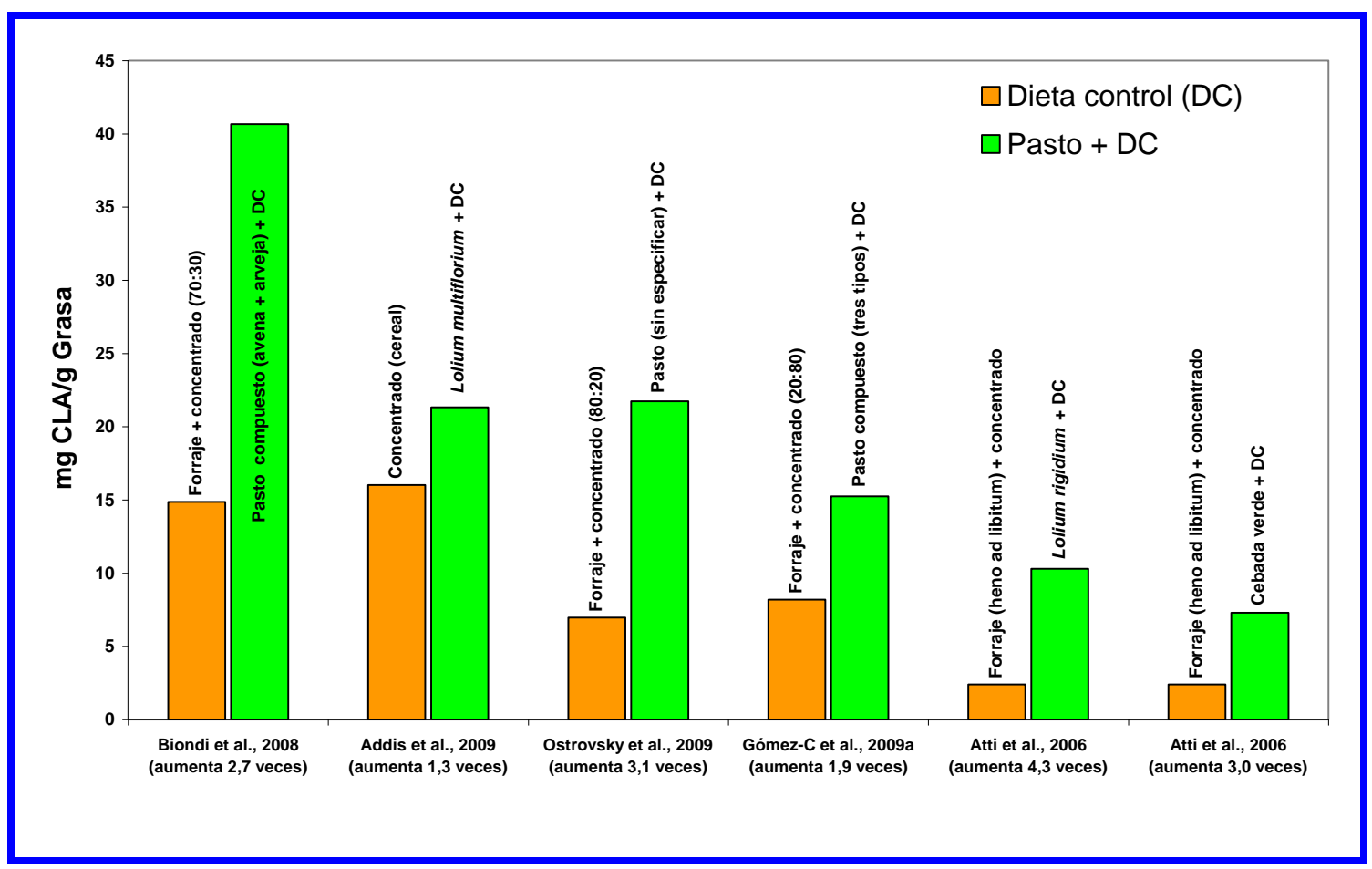

Figura 1.5. Contenido de CLA total en leche de ovejas alimentadas con diferentes tipos de pasto fresco.

El incremento de CLA en leche de ovejas alimentadas con pasto fresco puede atribuirse a la biohidrogenación y principalmente a la presencia en el pasto de ácido $\alpha$ linolénico, que sirve como sustrato para la formación de ácido vacénico (TVA, trans-11 $\mathrm{C}_{18: 1}$ ) en el rumen (Collomb et al., 2006). Como se muestra en la Tabla 1.13, la presencia de este ácido graso en el pasto fresco supera el $50 \%$ del total de ácidos grasos; esto justifica el aumento del contenido de CLA en leche de oveja, según los estudios mostrados en la Figura 1.5. De acuerdo a los datos que se representan en esta 
figura, es posible aumentar el contenido de CLA en leche ovina por encima de los 40 $\mathrm{mg} / \mathrm{g}_{\text {Grasa }}$ (Biondi et al., 2008). Sin embargo, este incremento también depende del tipo de dieta control, ya que según los datos mostrados en Figura 1.5, el mayor aumento relativo de CLA en leche (4,3 veces respecto a la dieta base) lo experimenta la muestra cuyo contenido de CLA total apenas supera los $10 \mathrm{mg} / \mathrm{g}_{\text {Grasa }}$ (Atti et al., 2006). Este mismo efecto también se ha observado en numerosos estudios realizados en leche y lácteos de vacuno, algunos de ellos recogidos en distintas revisiones bibliográficas (Collomb et al., 2006; Dewhurst et al., 2006; Chilliard et al., 2007; Kalac y Samková et al., 2010). Por lo tanto, para valorar el efecto real que tienen los pastos frescos sobre el contenido de CLA en leche, es importante considerar cuál es la contribución de ácidos grasos precursores que se encuentran presentes tanto en el pasto fresco como en la dieta seca que se suministre junto con el pasto.

El contenido de ácido $\alpha$-linolénico en el pasto está condicionado por los cambios estacionales y la disminución de este ácido graso en el pasto se asocia a un menor contenido de CLA en leche (Pulina et al., 2006). Dependiendo de la época del año, la etapa fenológica de los pastos puede ser distinta, encontrándose un mayor contenido de ácido $\alpha$-linolénico en la etapa vegetativa o de crecimiento que en la etapa reproductiva o de maduración (Cabiddu et al., 2005). Esto explicaría que, en general, los mayores niveles de ácido $\alpha$-linolénico se encuentren en pastos primaverales y, por consiguiente, que su consumo se traduzca en una leche más rica en CLA durante esta época del año que en cualquier otra (Addis et al., 2005; Cabiddu et al., 2006a). Cuando llega el verano, los niveles de ácido $\alpha$-linolénico en el pasto tienden a disminuir, por lo que es probable que la leche obtenida durante esta época tenga una menor concentración de CLA que en primavera (Nudda et al., 2005; Tsiplakou et al., 2006b; Cabiddu et al., 2009). En otoño e invierno, la disponibilidad de pasto fresco es mucho más limitada, sobre todo en determinadas regiones y países, siendo frecuente el suministro de forrajes secos y piensos que no suelen contribuir significativamente al aumento del contenido de CLA en leche (ver el apartado 1.3.1.2). La excepción parece encontrarse en pastos característicos de épocas invernales, como la Medicago polymorpha $L$., ya que cuando se ha suministrado el mismo en la dieta animal, el contenido de CLA en leche es mayor en invierno que en primavera (Addis et al., 2005; Cabiddu et al., 2006a). Por lo que hay que tener en cuenta el tipo de pasto disponible, independientemente de la época en que se suministre. 
La Tabla 1.14 muestra los valores del contenido de CLA en leche de oveja, según la época en la que se proporciona el pasto fresco. Hay que decir que no se encontraron datos suficientes para los meses otoñales, debido quizás a que, como se ha dicho previamente, la disponibilidad de pasto fresco en esta época es menor.

Tabla 1.14. Variación del contenido de CLA en leche de oveja según la época del año y el pasto fresco suministrado

\begin{tabular}{|c|c|c|c|}
\hline \multirow[b]{2}{*}{ Tipo de pasto } & \multicolumn{3}{|c|}{ Contenido de CLA (mg/g grasa ) } \\
\hline & $\begin{array}{c}\text { Invierno } \\
\text { (Ene. - Feb.) }\end{array}$ & $\begin{array}{c}\text { Primavera } \\
\text { (Mar. - May.) }\end{array}$ & $\begin{array}{c}\text { Verano } \\
\text { (Jun. - Ago.) }\end{array}$ \\
\hline Varios (sin especificar) ${ }^{(1)(2)(3)(4)(5)}$ & $6,50-9,22$ & $15,25-22,59$ & $10,64-14,78$ \\
\hline Lolium rigidium Gaudin ${ }^{(6)(7)}$ & $9,32-11,30$ & $12,05-14,02$ & --- \\
\hline Chrysanthemum coronarium L. ${ }^{(6)(7)}$ & $19,20-23,91$ & $19,39-21,93$ & --- \\
\hline Medicago polymorpha L. $^{(6)(7)}$ & $15,62-21,65$ & $10,82-15,53$ & --- \\
\hline Hedysarum coronarium L. ${ }^{\text {(6) (7) (8) }}$ & $11,20-12,42$ & $10,30-16,40$ & --- \\
\hline
\end{tabular}

Otro aspecto a tener en cuenta es la composición botánica del pasto. Como se puede observar en la Tabla 1.14, la tendencia general es encontrar un alto contenido de CLA en la leche de ovejas alimentadas con pasto fresco primaveral. Con algunas especies botánicas (como Lolium rigidium G. o Chrysanthemum coronarium L.), el contenido de CLA en leche suele ser casi constante, independientemente de la época del año en que se suministren, mientras que con otras (como la Medicago polymorpha L.), parece ser que el contenido de CLA en invierno es algo mayor que en primavera.

La principal explicación por la que se da esta variación en el contenido de CLA en leche de ovejas alimentadas con diferentes especies botánicas puede estar en el contenido de ácido $\alpha$-linolénico que se encuentre en cada tipo de pasto (ver Tabla 1.13). Las leguminosas forrajeras o las mezclas de éstas con otras familias botánicas de pasto (como las gramíneas o las compuestas), son las dietas frescas que parecen proporcionar los niveles más altos de CLA en leche (Addis et al., 2005; Cabiddu et al., 2005, 2006a y 2006b; Lourenço et al., 2008).

Por último, es importante destacar que una alimentación con pasto fresco puede llegar a influir en los niveles de ciertos isómeros minoritarios presentes en la leche. El trans-11,cis-13 $\mathrm{C}_{18: 2}$ y el trans-11,trans-13 $\mathrm{C}_{18: 2}$ son los ejemplos más destacados, ya que su contenido en leche puede llegar a alcanzar concentraciones tan altas o incluso 
mayores de las que se obtienen para el trans-7,cis-9. Gómez-Cortés et al. (2009a) encuentran que con el suministro de una mezcla de pasto fresco en la dieta ovina se puede aumentar de 0,04 a $1,15 \mathrm{mg} / \mathrm{g}_{\text {Grasa }}$ el contenido de trans-11,cis-13 en leche, mientras que con la misma dieta, el contenido de trans-7, cis-9 no supera los 0,41 $\mathrm{mg} / \mathrm{g}_{\text {Grasa }}$. Otros isómeros minoritarios que pueden incrementar significativamente su contenido en leche, cuando la alimentación de las ovejas consiste en pasto fresco, son el trans-12,trans-14 y el 12,14-(cis-trans/trans-cis) (Abilleira et al., 2009; Gómez-Cortés et al., 2009a; Ostrovsky et al., 2009).

\subsubsection{Alimentación con forraje y concentrado}

Este tipo de alimentación, conocida también como ración integral (TMR) consiste en suministrar a los animales distintas mezclas de forrajes secos y concentrados, sobre todo en aquellas épocas del año donde escasea el pasto fresco.

Los forrajes se componen de uno o más tipos de plantas secas, las cuales se someten a procesos de henificado o ensilado, como los henos de pasto seco (centeno, alfalfa, zulla o cualquier otra leguminosa forrajera) y los ensilados de maíz forrajero. La Tabla 1.15 muestra los contenidos porcentuales de ácidos grasos en algunos tipos de henos y ensilados empleados como forrajes. La composición de los concentrados es mucho más compleja que la de los forrajes. Generalmente se emplean granos de maíz (entero o molido), pulpa de remolacha, harina de soja, cebada, melaza y un pequeño porcentaje de minerales y complementos vitamínicos. En la Tabla 1.16 se recoge la composición porcentual de ácidos grasos presentes en algunos ingredientes empleados en concentrados. Hay que destacar el maíz por su contenido en grasa, lo que hace que su aporte en ácido linoleico sea más elevado.

Tabla 1.15. Composición de ácidos grasos (AG) en diferentes tipos de heno y ensilados empleados como forrajes en la alimentación animal

\begin{tabular}{c|c|ccccc}
\hline \multirow{2}{*}{ Heno y/o ensilado } & \multirow{2}{*}{ Total de AG $(\%)$} & \multicolumn{4}{|c}{ \% del total de ácidos grasos } \\
\cline { 3 - 6 } & & Palmítico & $\begin{array}{c}\text { Esteárico } \\
\text { C18:0 }\end{array}$ & $\begin{array}{c}\text { Oleico } \\
\text { C18:1 }\end{array}$ & $\begin{array}{c}\text { Linoleico } \\
\text { C18:2 }\end{array}$ & $\begin{array}{c}\boldsymbol{\alpha}-\text { Linolénico } \\
\text { C18:3 }\end{array}$ \\
\hline Alfalfa henificada & 1,20 & 27,00 & 3,50 & 10,00 & 22,00 & 33,00 \\
Dáctilo (heno) & 1,80 & 24,10 & 2,80 & 3,40 & 15,50 & 35,00 \\
Raigrás perenne (heno) & 3,20 & 15,80 & 1,80 & 2,00 & 14,00 & 55,90 \\
Raigrás perenne (ensilado) & 3,70 & 21,20 & 2,00 & 2,80 & 13,40 & 52,20 \\
Maíz forrajero (ensilado) & 4,00 & 15,60 & 2,40 & 23,70 & 48,60 & 3,40 \\
\hline
\end{tabular}

De Blas et al. (2003); Ferlay et al. (2006). 
Tabla 1.16. Composición de ácidos grasos (AG) en diferentes tipos de ingredientes utilizados como concentrados en la alimentación animal

\begin{tabular}{c|cc|ccccc}
\hline \multirow{2}{*}{ Concentrados } & \multirow{2}{*}{$\begin{array}{c}\text { Extracto etéreo } \\
(\boldsymbol{\%})\end{array}$} & $\begin{array}{c}\text { Total de AG } \\
(\boldsymbol{\%})\end{array}$ & \multicolumn{4}{|c}{ \% del total de ácidos grasos } \\
\cline { 4 - 7 } & & & $\begin{array}{c}\text { Palmítico } \\
\mathbf{C 1 6 : 0}\end{array}$ & $\begin{array}{c}\text { Esteárico } \\
\mathbf{C 1 8 : 0}\end{array}$ & $\begin{array}{c}\text { Oleico } \\
\text { C18:1 }\end{array}$ & $\begin{array}{c}\text { Linoleico } \\
\text { C18:2 }\end{array}$ & $\begin{array}{c}\boldsymbol{\alpha} \text {-Linolénico } \\
\text { C18:3 }\end{array}$ \\
\hline Cebada cervecera & 2,00 & 1,40 & 23,00 & 1,00 & 13,00 & 56,00 & 6,00 \\
Harina de soja & 1,70 & 1,10 & 11,00 & 4,00 & 22,00 & 54,00 & 8,00 \\
Maíz común español & 3,60 & 3,24 & 11,00 & 2,00 & 27,00 & 56,00 & 1,00 \\
Pulpa de remolacha & 0,80 & 0,32 & 21,50 & 1,50 & 10,00 & 57,10 & 10,50 \\
\hline
\end{tabular}

De Blas et al. (2003).

En muchos estudios experimentales, se han utilizado como dieta control distintas combinaciones de forraje y concentrado, con el fin de observar cuáles son los cambios que se producen en la composición de la leche cuando los animales son alimentados con otros tipos de dietas, especialmente cuando se suministran determinados suplementos lipídicos.

Sin embargo, los forrajes y concentrados por sí mismos también influyen sobre la composición de ácidos grasos en la leche; esto dependerá no solamente del tipo de forraje o concentrado que se suministre, sino también de las cantidades en que se proporcionen. Cuando el porcentaje de concentrado en la dieta no excede el $50-60 \%$, el contenido de grasa en leche no varía significativamente; sin embargo, por encima de este porcentaje es probable que disminuya el contenido de grasa y pueda modificarse la composición de ácidos grasos. Una posible explicación a estos cambios puede estar en que al variar la proporción forraje-concentrado, se produzcan modificaciones en la biohidrogenación ruminal de los ácidos grasos presentes en la dieta (Chilliard et al., 2007).

Tabla 1.17. Contenido de CLA en leche de ovejas alimentadas con distintas proporciones de forraje y concentrado

\begin{tabular}{|c|c|c|c|}
\hline \multirow{2}{*}{$\begin{array}{l}\text { Proporción } \\
\text { Forraje-Concentrado }\end{array}$} & \multicolumn{2}{|c|}{ Intervalo de variación $\left(\mathrm{mg} / \mathrm{g}_{\text {Grasa }}\right) *$} & \multirow{2}{*}{ Referencias } \\
\hline & Mín. & Máx. & \\
\hline $20: 80$ & 7,53 & 10,50 & Toral et al. (2010a); Hervás et al. (2008b) \\
\hline $50: 50$ & $(4,19)$ & $(10,35)$ & Toral et al. (2010b); Tsiplakou et al. (2010) \\
\hline $60: 40$ & 2,45 & 9,41 & Reynolds et al. (2006); Martini et al. (2010) \\
\hline $75: 25$ & 4,70 & 4,98 & Antongiovani et al. (2004); Mele et al. (2006) \\
\hline Otras & $(6,20)$ & $(14,87)$ & Ostrovsky et al. (2009); Biondi et al. (2008) \\
\hline
\end{tabular}

${ }^{(*)}$ Los valores entre paréntesis se refieren al contenido de CLA como cis-9,trans-11; el resto de valores corresponden al contenido de CLA total. 
En la Tabla 1.17 se dan algunos valores máximos y mínimos del contenido de CLA en leche de oveja, según la proporción forraje-concentrado (F/C) suministrado. El contenido de CLA total más bajo encontrado en la bibliografía fue de $2,45 \mathrm{mg} / \mathrm{g}_{\text {Grasa }}$ (F/C 60:40, Reynolds et al., 2006), mientras que el más alto era de $14,87 \mathrm{mg} / \mathrm{g}_{\text {Grasa }}$ (F/C 80:20, Biondi et al., 2008).

Al observar estos resultados, es posible llegar a pensar que, cuanto mayor sea la proporción de concentrado en la dieta, mayor será el contenido de CLA en la leche. Sin embargo, este aumento no necesariamente dependerá de la proporción forrajeconcentrado, sino más bien de la cantidad de ácido linoleico y $\alpha$-linolénico que ambos (forraje y concentrado) aporten a la dieta. En todo caso, hay que decir que la repercusión del forraje-concentrado sobre el contenido de CLA en leche no parece ser muy importante. Primero, porque los niveles de ácido linoleico y/o $\alpha$-linolénico suelen ser mucho más bajos que los encontrados en pasto fresco u otro tipo de suplemento. Y segundo, porque el incremento de CLA, observado en la leche de ovejas alimentadas con determinados tipos de forrajes y concentrados, es mínimo y poco significativo (Dewhurst et al., 2006). Esta última afirmación es consistente con los datos publicados en dos estudios experimentales diferentes (Antongiovani et al., 2004; Mele et al., 2006). Utilizando las mismas proporciones de forraje-concentrado (75:25 y 60:40), observaron un ligero incremento en el contenido de CLA en leche de oveja. En el primero de ellos, el incremento medio fue de $+2,09 \mathrm{mg} / \mathrm{g}_{\text {Grasa }}$ (de 4,98 a 7,07 mg/g $/ \mathrm{g}_{\text {Grasa }}$ ) y en el segundo de $+1,98 \mathrm{mg} / \mathrm{g}_{\text {Grasa }}$ (de 4,70 a $6,68 \mathrm{mg} / \mathrm{g}_{\text {Grasa }}$ ).

\subsubsection{Suplementos de origen vegetal}

Estos suplementos están constituidos principalmente por semillas o aceites provenientes de plantas oleaginosas. En la alimentación animal se suelen suministrar junto con las raciones integrales (TMR), ya que pueden llegar a cubrir las deficiencias de ciertos ácidos grasos, especialmente la de aquellos que pueden servir como precursores de CLA en el organismo animal. Los suplementos grasos de origen vegetal pueden condicionar la composición de ácidos grasos en la leche de oveja. Esto dependerá de la forma en que se suministren (ya sea como semillas o como aceites) y de la cantidad de ácidos grasos que estos aporten a la dieta. En la Tabla 1.18 se muestra la composición en ácidos grasos de algunas semillas y aceites vegetales. 
Tabla 1.18. Composición de ácidos grasos (AG) en diferentes tipos de semillas y aceites vegetales

\begin{tabular}{cc|c|ccccc}
\hline \multirow{2}{*}{ Suplemento } & \multirow{2}{*}{ \% Grasa } & \multicolumn{5}{|c}{ \% del total de ácidos grasos } \\
\cline { 3 - 7 } & & $\begin{array}{c}\text { Palmítico } \\
\text { C16:0 }\end{array}$ & $\begin{array}{c}\text { Esteárico } \\
\text { C18:0 }\end{array}$ & $\begin{array}{c}\text { Oleico } \\
\text { C18:1 }\end{array}$ & $\begin{array}{c}\text { Linoleico } \\
\text { C18:2 }\end{array}$ & $\begin{array}{c}\text { a-Linolénico } \\
\text { C18:3 }\end{array}$ \\
\hline \multirow{4}{*}{ Algodón } & --- & 23,80 & 2,50 & 18,80 & 50,20 & 0,20 \\
& Cártamo & --- & 6,10 & 2,30 & 13,40 & 76,00 & 0,30 \\
& Colza & --- & 5,00 & 2,00 & 57,50 & 20,50 & 8,50 \\
& Girasol & --- & 6,40 & 4,50 & 22,10 & 65,60 & 0,50 \\
& Lino & --- & 6,10 & 3,40 & 18,40 & 16,80 & 55,00 \\
& Oliva & --- & 12,10 & 2,60 & 72,50 & 9,40 & 0,60 \\
& Maíz & --- & 10,70 & 2,40 & 27,10 & 55,80 & 1,00 \\
& Palma & --- & 42,50 & 4,80 & 40,10 & 9,70 & Trazas \\
& Soja & --- & 10,80 & 3,90 & 23,90 & 52,10 & 7,80 \\
\hline \multirow{3}{*}{ Semillasyyyyyyyyyyyy} & Algodón & 17,9 & 24,00 & 2,00 & 19,00 & 51,00 & 0,20 \\
& Colza & 40,7 & 5,00 & 2,00 & 56,00 & 22,00 & 9,00 \\
& Girasol & 44,6 & 6,50 & 4,00 & 22,00 & 65,00 & 0,40 \\
& Linaza & 34,7 & 6,50 & 5,00 & 21.00 & 13,00 & 51,00 \\
\hline
\end{tabular}

De Blas et al. (2003); Dubois et al. (2007).

En lo que respecta al CLA, su contenido en leche aumentará según la cantidad de ácido linoleico y $\alpha$-linolénico que aportan tanto el suplemento graso como la dieta base (o TMR). Ambos ácidos grasos son capaces de aumentar los niveles de ácidos trans- $\mathrm{C}_{18: 1}$ en el rumen. Sin embargo, sólo con el ácido linoleico se favorece la formación de CLA mediante las dos vías de biosíntesis (ruminal y endógena), mientras que con el ácido $\alpha$-linolénico sólo es posible la formación de CLA mediante síntesis endógena a partir del ácido vacénico (ver el apartado 1.2.2). Este hecho podría explicar la mayor efectividad del ácido linoleico respecto al $\alpha$-linolénico.

Entre los suplementos ricos en ácido linoleico y $\alpha$-linolénico, hay que destacar los aceites y semillas provenientes de soja, algodón, lino, girasol, cártamo y colza. Su contenido en estos precursores de CLA es bastante elevado, algo que contrasta con los bajos niveles de ácido linoleico y $\alpha$-linolénico presentes en las TMR. Sin embargo, es importante tener en cuenta el aporte a la dieta de dichas TMR a la hora de evaluar el efecto real de los suplementos grasos sobre el contenido de CLA en leche.

Otro aspecto a tener en cuenta es la forma de incorporar estos suplementos grasos en la dieta animal, siendo frecuente el uso de aceites y semillas oleaginosas. La efectividad de una u otra forma de adición dependerá de la facilidad con la que los microorganismos del rumen puedan acceder a la matriz y, por tanto, disponer de los 
ácidos grasos necesarios para llevar a cabo la biohidrogenación (Dhiman et al., 2000; Khanal y Olson, 2004).

Adición como aceites: En general, los aceites suelen ser mucho más efectivos que las semillas en el aumento del CLA en leche. Varios estudios han demostrado esta efectividad, empleando en la dieta animal distintos tipos de aceites vegetales, cuyos porcentajes, dentro de la ración suministrada, oscilan entre un 1 y un 6\%. En ovejas alimentadas con este tipo de aceites, se han encontrado aumentos significativos del contenido de CLA en leche, sobre todo con aceite de soja (Gómez-Cortés et al., 2008a), aceite de girasol (Hervás et al., 2008b; Castro et al., 2009; Bodas et al., 2010; GómezCortés et al., 2011) y aceite de lino (Bodas et al., 2010). Esta efectividad es menor cuando se emplea aceite de oliva (Gómez-Cortés et al., 2008b; Bodas et al., 2010) o aceite de palma hidrogenado (Castro et al., 2009; Bodas et al., 2010), debido a que en estos aceites, el contenido de ácido linoleico es mucho más bajo, mientras que el de ácido $\alpha$-linolénico es prácticamente inexistente. En la Figura 1.6 se muestran los valores máximos de CLA encontrados en leche de oveja, alimentadas con algún tipo de aceite vegetal. Según los resultados, parece que el mayor aumento en el contenido de CLA se da con aceite de girasol y con el aceite de lino.

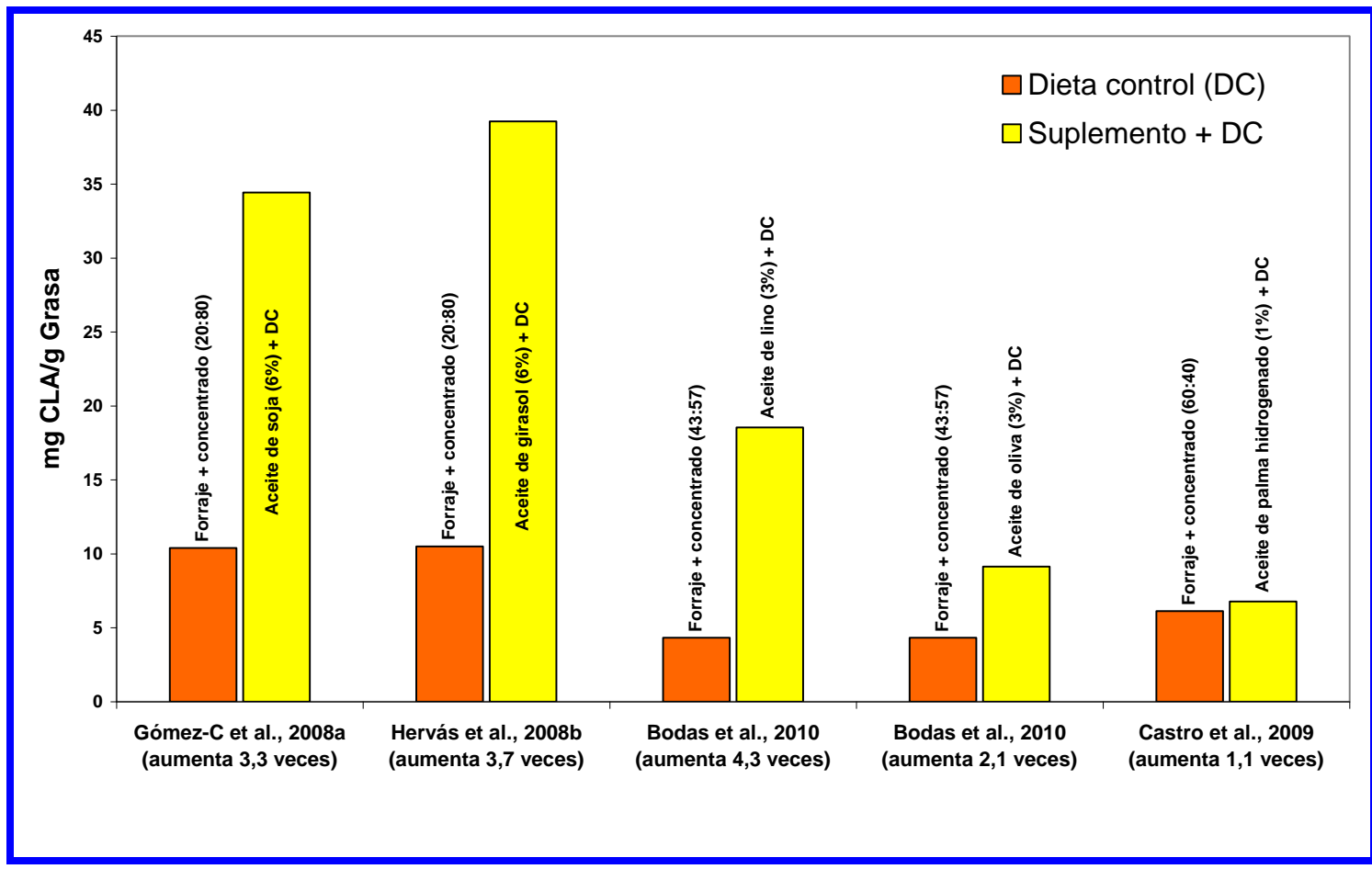

Figura 1.6. Contenido de CLA total en leche de ovejas alimentadas con distintos suplementos de aceites vegetales. 
Una de las desventajas de proporcionar dietas con grandes cantidades de aceites vegetales es la posible inhibición de la actividad microbiológica en el rumen, pudiendo afectar de forma negativa al rendimiento lácteo y a la composición de la leche (Pulina et al., 2006). Diversos estudios han demostrado que, con la adición de hasta un $6 \%$ de aceite en la dieta de ovinos, es posible aumentar el contenido de CLA en leche, sin que se vea afectado el rendimiento lácteo o la composición de la leche (Gómez-Cortés et al., 2008a y 2011; Hervás et al., 2008a y 2008b). En bovinos, estos suplementos lipídicos están restringidos en su dieta a niveles menores del 7\% en materia seca, según Gómez-Cortés (2010). Las alternativas que se dan para superar estos porcentajes en la dieta animal son el uso de semillas o de aceites protegidos, ya que sus efectos fisiológicos en el rumen son menos agresivos (Gómez-Cortés, 2010).

Adición como semillas: Las semillas añadidas a la dieta pueden estar intactas (Luna et al., 2005b) o ser sometidas previamente a procesos como tratamientos térmicos, molienda, micronización o extrusión (Gómez-Cortés et al., 2009b; Mele et $a l ., 2011)$. Con el uso de determinadas semillas (como la linaza o el girasol) es posible aumentar los niveles de CLA en la leche de oveja (Luna et al., 2005b; Zhang et al., 2006a; Addis et al., 2009). Este incremento, comparado con el de sus respectivos aceites, suele ser menor; sin embargo, en la dieta animal es posible utilizar porcentajes mucho más altos de semillas que de aceites (Zhang et al., 2006b). En la Figura 1.7 se muestra que las semillas extrusionadas dan un contenido de CLA en leche mucho más alto con menor porcentaje añadido que con las semillas enteras.

Adición como constituyente graso protegido: En la dieta animal, los aceites vegetales también se pueden suministrar de forma protegida. De esta manera, es posible evitar que determinados ácidos grasos puedan sufrir transformaciones o degradaciones en el rumen. Esto se puede lograr mediante la emulsificación o encapsulación en una matriz proteica o mediante la conversión en sales de calcio, inertes al $\mathrm{pH}$ ruminal (Chouinard et al., 2001; Huang et al., 2009). Estos constituyentes son muy efectivos en el aumento de los niveles de CLA en la grasa láctea. Sin embargo la suplementación con este tipo de dietas tiene un coste muy alto y en algunos casos, su aplicación se ha traducido en una disminución del contenido graso en leche y de ciertos ácidos grasos de cadena corta y media (Stanton et al., 2003; De la Fuente y Juárez, 2004). 


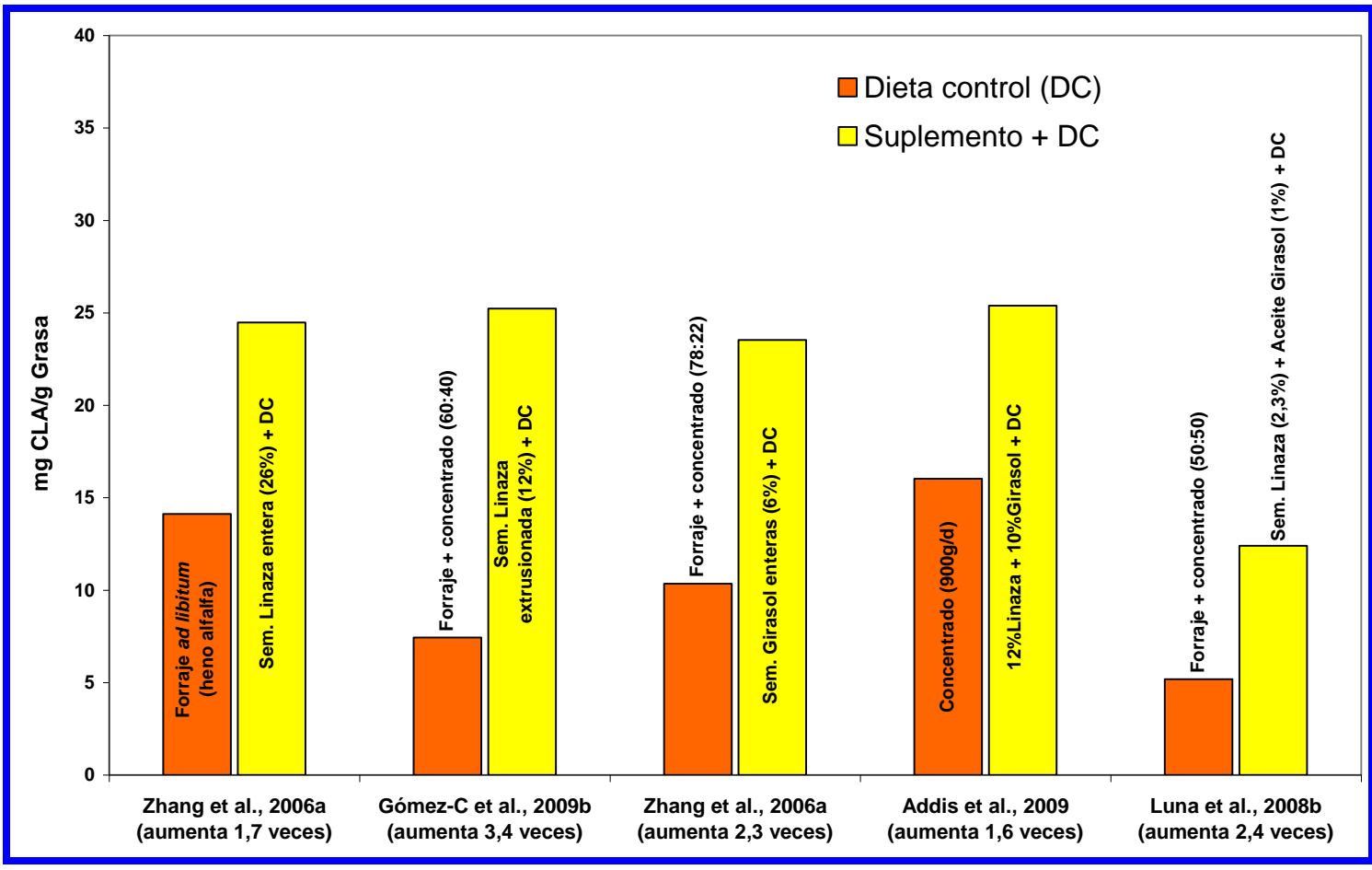

Figura 1.7. Contenido de CLA total en leche de ovejas alimentadas con distintos suplementos de semillas vegetales.

\subsubsection{Suplementos de origen marino}

Algunos de estos suplementos se han añadido a la dieta de los animales como aceite de pescado (Shingfield et al., 2003; Capper et al., 2007; Toral et al., 2010a), aceite de algas (Reynolds et al., 2006), harinas de pescado (AbuGhazaleh et al., 2002 y 2004) o como algas marinas (Toral et al., 2010b). De todos ellos, los que parecen ser más efectivos a la hora de aumentar el contenido de CLA en leche son los aceites marinos.

A diferencia de los suplementos de origen vegetal, los de origen marino contienen un bajo porcentaje de ácido linoleico y $\alpha$-linolénico, pero son ricos en ácidos grasos poliinsaturados de 20 y 22 átomos de carbono (PUFA). Se podría pensar que estos ácidos grasos no son capaces de inducir la formación de CLA en el rumen. De hecho, el mecanismo mediante el cual estos suplementos lipídicos aumentan el contenido de CLA en leche aún no está suficientemente esclarecido (Luna, 2006). Sin embargo, algunos autores coinciden en que los PUFA, suministrados junto con otros suplementos ricos en ácido linoleico o $\alpha$-linolénico, podrían inhibir la transformación de ácido vacénico en ácido esteárico en el rumen, y por este mecanismo incrementar el contenido de CLA en leche (De la Fuente y Juárez, 2004; Khanal y Olson, 2004). 
La suplementación de aceites y algas marinas en la dieta animal podría provocar una disminución del rendimiento lácteo y del contenido total de grasa en leche. Además, la leche contendría ácidos grasos más susceptibles a la oxidación (De la Fuente y Juárez, 2004; Haro et al., 2006). Estos inconvenientes se podrían contrarrestar en cierta medida, combinando los suplementos marinos con aquellos que son ricos en ácido linoleico y/o $\alpha$-linolénico.

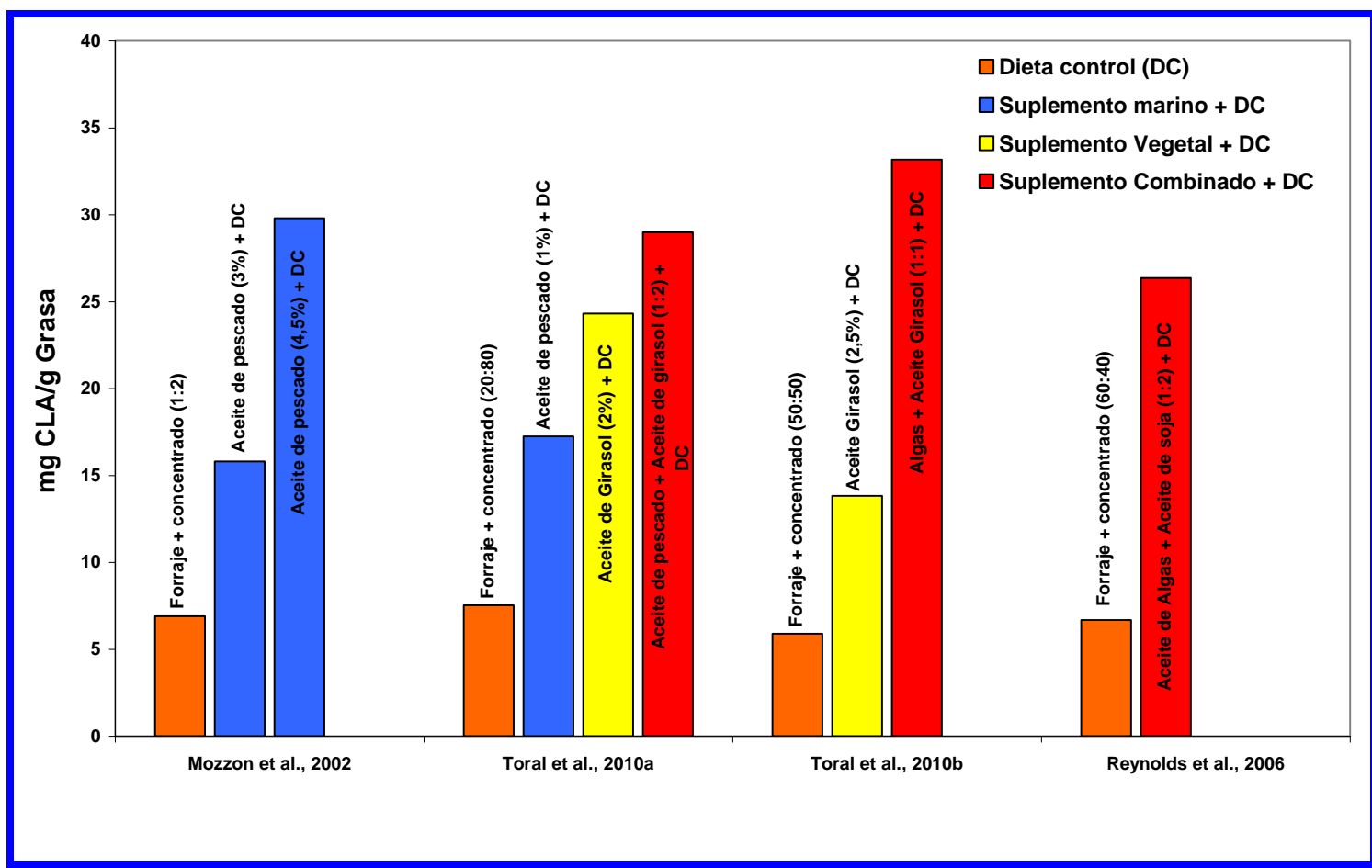

Figura 1.8. Contenido de CLA total en leche de ovejas alimentadas con distintos suplementos de origen marino o combinaciones de los mismos con aceites vegetales.

La Figura 1.8 muestra algunos estudios relacionados con la utilización de suplementos de origen marino en la dieta animal, ya sea como aceites, como algas o combinación de los mismos con aceites vegetales. En general, la efectividad de los aceites marinos y las algas en el aumento del contenido de CLA en leche es comparable a la de los aceites vegetales. Incluso con cantidades más bajas de aceite de pescado (1\%) fue posible obtener una leche de oveja con niveles de CLA casi comparables a los encontrados cuando se suministró el doble de aceite de girasol, aunque el mayor aumento en el contenido de CLA $\left(28,98 \mathrm{mg} / \mathrm{g}_{\text {Grasa }}\right.$, casi cuatro veces el contenido de CLA inicial) se encontró combinando ambos suplementos (Toral et al., 2010a). Reynolds et al., (2006) obtuvieron resultados similares (el contenido de CLA en leche 
aumentó de 6,68 a 26,36 mg/g $\mathrm{g}_{\text {Grasa }}$ ), suministrando aceite de algas y aceite de soja (en una proporción 1:2). Finalmente, en el estudio publicado por Toral et al. (2010b) se observó que con la utilización de cantidades equivalentes de algas marinas y aceite de girasol (2,4 y 2,5\%, respectivamente), el contenido de CLA en leche podría aumentar hasta casi seis veces, respecto al encontrado en la dieta básica empleada (de 5,90 a $\left.34,80 \mathrm{mg} / \mathrm{g}_{\text {Grasa }}\right)$.

De estos resultados se podría deducir que con los suplementos de origen marino, solos o combinados con aceites vegetales, es posible aumentar considerablemente los niveles de CLA en leche (Pulina et al., 2006; Chilliard et al., 2007). Algo que parece bastante prometedor, sobre todo si se utilizan combinaciones de ambos suplementos, ya que además de ser más efectivas que cuando se suministran de forma individual, repercuten en menor grado sobre el rendimiento lácteo.

\subsubsection{Factores asociados a procesos tecnológicos}

Entre los procesos tecnológicos utilizados para el procesado y transformación de la leche, se pueden mencionar los siguientes: tratamientos térmicos, homogeneización, fermentación, maduración, conservación, almacenamiento, etc. Algunos de ellos han sido estudiados con el fin de observar su influencia sobre el contenido de CLA en productos lácteos (Rodríguez-Alcalá et al., 2007 y 2009), principalmente en quesos (Luna et al., 2005c y 2007).

Hay que señalar que la influencia de los procesos tecnológicos sobre el contenido de CLA en leche y derivados lácteos, ha generado cierta controversia. En los primeros trabajos se encontró una gran variabilidad en las concentraciones de CLA, con aumentos que se atribuyeron principalmente al calentamiento previo de la leche (Aneja y Murthy, 1990; Shantha et al., 1992; García-López et al., 1994), al proceso de maduración (Ha et al., 1989) o a la utilización de bacterias productoras de isomerasas (Parodi, 2003). Este posible aumento del contenido de CLA en determinados productos lácteos se intentó explicar a través de la oxidación del ácido linoleico durante las etapas del procesado y maduración. Según este mecanismo, el ácido linoleico presente en la leche se convierte en un radical libre, el cual posteriormente reacciona con un agente donador de hidrógeno para formar un sistema de dobles enlaces conjugados. La temperatura, el oxígeno y la presencia de moléculas donadoras de hidrógeno son 
factores que podrían ejercer una influencia decisiva (Ha et al., 1989; De la Fuente y Juárez, 2004).

García-López et al. (1994) encontraron que el contenido de CLA en quesos aumentaba únicamente en las etapas relacionadas con el tratamiento térmico. Estos incrementos podían alcanzar un $14 \%$ y se atribuyeron a la auto-oxidación del ácido linoleico bajo condiciones anaerobias durante las etapas de calentamiento. Shantha et al. (1995) también atribuyeron los aumentos en el contenido de CLA en muestras de yogur y mantequilla a los procesos de fabricación de los mismos, aunque no observaron variaciones en el contenido de CLA cuando estos productos lácteos fueron almacenados durante 6 semanas.

El empleo de temperaturas muy elevadas $\left(200^{\circ} \mathrm{C}, 15 \mathrm{~min}.\right)$, puede inducir pérdidas significativas en el contenido de CLA presente en la grasa láctea, llegando a alcanzar el 20 y 32\% (Precht et al., 1999). A esa temperatura, el ácido ruménico (cis9,trans-11) puede sufrir una isomerización posicional, conocida como reordenamiento sigmatrópico, transformándose en el isómero trans-8,cis-10. Dicho isómero podría emplearse como indicador del tratamiento térmico en grasas naturales y en aceites que contienen CLA (Destaillats et al., 2005). También se han encontrado descensos importantes en el contenido de CLA en quesos calentados en horno de microondas (a temperaturas por encima de $94{ }^{\circ} \mathrm{C}$ ). Dichas pérdidas eran del $20 \%$ y del $52 \%$, cuando las muestras se calentaban durante 5 y 10 minutos, respectivamente (Herzallah et al., 2005).

Sin embargo, en ninguno de los estudios más recientes se ha podido demostrar que tales procesos tecnológicos contribuyan de manera significativa al aumento o disminución del contenido de CLA en la grasa láctea (Luna et al., 2005c y 2007). Además, estos pequeños cambios no son comparables con los efectos ocasionados por la adición a la dieta de determinados suplementos. Según Herzallah et al. (2005), la pasteurización de la leche no tiene un efecto significativo sobre el contenido de CLA, aunque sí observan una disminución del contenido de CLA en leche sometida a un proceso UHT o a calentamiento con microondas. Resultados publicados recientemente corroboran que la pasteurización, aunque se empleen temperaturas relativamente elevadas (70 a $90^{\circ} \mathrm{C}, 5$ minutos), permite mantener la cantidad de CLA inicialmente presente en leche sin tratar (Zengin et al., 2011). 
En leche de oveja pasteurizada $\left(73^{\circ} \mathrm{C}, 15\right.$ segundos), se encontró que el contenido de CLA total no varía, pero sí se producen cambios en la distribución de algunos isómeros: el cis-9,trans-11 y el trans-10,trans-12 aumentan y, por el contrario, el cis-10,cis-12 y otros isómeros no especificados, se reducen (Buccioni et al., 2010). A efectos comparativos entre trabajos, las modificaciones en el perfil de isómeros hay que considerarlas con cautela puesto que, en muchos casos, no se están determinando los mismos isómeros y a veces se trata de variaciones relativas pero que no tienen el mismo significado cuando se refieren a valores absolutos.

La homogeneización de leche de vaca, oveja o cabra, con altas presiones (350 $\mathrm{MPa}$ ) no provocó modificaciones en el contenido de CLA total, ni en la distribución de isómeros (Rodríguez-Alcalá et al., 2009). En leche materna, se han comparado los efectos que sobre algunos nutrientes puede producir un tratamiento con altas presiones $\left(400,500\right.$ y $600 \mathrm{MPa} ; 22,24,5$ y $\left.27^{\circ} \mathrm{C}\right)$ y una pasteurización clásica $\left(62,5^{\circ} \mathrm{C}, 30\right.$ minutos). En lo que respecta al CLA, no se encontraron variaciones en los isómeros cis9,trans-11 y trans-10,cis-12 (Moltó-Puigmartí et al., 2011).

La mayoría de los resultados encontrados en la bibliografía están relacionados con el efecto del procesado en quesos. Werner et al. (1992), determinan cambios poco significativos en el contenido de CLA de diversos tipos de quesos. En un estudio con quesos tipo Mozzarella y Cheddar, tampoco se observaron cambios en los niveles de CLA durante las 32 semanas que fueron almacenados (Boylston y Beitz, 2002). Partidario et al. (2008) no encontraron diferencias significativas en el contenido individual de isómeros CLA en tres tipos de quesos ovinos portugueses, aunque sí observaron ligeros aumentos de cis-9,trans-11 y ligeros descensos de trans-7,cis-9, cuando se compararon con la leche de partida. Luna et al. (2005c) tampoco determinaron pérdidas importantes en el contenido de este isómero en quesos de leche de vaca. Luna et al. (2007) no detectan diferencias significativas en el contenido de CLA de diferentes quesos españoles con denominación de origen (Manchego, Mahón y Cabrales), cuando se sometieron a períodos de maduración de 3 y 6 meses. Herzallah et al. (2005) no observaron variaciones importantes en el contenido de CLA presente en quesos, cuando se sometieron a un calentamiento con agua a ebullición (la pérdida en el contenido de CLA total no superó el 1\%) o durante su almacenamiento. 
Rodríguez-Alcalá y Fontecha (2007), evaluaron el contenido de CLA en 6 productos lácteos enriquecidos con Tonalín ${ }^{\circledR}$, analizados después de procesados y varias semanas después de estar almacenados en refrigeración. Aunque observaron una disminución del CLA total en muestras de queso fresco analizadas después de 10 semanas (relacionada posiblemente con un aumento de la microbiota), cabe decir que, en general, la influencia del procesado y del almacenamiento sobre el contenido de isómeros mayoritarios fue insignificante. Respecto a los isómeros minoritarios, sí encontraron que algunos de ellos pueden disminuir (cis-11,trans-13 y trans-8,cis-10) o desaparecer (algunos $c i s$-cis) durante estos procesos, en particular cuando se realiza un tratamiento térmico. Además, en leche en polvo, se observan incrementos significativos de isómeros trans-trans, en concreto trans-9,trans-11 y trans-10,trans-12.

En general, se considera que la concentración de CLA en la leche procesada y/o almacenada depende fundamentalmente del contenido en la leche cruda, siendo poco relevante el efecto del procesado (Dhiman et al., 2005; Luna, 2006; Luna et al., 2005c Bisig et al., 2007; Prandini et al., 2009; Gómez-Cortés, 2010). En todo caso, es necesario conocer la influencia real en leches comerciales.

El empleo de fermentos lácticos o cepas de cultivo iniciadores, capaces de convertir ciertos ácidos grasos poliinsaturados no esterificados (como el ácido linoleico "libre") en CLA, incrementa su contenido en productos fermentados, como el yogur (Akalin et al., 2007; Yadav et al., 2007). Estudios in vitro con determinadas bacterias han demostrado que este efecto se debe a las isomerasas presentes en las bacterias utilizadas. Akalin et al. (2007) emplearon Lactobacillus acidophilus o Bifidobacterium animalis en yogures que contenían un $2 \%$ de fructooligosacáridos, observando un incremento en el contenido de CLA hasta 3 veces superior, comparado con los yogures no tratados con este tipo de fermentos. Yadav et al. (2007) observaron este mismo efecto al añadir L. acidophilus y L. casei, también en yogures. Sin embargo, a pesar de parecer un procedimiento bastante interesante para conseguir mayores contenidos de CLA, se desconoce si dichos efectos pueden darse a escala industrial. Además, una desventaja de utilizar estas cepas de cultivo es la necesidad de un ácido graso poliinsaturado como sustrato, el cual podría influir negativamente sobre la calidad organoléptica del producto fermentado, ya que es más susceptible a la oxidación (Collomb et al., 2006; Bisig et al., 2007). En trabajos posteriores se recoge que 
determinadas bacterias son capaces de aumentar el contenido de CLA cuando el ácido linoleico se añade en forma de triglicérido, pero el porcentaje de conversión es menor y se necesita un período de incubación más largo que cuando se añade en forma libre (Rodríguez-Alcalá et al., 2011). Todo ello indica la necesidad de realizar investigaciones que permitan no sólo conocer la viabilidad económica de estos procesos en la industria, sino también obtener un producto con un buen sabor.

En leche fermentada con la fracción grasa modificada para enriquecerla en ácidos grasos n-3, no se detectaron cambios en el contenido de CLA atribuibles al proceso de fermentación ni a su almacenamiento en refrigeración $\left(4^{\circ} \mathrm{C}\right)$ durante 21 días. Se emplearon Streptococcus thermophilus, Lactobacillus acidophilus y Bifidobacterium BB-12. Además, se estudió el efecto de las proteínas del suero, concluyéndose que la presencia de las mismas no altera el contenido de CLA (Luna et al., 2004).

\subsubsection{Otros factores relacionados con el propio animal}

La influencia que pueden tener estos factores sobre el contenido de CLA en leche puede ser variada y relativa. Entre estos factores, se pueden mencionar: la población microbiana en el rumen, el rendimiento lechero, la producción de grasa láctea y la actividad enzimática de la $\Delta^{9}$-desaturasa en la glándula mamaria (Gómez-Cortés, 2010). Este último factor es el que más se ha estudiado (Palmquist et al., 2005), y aunque existe cierta controversia sobre el mecanismo que regula la actividad enzimática de la $\Delta^{9}$-desaturasa, lo que si parece estar claro es que entre dos animales de la misma especie y raza, dicha actividad puede ser muy diferente (Bauman et al., 2003).

Se han encontrado, por ejemplo, diferencias significativas entre los contenidos de ácido linoleico conjugado de distintas razas de ovejas (Tabla 1.19). Se cree que estas diferencias vienen marcadas por la presencia del sustrato (ácido vacénico) y no tanto por la propia actividad enzimática de la $\Delta^{9}$-desaturasa en la glándula mamaria (Tsiplakou et al., 2008b). Otros factores como el período de lactancia (De la Fuente et al., 2009) y la edad del animal (Barbosa et al., 2003) pueden afectar al contenido de CLA en leche. Aun así, muchos de estos resultados no han podido ser contrastados con datos de otras publicaciones, y además, las variaciones encontradas son poco relevantes, si se compara con la variación de CLA que puede ejercer la dieta animal. Según De la Fuente et al. (2009), las variaciones en el contenido de CLA en leche durante la 
lactación pueden llegar a ser significativas, debido quizás a que en este período hay una variación del contenido de grasa en la leche y un aumento de la relación CLA/TVA. Barbosa et al. (2003) observaron un mayor contenido de CLA en la leche de ovejas con un rango de edad de entre 8 y 10 años $(1,73 \%)$, comparadas con aquellas cuya edad estaba entre $1-4$ años $(1,53 \%)$ y entre $5-7$ años $(1,27 \%)$.

Tabla 1.19. Contenido de CLA en leche según la raza ovina

\begin{tabular}{|c|cccc}
\hline Referencia & \multicolumn{4}{|c}{ CLA total (\% respecto al total de ácidos grasos) } \\
\hline Tsiplakou et al., 2008a & Awassi & Lacaune & Friesland & Chios \\
Dieta control (F/C 50:50) & 0,72 & 0,64 & 0,64 & 0,68 \\
Pasto (sin especificar cuál) & 0,96 & 0,88 & 1,00 & 0,90 \\
\hline Luna et al., 2005a & Awassi & Manchega & Churra & Assaf \\
No especifican dieta & 0,97 & 0,62 & 0,96 & 0,57 \\
\hline Barbosa et al., 2003 & Blanca & Negra & Churra & Várzea \\
No especifican dieta & 1,46 & 1,46 & 1,45 & 1,59 \\
\hline
\end{tabular}




\subsection{ASPECTOS FUNCIONALES DEL CLA}

El ácido linoleico conjugado ha despertado un interés creciente por sus potenciales efectos beneficiosos sobre la salud. Entre los efectos fisiológicos que se le atribuyen destacan su papel protector frente al desarrollo de procesos tumorales, obesidad, aterosclerosis, diabetes, enfermedades óseas, así como modulador de la respuesta inmune.

Las actividades biológicas del CLA se relacionan con dos isómeros, el cis9,trans-11 y el trans-10,cis-12. Muchas de las investigaciones se han realizado con mezclas de ambos isómeros en proporción 1:1 y pequeñas cantidades de otros isómeros, y en menor medida con isómeros individuales, que han aportado evidencias sobre algunas de sus funciones fisiológicas específicas. Así el isómero trans-10,cis-12 se considera responsable de la reducción de la grasa corporal, mientras que el cis-9,trans11 estaría implicado en la mejora del crecimiento y eficiencia de la dieta en roedores. Los dos serían activos como inmunomoduladores o como agentes anticancerígenos y en ciertos casos podrían actuar sinérgicamente. Incluso no se descarta que tengan efectos opuestos en algunas acciones (Pariza et al., 2001; Churruca et al., 2009; Park, 2009).

Las actividades atribuidas al CLA se han demostrado en numerosas y extensas investigaciones desarrolladas en animales y estudios in vitro, aunque los posibles mecanismos de acción no están totalmente clarificados. En la mayoría de los casos, la magnitud de los efectos observados hacía prever que también se reflejarían en humanos. Sin embargo, en general, los resultados son más modestos, no siempre concluyentes e incluso a veces controvertidos (Bhattacharya et al., 2006; Benjamin y Spener, 2009; Park, 2009; Reynolds y Roche, 2010).

\subsubsection{Efectos anticarcinógenos}

(Lee et al., 2005; Kelley et al., 2007; Gómez-Cortés y De la Fuente, 2010)

En 1987 se identificó al CLA como el factor responsable de la inhibición del desarrollo de tumores de piel inducidos en ratones. Posteriormente, múltiples estudios tanto con mezclas equimoleculares de los isómeros cis-9,trans-11 y trans-10,cis-12 como con los isómeros individuales han confirmado su actividad anticarcinógena. Pueden actuar en las distintas etapas del proceso carcinogénico: iniciación, promoción y 
metástasis y regular el crecimiento de tumores por diferentes mecanismos de acción sobre el metabolismo lipídico, la expresión génica de apoptosis y el control del ciclo celular, entre otros.

La capacidad anticarcinógena del ácido ruménico (RA) se ha demostrado en ratas con tumores de mama inducidos químicamente con metilnitrosourea, cuando se incorporaba a su dieta en dosis entre 0,5 y $1 \%$. Asimismo, se ha puesto de manifiesto la disminución de la incidencia de tumores de estómago y colon inducidos químicamente en ratones y ratas, respectivamente. Incluso, cantidades inferiores $(0,1 \%)$ reducían la metástasis pulmonar espontánea generada tras la implantación de un tipo de tumor de mama en ratones. En todos estos modelos, también era eficaz el isómero trans-10,cis12.

En relación con los tumores de la glándula mamaria, también se observaba el efecto anticancerígeno cuando se incluía en la dieta mantequilla enriquecida de forma natural con cis-9,trans-11 y cuando se administraba ácido vacénico, probablemente por su transformación endógena en ácido ruménico.

Por otra parte, en dos modelos animales de ratón con alteraciones genéticas que favorecen el desarrollo de tumores de mama o de intestino, el cis-9,trans-11 no producía ningún efecto.

Además de los estudios in vivo, se han realizado numerosos estudios in vitro con cultivos de células cancerosas humanas y de animales procedentes de tumores de mama, colon, estómago y próstata, entre otros. De los resultados obtenidos, se deduce que el potencial inhibitorio de la proliferación celular del ácido ruménico es moderado, depende del tipo celular concreto y, excepto en algunos estudios, cuando presenta actividad, suele ser menos potente que el trans-10,cis-12, que es efectivo en todas las líneas celulares ensayadas. También han mostrado actividad en algunas líneas celulares tumorales de mama y colon los isómeros cis-9,cis-11 y trans-9,trans-11, presentando este último compuesto la mayor capacidad inhibitoria del crecimiento.

En humanos las relaciones entre el ácido ruménico y el cáncer se han valorado en estudios epidemiológicos y los resultados no son homogéneos. 
En un estudio en Finlandia en mujeres pre y posmenopáusicas, se estableció que la ingesta de CLA y sus niveles en suero eran significativamente inferiores en las pacientes con cáncer de mama que en los controles, sólo en el segundo grupo de mujeres (Aro et al., 2000). Sin embargo, en una cohorte de mujeres posmenopáusicas en Holanda, se observó una débil asociación positiva entre la ingesta de CLA (ingesta media: 200mg/día) y la incidencia de cáncer de mama (Voorrips et al., 2002). Por otra parte, en una población de pacientes francesas con tumores de mama, no se encontró una asociación significativa con los niveles de CLA en tejido adiposo mamario en relación con los controles, ni tampoco con el riesgo de desarrollo posterior de metástasis, pero el intervalo de variación en las concentraciones de CLA era estrecho (Chajes et al., 2002 y 2003).

En otro amplio estudio de casos y controles llevados a cabo en Estados Unidos, no se detectó ninguna correlación entre la ingesta de CLA y el riesgo global de cáncer de mama. No obstante, se observó una ligera reducción del riesgo de tumores de mama, negativos para el receptor de estrógenos, sólo en mujeres premenopáusicas pertenecientes al cuartil con ingestas de cis-9,trans-11 más altas (> 155mg/día) cuando se comparaban con el grupo de ingestas más bajas (<66mg/día) (McCann et al., 2004). Un estudio de cohorte prospectivo realizado en Suecia ha confirmado la ausencia de asociación entre la ingesta de CLA (quintiles inferior y superior, $<78$ y >156mg/día) y la incidencia total de cáncer de mama, que no se modifica cuando se considera el estatus en relación con los receptores de estrógenos y progesterona, así como cuando se tratan de forma independiente las mujeres pre y posmenopáusicas (Larsson et al., 2009). En esta misma cohorte, en un estudio previo, se encontró que la ingesta de CLA y productos lácteos ricos en grasa reducían el riesgo de desarrollo de cáncer colorrectal (Larsson et al., 2005).

A partir de los datos obtenidos en estudios epidemiológicos, no es posible extraer conclusiones definitivas acerca del papel del ácido ruménico como agente preventivo del cáncer. Es posible que las ingestas sean bajas y las diferencias entre ellas en las distintas poblaciones insuficientes, para establecer claramente una relación. Aún teniendo en cuenta las limitaciones de extrapolar directamente las dosis utilizadas en los ensayos en animales, algunos autores consideran como cantidad de referencia la ingesta de 3,0 gramos diarios por un adulto de $70 \mathrm{~kg}$. Este valor se ha estimado a partir de la 
proporción de una mezcla de CLA en la dieta $(0,1 \%)$ administrada a ratas, que producía una reducción significativa en el número de tumores de mama (Ip et al., 1994). Por otra parte, Gómez-Cortés y De la Fuente (2010) recogen la información aportada por otros autores, indicando que parece probable que los potenciales efectos protectores podrían alcanzarse con alimentos funcionales obtenidos aumentando de forma natural los niveles de ácidos ruménico y vacénico, por su contribución a incrementar la disponibilidad de CLA en el organismo.

Por todo ello, es prioritario conocer las cantidades efectivas del CLA y, dadas las dificultades de realizar estudios de intervención en humanos para evaluar su influencia en el proceso carcinógenico, también sería recomendable seguir profundizando en la investigación con modelos animales apropiados para mejorar su extrapolación a la población humana.

\subsubsection{Efectos en el peso y la composición corporal}

La capacidad del CLA para modificar la composición corporal se demostró por primera vez en 1997 en ratones (Park et al., 1997). La suplementación de la dieta con 0,5\% de una mezcla de CLA durante 4 semanas producía una reducción de la masa grasa próxima al $60 \%$ e incrementos significativos de la masa magra en relación con los controles. Estudios posteriores confirmaron estos efectos en otras especies animales, comprobándose que existían grandes diferencias en la sensibilidad, siendo el ratón la especie más sensible. Del conjunto de los resultados en modelos animales se puede deducir que esta actividad depende del isómero trans-10,cis-12, varía con la dosis, parece más eficaz para prevenir la ganancia de grasa que para eliminar la acumulada y no todos los depósitos adiposos se afectan en grado similar. En algún caso se han observado efectos adversos como hipertrofia, esteatosis hepática y resistencia a la insulina (Fernández-Quintela et al., 2004; Navarro et al., 2006).

Entre los estudios de intervención con CLA en humanos, el mayor porcentaje se ha centrado en su influencia en la obesidad. Desde el año 2000 se han publicado más de 30 trabajos diseñados específicamente para valorar la eficacia del CLA sobre la composición y el peso corporal (Plourde et al., 2008; Jutzeler, 2011). Las características generales son las siguientes: 
- En la mayoría se emplean mezclas de los isómeros cis-9,trans-11 y trans-10,cis12 en proporción 1:1, puesto que sólo en tres se ha utilizado el isómero trans10,cis-12 aislado (Risérus et al., 2002a; Malpuech et al., 2004; Tricon et al., 2004a) y no se consideran los realizados con el isómero cis-9,trans-11 ya que en ninguno se observaban cambios en la masa grasa.

- Las dosis varían entre 0,7 y 6,8g de CLA al día, administradas a grupos de población adulta con diferentes índices de masa corporal, sobre todo con sobrepeso y obesos. En algún caso los participantes tenían síndrome metabólico o eran diabéticos (Risérus et al., 2002a; Norris et al., 2009). Sólo uno de los estudios se ha realizado en niños (Racine et al., 2010).

- El período de intervención duraba entre 1 y 6 meses, excepto en tres estudios en los que la suplementación se mantenía hasta 1 año (Gaullier et al., 2004; Larsen et al., 2006) o 2 años (Gaullier et al., 2005).

En relación con el peso corporal, sólo en cuatro estudios se produjeron pérdidas pequeñas pero significativas (1-2\%), por lo que puede deducirse que la acción del CLA apenas tiene relevancia.

En cuanto a la masa grasa, se observan efectos significativos en aproximadamente el $50 \%$ de los estudios, obteniéndose reducciones entre el 1 y el $8 \%$ y detectándose algunas inconsistencias cuando se comparan entre ellos. Whigham et al. (2007) realizaron un meta-análisis que incluía los ensayos doble ciego controlados con placebo y que utilizasen técnicas validadas para medir la composición corporal (15 estudios). Los autores concluyen que una dosis mediana de 3,2 gramos de CLA al día produce una reducción de la masa grasa de 0,09 $\pm 0,08 \mathrm{~kg} / \mathrm{semana}$ en el grupo tratado, comparado con el placebo. Además, constatan la existencia de una respuesta lineal frente a la dosis hasta los 6 meses, luego la pérdida de masa grasa es menos acusada hasta que prácticamente se estabiliza entre 1 y 2 años. Por otra parte, indican que la ausencia de efectos pueda deberse a que el tiempo de tratamiento sea corto y/o el número de participantes muy reducido como para detectar los cambios. Jutzeler (2011) en una revisión sobre este tema, propone considerar sólo los estudios con 3 meses de tratamiento como mínimo. 
Algunos estudios valoran los efectos de la suplementación inmediatamente después de haber realizado una dieta hipocalórica (Kamphuis et al., 2003; Whigham et al., 2004; Larsen et al., 2006). En ninguno de ellos encuentran diferencias significativas en el peso y la grasa corporal en relación con los controles.

Otro efecto que se le atribuye al CLA es el aumento de la masa magra. Schoeller et al. (2009) han realizado un meta-análisis con los mismos 15 estudios mencionados anteriormente y concluyen que la ingesta de CLA resulta en un pequeño incremento en la masa libre de grasa $(<1 \%)$, no significativo estadísticamente. El panel de Alergias, Nutrición y Productos Dietéticos (NDA) de la EFSA también ha concluido que no se puede establecer una relación entre la ingesta de CLA y un aumento de la masa magra en humanos (EFSA, 2010c).

Del conjunto de los resultados, se puede deducir que las ingestas de 3,0 g/día de mezclas de CLA en humanos producen un efecto pequeño pero significativo en la pérdida de masa grasa sin afectar al peso corporal ni a la masa magra. En cualquier caso, la variabilidad de la respuesta en humanos y las discrepancias con los resultados obtenidos en ensayos con animales podrían deberse a factores relacionados con el diseño experimental (las dosis, fundamentalmente), la ingesta dietética y a diferencias de tipo genético y metabólico (Navarro et al., 2006; Plourde et al., 2008).

\subsubsection{Efectos sobre los factores relacionados con el desarrollo de diabetes tipo 2 y enfermedades cardiovasculares}

En los estudios de intervención realizados en humanos para investigar los efectos del CLA sobre la composición corporal y en otros específicos, con frecuencia se evalúa el impacto del CLA sobre factores de riesgo de estas patologías. Los principales parámetros estudiados son: la sensibilidad a la insulina, los lípidos en sangre, marcadores de peroxidación lipídica, de inflamación y de la función vascular.

En la Tabla 1.20 se recogen ensayos en humanos con ácido ruménico y su influencia en distintos indicadores metabólicos.

El panel NDA de la EFSA ha publicado dos opiniones científicas acerca de la seguridad del CLA (una para el Clarinol ${ }^{\circledR}$ y otra para el Tonalín ${ }^{\circledR}$ ) como paso previo a su posible autorización como nuevo ingrediente alimentario en las condiciones de uso 
propuestas: 3 - 3,5g/día respectivamente, de una mezcla en proporción 1:1 de los isómeros cis-9,trans-11 y trans-10,cis-12 (EFSA, 2010a; EFSA, 2010b). Las diferencias entre ambas opiniones radican solamente en las características de los productos utilizados. De la evaluación de los datos científicos disponibles han extraído conclusiones sobre la seguridad de mezclas de CLA a los que haremos referencia en este apartado. Por otra parte, estos mismos aspectos se han recopilado y analizado en la revisión de Jutzeler (2011).

\subsubsection{Efectos sobre la sensibilidad a la insulina y homeostasis de glucosa}

Entre los procedimientos para valorar la sensibilidad a la insulina es frecuente medir las concentraciones sanguíneas de glucosa e insulina e índices derivados de dichos valores como el HOMA-IR (homeostatic model assessment - insulin resistance). Hay un meta-análisis, recogido en una tesis doctoral y por el momento no publicado en revistas científicas (Herrmann, 2009), que evalúa el efecto de la mezcla de CLA en proporción 50:50 sobre la glucosa plasmática (16 estudios), la concentración de insulina (15 estudios) y el índice HOMA-IR (7 estudios). Incluye ensayos publicados entre el 2000 - 2008 y concluye que, en personas con normopeso, sobrepeso y obesos no diabéticos, la mezcla de CLA no ejercería ningún efecto en estos parámetros (EFSA, 2010a). Estudios posteriores (Raff et al., 2009; Joseph et al., 2011; Pfeuffer et al., 2011) y otros ensayos (Risérus et al., 2002a; Syvertsen et al., 2007), que utilizan medidas más específicas de la resistencia a la insulina, confirman la ausencia de efectos.

En cuanto a los isómeros individuales, son sorprendentes los resultados obtenidos en los trabajos del grupo de Risérus. La administración de 3,4 g/día de trans10,cis-12 o 3,0 g/día de cis-9,trans-11 a varones obesos con síndrome metabólico durante 3 meses, producía un incremento en la resistencia a la insulina que no se observaba cuando consumían 3,4 g/ día de la mezcla de ambos isómeros (Risérus et al., 2002a y 2004). Hasta el momento, no se ha encontrado una explicación convincente para estas observaciones y, en el caso del ácido ruménico, el resto de estudios muestran que no afecta a la sensibilidad a la insulina (ver Tabla 1.20).

Sólo hay dos estudios con mezclas de CLA en personas diabéticas (Moloney et al., 2004; Norris et al., 2009) y por los efectos detectados se plantean serias dudas en cuanto a su seguridad. 


\subsubsection{Efectos en lípidos plasmáticos}

Respecto a los efectos del CLA sobre el perfil lipídico, hay publicados muchos estudios en diferentes poblaciones. Un meta-análisis evalúa los efectos del CLA, en proporción 1:1, sobre los lípidos en sangre (Herrmann, 2009). Incluye 25 estudios publicados entre el 2000 y el 2008, que suponían ingestas de CLA entre 1,1 y 4,5 g/día entre cuatro y 52 semanas. Los resultados muestran que no existen diferencias significativas entre el grupo tratado y el grupo control en cuanto al colesterol-LDL y el colesterol-HDL, mientras que los niveles de triglicéridos son ligeramente superiores en el primero. Tiene interés el análisis de un subgrupo de estudios que sólo consideraba aquellos que utilizaban aceite de oliva como placebo $(n=9)$ en vez de aceite de cártamo o de girasol. En ese caso, se observaban concentraciones de colesterol-HDL inferiores significativamente en el grupo que ingería el CLA, aunque la reducción era baja. Existe la posibilidad de que este efecto se detecte al comparar con el ácido oleico como control, por su influencia positiva en los niveles de colesterol-HDL. En cualquier caso, la magnitud de los cambios en los triglicéridos y en el colesterol-HDL tendrían poco impacto en el riesgo cardiovascular (EFSA, 2010a).

Los resultados referentes al isómero cis-9,trans-11 muestran que la mayoría no tienen un efecto significativo en los niveles de triglicéridos ni de colesterol. Sólo en el estudio de Tricon et al. (2004a) se observa una reducción del colesterol total y del colesterol-LDL en función de la dosis y cuando se compara con el isómero trans-10,cis12.

\subsubsection{Efectos sobre la peroxidación lipídica}

La determinación de las concentraciones de algunos isoprostanos- $\mathbf{F}_{2 \alpha}$ en plasma y en orina se utilizan como marcadores de peroxidación lipídica y por ello de estrés oxidativo in vivo. Se considera que podrían ser marcadores independientes de riesgo de ateroesclerosis.

En nueve estudios (publicados entre 2000 y 2008) y en otro más reciente (Pfeuffer et al., 2011) se han evaluado los efectos del CLA en los niveles de isoprostanos- $\mathrm{F}_{2 \alpha}$ (8-isoprostaglandina- $\mathrm{F}_{2 \alpha} \quad \mathrm{y} / \mathrm{o} \quad$ 15-cetodihidroprostaglandina- $\left.\mathrm{F}_{2 \alpha}\right)$ en orina y/o plasma. Cuando se utilizaban mezclas de CLA en proporción 1:1, con dosis 
entre 3,4 y 5,5 g/día, en todos los casos se producían incrementos en las concentraciones de los compuestos determinados. En dos de ellos se administró a otro grupo el isómero trans-10,cis-12 y los valores eran superiores a los encontrados con la mezcla (Risérus et al., 2002a; Smedman et al., 2004); mientras que si se trataba del isómero cis-9,trans-11, los incrementos eran inferiores a los correspondientes a la mezcla para las mismas dosis (Risérus et al., 2004; Tholstrup et al., 2008).

Aunque los resultados son concluyentes en relación con este efecto del CLA, Iannone et al. (2009) han comprobado, en estudios in vitro y en animales, que el aumento de 8 -isoprostaglandina- $\mathrm{F}_{2 \alpha}$ podría resultar, al menos en parte, de su menor catabolismo debido a que el CLA compite con este compuesto por su $\beta$-oxidación en peroxisomas y bloquearía su degradación. Por ello cabe la posibilidad de que los incrementos en isoprostanos- $\mathrm{F}_{2 \alpha}$ en los tratamientos con CLA no sean claramente indicativos de favorecer los procesos de peroxidación lipídica y es necesario realizar más investigaciones para clarificar estas interacciones.

\subsubsection{Efectos sobre la inflamación}

Uno de los parámetros estudiados es la Proteína C Reactiva (PCR). Tras la administración de mezclas de isómeros se observan respuestas diferentes: en cinco estudios se encuentran incrementos en las concentraciones de PCR, en dos de ellos no muy significativos y en otro, sólo con dosis altas (6,4 g/día). Además, hay otros tres estudios en los que no se detecta ningún efecto en este marcador. Herrmann (2009) considera 6 estudios para hacer un meta-análisis y concluye que se produce un aumento de la PCR en el grupo tratado con CLA 1:1 comparado con el grupo control (EFSA, 2010a).

También hay información respecto a los isómeros aislados, 6 estudios con cis9,trans-11 y otros 4 con trans-10, cis-12, en los que se demuestra que no afectan a los niveles de PCR excepto en uno de los ensayos con el isómero trans-10,cis-12. Este estudio se realizó en varones con síndrome metabólico y se incrementaban las concentraciones de la proteína, aunque con la mezcla de CLA no se modificaban los valores correspondientes (Risérus et al., 2002b). 
Otros marcadores de inflamación, como el TNFa y la IL-6, no se afectan por el tratamiento con mezclas de CLA (6 estudios) ni tampoco con el isómero cis-9,trans-11 (ver Tabla 1.20).

\subsubsection{Efectos sobre la función vascular}

El endotelio vascular es un regulador clave de la homeostasis vascular e interviene de forma determinante en el desarrollo de ateroesclerosis. Los resultados obtenidos con mezclas de CLA en los tres estudios disponibles son heterogéneos. En uno de ellos se comprueba que produce un deterioro de la función endotelial (Taylor et al., 2006), mientras que Pfeuffer et al. (2011), no observan este efecto, sino incluso una tendencia favorable y Raff et al. (2006) demuestran que no se afecta la elasticidad arterial. Sluijs et al. (2010) obtienen resultados similares cuando administran cis9,trans-11 con pequeñas cantidades de trans-10,cis-12

Por otra parte, hay cuatro estudios con mezclas o con el isómero cis-9,trans-11 (dos estudios) que determinan otros marcadores de la función endotelial, en concreto las moléculas de adhesión vascular (VCAM) e intercelular (ICAM). Estos parámetros no se ven afectados excepto en un estudio, en el que se encontraba una reducción de la VCAM (Watras et al., 2007).

Teniendo en cuenta el conjunto de los resultados, el panel NDA de la EFSA concluye que el consumo de 3,0 - 3,5g/día de una mezcla de isómeros cis-9,trans-11 y trans-10,cis-12 en proporción 50:50 durante seis meses es seguro. No se ha establecido su seguridad para diabéticos tipo 2, ni para periodos de tratamiento más prolongados para la población en general, porque los resultados son limitados o no concluyentes. Incluso plantean ciertas reservas en cuanto a su seguridad por los incrementos observados en las concentraciones de isoprostanos y en otros marcadores de inflamación. Sin embargo, la FDA de Estados Unidos considera que los posibles efectos adversos sobre la sensibilidad a la insulina y las enfermedades cardiovasculares no serían significativos cuando se consuman 3g/día de estas mismas mezclas. De hecho, en julio de 2008 incluyó al CLA entre las sustancias GRAS (generalmente reconocidas como seguras) para su uso como ingrediente alimentario en algunos alimentos (FDA, 2008). 
En relación con el isómero cis-9,trans-11 y admitiendo que la información disponible es escasa, los datos científicos indican que no afectaría de forma significativa a la sensibilidad a la insulina ni a los factores de riesgo de enfermedades cardiovasculares. Sin embargo Smit et al. (2010) han encontrado que su concentración en tejido adiposo subcutáneo se asocia de forma inversa con menor riesgo de infarto de miocardio no fatal. El estudio se realizó en 3626 personas con y sin historia de infarto de miocardio en Costa Rica. Se comprobó que las personas con niveles más altos en tejido adiposo tenían mayores ingestas de CLA (cis-9,trans-11) y de productos lácteos. Por todo ello parece necesario plantear nuevas investigaciones, con especial énfasis en ampliar los períodos de estudio y el número de participantes, para poder obtener evidencias concluyentes al respecto.

\subsubsection{Efectos inmunomoduladores}

Los estudios en animales e in vitro indican que el CLA puede modular la función inmune siendo activos tanto el isómero cis-9,trans-11 como el trans-10,cis-12. Pueden influir en la respuesta inmune humoral y celular y afectar a la producción de citocinas, inmunoglobulinas y a la proliferación de linfocitos, entre otros efectos (O’Shea et al., 2004; Bhattacharya et al., 2006; Park, 2009).

En humanos hay muy pocos estudios que evalúen la actividad del CLA sobre el sistema inmune. Albers et al. (2003) encontraron que la administración de mezclas de los isómeros cis-9,trans-11 y trans-10,cis-12 en proporciones 50:50 y 80:20 incrementaba los niveles de anticuerpos frente al virus de la hepatitis pero no modificaba otros parámetros. Un estudio con las mismas mezclas concluía que el CLA producía un efecto mínimo en marcadores de la función inmune y no suponía ningún beneficio comparado con el control (Nugent et al., 2005). Sin embargo, Song et al. (2005) comprobaron que la ingesta de 3g/día de una mezcla de CLA (50:50) influía positivamente en la respuesta inmune. Se incrementaban las concentraciones de IgA e $\operatorname{IgM}$ y la citocina antiinflamatoria IL-10 y se reducían los niveles de IgE y de citocinas proinflamatorias (TNF- $\alpha$ y IL-1 $\beta)$. Asimismo, disminuía la respuesta de hipersensibilidad retardada. Sugieren que la suplementación con CLA podría mejorar la capacidad de respuesta de personas sanas frente a agentes infecciosos e incrementar su resistencia a alergenos. 
Tricon et al. (2004b) valoraron la eficacia de los isómeros cis-9,trans-11 y trans10,cis-12 individualmente, tras la administración de 0,6,1,2 y 2,4 g/día, y observaron que ambos isómeros presentaban una capacidad similar para reducir la activación de linfocitos $\mathrm{T}$ pero no modificaban la producción de citocinas.

Los estudios mencionados se han realizado en personas sanas y tendría interés conocer los efectos del CLA en grupos de población con enfermedades de base inmunológica. En este sentido, se ha llevado a cabo un ensayo en personas alérgicas al polen de abedul. La suplementación con 2g de CLA (mayoritariamente cis-9,trans-11) mejoraba algunos síntomas y reducía la producción de algunas citocinas inflamatorias. Sin embargo, no había diferencias en los niveles de IgE total y específica, IgG e IgM y disminuyeron las concentraciones de $\operatorname{IgA}$. Además se incrementaba la excreción urinaria de isoprostanos (Turpeinen et al., 2008).

Recientemente, se han publicado los resultados de un estudio de cohorte realizado en Holanda. Thijs et al. (2011) demuestran por primera vez la existencia de una asociación consistente entre los altos niveles de ácidos ruménico y vacénico en leche materna, y el menor riesgo de padecer eczema en las madres y dermatitis atópica y sensibilización alérgica en niños al año de vida, que es independiente del efecto protector de los ácidos grasos poliinsaturados omega-3.

La escasez de evidencias en humanos impiden obtener conclusiones, pero plantean nuevos interrogantes sobre los posibles beneficios del CLA en la prevención y desarrollo de enfermedades que afectan al sistema inmunitario. 
Tabla 1.20. Estudios con $c i s-9$, trans-11 en humanos e influencia en indicadores metabólicos

\begin{tabular}{|c|c|c|c|c|c|c|c|c|}
\hline Referencia & $\begin{array}{c}\mathrm{N}^{\circ} \text { Personas } \\
\text { tratadas } \\
(\mathrm{M} / \mathrm{H})\end{array}$ & Placebo & $\begin{array}{l}\text { Dosis } \\
\text { (g/día) }\end{array}$ & $\begin{array}{c}\text { Duración } \\
\text { (semanas) }\end{array}$ & $\begin{array}{l}\text { Triglicéridos/ } \\
\text { Colesterol }\end{array}$ & $\begin{array}{l}\text { Glucosa/ } \\
\text { Insulina/ } \\
\text { Índices }\end{array}$ & Isoprostanos & Otros indicadores sin efectos \\
\hline $\begin{array}{l}\text { Risérus et al., } \\
2004\end{array}$ & $13(\mathrm{H})$ & Oliva & 3,0 & 12 & SE & $\begin{array}{l}>\text { resistencia } \\
\text { insulina }\end{array}$ & Incremento & \\
\hline $\begin{array}{c}\text { Malpuech et al., } \\
2004\end{array}$ & $18 / 18$ & $\begin{array}{c}\text { Girasol } \\
\text { (alto oleico) }\end{array}$ & $1,5 / 3,0$ & 18 & ND & SE & ND & PCR; función renal/ hepática \\
\hline $\begin{array}{c}\text { Tricon } \text { et al., } \\
2004 \\
\end{array}$ & 24 & $\begin{array}{c}\text { Sin placebo } \\
\text { Cruzado }\end{array}$ & $0,6 / 1,2 / 2,4$ & $8+8+8$ & $\begin{array}{l}<\text { colesterol total } \\
\text { y colesterol LDL }\end{array}$ & SE & ND & \\
\hline $\begin{array}{l}\text { Desroches et al., } \\
2005\end{array}$ & $16(\mathrm{H})$ & $\begin{array}{c}\text { Mantequilla } \\
\text { CLA (bajo/alto) } \\
\text { Natural. Cruzado } \\
\end{array}$ & $0,24 / 2,60$ & $4+4$ & SE & ND & ND & PCR; leptina \\
\hline $\begin{array}{l}\text { Naumann et al., } \\
2006\end{array}$ & 34 & $\begin{array}{c}\text { Girasol } \\
\text { (alto oleico) }\end{array}$ & 3,0 & 13 & SE & SE & ND & PCR; función renal/ hepática \\
\hline $\begin{array}{c}\text { Tricon } \text { et al., } \\
2006 \\
\end{array}$ & $32(\mathrm{H})$ & $\begin{array}{l}\text { Lácteos Natural } \\
\text { CLA (bajo/alto) } \\
\text { Cruzado }\end{array}$ & $0,15 / 1,4$ & $6+6$ & SE & SE & ND & PCR; IL-6; VCAM, ICAM \\
\hline $\begin{array}{l}\text { Tholstrup et al., } \\
2008 \\
\end{array}$ & $24(\mathrm{M})$ & Oliva & 5,1 & 16 & SE & ND & Incremento & $\begin{array}{l}\text { PCR; IL-6; TNF- } \alpha \text {; VCAM; } \\
\text { ICAM; MCP1, PAI-1, fibrinógeno }\end{array}$ \\
\hline $\begin{array}{l}\text { Raff et al., } \\
2009\end{array}$ & $24(\mathrm{M})$ & Oliva & 4,7 & 16 & ND & SE & ND & Adiponectina; mRNA genes \\
\hline $\begin{array}{l}\text { Sluijs } \text { et al., } \\
2010\end{array}$ & 173 & $\begin{array}{l}\text { Palma + Soja } \\
(80+20)\end{array}$ & $\begin{array}{c}2,5+ \\
0,6(\mathrm{t} 10 \mathrm{c} 12)\end{array}$ & 24 & SE & SE & ND & PCR; elasticidad y tensión arterial \\
\hline $\begin{array}{l}\text { Venkatramanan et al., } \\
2010\end{array}$ & 32 & $\begin{array}{c}\text { CLA (bajo/alto) } \\
\text { Natural } \\
\end{array}$ & $0,2 / 1,3$ & 8 & SE & ND & ND & PCR; TNF- $\alpha$; función hepática \\
\hline $\begin{array}{c}\text { Brown et al., } \\
2011 \\
\end{array}$ & $18(\mathrm{M})$ & $\begin{array}{l}\text { CLA (bajo/alto) } \\
\text { Natural } \\
\end{array}$ & $0,35 / 1,2$ & 8 & SE & SE & ND & $\begin{array}{l}\text { Adiponectina; función hepática; } \\
\text { masa ósea }\end{array}$ \\
\hline $\begin{array}{c}\text { Joseph et al., } \\
2011\end{array}$ & $27(\mathrm{H})$ & $\begin{array}{l}\text { Cártamo } \\
\text { Cruzado } \\
\end{array}$ & 2,8 & $8+8$ & SE & SE & ND & $\begin{array}{l}\text { PCR; IL-6; TNF- } \alpha \text {; adiponectina; } \\
\text { LDL oxidada }\end{array}$ \\
\hline
\end{tabular}

M: Mujer; H: Hombre; SE: Sin Efecto; ND: No Determinado; PCR: Proteína C Reactiva; IL-6: Interleucina-6; VCAM: molécula de adhesión vascular; ICAM: molécula de adhesión intercelular; TNF-a: Factor de necrosis tumoral; MCP1: proteína quimiotáctica de monocitos 1; PAI-1: inhibidor del activador del plasminógeno 1. 


\subsection{ANÁLISIS DE CLA EN LÁCTEOS}

\subsubsection{Introducción}

El análisis de CLA puede llegar a ser una tarea bastante compleja, debido a la gran variedad de ácidos grasos presentes en la grasa de la leche y a la desigual proporción de los isómeros CLA en este tipo de muestra. Para la determinación de estos isómeros en leche, se han aplicado distintas metodologías analíticas (Figura 1.9), que incluyen: la extracción de la grasa láctea; la derivatización de los ácidos grasos a compuestos que sean más fáciles de analizar; y finalmente, la aplicación de una técnica analítica precisa y fiable capaz de separar, identificar y cuantificar cada uno de los isómeros presentes en la muestra de leche.

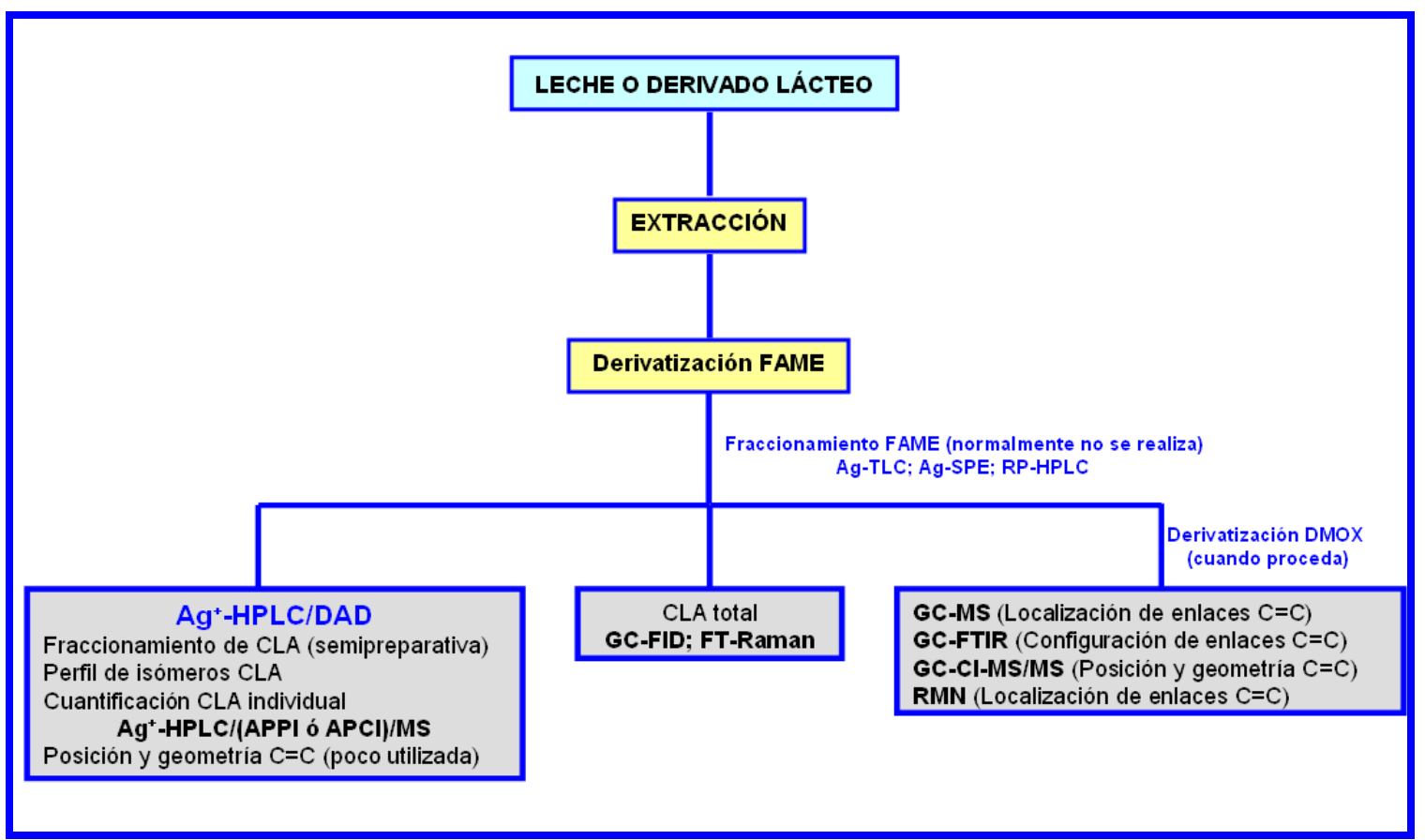

Figura 1.9. Diagrama general del análisis de isómeros CLA en lácteos.

De entre todas las técnicas instrumentales que existen para el análisis de isómeros CLA en leche, la más utilizada ha sido la cromatografía de gases con detector de ionización de llama (GC-FID). Su acoplamiento a técnicas como la espectrometría de masas (GC-MS) o la espectroscopía infrarroja con transformada de Fourier (GCFTIR) la han hecho una potente herramienta instrumental, sobre todo cuando se quiere obtener información estructural que permita identificar algunos de los isómeros. Sin embargo, en los últimos años, la cromatografía líquida de alta resolución con 
intercambiador de iones plata con detector de diodos ( $\mathbf{A g}^{+}$-HPLC/DAD) está teniendo mucha aceptación como técnica de análisis de estos isómeros, debido a su eficacia resolutiva. Otras técnicas aplicadas a la determinación de CLA en lácteos son la espectroscopía de resonancia magnética nuclear (RMN) y la espectroscopía Raman con transformada de Fourier (FT-Raman). Sin embargo, ambas se limitan al análisis de muestras con un elevado contenido de CLA, siendo más restringida su aplicación en el análisis de muestras lácteas. A continuación, se describirá la metodología analítica para la determinación de CLA en productos lácteos, haciendo énfasis en la técnica cromatográfica que se utilizará en este trabajo: la cromatografía líquida de alta resolución con intercambiador de iones plata $\left(\mathrm{Ag}^{+}-\mathrm{HPLC} / \mathrm{DAD}\right)$.

\subsubsection{Extracción de la grasa láctea}

Para el análisis de CLA en muestras lácteas, conviene evitar procedimientos de extracción que impliquen reactivos ácidos, pues así se evita la isomerización de los dobles enlaces conjugados y la formación de productos secundarios que puedan afectar a la fiabilidad de la determinación (Luna, 2006; Ruiz-Rodríguez et al., 2010). En la Norma ISO 14156/IDF 172:2001 se contempla una serie de procedimientos utilizados como métodos de referencia para extraer la grasa en distintos tipos de muestras lácteas, la mayoría de ellos basados en la extracción con disolventes orgánicos. Otros métodos de extracción que se han utilizado para este fin son: la extracción Soxhlet (Atti et al., 2006), el método de Folch (Mel'uchova et al., 2008; Domagala et al., 2010) y el método de Röse-Gottlieb (Prandini et al., 2009). Aunque la validez analítica de muchos de ellos está plenamente demostrada, se debe tener en cuenta que suelen ser métodos de extracción bastante laboriosos, lo cual precisa de gran atención por parte del analista. Otra desventaja de los métodos anteriormente mencionados es la utilización de disolventes orgánicos, por lo que podría ser conveniente, siempre que sea posible, sustituir estos métodos de extracción por técnicas más limpias, como la utilización de $\mathrm{CO}_{2}$ supercrítico (Domagala et al., 2010) o la separación por centrifugación en muestras de leche cruda (Feng et al., 2004; Luna et al., 2005d).

\subsubsection{Derivatización de los ácidos grasos}

Una vez extraída la grasa láctea, es necesario aplicar un procedimiento de derivatización que facilite la obtención de derivados de una forma rápida y eficiente. En 
lo que respecta al análisis de isómeros CLA, interesa además que los métodos de derivatización no produzcan la transformación o "isomerización" de un isómero a otro y/o eviten la formación de otros compuestos interferentes.

Aunque se han descrito distintos tipos de derivados para ácidos grasos (RuizRodríguez et al., 2010), el procedimiento de derivatización más utilizado en la actualidad, tanto para determinación del CLA como la de cualquier otro ácido graso presente en la grasa láctea, es la transformación de los mismos en sus respectivos ésteres metílicos (FAME, fatty acid methyl ester). Estos FAME se obtienen mediante la transesterificación (metanólisis o metilación) de los ácidos grasos, empleando un exceso de metanol y en presencia de un catalizador, ácido o alcalino.

Tanto la metilación alcalina como la metilación ácida podrían utilizarse para derivatizar los ácidos grasos en la leche, sin embargo, resulta más conveniente emplear procedimientos con metilación alcalina. Aunque los procedimientos alcalinos no son útiles para la esterificación de ácidos grasos libres y fosfolípidos, la baja proporción de estos componentes en la grasa láctea hace que este inconveniente carezca de importancia, ya que la mayor parte de los ácidos grasos presentes en este tipo de muestras se encuentran como triglicéridos (De la Fuente et al., 2006; Christie et al., 2007). Los estudios más recientes sobre los procedimientos de metilación se están enfocando en buscar las mejores condiciones experimentales para realizar una derivatización lo más completa posible; los mejores resultados se han obtenido con el uso combinado de catalizadores ácido y alcalino (Nuernberg et al., 2007; Lee y Tweed, 2008; Luna et al., 2008a; Dance et al., 2010).

En lo que respecta al análisis de CLA, la utilización de la metilación alcalina se justifica aun más, ya que a diferencia de las metilaciones ácidas, los procedimientos alcalinos no producen isomerizaciones indeseadas ni generan metóxidos interferentes. Para que la metilación alcalina sea adecuada y eficiente, es importante emplear metanol en exceso. Además, hay que evitar la presencia de agua, ya que al ser una reacción catalizada por una base fuerte, se podrían producir saponificaciones. La Norma ISO 15884 /IDF 182:2002 (ISO-IDF, 2002) describe un procedimiento de metilación alcalina que se utiliza como referencia en el análisis de ácidos grasos en leche. Dicho 
método es el que emplearemos en nuestros ensayos para la derivatización de la grasa de leche ovina, cuya descripción se recoge en el apartado 3.1.2.

Con los ésteres metílicos (FAME) no es posible obtener información estructural para identificar cada uno de los isómeros CLA. Para lograr este propósito es necesario emplear otros procedimientos de derivatización más específicos, además de disponer de técnicas analíticas tan potentes como la cromatografía de gases acoplada a la espectrometría de masas (GC-MS) o al infrarrojo con transformada de Fourier (GCFTIR). En la identificación de isómeros CLA interesan aquellos derivados específicos que, en el momento de ser analizados por cualquiera de estas técnicas, proporcionen información estructural sobre la posición y/o la configuración geométrica de los dobles enlaces del sistema conjugado (Christie et al., 2007).

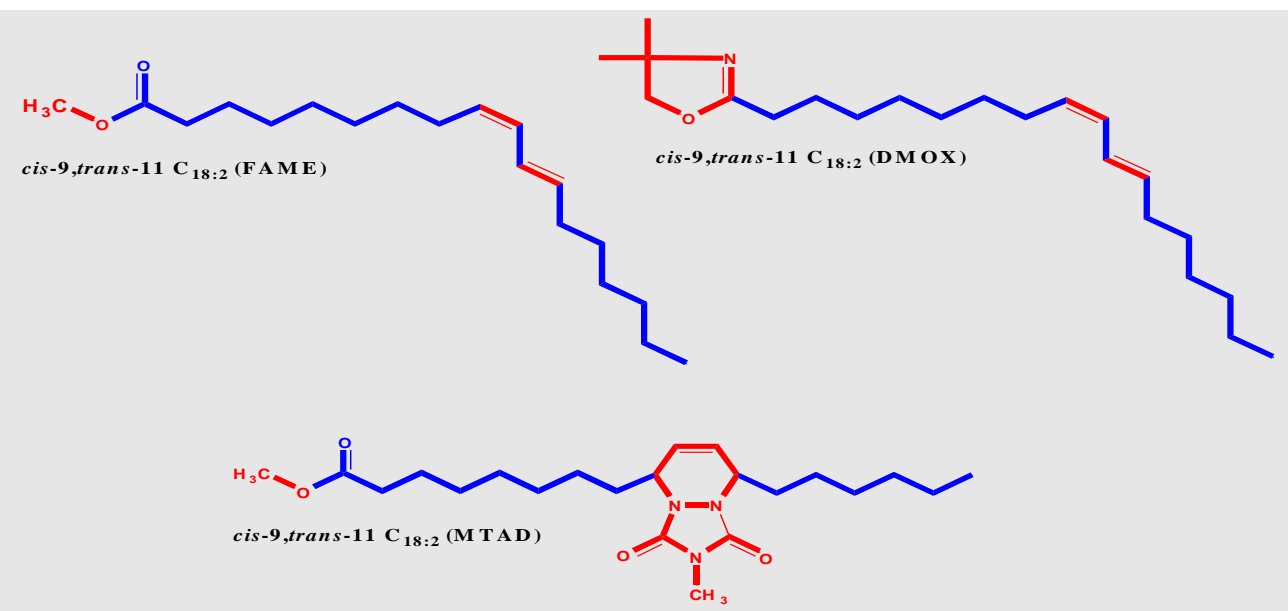

Figura 1.10. Estructuras de los derivados FAME, DMOX y MTAD, correspondientes al isómero cis-9,trans-11 $\mathrm{C}_{18: 2 \cdot}$.

De todos los derivados específicos que se conocen (Spitzer, 1999) el que más interesa destacar son los derivados de la dimetiloxazolina (DMOX, Figura 1.10). Este derivado nitrogenado es específico para el grupo carboxílico, útil en la identificación de isómeros CLA cuando se utiliza GC-MS (Dobson, 2003; De la Fuente et al., 2006; Luna, 2006; Christie et al., 2007; Ruiz-Rodríguez et al., 2010). Luna et al. (2005a y 2005b) describen un procedimiento sencillo para la obtención de derivados DMOX a partir de la grasa láctea. Otro procedimiento alternativo a los DMOX es aquél en el que se utilizan derivados de la 4-metil-1,2,4-triazolina-3,5-diona (MTAD, Figura 1.10), el cual es específico para los enlaces conjugados, sin embargo, no es tan frecuente su uso en el análisis de CLA (Spitzer, 1999; Dobson, 2003; Luna, 2006; Christie et al., 2007). 


\subsubsection{Técnicas de fraccionamiento para el análisis de CLA}

Debido a la complejidad y variedad de los lípidos presentes en ciertos tipos de muestras, puede que sea necesario realizar un fraccionamiento previo de los mismos. Las técnicas de fraccionamiento se han empleado para el análisis de CLA como técnicas complementarias a la cromatografía de gases (GC). Entre ellas podemos mencionar: cromatografía líquida de alta resolución en fase reversa (RP-HPLC), cromatografía en capa fina con intercambiador de iones plata $\left(\mathrm{Ag}^{+}-\mathrm{TLC}\right)$ y extracción en fase sólida con intercambiador de ión plata $\left(\mathrm{Ag}^{+}-\mathrm{SPE}\right)$. En lo que respecta a la grasa láctea, son pocos los trabajos publicados en los que se utilizan técnicas de fraccionamiento (Contarini et al., 2009). Además, las constantes mejoras analíticas y experimentales en la determinación de isómeros CLA (columnas, detectores, acoplamientos, etc.) han hecho que estas técnicas sean cada vez menos utilizadas.

En el análisis de CLA, la cromatografía RP-HPLC permite la preconcentración de los isómeros presentes en muestras con bajo contenido de estos isómeros, como es el caso de la grasa láctea. Sin embargo, su pobre resolución y la no discriminación de los isómeros CLA han sido los grandes inconvenientes de esta modalidad, algo que en la actualidad se ha resuelto con la utilización de $\mathrm{Ag}^{+}$-HPLC semipreparativa (Adlof, 2004; Delmonte et al., 2004a y 2004b).

La cromatografía en capa fina con intercambiador de iones plata $\left(\mathrm{Ag}^{+}-\mathrm{TLC}\right)$ es una técnica que puede ser muy útil cuando se quiere obtener grandes cantidades de isómeros CLA en muestras cuyo contenido es relativamente bajo. Aunque en la actualidad, este procedimiento se utiliza muy poco, ya que con las mejoras que se han conseguido en la cromatografía líquida de alta resolución con intercambiador de iones plata (Ag ${ }^{+}$-HPLC), resulta innecesario (Adlof, 2003; Christie et al., 2007).

Otra técnica de fraccionamiento que también ha sido empleada en la grasa láctea (Luna et al., 2009), es la extracción en fase sólida con intercambiador de iones plata $\left(\mathrm{Ag}^{+}-\mathrm{SPE}\right)$. Además de su rapidez, su sencillez y su posibilidad de automatización (Kramer et al., 2008), $\mathrm{Ag}^{+}-\mathrm{SPE}$ tiene una gran capacidad de discriminar ácidos grasos monoinsaturados según la configuración geométrica (cis y trans) de sus dobles enlaces. Sin embargo, su utilidad en la separación de isómeros CLA es bastante limitada. 


\subsubsection{Patrones y mezclas sintéticas}

Hasta el momento, una de las limitaciones analíticas más importantes en la identificación de los isómeros CLA es la escasa disponibilidad de patrones y de otros materiales de referencia. En varias casas comerciales como Nu-Check Prep. Inc. (Elysian, MN), Larodan Fine Chemicals (Malmo, Suecia), Matreya Inc. (Pleasant Gap, PA), entre otras, se pueden encontrar mezclas que contienen los ésteres metílicos de los siguientes isómeros CLA: trans-8,cis-10, cis-9,trans-11, trans-10, cis-12, cis-11,trans13 y pequeñas cantidades de sus respectivos isómeros trans-trans y cis-cis. También suministran algunos isómeros con una pureza superior al 90\%: cis-9,trans-11, cis-9, cis11, trans-9,trans-11, trans-10,cis-12 y cis-11,trans-13.

Sin embargo, aún no se dispone de patrones o mezclas sintéticas comerciales que contengan todos los isómeros presentes en alimentos (como por ejemplo, el trans-7, cis9, característico de la grasa láctea). Estas mezclas se podrían obtener en el laboratorio, empleando algunas reacciones de síntesis orgánica, entre las que podemos destacar: el reordenamiento sigmatrópico (Destaillats y Angers, 2003; Saebo, 2003; Destaillats et al., 2005); la hidrogenación parcial con hidrazina (Delmonte et al., 2003 y 2004a) y la isomerización catalizada con yodo (Eulitz et al., 1999; Delmonte et al., 2004a). Mediante el uso de estas reacciones, se han sintetizado los 32 isómeros posibles, desde 6,8- hasta 13,15-CLA (Delmonte et al., 2004a).

\subsection{6. $\mathrm{Ag}^{+}-$HPLC: Aplicación a la determinación de CLA en lácteos}

\subsubsection{Introducción}

Durante décadas, la cromatografía del ión plata (o cromatografía de argentación) ha sido una importante metodología en el fraccionamiento y caracterización de lípidos; ya que con ella es posible separar los ácidos grasos de acuerdo a su configuración geométrica y al número y posición de sus dobles enlaces (De la Fuente et al., 2006). Dos de sus modalidades $\left(\mathbf{A g}^{+}\right.$-TLC y $\mathbf{A g}^{+}$-SPE) ya han sido comentadas previamente (véase el apartado 1.5.4), por lo que en este apartado nos centraremos en la cromatografía líquida de alta eficacia con intercambiador de iones plata ( $\mathbf{A g}^{+}$-HPLC) y su importancia en la determinación analítica de isómeros CLA. 
Desde sus primeras aplicaciones como técnica complementaria a la

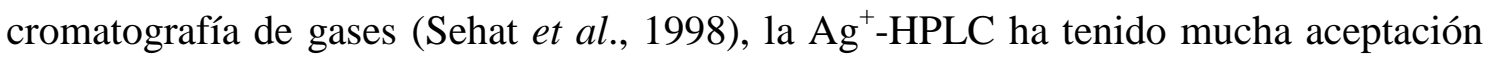
en el análisis de CLA, ya que proporciona una óptima separación de la mayor parte de los isómeros (De la Fuente et al., 2006; Christie et al., 2007). De hecho, tanto los isómeros posicionales como los geométricos se resuelven mejor mediante esta técnica que por ninguna otra. Su aplicación como técnica semipreparativa ha permitido aislar miligramos de isómeros CLA presentes en mezclas isoméricas (Adlof, 2004; Delmonte et al., 2004a y 2004b). Su uso complementario con la cromatografía de gases, la hacen ser la técnica más completa para la determinación de CLA en la leche (Collomb et al., 2004; Luna et al., 2005a, 2005b, 2005c y 2008a; Gómez-Cortés et al., 2008a, 2008b, 2009a y 2009b; Hervás et al., 2008b). Los últimos avances han permitido desarrollar interfases a presión atmosférica (Marchi et al., 2009) para su acoplamiento a la espectrometría de masas (Müller et al., 2006a; Demir y Talpur, 2010), que de momento, no han tenido mucha utilidad para el análisis de CLA en lácteos.

\subsubsection{Condiciones analíticas utilizadas en la cromatografía $\mathrm{Ag}^{+}-H P L C$}

Con la $\mathrm{Ag}^{+}$-HPLC, es posible separar la mayoría de los isómeros CLA presentes en matrices como la leche. Aunque se han publicado trabajos científicos para determinar dichos isómeros como ácidos grasos libres (Ostrowska et al., 2000; Dance et al., 2010; Czauderna et al., 2011) o como triglicéridos (Adlof et al., 2002, Adlof, 2007), lo más frecuente es que se trabaje con derivados de ésteres metílicos (FAME). Estos derivados son muy utilizados para la determinación de ácidos grasos por cromatografía de gases, debido principalmente a la volatilidad de los mismos. Sin embargo, los FAME también son útiles en $\mathrm{Ag}^{+}$-HPLC, no por su volatilidad, sino más bien por la necesidad de emplear un procedimiento sencillo y rápido que logre romper la unión entre los ácidos grasos y la molécula de glicerol (Delmonte et al., 2005; Luna et al., 2005a, 2005b, 2005c y 2007; Gómez-Cortés et al., 2008a y 2008b; Rodríguez-Alcalá et al., 2009). Con los FAME se evitaría emplear procedimientos que impliquen ácidos grasos libres, que si bien pueden ser válidos para este tipo de análisis, suelen ser procesos más laboriosos, que conllevan pasos previos de saponificación y acidificación, y que utilizan reactivos ácidos capaces de ocasionar isomerizaciones indeseadas. Para evitar dichas isomerizaciones, los derivados FAME deben obtenerse eligiendo una metilación alcalina, en condiciones suaves de temperatura y tiempos de reacción cortos. 


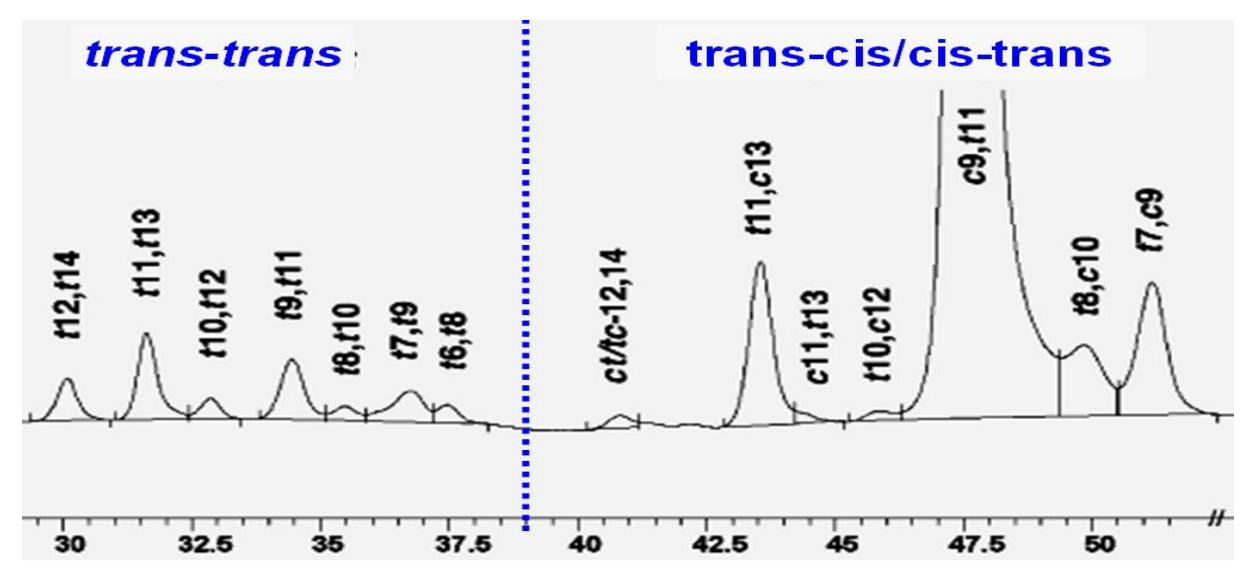

Figura 1.11. Separación $\mathrm{Ag}^{+}$-HPLC/DAD de los ésteres metílicos de la grasa láctea usando tres columnas en serie. Modificada de Collomb et al. (2004).

Como se observa en la Figura 1.11, la separación de los isómeros CLA-FAME se lleva a cabo utilizando varias columnas analíticas conectadas en serie (Sehat et al., 1999; Adlof, 2003; Collomb et al., 2004; Delmonte et al., 2004b). Estas columnas se comercializan con el nombre de ChromSpher 5 Lipids, las cuales están hechas a base de sílice-ácido fenilsulfónico, matriz en la que los iones plata se encuentran unidos mediante enlaces iónicos, sustituyendo al protón del ácido fenilsulfónico (Christie et al., 2007; Nikolova-Damyanova, 2009). Cerca del 30\% de los grupos silanoles originales están libres, lo que le da un carácter parcial de fase normal. Esto facilita la unión "transitoria" entre los iones plata y los electrones $\pi$ que se encuentran en los dobles enlaces de los isómeros CLA (Nikolova-Damyanova, 2009). La configuración geométrica de los dobles enlaces también es importante, ya que los dobles enlaces "cis" son retenidos con más fuerza que los dobles enlaces "trans" (Kramer et al., 1999; De la Fuente et al., 2006; Christie et al., 2007). El volumen de muestra inyectado suele estar entre $10-30 \mu \mathrm{L}$, y no debe superar los $250 \mu \mathrm{g}$ de ácidos grasos, para evitar saturaciones dentro de las columnas (De la Fuente et al., 2006).

Para lograr una buena separación de los isómeros CLA en leche, es fundamental la composición de la fase móvil. Para el análisis de CLA en la grasa láctea, la mezcla eluyente que más se ha utilizado está constituida de hexano, al cual se le añade una pequeña proporción de acetonitrilo (entre 0,1 y $1 \%$ ), sugiriéndose que la mezcla acetonitrilo-hexano sea preparada recientemente y se mantenga en constante agitación (Cruz-Hernández et al., 2004; Delmonte et al., 2004b; Luna et al., 2005a, 2005b, 2005c; Nuernberg et al., 2007). Sin embargo, la baja solubilidad del acetonitrilo en hexano (menor al 5\%) hace que este eluyente sea relativamente inestable, lo que puede causar 
variaciones en los volúmenes de retención de los isómeros CLA entre distintas inyecciones. Algunos investigadores han añadido a esta mezcla pequeñas cantidades de éter etílico (Collomb et al., 2004; Delmonte et al., 2005; Gómez-Cortés et al., 2008a, 2008b, 2009a y 2009b; Luna et al., 2008b); otros en cambio, han ensayado con distintas mezclas de fase móvil (Delmonte et al., 2005; Müller et al., 2006b; Kuhnt et al., 2010). En cualquier caso, con ninguno de estos sistemas de elución se ha podido evitar por completo los desplazamientos que se observan en los volúmenes de retención (RV) de los isómeros CLA. Una forma de controlar las variaciones en los RV's de los diferentes isómeros CLA, es conociendo sus volúmenes de retención relativos (RRV) como sugieren Delmonte et al. (2005).

La detección de los CLA-FAME se lleva a cabo por absorción UV, a una longitud de onda de $233 \mathrm{~nm}$, característica de los dienos conjugados (Delmonte et al., 2005; De la Fuente et al., 2006). Dicha longitud de onda puede variar entre 230 y 235 $\mathrm{nm}$, dependiendo del equipo instrumental con el que se trabaja, por lo que para determinarla con mayor exactitud, resulta mucho más útil realizar un barrido espectral previo al análisis, utilizando un detector de diodos (DAD). El uso del DAD también permite evaluar la posibilidad de que se produzcan interferencias, al detectar de manera simultánea la presencia de ácidos grasos monoinsaturados (cuyo máximo de absorción es $205 \mathrm{~nm})$ y trienos conjugados $(268 \mathrm{~nm})$.

\subsubsection{Orden de elución de los isómeros CLA por $\mathrm{Ag}^{+}-H P L C$}

En general, el orden de elución de los isómeros CLA-FAME, cuando se utiliza $\mathrm{Ag}^{+}$-HPLC, es el siguiente (ver Figura 1.12 y Tabla 1.21): trans-trans < cis-trans/transcis < cis-cis. Los primeros en aparecer son los isómeros trans-trans, cuya resolución cromatográfica es bastante buena. Posteriormente, aparece una zona en donde eluyen los isómeros cis-trans/trans-cis, los cuales eluyen juntos y presentan una peor resolución, comparados con los trans-trans. Finalmente, deberían aparecer los isómeros cis-cis, pero generalmente no se detectan por $\mathrm{Ag}^{+}-\mathrm{HPLC} / \mathrm{DAD}$, ya que en la grasa láctea estos isómeros se encuentran en proporciones casi inapreciables. 


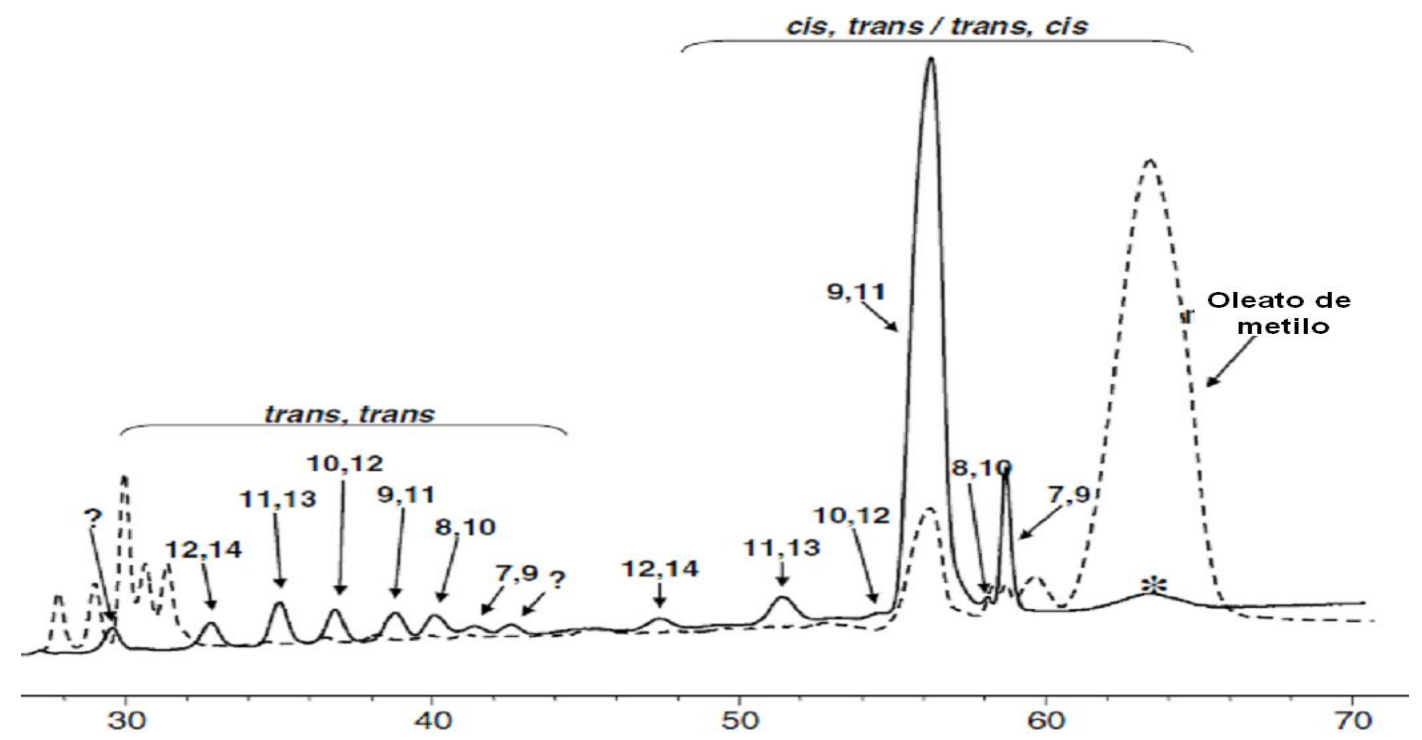

Figura 1.12. Perfil $\mathrm{Ag}^{+}$-HPLC de los isómeros CLA-FAME presentes en la grasa láctea ovina (Luna et al., 2005a). Línea continua: registro a 233nm; línea entrecortada: registro a 205nm.

Tabla 1.21. Orden de elución $\mathrm{Ag}^{+}$-HPLC de los ésteres metílicos de isómeros CLA

\begin{tabular}{|c|c|c|}
\hline trans-trans & cis-trans/trans-cis & cis-cis \\
\hline $\begin{array}{c}(13 t, 15 t) \\
12 t, 14 t \\
11 t, 13 t \\
10 t, 12 t \\
9 t, 11 t \\
8 t, 10 t \\
7 t, 9 t \\
6 t, 8 t\end{array}$ & $\begin{array}{c}(13,15 \mathrm{c} / \mathrm{t}) \\
12,14 \mathrm{c} / \mathrm{t} \\
11 \mathrm{t}, 13 \mathrm{c} \\
11 \mathrm{c} 13 \mathrm{t} \\
10,12 \mathrm{c} / \mathrm{t} \\
9 \mathrm{c}, 11 \mathrm{t} \\
9 \mathrm{t}, 11 \mathrm{c}+\mathbf{8 c}, 10 \mathrm{t} \\
8 \mathrm{t}, 10 \mathrm{c} \\
7 \mathrm{t}, 9 \mathrm{c}\end{array}$ & $\begin{array}{c}(13 c, 15 c) \\
12 c, 14 c \\
11 c, 13 c \\
10 c, 12 c \\
9 c, 11 c \\
8 c, 10 c \\
7 c, 9 c\end{array}$ \\
\hline
\end{tabular}

Datos tomados de Kramer et al. (1999). Según estos autores, los isómeros que se muestran entre paréntesis aún no han sido confirmados.

\subsubsection{Identificación de los isómeros CLA}

La característica común de todos los isómeros CLA es su máximo de absorción ultravioleta, por lo que una forma de distinguir los picos CLA de los que no lo son, es a través de sus espectros ultravioleta característicos (Delmonte et al., 2004b). Otra forma de identificar los isómeros CLA es mediante la co-inyección de la muestra problema con patrones o mezclas sintéticas de CLA (Eulitz et al., 1999; Collomb et al., 2004; Luna et al., 2005a y 2005c; Rodríguez-Alcalá et al., 2009). De forma tentativa, también es posible deducir el orden de elución de los isómeros, comparando los resultados obtenidos con los encontrados en trabajos previamente publicados (Luna et al., 2005a y 2005c; Alfaia et al., 2006; Martins et al., 2007). Sin embargo, uno de los inconvenientes 
más importantes del análisis $\mathrm{Ag}^{+}$-HPLC, y que dificulta la identificación de los picos, es la no reproducibilidad en los volúmenes de retención (RV), por lo que otra forma de identificar cada uno de los isómeros CLA es a través de sus respectivos volúmenes de retención relativos (RRV). La aplicación de los mismos en la identificación de estos isómeros se realiza asumiendo, en todos los casos, que cualquier cambio en la composición de la fase móvil afectará de la misma manera a la elución de cada isómero CLA presente en la mezcla que se analiza (Delmonte et al., 2004a y 2005).

\subsubsection{Cuantificación por $\mathrm{Ag}^{+}-\mathrm{HPLC}$}

Es habitual que, en el análisis de isómeros CLA, $\mathrm{Ag}^{+}$-HPLC se utilice como técnica complementaria de la cromatografía de gases (GC-FID). Como esta última técnica utiliza un patrón interno para determinar la concentración de ácidos grasos presentes en la muestra, el contenido de CLA total se suele cuantificar de esta manera y la distribución porcentual de los isómeros se calcula con las áreas cromatográficas obtenidas por $\mathrm{Ag}^{+}$-HPLC. A veces, la combinación de ambas técnicas también hace posible la determinación de isómeros individuales. En estos casos, se cuantifica el pico mayoritario que se observa en el cromatograma obtenido por GC-FID. Este pico corresponde a la suma de tres isómeros (cis-9,trans-11, trans-7,cis-9 y trans-8,cis-10), por lo que el contenido de cada uno de ellos se obtiene relativizándolos a las áreas en el cromatograma $\mathrm{Ag}^{+}$-HPLC. Los isómeros CLA restantes se cuantifican a partir de cada una de sus áreas $\mathrm{Ag}^{+}$-HPLC, comparándolas con el área correspondiente al isómero mayoritario, es decir, al cis-9,trans-11 (Collomb et al., 2004; Gómez-Cortés et al., 2008a; Luna et al., 2008a). Los resultados se pueden expresar en: miligramos por gramo de grasa $\left(\mathrm{mg} / \mathrm{g}_{\text {Grasa }}\right)$, \% respecto al contenido total de ácidos grasos (libres o como FAME) o \% respecto al contenido total de CLA.

Cuando únicamente se utiliza $\mathrm{Ag}^{+}$-HPLC, la cuantificación de los isómeros CLA se realiza mediante rectas de calibrado con patrones externos, empleando para su elaboración diferentes concentraciones de isómeros puros. Esta forma de trabajar fue descrita por Fritsche et al. (2000) para la determinación de CLA en grasa de bovino, y ha sido aplicada, con pequeñas modificaciones, para determinar CLA en alimentos procedentes de rumiantes (Mele et al., 2006; Martins et al., 2007; Nuernberg et al., 2007). 
1.5.6.6. $\mathrm{Ag}^{+}-H P L C$ como técnica complementaria de la cromatografía de gases

En los últimos años, la cromatografía de gases ha tenido un papel fundamental y destacado como técnica de determinación de CLA, sobre todo en muestras de origen lácteo. De todas sus modalidades, la cromatografía de gases con detector de ionización de llama (GC-FID) es la que más se ha utilizado, aunque su acoplamiento a otras técnicas como la espectrometría de masas (GC-MS) o el infrarrojo con transformada de Fourier (GC-FTIR) suelen tener interés como técnicas de determinación estructural. Su complementación con la $\mathrm{Ag}^{+}$-HPLC ha sido, es y sigue siendo clave en la separación, identificación estructural y cuantificación de la mayor parte de los isómeros CLA (Collomb et al., 2004; Luna et al., 2005a, 2005b, 2005c y 2008a; Gómez-Cortés et al., 2008a, 2008b, 2009a y 2009b; Hervás et al., 2008b). Algunas de las razones por las que se recomienda un uso complementario de ambas técnicas, son las siguientes:

- Mediante la cromatografía de gases con detector de ionización de llama (GC-FID) es posible determinar tanto el contenido total de CLA como el de cualquier otro ácido graso presente en la grasa láctea. Sin embargo, los isómeros CLA no presentan una buena resolución, lo que no permite diferenciarlos entre si. $\mathbf{A g}^{+}-$ HPLC ayudaría a resolver este problema, ya que su resolución cromatográficas es superior.

- Como los dienos conjugados absorben a $233 \mathrm{~nm}$, la determinación de los isómeros CLA mediante $\mathrm{Ag}^{+}$-HPLC con detector de diodos ( $\mathbf{A g}^{+}$-HPLC/DAD) es muy selectiva. A través de esta técnica, no sólo es posible separar y diferenciar los isómeros entre sí, sino que también se podrían determinar otros ácidos grasos insaturados. Sin embargo, $\mathrm{Ag}^{+}-\mathrm{HPLC} / \mathrm{DAD}$ no es capaz de cuantificar ácidos grasos saturados, por lo que para ello es necesario recurrir a la cromatografía de gases.

- A través de la $\mathbf{A g}^{+}$-HPLC se pueden diferenciar los distintos isómeros CLA, mediante el cálculo de sus respectivos volúmenes de retención relativos. Pero para identificarlos inequívocamente, es necesario emplear técnicas de identificación estructural más potentes, como la cromatografía de gases acoplada a un espectrómetro de masas (GC-MS) o a un infrarrojo con transformada de Fourier (GC-FTIR). 
- Con $\mathrm{Ag}^{+}$-HPLC, los isómeros trans-trans (o los cis-cis), presentan una mejor resolución cromatográfica, ya que es posible separar cada uno de ellos sin que estén superpuestos o enmascarados por otros isómeros CLA. En cambio, cuando el análisis se realiza mediante GC, la mayor parte de los isómeros trans-trans (a excepción del trans-11,trans-13) no se separan adecuadamente, y en algunos casos se pueden encontrar superpuestos (parcial o totalmente) con otros isómeros de configuración geométrica distinta (Figura 1.13).

- Cuando se trata de separar isómeros CLA en muestras como la grasa láctea, se observa que el isómero mayoritario (cis-9,trans-11) enmascara a otros isómeros menores. En GC, el cis-9,trans-11 enmascara al trans-7,cis-9 y al trans-8,cis-10. Dichos isómeros pueden llegar a separarse de forma adecuada mediante $\mathrm{Ag}^{+}-\mathrm{HPLC}$ con tres columnas conectadas en serie. Cuando la separación se realiza mediante $\mathrm{Ag}^{+}-\mathrm{HPLC}$, el mayoritario cis-9,trans-11 se superpone al trans-9,cis-11 y parcialmente al cis-8,trans-10, que pueden llegar a separarse adecuadamente mediante GC.

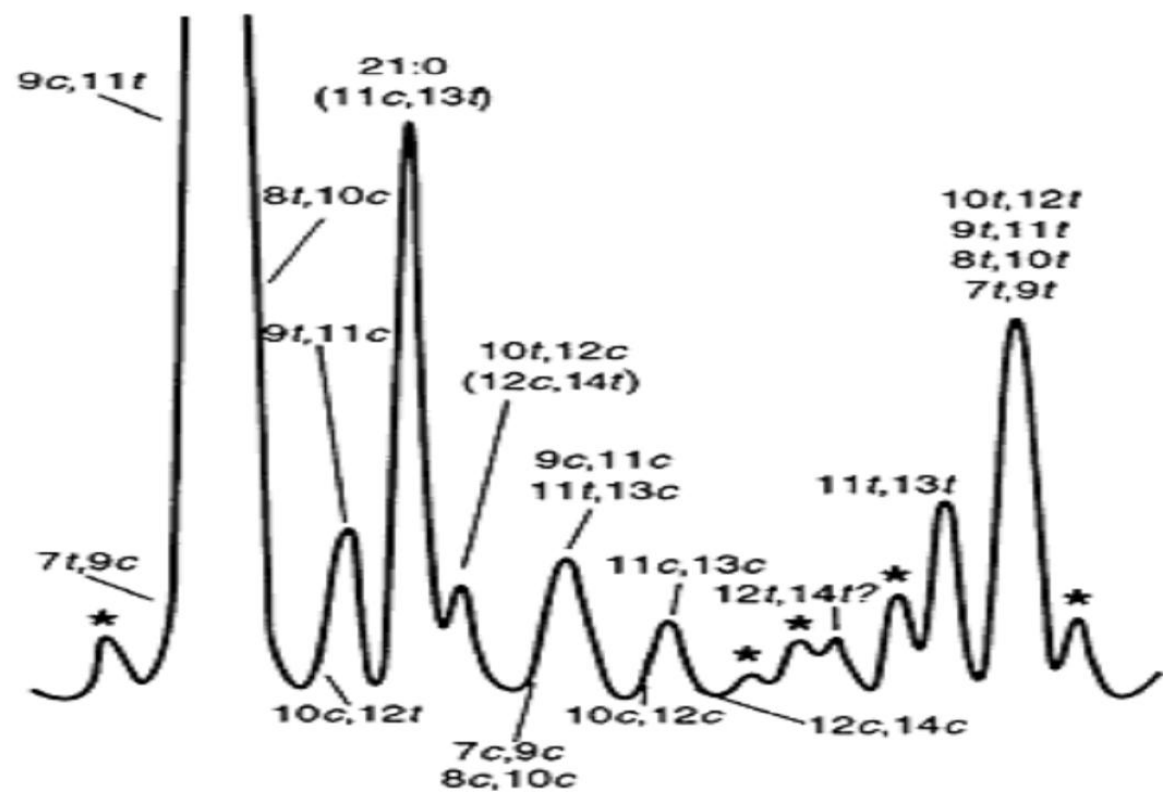

Figura 1.13. Cromatograma parcial GC de los isómeros CLA (separados como FAME en una columna CP Sil 88) presentes en la grasa láctea de queso. Los picos con asterisco (*) indican que no corresponden a isómeros CLA. Tomada de Christie et al. (2007). 
En un análisis de CLA por cromatografía de gases, es importante utilizar una columna capilar cuyas características permitan garantizar una buena resolución de los isómeros. Cuanto mayor sea la polaridad y la longitud de la columna, mejor será la resolución de los mismos. Columnas polares de 100 m, como la CP-Sil 88, suelen ser las preferidas en el análisis de los isómeros CLA (Ledoux et al., 2005; Luna et al., 2005a, 2005b, 2005c; Rodríguez-Alcalá y Fontecha, 2007). El tipo de gas portador y, sobre todo, la temperatura del horno, también influyen sobre la resolución cromatográfica de los picos. Una buena elección del gradiente de temperatura será fundamental para obtener un cromatograma en el cual los isómeros presenten una buena resolución, evitándose también posibles errores de identificación causados por desplazamientos de otros picos a la zona correspondiente al CLA (Christie et al., 2007). Del sistema de detección, el más utilizado con diferencia es el detector de ionización de llama (FID). Otros tipos de detectores son el espectrómetro de masas (MS) y el infrarrojo (FTIR), los cuales tienen más utilidad cuando se quiere obtener información estructural de los isómeros. Finalmente, el orden de elución en cromatografía de gases difiere al observado en la cromatografía $\mathrm{Ag}^{+}-\mathrm{HPLC}$, y es el siguiente:

cis-trans/trans-cis < cis-cis < trans-trans. 


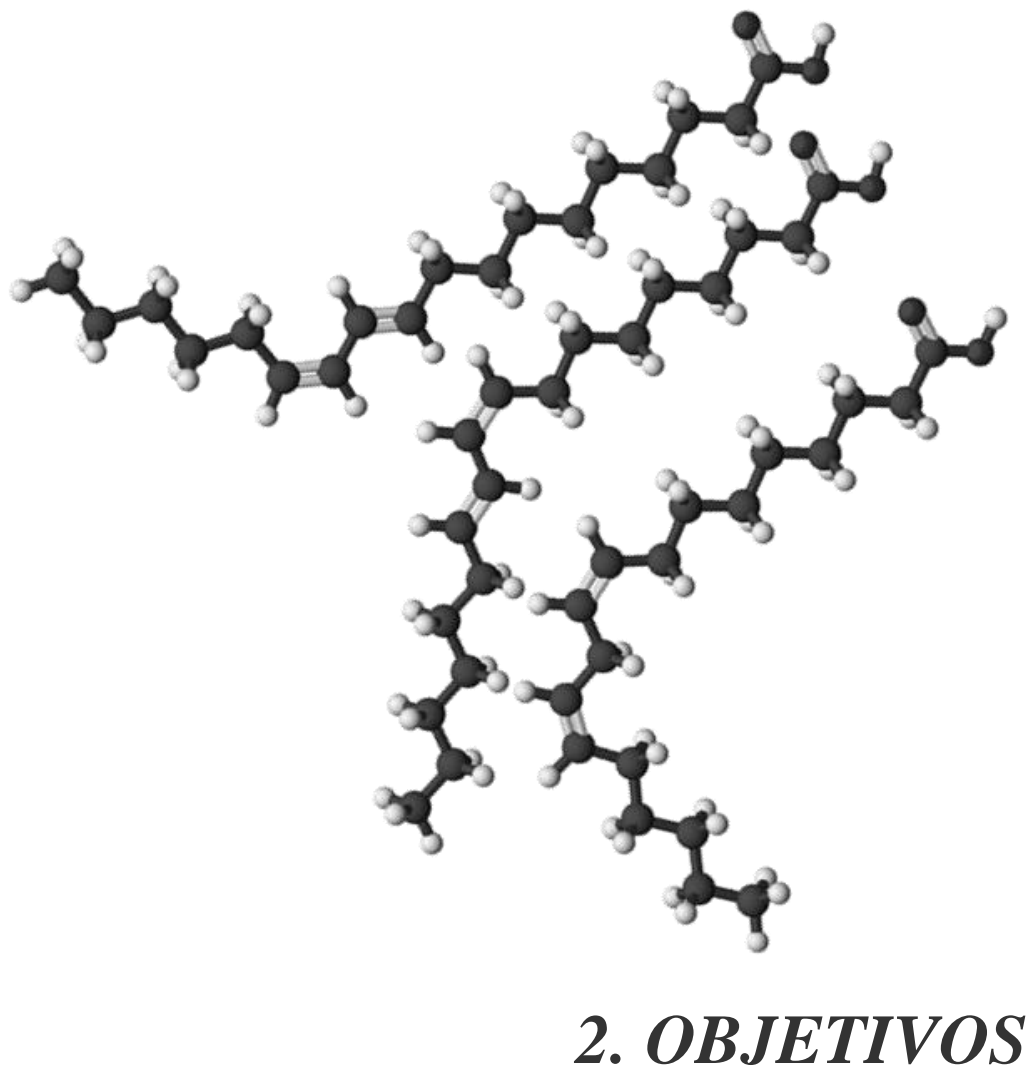





\section{OBJETIVOS}

El objetivo general de este trabajo es conocer el contenido de isómeros del Ácido Linoleico Conjugado (CLA) en leche de oveja parcialmente desnatada y tratada térmicamente, así como en yogur y cuajada elaborados con leche de la misma especie animal. Hasta el momento, no existen datos en productos españoles destinados al consumo. Para alcanzar el objetivo general, se han planteado tres objetivos parciales que se exponen a continuación:

1) Puesta a punto de un método que permita la cuantificación individual de isómeros CLA en leche y derivados lácteos, recurriendo únicamente a la determinación por $\mathrm{Ag}^{+}-\mathrm{HPLC}$.

Como ya ha quedado recogido en "Antecedentes Bibliográficos", para resolver el análisis de los isómeros CLA presentes en un alimento es imprescindible combinar varias técnicas, tales como la cromatografía de gases - espectrometría de masas (GCMS) y la cromatografía líquida de alta resolución con intercambiador de iones plata $\left(\mathrm{Ag}^{+}-\mathrm{HPLC}\right)$. Una buena separación entre isómeros sólo se consigue con ésta última, pero para la cuantificación se suele recurrir a la cromatografía de gases con detector de ionización de llama (GC-FID). De esta manera se cuantifica el conjunto de los mismos y para los distintos isómeros se fija la contribución al total.

El poder disponer de un método que posibilite la separación y cuantificación de isómeros CLA recurriendo a una única técnica, permitirá valorar los contenidos reales de diferentes isómeros en alimentos y, con ello, establecer la ingesta individual de los mismos. Además, será una herramienta a disposición de otros investigadores, para el estudio de las rutas biosintéticas y de la efectividad de la dieta suministrada a los animales para aumentar el contenido de CLA de la leche y carne que producen.

Para la puesta a punto de dicho método, es necesario resolver varias dificultades, entre otras, los cambios en los volúmenes de retención. Estas variaciones, que son recogidas en la bibliografía por distintos autores, parecen características de las condiciones cromatográficas establecidas para la separación de los isómeros CLA, y pueden deberse a pequeñas modificaciones en la composición del eluyente. Se estudiará la manera de fijar las variables experimentales, con el fin de obtener resultados 
reproducibles. Una vez conseguida la reproducibilidad, hay que establecer el procedimiento de cuantificación externa con patrones y validar el método propuesto.

2) Conocer el contenido de los diferentes isómeros CLA en leche de oveja parcialmente desnatada y tratada térmicamente.

Existen muchos datos en la bibliografía respecto a la leche de vaca, pero en leche de oveja son escasos y se refieren, casi siempre, a contenido global de isómeros CLA en leche cruda. En algunos casos se detalla la concentración de los isómeros cis9,trans-11 y trans-10,cis-12, pero en realidad estos contenidos suelen incluir otros isómeros, ya que la cromatografía de gases no permite la separación de algunos de ellos. En leche de ovejas españolas, se dispone de un trabajo en el que se establece el porcentaje de contribución de los diferentes isómeros determinados por $\mathrm{Ag}^{+}-\mathrm{HPLC}$. Los trabajos publicados en los últimos años recogen el efecto que produce, sobre los isómeros CLA, la modificación de la dieta que se suministra a los animales.

Es conocido que la leche de oveja presenta una cantidad de grasa elevada (5 a 8 $\%$ ), por lo que eliminar parte de la misma parece una medida adecuada desde el punto de vista dietético, si se pretende comercializar como leche líquida o bien destinarla a la elaboración de algunos derivados lácteos.

El establecer la composición y contenido de CLA en leche de oveja comercial parcialmente desnatada y tratada térmicamente, permitirá disponer de información nueva y valorar la contribución de este alimento a la ingesta de distintos isómeros. Además, se evaluará el efecto estacional y la influencia del tratamiento y almacenamiento, sobre el contenido total e individual de los isómeros presentes.

3) Estudio de los isómeros CLA en yogur y cuajada elaborados con leche de oveja.

Según nuestros conocimientos, se dispone de muy poca información al respecto y tendría mucho interés porque podrían ser una buena fuente de CLA, incluso superior a la leche de oveja semidesnatada, puesto que se comercializan con un contenido de grasa mayor. Además, en el caso del yogur, cabe la posibilidad de que aumente el contenido de CLA respecto a la leche utilizada para su elaboración, debido a la presencia de 
microorganismos. También se estudiará el efecto del procesado y almacenamiento sobre los isómeros individuales.

Dado que puede existir una elevada variabilidad en los niveles de CLA en función de diversos factores exógenos, como la alimentación, estación del año, entre otros, se controlará en todos los casos la leche de partida y se tratará de establecer la influencia global de estos factores, realizando el muestreo en distintos meses del año.

Los resultados obtenidos permitirán asignar contenidos representativos en leche de oveja, yogur y cuajada fabricados con leche de la misma especie animal, que pueden utilizarse para estimar la contribución de estos alimentos a la ingesta de CLA total y de isómeros individuales. Debe recordarse que el CLA ha despertado un interés creciente en los últimos años porque se le han atribuido efectos beneficiosos en la prevención de algunas enfermedades. 



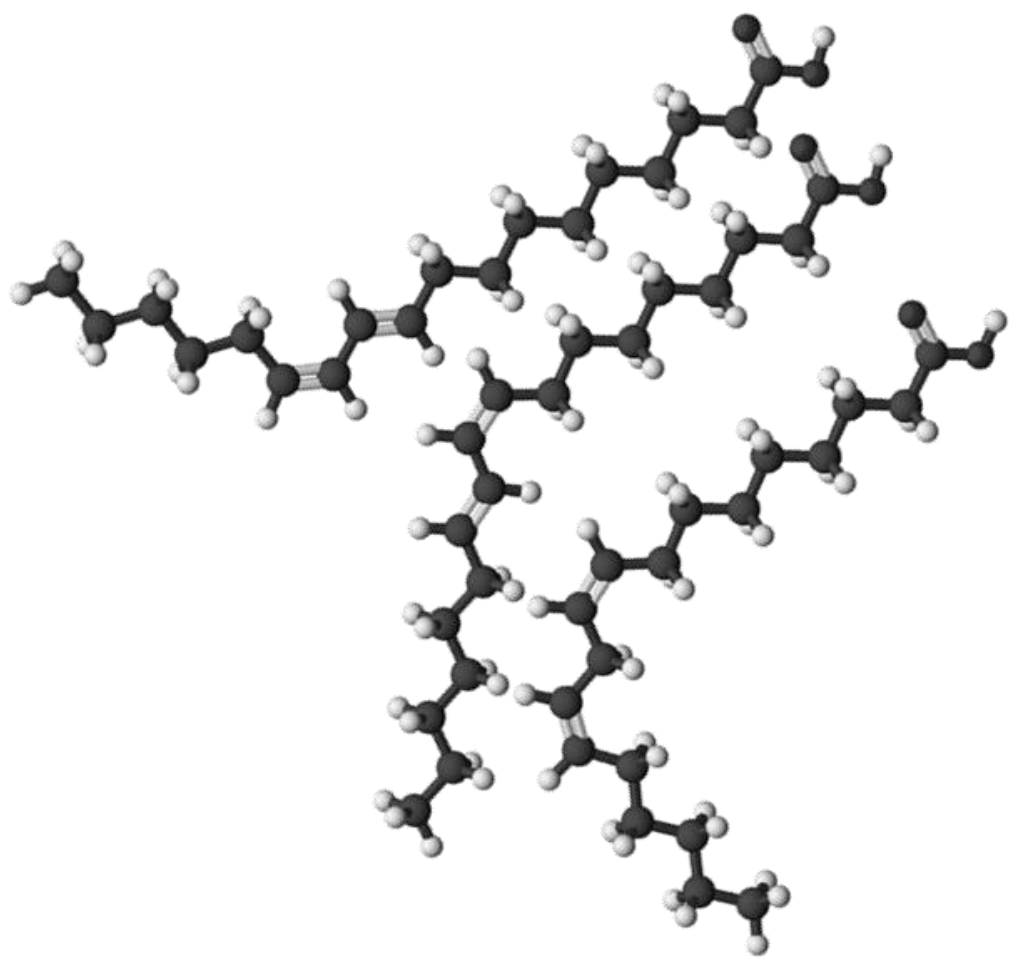

3. PUESTA A PUNTO Y VALIDACIÓN DEL MÉTODO DE ANÁLISIS 



\section{PUESTA A PUNTO Y VALIDACIÓN DEL MÉTODO DE ANÁLISIS}

Para cumplir con este objetivo, se recurrió a la cromatografía líquida de alta resolución con intercambiador de iones plata $\left(\mathrm{Ag}^{+}-\mathrm{HPLC}\right)$ como único método de análisis. Será necesario emplear varios procedimientos de identificación: volúmenes de retención $(\mathrm{RV})$, volúmenes de retención relativos (RRV), co-inyección de patrones con muestras y espectros de absorción en el ultravioleta. La cuantificación se llevará a cabo utilizando patrones externos y fijando las condiciones experimentales más adecuadas. Una vez se haya establecido el procedimiento, se validará el método de análisis. Los ensayos de puesta a punto y validación se desarrollaron mediante la determinación del contenido de isómeros CLA en muestras de leche de oveja semidesnatada (1,6\% de materia grasa) tratada térmicamente y envasada en tetrabrik, que fueron suministradas por la empresa Leche GAZA, S.L. La extracción de la grasa y la derivatización de los ácidos grasos presentes en la misma se llevaron a cabo utilizando, respectivamente, los procedimientos ISO 14156 (2001) e ISO 15884 (2002). Los ésteres metílicos obtenidos se inyectaron en el cromatógrafo, cuantificándose, después de la separación con $\mathrm{Ag}^{+}$HPLC/DAD, todos los picos detectados como dienos conjugados.

\subsection{MÉTODO DE ANÁLISIS}

\subsubsection{Extracción de la grasa}

El procedimiento que se utilizó para la extracción de la grasa láctea de todas las muestras (tanto de leche cruda como de sus productos procesados) está contemplado dentro de la Norma ISO 14156 / IDF 172: 2001 (ISO-IDF, 2001). Para dicha extracción, se siguieron los pasos que se representan en el esquema de la Figura 3.1. La muestra previamente atemperada $\left(20^{\circ} \mathrm{C} \pm 2\right)$ fue sometida a un proceso de digestión con amoníaco y etanol; luego se procedió a la extracción de la grasa, empleando como disolvente una mezcla de éter etílico-pentano (1:1). Una vez que se desechó la fase acuosa, fue necesario eliminar restos de agua de la fase orgánica, para lo cual se empleó sulfato sódico anhidro. La fase orgánica se eliminó por evaporación a presión reducida y a una temperatura que no superó $\operatorname{los} 50^{\circ} \mathrm{C}$. Es posible que el residuo de dicha evaporación, correspondiente a la grasa extraída, presente cierta turbidez. En ese caso, lo recomendable es trasvasar dicho residuo a un vial eppendorf y someterlo a una centrifugación durante 5 minutos $\left(10000 \mathrm{rpm}, 20^{\circ} \mathrm{C}\right)$, utilizando para ello una 
microcentrífuga refrigerada (Heraeus Biofuge "Fresco", Sorvall). Finalmente, y para evitar una posible degradación de los ácidos grasos, la grasa extraída debe guardarse en un vial de vidrio color ámbar (Supelco, 8 x $40 \mathrm{~mm}, 1 \mathrm{~mL}$ ) y a $-20^{\circ} \mathrm{C}$, hasta su metilación.

\section{$100 \mathrm{~mL}$ leche UHT ó $50 \mathrm{~mL}$ leche cruda ó $50 \mathrm{~g}$ cuajada o yogur} Depositar en un embudo de decantación de $500 \mathrm{~mL}$

- Añadir: $80 \mathrm{~mL}$ etanol + $20 \mathrm{~mL} \mathrm{NH} \mathrm{NH}_{3} 100 \mathrm{~mL}$ éter etílico

- Agitar durante 1 minuto. Separar las fases

- $100 \mathrm{~mL}$ n-pentano. Separar las fases

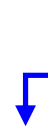

Fase acuosa

(Desechar)

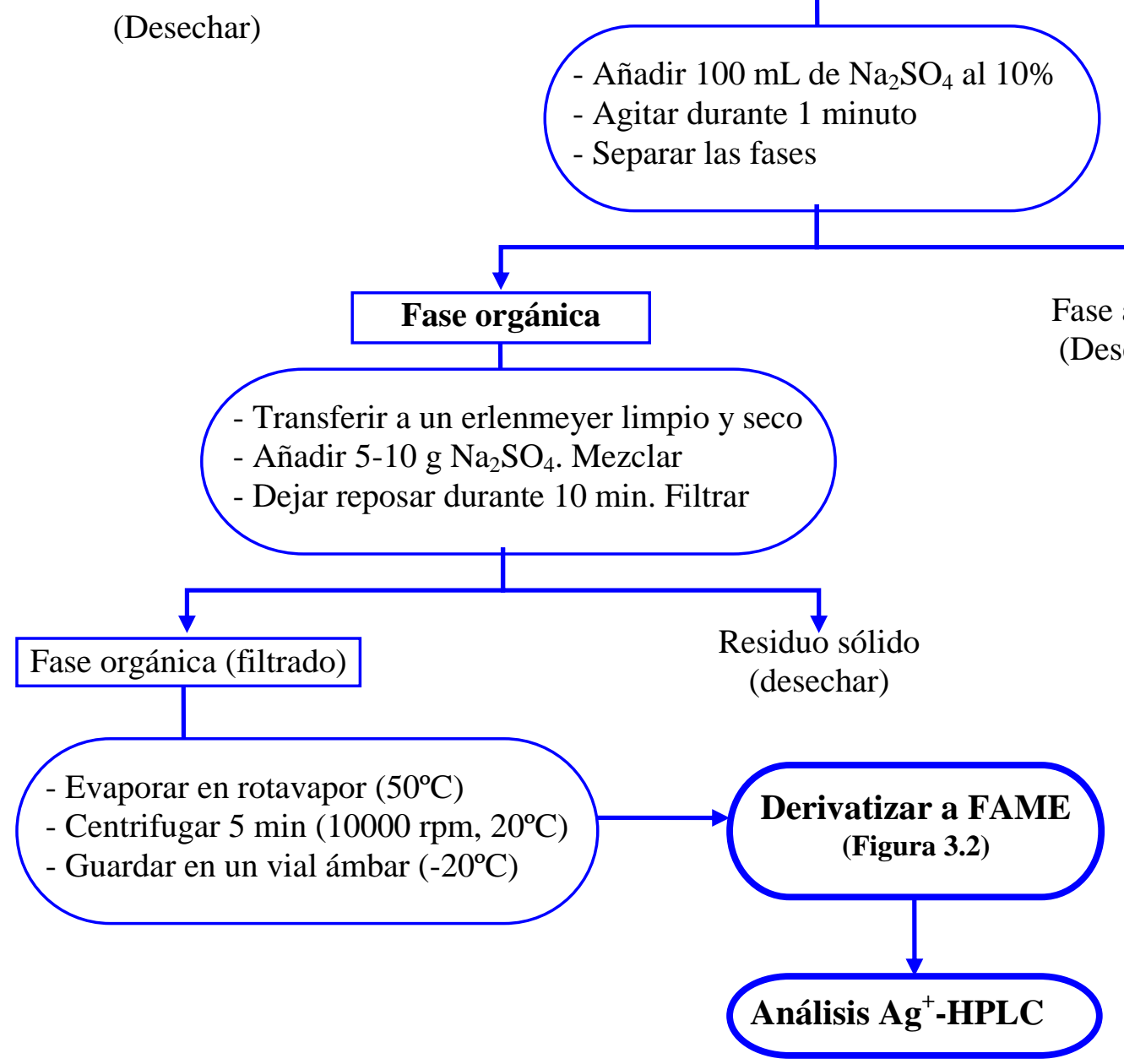

Figura 3.1. Esquema de extracción de la grasa láctea, según la Norma ISO 14156 / IDF 172:2001. 


\subsubsection{Metilación de los ácidos grasos}

Antes de proceder a la identificación y cuantificación de los isómeros CLA por $\mathrm{Ag}^{+}$-HPLC, es necesario transformar los mismos en ésteres metílicos (FAME). La Norma ISO 15884 / IDF 182: 2002 (ISO-IDF, 2002) es el método de referencia para la metilación de ácidos grasos en leche y productos lácteos y es el que utilizaremos para nuestros ensayos. Durante la metilación y en los pasos posteriores a la misma, es importante evitar la interferencia del agua, por lo que todo el material que se vaya a utilizar debe estar seco.

Grasa láctea (25-30 mg de grasa fundida, exactamente pesada en un tubo eppendorff)

- Añadir: $250 \mu \mathrm{L}$ de hexano. Mezclar

- Añadir $50 \mu \mathrm{L}$ disolución de $\mathrm{KOH} / \mathrm{MeOH}$. Tapar bien

- Agitar durante $1 \mathrm{~min}$. Dejar reposar durante $5 \mathrm{~min}$.

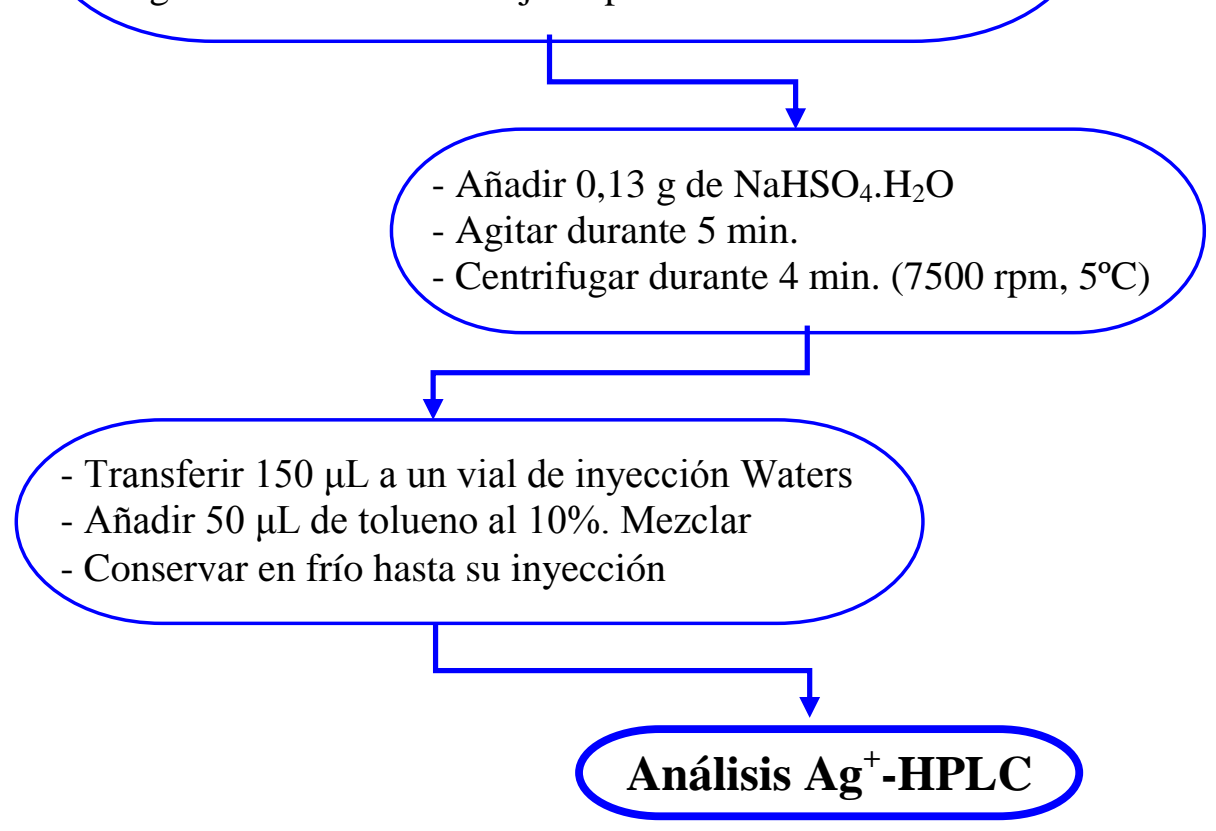

Figura 3.2. Esquema de metilación de la grasa láctea, según la Norma ISO 15884 / IDF 182:2002.

Una cantidad exactamente pesada de grasa fundida (entre 25 y $30 \mathrm{mg}$ ) se colocó en un tubo eppendorff para microcentrífuga (Sorenson, 2,0 mL) y se disolvió en un volumen conocido de hexano $(250 \mu \mathrm{L})$. Esta mezcla se hizo reaccionar con $50 \mu \mathrm{L}$ del reactivo de transesterificación alcalino; dicho reactivo se preparó diariamente, 
disolviendo aproximadamente $0,18 \mathrm{~g}$ de $\mathrm{KOH}$ en $1 \mathrm{~mL}$ de metanol (con esta cantidad de reactivo, es posible la metilación de, al menos, 12 muestras). Después de mezclarlo durante un minuto, se dejó reaccionar durante 5 minutos. Pasado este tiempo se le adicionó $\mathrm{NaHSO}_{4}$ (como reactivo de terminación) y se centrifugó durante 4 minutos (7500 rpm, $5^{\circ} \mathrm{C}$ ). Del sobrenadante, el cual contiene los ésteres metílicos (FAME), se recogió un alícuota $(150 \mu \mathrm{L})$ y se depositó en un vial (Waters) junto con $50 \mu \mathrm{L}$ de tolueno al 10\%. Esta mezcla, previamente homogenizada, se colocó en el autoinyector para su análisis por $\mathrm{Ag}^{+}$-HPLC (el autoinyector se programó previamente a $5^{\circ} \mathrm{C}$ para evitar posibles pérdidas por volatilización). En la Figura 3.2, se representa el esquema de metilación de los ácidos grasos presentes en la leche, según esta metodología. Como ya se expuso previamente (véase el apartado 1.5.3) los derivados FAME son útiles porque se obtienen fácilmente con un procedimiento sencillo y rápido, capaz de romper la unión entre los ácidos grasos y la molécula de glicerol.

\subsubsection{Determinación de CLA por $\mathbf{A g}^{+}$-HPLC con detector de diodos}

\subsubsection{Especificaciones instrumentales y analíticas}

Equipo instrumental: El análisis $\mathrm{Ag}^{+}-\mathrm{HPLC}$ de los ésteres metílicos de CLA se realizó en un cromatógrafo líquido, equipado con una bomba cuaternaria Agilent 1100, un detector de diodos Hewlett Packard 1040M (que opera entre longitudes de onda de 190 y $600 \mathrm{~nm}$ ) y un inyector automático Waters TM 717 Plus refrigerado, para evitar la degradación de los ésteres metílicos o la volatilización del hexano en el que se encuentran disueltos. El equipo se controló mediante el software Chemstation, de Agilent Technologies.

Columnas analíticas: Para conseguir una buena resolución de los isómeros, se utilizaron 3 columnas analíticas "ChromSpher 5 Lipids" (4,6 mm de diámetro interno, $250 \mathrm{~mm}$ de largo y $5 \mu \mathrm{m}$ de diámetro de partícula, Varian Chrompack Int.) con intercambiador de iones plata, conectadas en serie. Durante el análisis, estas columnas se mantuvieron a temperatura ambiente $\left(23^{\circ} \mathrm{C}\right)$. Para su buen funcionamiento y para prolongar la vida útil de las mismas, es importante que la muestra a inyectar esté previamente diluida y, si fuera necesario, filtrada, ya que así se evitará una saturación de las columnas. 
Fase móvil: La separación se realizó empleando como eluyente una mezcla de hexano con un $0,1 \%$ de acetonitrilo $(1 \mathrm{~mL}$ de acetonitrilo en $\mathrm{n}$-hexano, hasta completar $1 \mathrm{~L}$ ), ambos disolventes han de ser grado UV. El acetonitrilo y el hexano son poco miscibles entre sí, por lo que para asegurar una mezcla completa de ambos disolventes, es recomendable agitar mecánicamente el hexano mientras se añade el acetonitrilo. Esta mezcla debe prepararse el mismo día del ensayo, para así evitar en la medida de lo posible, los desplazamientos en los volúmenes de retención de los FAME. Es importante realizar un pretratamiento de la columna con la fase móvil (al menos durante los 30 minutos previos a la primera inyección). Aunque algunos autores han sugerido que la mezcla eluyente esté en constante agitación durante el análisis cromatográfico (Cruz-Hernández et al., 2004; Delmonte et al., 2004b), hemos optado por descartar esta práctica en nuestros ensayos, debido a que cuando se intentó trabajar con mezclas agitadas, los cromatogramas obtenidos no mantenían la línea base.

Disolución de lavado: Se utilizó una disolución de lavado, compuesta de hexano con un $1 \%$ de acetonitrilo $(10 \mathrm{~mL}$ de acetonitrilo, completar con hexano hasta 1 L). Esta mezcla fue útil para el pretratamiento de la columna antes de los ensayos (durante 1 hora) y para el lavado de la misma al finalizar todas las inyecciones del día (durante 2 horas) a un flujo de $1,0 \mathrm{~mL} / \mathrm{min}$.

Flujo de trabajo: Se aumentó gradualmente el flujo hasta alcanzar un valor constante de 1,0 $\mathrm{mL} / \mathrm{min}$, trabajando en régimen isocrático. La presión en cabeza de columna, para la unión de 3 columnas, se mantuvo entre 65 y 70 bar.

Detección: Se utilizó un detector de diodos (DAD), ya que con este detector no sólo es posible realizar barridos espectrales entre 190 y 600nm, sino que también se pueden registrar simultáneamente la absorción de los picos cromatográficos a diferentes longitudes de onda. Para conocer cuál es el máximo de absorción de los isómeros CLA, según el detector que hemos empleado en este trabajo, se registraron los espectros ultravioleta de los patrones CLA correspondientes. Una vez fijada la longitud de onda en la que los isómeros CLA experimentan su máximo de absorción (231 nm), se programó en el software un método para detectar todos los picos posibles, trabajando con 3 longitudes de onda: $231 \mathrm{~nm}$ (máximo de absorción de los dienos conjugados de CLA), 205 nm (máximo de absorción de los ácidos grasos insaturados no conjugados), 
y $268 \mathrm{~nm}$ (máximo de absorción para trienos conjugados). Estas dos últimas longitudes de onda se emplearon con el fin de observar cualquier tipo de interferencias.

Patrones y mezclas sintéticas de CLA: Para la identificación y cuantificación de los isómeros presentes en las muestras de leche, se utilizaron patrones de isómeros individuales y mezclas de CLA en forma de ésteres metílicos (CLA-FAME). La mezcla sintética empleada (UC-59M, $500 \mathrm{mg}, 99 \%$ pureza) contenía proporciones similares de cis-9,trans-11 y trans-10,cis-12, además de pequeñas cantidades de cis-11,trans-13, trans-8,cis-10 y otros isómeros trans-trans. También se utilizaron dos patrones de isómeros individuales: el UC-60M (cis-9,trans-11 $\mathrm{C}_{18: 2}$, > 90\% pureza) y el UC-61M (trans-10,cis-12 $\mathrm{C}_{18: 2},>90 \%$ pureza). Todos ellos fueron suministrados por Nu-Check Prep., Inc. (Elysian, USA), y una vez abiertos, se almacenaron en viales color ámbar para protegerles de la luz, manteniéndolos a baja temperatura (entre -20 y $-30^{\circ} \mathrm{C}$ ).

Volumen de inyección: En cada vial (Waters, $700 \mu \mathrm{L}$ ) se depositaron $150 \mu \mathrm{L}$ del sobrenadante obtenido en la metilación y $50 \mu \mathrm{L}$ de tolueno al $10 \%$ (diluido en hexano). Esta misma proporción (150:50) se utilizó también con los patrones de CLA necesarios para elaborar las distintas rectas de calibrado. Nuestro ensayo fue programado para inyectar $10 \mu \mathrm{L}$ de cada vial.

\subsubsection{Identificación}

Con el fin de comprobar el máximo de absorción característico de los dienos conjugados y así confirmar la identidad de los mismos, se registraron para todos los picos cromatográficos su correspondiente espectro de absorción ultravioleta, en un intervalo de 190 a $350 \mathrm{~nm}$. La identificación de algunos de los isómeros presentes en la grasa de la leche se llevará a cabo mediante comparación de los volúmenes de retención (RV), al co-inyectar la muestra con una mezcla sintética de isómeros CLA (UC-59M). Los isómeros que no se hayan podido confirmar con este tipo de mezcla, se identificarán comparando el orden de elución de los mismos con datos publicados en investigaciones realizadas previamente (Eulitz et al., 1999; Adlof, 2003; CruzHernández et al., 2004; Luna et al., 2005a).

Para asegurarse de que los distintos isómeros CLA en leche han sido identificados correctamente, se calcularán sus correspondientes volúmenes de retención relativos (RRV), según Delmonte et al. (2004a y 2005). Como ya se ha 
dicho previamente (apartado 3.1.3.1), en cada vial de inyección (Waters, $700 \mu \mathrm{L}$ ) se añadió tres partes de patrón (o de grasa metilada) y una parte de una disolución de tolueno al 10\% (véase esquema del procedimiento de metilación, Figura 3.2). Tomando como referencia el isómero cis-9,trans-11 (ácido ruménico, RA), los volúmenes de retención $(\mathrm{RV})$ de los diferentes isómeros se relativizaron a través de la siguiente expresión:

$$
\boldsymbol{R} \boldsymbol{R} \boldsymbol{V}_{i}=\left(\boldsymbol{R} \boldsymbol{V}_{i}-\boldsymbol{R} \boldsymbol{V}_{\text {tolueno }}\right) /\left(\boldsymbol{R} \boldsymbol{V}_{\boldsymbol{R}}-\boldsymbol{R} \boldsymbol{V}_{\text {tolueno }}\right)
$$

En donde “i” indica el isómero CLA que nos interesa conocer. La adición de tolueno fue necesaria, ya que permitió conocer su volumen de retención $\left(\mathrm{RV}_{\text {tolueno }}\right) \mathrm{y}$ estimar el volumen muerto de nuestro sistema HPLC. La aplicación de los RRV's en la identificación de isómeros CLA se realizará asumiendo, en todos los casos, que cualquier cambio en la composición de la fase móvil afectará de la misma manera a la elución de cada isómero CLA presente en la mezcla que se analiza.

\subsubsection{Rectas de calibrado y cuantificación}

Para cuantificar los distintos isómeros CLA que se encontrarán en las muestras, se construyeron 3 rectas de calibrado a partir de los patrones suministrados por $\mathrm{Nu}$ Check Prep., Inc. (Elysian, USA). La primera de las rectas se realizó para cuantificar cis-9,trans-11, isómero mayoritario en la leche. En ella se emplearon distintas disoluciones de UC-60M (dicho patrón contiene mayoritariamente cis-9,trans-11), cuyas concentraciones oscilaron entre 0,05 y $1,00 \mu \mathrm{g} / \mu \mathrm{L}$. La segunda de las rectas se realizó con el mismo patrón (UC-60M), pero empleando concentraciones más bajas (de 0,001 a $0,015 \mu \mathrm{g} / \mu \mathrm{L}$ ); esta recta de calibrado será útil para cuantificar el resto de los isómeros CLA, excepto el trans-10,cis-12. Para este último, se elaboró una recta con un intervalo de concentración similar a la anterior, $(0,001-0,015 \mu \mathrm{g} / \mu \mathrm{L})$, pero partiendo de un patrón distinto (UC-61M, que contiene mayoritariamente trans-10,cis-12).

La cuantificación de los distintos isómeros CLA encontrados en las muestras lácteas se realizó mediante las ecuaciones de regresión lineal obtenidas a partir del calibrado. Cada uno de los cromatogramas se procesó de manera minuciosa, aplicando, cuando fue necesario, integraciones manuales y optimizando los parámetros de integración, para así obtener valores más adecuados de las áreas de pico que nos permitieran conocer los contenidos de los distintos isómeros CLA en leche. 


\subsection{RESULTADOS Y DISCUSIÓN}

\subsubsection{Identificación de los isómeros CLA}

En el apartado siguiente, se detallan y discuten los procedimientos utilizados para la identificación de isómeros CLA. Después, se pasará a exponer los ensayos de validación del método, que incluyen el estudio de linealidad, límite de cuantificación, precisión y exactitud.

\subsubsection{Espectros de absorción}

En los cromatogramas $\mathrm{Ag}^{+}$-HPLC/DAD, correspondientes a la mezcla patrón de isómeros CLA-FAME (Figura 3.3) y a la muestra de grasa de leche ovina (Figura 3.4), se distinguen claramente tres zonas: la primera corresponde a la región trans-trans; en la segunda zona eluyen los picos cis-trans/trans-cis; mientras que en la tercera, deberían aparecer los picos cis-cis, aunque en las muestras de leche que hemos analizado, no se detectaron picos dentro de esta última zona. Lejos de estas tres zonas, se distingue al tolueno, un pico bien definido que aparece al inicio del cromatograma. En muestras de grasa de leche, también se observan una serie de picos cercanos al tolueno, pero que no están relacionados con los isómeros CLA.

Con estas figuras y teniendo presente los cromatogramas recogidos por Luna et al. (2005a; ver Figura 1.12, apartado 1.5.6.3), fue posible identificar varios isómeros CLA: seis de ellos aparecen dentro de la zona trans-trans, mientras que otros seis eluyen en la región cis-trans/trans-cis. Se confirmó que todos estos picos, asociados a isómeros CLA, presentan un espectro de absorción característico de dienos conjugados (Figura 3.3 y 3.4 ).

En los espectros mostrados en la Figura 3.5, se puede observar que el máximo de absorción a $231 \mathrm{~nm}$ se localiza en una pequeña meseta, con una ligera inclinación. Para los espectros de isómeros trans-trans, esta inclinación se encuentra entre 227 y $231 \mathrm{~nm}$ (Figura 3.5-A), mientras que en isómeros cis-trans/trans-cis, aparece entre 231 y 235 nm (Figura 3.5-B). Esta podría ser una manera de distinguir isómeros trans-trans de cistrans/trans-cis, pero es algo que no podemos afirmar con seguridad. 


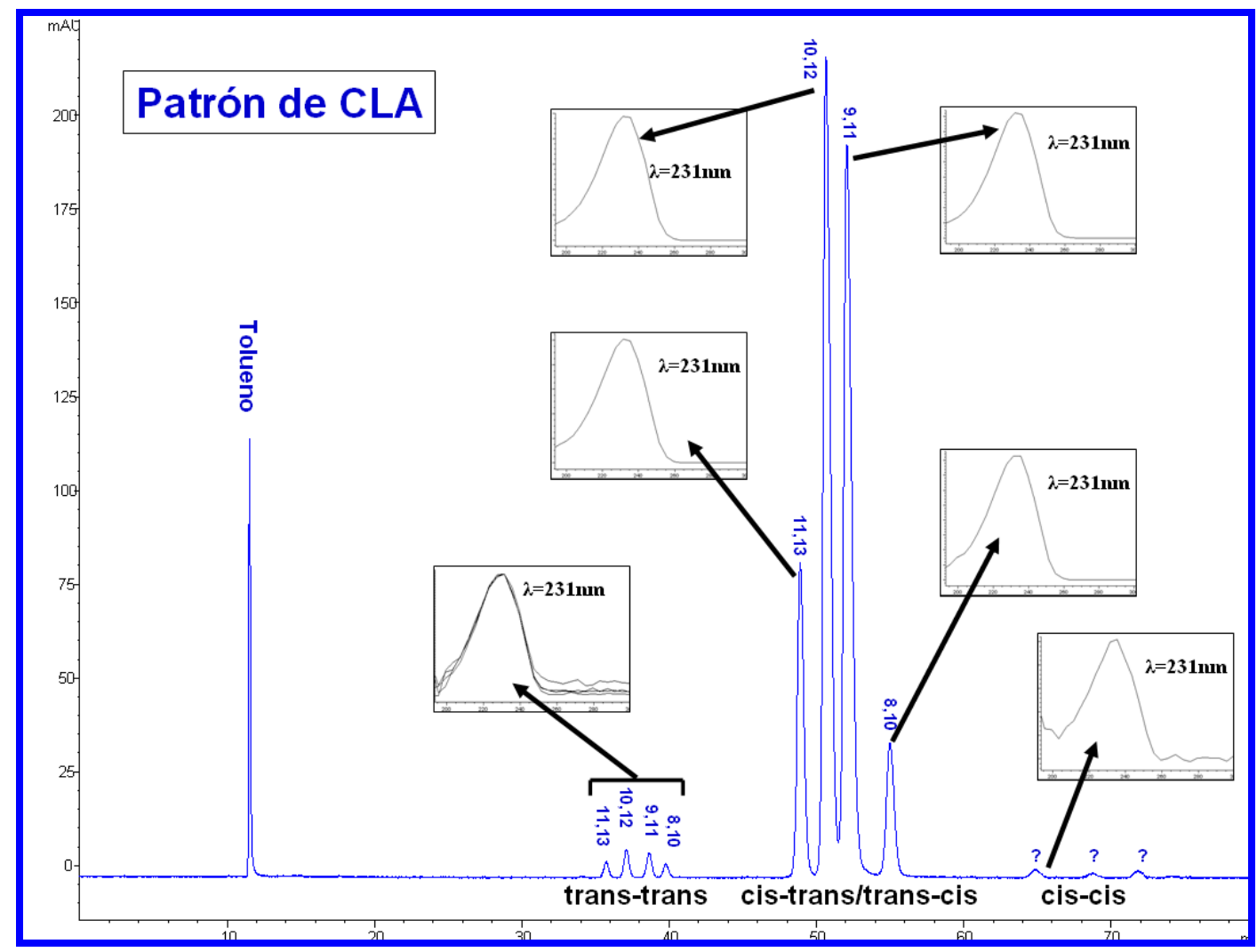

Figura 3.3. Cromatograma y espectros UV, correspondientes al patrón de CLA (UC-59M).

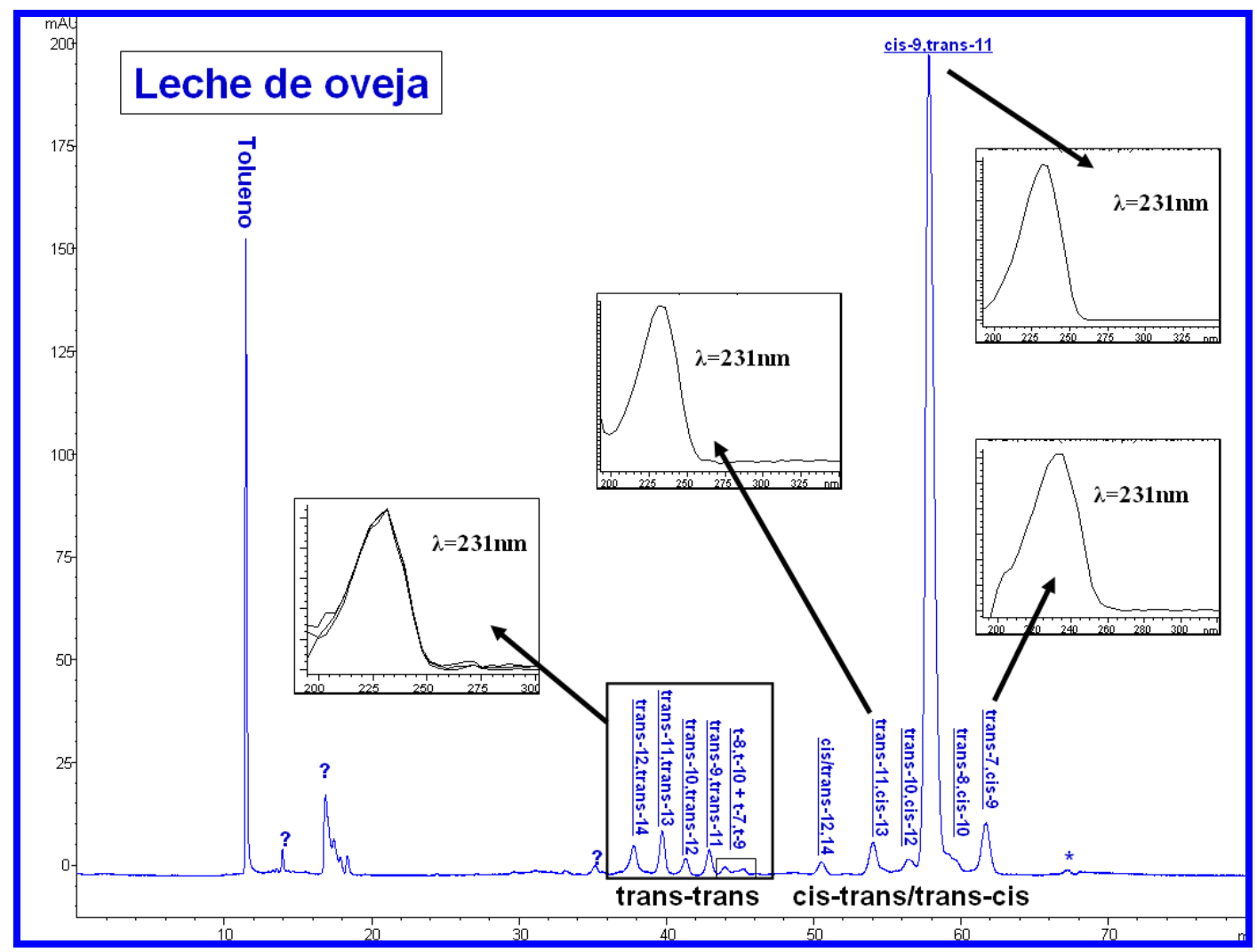

Figura 3.4. Cromatograma y espectros UV, correspondientes a leche de oveja parcialmente desnatada y tratada térmicamente. 


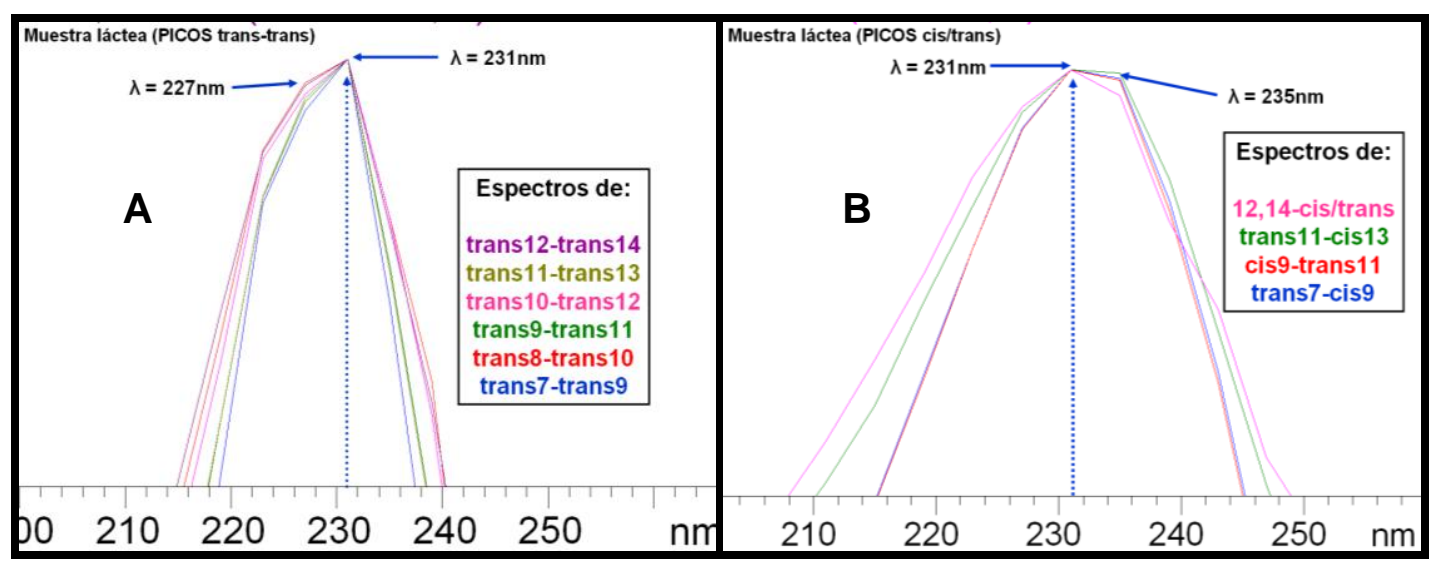

Figura 3.5. Espectros de absorción ultravioleta de los isómeros CLA encontrados en las muestras de leche de oveja parcialmente desnatada y tratada térmicamente.

Delmonte et al. (2004b) establecieron que, bajo sus condiciones de trabajo, los isómeros CLA presentan máximos de absorción a las siguientes longitudes de onda: 229,8 nm (trans-trans); 232,1 nm (cis-trans/trans-cis) y 234,5 nm (cis-cis). Según señalan los mismos autores, los máximos de absorción ultravioleta de estos isómeros geométricos pueden presentar ligeras variaciones de un detector a otro, pero que por lo general, son diferencias que en un mismo instrumento suelen mantenerse y percibirse. En nuestros ensayos, dichas variaciones se ponen de manifiesto por la inclinación de la meseta en los espectros comentados hace poco. Sin embargo, este tipo de cambios no se da en el máximo de absorción, el cual coincide en $231 \mathrm{~nm}$ para todos los isómeros.

\subsubsection{Identificación mediante la co-inyección de una mezcla sintética de CLA}

En el cromatograma de la mezcla sintética de isómeros CLA (Figura 3.3) aparecen registrados 8 picos bien definidos. La identidad de los mismos se confirmó comparando los volúmenes de retención obtenidos con los publicados por otros autores (Eulitz et al., 1999; Adlof, 2003; Cruz-Hernández et al., 2004; Luna et al., 2005a). Los dos mayoritarios corresponden al 9,11-(cis-trans/trans-cis) y al 10,12-(cis-trans/transcis); también se encontraron cantidades importantes de 11,13-(cis-trans/trans-cis), de 8,10-(cis-trans/trans-cis) y pequeñas cantidades de los siguientes isómeros trans-trans: trans-11,trans-13; trans-10,trans-12; trans-9,trans-11 y trans-8,trans-10. La coinyección de esta mezcla sintética junto con la de muestras de grasa láctea hizo posible confirmar la presencia en la leche de oveja de estos 8 isómeros CLA. La Figura 3.6 muestra un cromatograma donde se observa que, en dicha co-inyección, se produce una 
superposición de los isómeros presentes en la muestra de grasa con los encontrados en la mezcla patrón.

Además, fue posible identificar otros isómeros dentro de la zona trans-trans (como el trans-12,trans-14 y el trans-7,trans-9) y dentro de la zona cis-trans/trans-cis (como el 12,14- y el 8,10-). En la Figura 3.4, se puede observar que el pico asignado al isómero 8,10-(cis-trans/trans-cis) no presenta una buena resolución cromatográfica. Sin embargo, podríamos asumir su identidad al coinyectar patrones de CLA junto con la muestra de grasa (Figura 3.6), ya que aumenta la cantidad de 8,10-(cis-trans/trans-cis) que se determinó en la grasa.

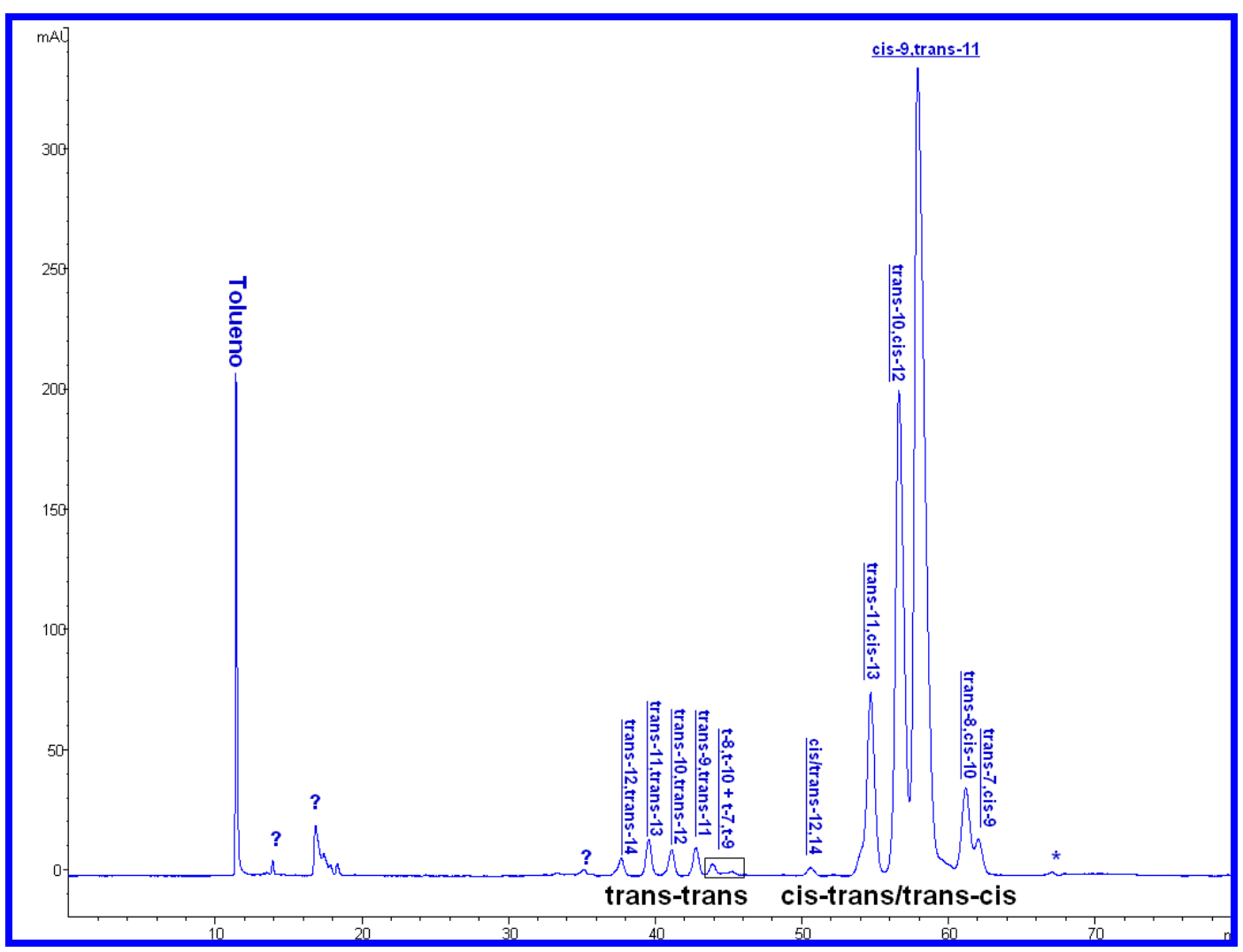

Figura 3.6. Cromatograma correspondiente a la co-inyección de una muestra de grasa de leche de oveja junto con la mezcla patrón UC-59M.

En nuestras condiciones experimentales no fue posible diferenciar los isómeros cis-trans de los trans-cis. A pesar de ello y teniendo presentes los resultados recogidos en la bibliografía (Luna et al., 2005a), puede asumirse que el 9,11-(cis-trans/trans-cis) corresponde en su mayoría al cis-9,trans-11. El 7,9-(cis-trans/trans-cis) es el segundo isómero más abundante; dicho pico debería asignarse al trans-7,cis-9. De igual manera, 
puede admitirse que los picos 10,12-(cis-trans/trans-cis) y 11,13-(cis-trans/trans-cis) corresponden casi en su totalidad al trans-10,cis-12 y al trans-11,cis-13, respectivamente, aunque ambos pueden incluir pequeñas cantidades de sus correspondientes isómeros cis-trans. Respecto al pico 8,10-(cis-trans/trans-cis), hemos comentado que no se separa adecuadamente. Para identificarlo, además de ayudarnos con la co-inyección de patrones, fue necesario recurrir a la comparación de los volúmenes de retención relativos (RRV).

\subsubsection{Identificación a través de los volúmenes de retención relativos (RRV)}

Varios autores señalan que, en cromatografía $\mathrm{Ag}^{+}$-HPLC, los volúmenes de retención no son reproducibles (Delmonte et al., 2004b y 2005). Esto se evidenció en nuestros experimentos, ya que a pesar de controlarse las condiciones experimentales (preparación del eluyente, control de la temperatura, acondicionamiento adecuado de la columna, etc.), los picos cromatográficos se desplazaban hacia valores de retención ligeramente mayores. Por lo que, para una identificación más segura de los isómeros CLA mediante $\mathrm{Ag}^{+}$-HPLC fue necesario calcular sus respectivos volúmenes de retención relativos (RRV) respecto al cis-9,trans-11 y al tolueno; este último se inyectó junto con la muestra, con el fin de obtener el volumen muerto en el sistema de elución.

Tabla 3.1. Volúmenes de retención relativos (RRV) para los ésteres metílicos de isómeros CLA en distintas muestras de grasa láctea

\begin{tabular}{|c|c|c|c|c|}
\hline \multirow[t]{2}{*}{ Isómero } & \multicolumn{2}{|c|}{$\begin{array}{c}\text { Delmonte } \text { et al., } 2005 \\
\text { Leche de vaca }(\mathrm{n}=48) \\
(\mathbf{0 , 1} \% \text { acetonitrilo }+\mathbf{0 , 5 \%} \text { éter etílico }) / \text { hexano }\end{array}$} & \multicolumn{2}{|c|}{$\begin{array}{c}\text { Valores calculados según nuestros datos } \\
\text { Leche de oveja }(\mathrm{n}=30) \\
\mathbf{0 , 1 \% a c e t o n i t r i l o ~ / ~ h e x a n o ~}\end{array}$} \\
\hline & RRV & $\sigma(n=48)$ & RRV & $\sigma(n=30)$ \\
\hline trans-12,trans-14 & 0,533 & 0,008 & 0,538 & 0,004 \\
\hline trans -11, trans -13 & 0,574 & 0,007 & 0,581 & 0,004 \\
\hline trans -10, trans -12 & 0,609 & 0,007 & 0,617 & 0,004 \\
\hline trans -9, trans -11 & 0,649 & 0,007 & 0,653 & 0,005 \\
\hline trans -8, trans -10 & 0,680 & 0,007 & 0,689 & 0,003 \\
\hline trans -7, trans -9 & 0,716 & 0,009 & 0,719 & 0,004 \\
\hline trans -6, trans -8 & --- & --- & 0,750 & 0,004 \\
\hline $12,14-(c-t / t-c)$ & --- & --- & 0,829 & 0,004 \\
\hline trans-11,cis-13 & 0,893 & 0,005 & 0,910 & 0,006 \\
\hline cis-11,trans-13 & 0,914 & 0,003 & --- & --- \\
\hline trans -10, cis -12 & 0,957 & 0,003 & 0,973 & 0,002 \\
\hline cis-9,trans-11 & 1,000 & 0,000 & 1,000 & 0,000 \\
\hline trans -8, cis -10 & 1,059 & 0,002 & 1,054 & 0,004 \\
\hline trans-7,cis-9 & 1,095 & 0,003 & 1,086 & 0,008 \\
\hline
\end{tabular}


Los RRV obtenidos se calcularon partiendo de 30 muestras de leche de oveja, recogiéndose en la Tabla 3.1 los valores medios para cada isómero. Comparando estos resultados con los que obtuvieron Delmonte et al. (2005) en leche de vaca, se puede observar que son bastante semejantes, salvo algunas excepciones en isómeros que eluyen dentro de la zona cis-trans/trans-cis. Estas ligeras diferencias se pueden atribuir a la composición del eluyente, ya que en nuestros experimentos no se empleó dietil éter en la mezcla eluyente. Los isómeros trans-11,cis-13 y trans-10,cis-12 fueron los que presentaron una mayor diferencia de RRV cuando se compararon los resultados de ambos ensayos. Uno de los isómeros que fue necesario identificar mediante estos valores fue el trans-8,cis-10, ya que no presentaba una resolución óptima. El RRV que obtuvimos para dicho isómero en leche de oveja registró un valor medio de 1,054 \pm 0,004 ( $\mathrm{n}=30$ ); este valor concuerda bastante con el encontrado por Delmonte et al. (2005) para el isómero trans-8,cis-10.

\subsubsection{Comentarios respecto a la resolución cromatográfica de los isómeros CLA}

En cuanto a la resolución cromatográfica, los picos trans-trans son los que presentan una mejor separación (Figura 3.7), confirmándose lo que se ha encontrado al respecto en las distintas publicaciones. Sin embargo, a pesar de su buena resolución, es posible encontrar picos solapados en muestras concretas.

Al inicio de la zona trans-trans, aparecía un pequeño pico que debería corresponder al trans-13,trans-15, según los criterios del orden de elución encontrados en algunas referencias bibliográficas (Rickert et al., 1999; Fritsche et al., 2001; Dobson, 2003). Rickert et al. (1999) identifican tentativamente este isómero en muestras de queso; sin embargo, la presencia del mismo en muestras de leche no ha podido ser constatada, según nuestro conocimiento. A este pico le sigue uno mucho más grande, el cual previamente hemos identificado como trans-12,trans-14.

El pico que se asigna al trans-11,trans-13, puede llegar a ser el más importante dentro de la zona trans-trans, aunque hay que recordar que esto depende mucho del tipo de alimentación suministrada al animal (véase el apartado 1.3.1). El segundo en cantidad suele ser el trans-9,trans-11, que presenta una resolución bastante buena. El trans-10,trans-12 suele aparecer como un pico relativamente pequeño, pero bien 
separado; sin embargo, su cuantificación puede complicarse por la presencia de un pico que aparece entre éste isómero y el trans-9,trans-11.

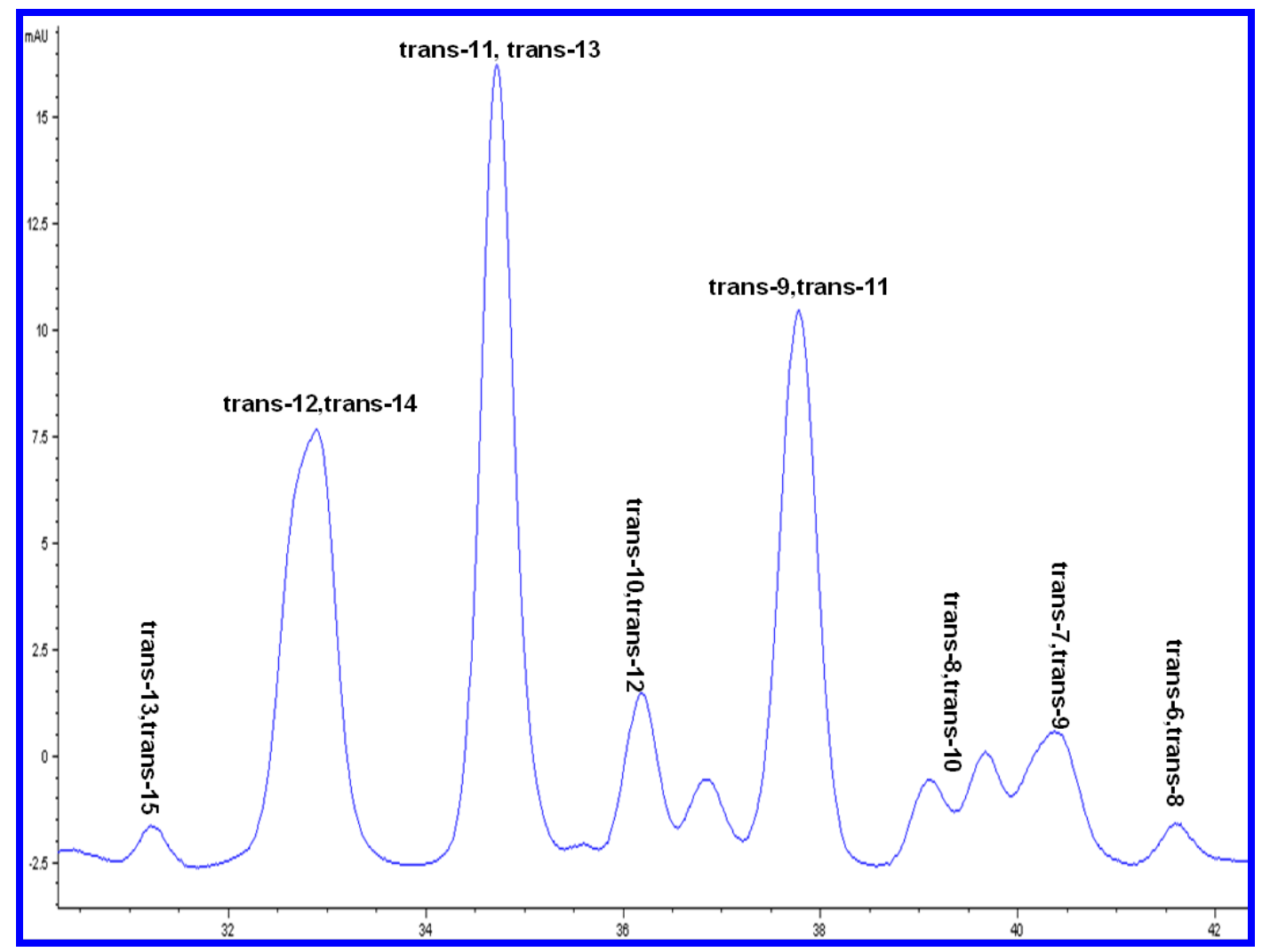

Figura 3.7. Cromatograma parcial $\mathrm{Ag}^{+}$-HPLC/DAD correspondiente a la zona trans-trans de los isómeros CLA presentes en la grasa láctea ovina. El pico asignado al isómero trans13,trans-15 $\mathrm{C}_{18: 2}$ no ha sido confirmado.

Al final de la zona trans-trans, se encuentran tres pequeños picos, que presentan una pobre resolución. Dos de estos picos han sido asignados al trans-8,trans-10 y al trans-7,trans-9. El otro pico, que aparece bastante pegado al trans-8,trans-10, presenta un valor RRV próximo al mismo y además, su espectro UV es característico de isómeros CLA. Pensamos que podría tratarse de una elución desdoblada del mencionado isómero. Finalmente y de forma tentativa, hemos asignado como trans6,trans-8 al pico que aparece al final de la zona trans-trans; aunque hay que decir que su espectro UV presenta una meseta entre 231 y 235, una excepción a lo que se ha afirmado anteriormente respecto a los picos trans-trans, cuya meseta aparece entre 227 y $231 \mathrm{~nm}$. 
Los isómeros cis-trans/trans-cis presentan peor resolución cromatográfica que los trans-trans, (Figura 3.8); sobre todo los más próximos al isómero mayoritario (cis9,trans-11).

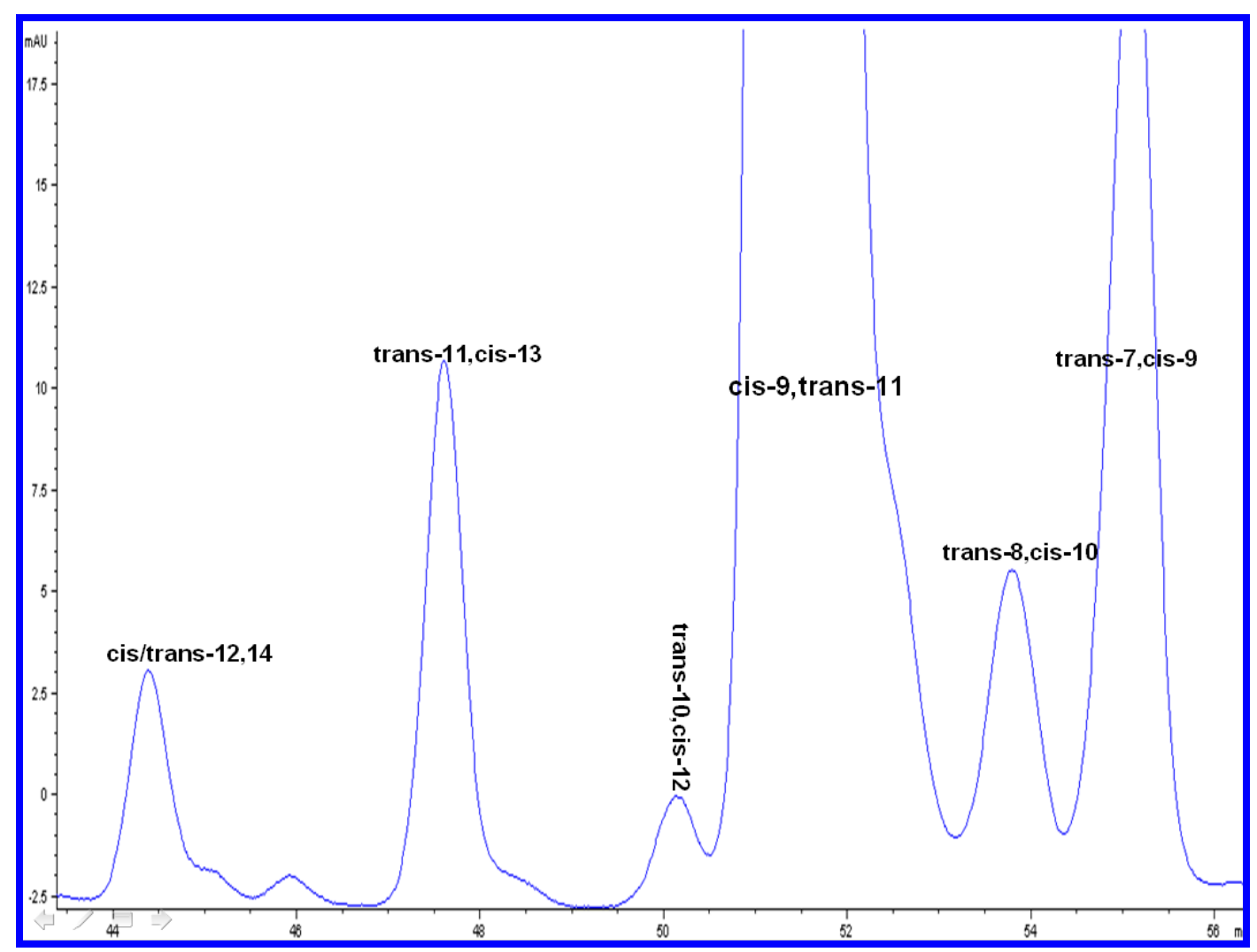

Figura 3.8. Cromatograma parcial $\mathrm{Ag}^{+}$-HPLC/DAD correspondiente a la zona cis-trans/ trans-cis de los isómeros CLA presentes en la grasa láctea ovina. Se cree que el pico asignado al isómero trans-8,cis-10 coeluye con otro compuesto que absorbe a $268 \mathrm{~nm}$.

El primer pico que aparece en esta zona ha sido asignado al 12,14-(cistrans/trans-cis). En la mayoría de las referencias bibliográficas no se atribuye dicho pico a un isómero geométrico en concreto. Sin embargo, si seguimos los criterios de asignación encontrados en los experimentos llevados a cabo por Delmonte et al. (2005), se podría pensar que corresponde casi exclusivamente al trans-12,cis-14.

El par trans-cis/cis-trans del 11,13-CLA es el que mejor resolución cromatográfica presentó en esta zona. El más abundante de los dos isómeros es el trans11,cis-13, pudiéndose encontrar cantidades más altas del mismo cuando se dispone de pasto fresco en la alimentación de los animales (Luna et al., 2005b y 2005c). 
Se asignó como 8,10-CLA (cis-trans/trans-cis), al pico que aparece entre los isómeros 9,11-CLA y 7,9-CLA; sin embargo, este se encuentra en la leche de forma minoritaria y su resolución cromatográfica suele ser bastante deficiente. Si se tiene en cuenta los resultados publicados por Eulitz et al. (1999) y su volumen de retención relativo (Tabla 3.1), este pico podría identificarse como trans-8,cis-10.

Respecto a los picos correspondientes a los cis-cis, en principio, estos isómeros aparecen en la zona posterior a los cis-trans/trans-cis; sin embargo, hay que decir que sus cantidades en muestras de leche deben ser muy bajas, ya que no se registraron picos en esta zona del cromatograma. Además, en dicha zona puede darse una interferencia de un compuesto que absorbe a $205 \mathrm{~nm}$ y que a $231 \mathrm{~nm}$ se observaría como una especie de "cola" (ver Figura 3.9). Dicho compuesto posiblemente sea ácido oleico (Luna et al., 2005a; De la Fuente et al., 2006). Algunos autores han detectado pequeñas cantidades de estos isómeros en leche de oveja, principalmente de cis-9,cis-11, utilizando derivados DMOX y determinándolos por cromatografía de gases - espectrometría de masas (GCMS); aunque los niveles encontrados estuvieron por debajo del 0,5\% respecto al total de isómeros CLA (Gómez-Cortés et al., 2008a, 2008b, 2009a y 2011; Hervás et al., 2008b; Luna et al., 2005b, 2007 y 2008b; Ostrovsky et al., 2009).

\subsubsection{Observaciones sobre los cromatogramas registrados a 205 y $268 \mathrm{~nm}$}

En el análisis de los isómeros CLA en lácteos, aparecieron picos que no tenían su máximo de absorción a $231 \mathrm{~nm}$ y que se visualizan mejor en los cromatogramas registrados a 205 y $268 \mathrm{~nm}$ (ver Figura 3.9 y 3.10).

En la zona trans-trans, se observó un pequeño pico que aparecía entre los isómeros trans-10,trans-12 y trans-9,trans-11, casi siempre solapado a este último (Figura 3.9). Aunque no se sabe exactamente a qué compuesto corresponde, su máximo de absorción ronda los $200 \mathrm{~nm}$, pudiendo asociarse a un compuesto monoinsaturado no identificado. Dentro de la zona cis-cis también se encontró otro pico, que como ya se dijo previamente, presenta un máximo de absorción por debajo de los $205 \mathrm{~nm}$ (Figura 3.9). Lo que se observa es un pico muy ancho y bastante irregular, que en algunos trabajos lo han relacionado con el oleato de metilo (Luna et al., 2005a; De la Fuente et al., 2006). La presencia de este último puede impedir la visualización y cuantificación de isómeros cis-cis en leche. 


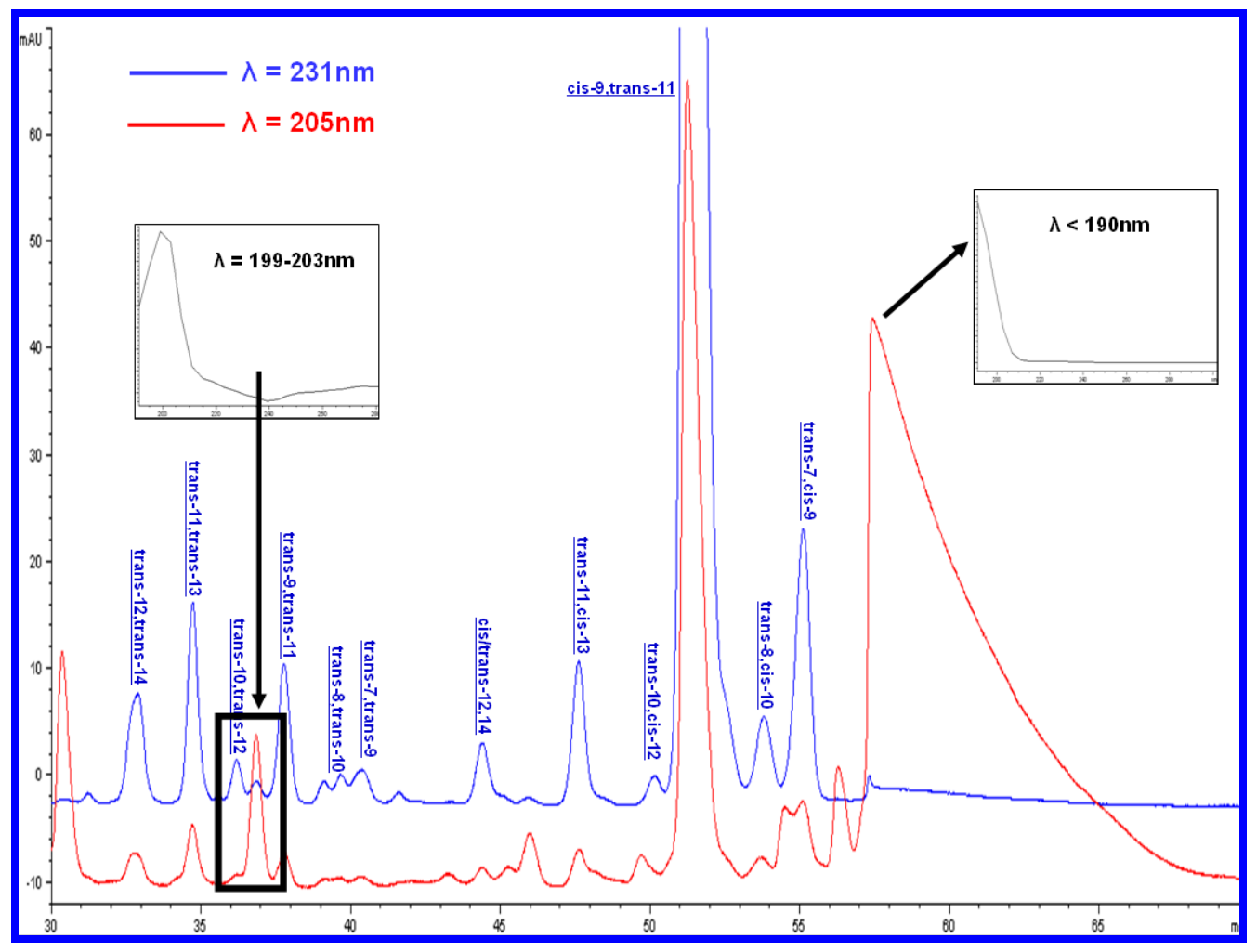

Figura 3.9. Cromatogramas Ag+-HPLC/DAD a 231 y 205 nm. El pico del cuadrante negro puede ser un compuesto monoinsaturado.

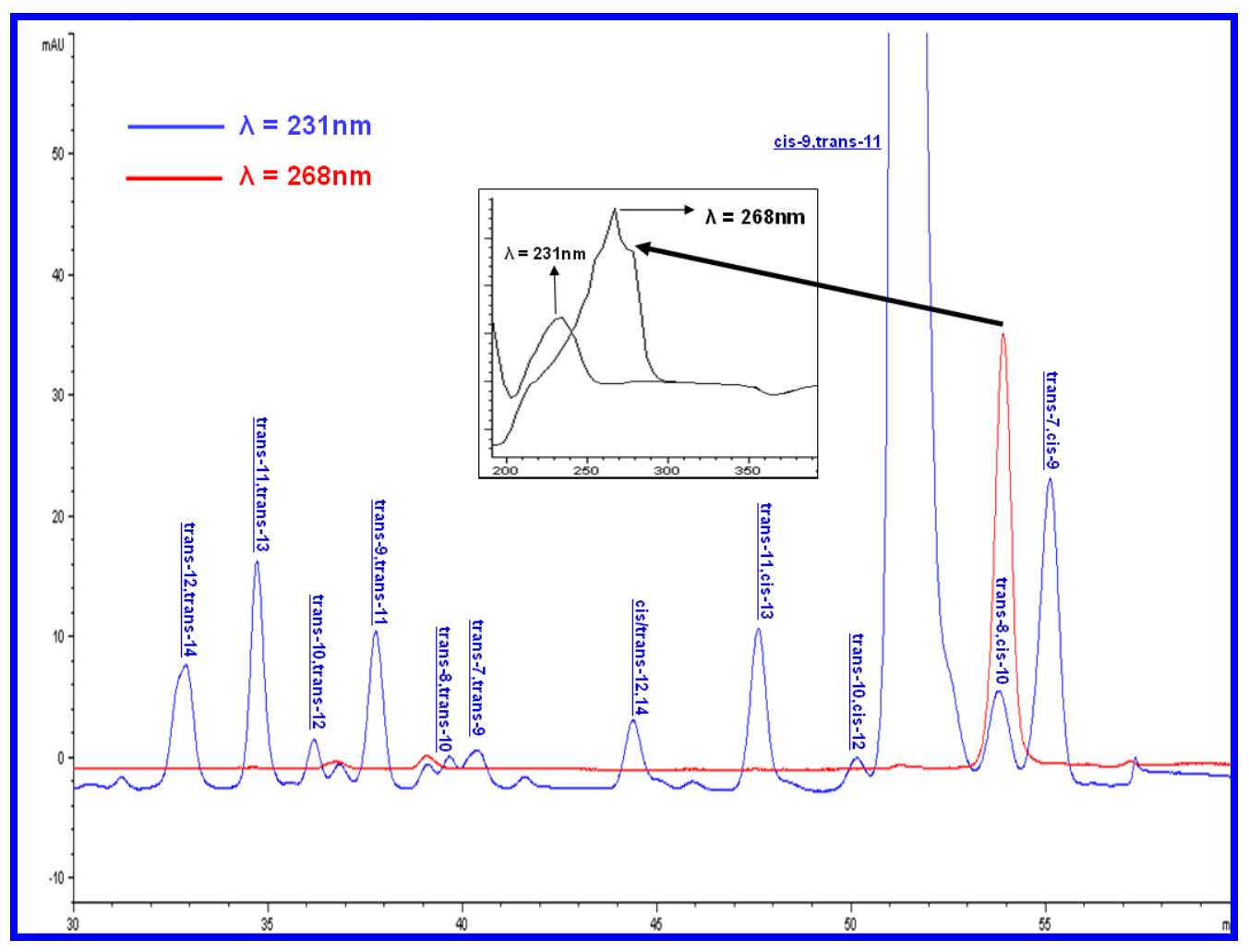

Figura 3.10. Cromatogramas $\mathrm{Ag}^{+}$-HPLC/DAD a 231 y 268 nm. El espectro muestra que, además del isómero trans-8,cis-10 $(\lambda=231 \mathrm{~nm})$ existe un compuesto cuyo máximo de absorción es $268 \mathrm{~nm}$, posiblemente relacionado con un trieno conjugado. 
Al observar el cromatograma a $268 \mathrm{~nm}$ (Figura 3.10), aparece un pico con un volumen de retención próximo al del trans-8,cis-10, que presenta un espectro correspondiente a un trieno conjugado y que además puede encontrarse en cantidades relativamente elevadas. Sin embargo, en la bibliografía no se recoge la presencia de ácidos grasos con triples enlaces conjugados en muestras de leche. Con las condiciones experimentales que hemos utilizado, no fue posible determinar su naturaleza, por lo que sería interesante caracterizar este componente y conocer de qué sustancia se trata.

\subsubsection{Rectas de calibrado}

En la Tabla 3.2 se recogen los parámetros de regresión estimados en el estudio de linealidad para las tres rectas de calibrado que se utilizarán en la cuantificación de los isómeros CLA. Las pendientes de dichas rectas son muy parecidas y los coeficientes de correlación (valores de $\mathrm{R}^{2}$ ) son superiores a 0,99 , lo que demuestra que la linealidad obtenida para las tres rectas de calibrado es bastante adecuada.

Tabla 3.2. Parámetros de regresión estimados para los patrones CLA-FAME en el estudio de linealidad $(n=4)$

\begin{tabular}{|c|c|c|c|c|}
\hline Isómero & $\begin{array}{c}\text { Intervalo } \\
\mu \mathrm{g} / \mu \mathrm{L}^{(a)}\end{array}$ & Pendiente $^{(b)}$ & $\begin{array}{c}\text { Ordenada en el } \\
\text { origen }^{(b)}\end{array}$ & $\mathbf{R}^{2(c)}$ \\
\hline cis-9,trans-11 & $0,05-1,2$ & $27,2 \pm 0,1$ & $0,07 \pm 0,06$ & 0,9996 \\
\hline cis-9,trans-11 & $0,001-0,015$ & $27,0 \pm 0,2$ & $0,001 \pm 0,001$ & 0,9991 \\
\hline trans -10, cis -12 & $0,001-0,015$ & $27,6 \pm 0,2$ & $0,0004 \pm 0,001$ & 0,9996 \\
\hline
\end{tabular}

(a) Valores expresados como ácidos grasos libres. ${ }^{\text {(b) }}$ Representa el valor medio y la desviación estándar de la pendiente y de la ordenada en el origen. ${ }^{(\mathbf{c})} \mathrm{R}^{2}=$ coeficiente de correlación.

\subsubsection{Límite de cuantificación}

El límite de cuantificación $(\boldsymbol{L} \boldsymbol{O Q})$ se determinó según el método de la pendiente de la recta y la desviación estándar de la ordenada en el origen (Dolan, 2009):

$$
L O Q=\frac{10 \sigma_{b}}{S^{\prime}}
$$

$\sigma_{b}=$ Desviación estándar de la ordenada en el origen

$\boldsymbol{S}^{\prime}=$ Pendiente de la recta 
El límite de cuantificación se estableció en $\mathbf{0 , 0 0 0 5} \boldsymbol{\mu \mathrm { g }} / \boldsymbol{\mu} \mathbf{L}$, tanto para el isómero cis-9,trans-11 como para el trans-10,cis-12. En el ensayo de confirmación, se inyectó cuatro veces una cantidad de patrón cercana al límite de cuantificación calculado, obteniéndose desviaciones estándar relativas (RSD) de 3,2\% para el cis-9,trans-11 y de 4,8\% para el trans-10,cis-12. Ambos valores permanecen por debajo del 5\% que se exige para que el límite de cuantificación estimado sea válido.

Dicho límite corresponde a $\mathbf{0 , 0 0 5} \boldsymbol{\mu g}$ de isómero inyectado en la columna (volumen de inyección $=10 \mu \mathrm{L}$ ). En lo que respecta a las muestras, el LOQ para ambos isómeros (cis-9,trans-11 y trans-10,cis-12), según las condiciones habituales de trabajo,

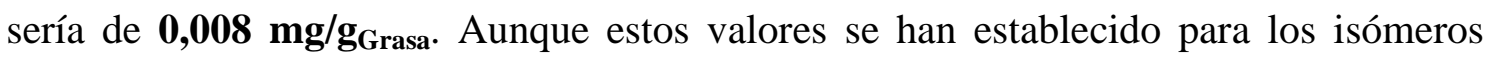
indicados, se podría asumir que dicho valor es prácticamente el mismo para el resto de los isómeros presentes en la muestra de grasa. Por tanto, cabría la posibilidad de que la ausencia de los isómeros cis-cis en las muestras analizadas, se deba a que se encuentren por debajo del límite de cuantificación.

Fritsche et al. (2000), en muestras de grasa de carne de vacuno, obtuvieron límites de determinación de 0,00025, 0,0005 y 0,001 $\mu \mathrm{g}$ /inyección para patrones de cis9,trans-11, trans-9,trans-11 y cis-9,cis-11, respectivamente. Estos valores se calcularon aplicando el criterio de multiplicar cinco veces la relación señal/ruido.

\subsubsection{Precisión}

Este parámetro se determinó mediante un ensayo de repetibilidad, en el que se cuantificó doce veces y en días distintos, el contenido de isómeros CLA de una misma muestra de leche de oveja UHT.

En la Tabla 3.3 se recogen los niveles de CLA encontrados para cada isómero, así como la desviación estándar (SD) y la desviación estándar relativa (RSDr). Como se puede observar en dicha tabla, los valores de desviación estándar relativa oscilan entre $\mathbf{2 , 0 8}$ y 7,50\%. Para el isómero mayoritario (cis-9,trans-11) este valor fue de $\mathbf{2 , 1 4 \%}$; mientras que la mayor desviación se encontró para el isómero trans-8,cis-10, algo que cabía esperar teniendo en cuenta la mala resolución cromatográfica de este isómero. En esta tabla no se incluyen los isómeros trans-8,trans-10, trans-7,trans-9 y trans-6,trans8 , ya que el contenido de los mismos en esta muestra fue muy bajo. 
Tabla 3.3. Ensayo de precisión (repetibilidad) del método de análisis de isómeros CLA en la grasa de leche de oveja $(n=12)$

\begin{tabular}{cccc}
\hline Isómero & $\tilde{\mathbf{x}}\left(\mathbf{m g} / \mathbf{g}_{\text {Grasa }}\right)$ & SD & RSDr $(\mathbf{\%})$ \\
\hline trans-12,trans-14 & 0,081 & 0,002 & 2,47 \\
trans-11,trans-13 & 0,077 & 0,002 & 2,60 \\
trans-10,trans-12 & 0,039 & 0,001 & 2,56 \\
trans-9,trans-11 & 0,113 & 0,003 & 2,65 \\
$12,14$ (cis-trans/trans-cis $)$ & 0,043 & 0,002 & 4,65 \\
trans-11,cis-13 & 0,048 & 0,001 & 2,08 \\
trans-10,cis-12 & 0,056 & 0,002 & 3,57 \\
cis-9,trans -11 & 4,491 & 0,096 & 2,14 \\
trans- 8, cis -10 & 0,133 & 0,010 & 7,50 \\
trans- - cis -9 & 0,379 & 0,008 & 2,11 \\
\hline
\end{tabular}

$\tilde{\mathbf{x}}=$ Valor promedio. $\mathrm{SD}=$ Desviación estándar. $\mathrm{RSDr}=$ Desviación estándar relativa.

Para estos ensayos, se calculó la desviación estándar relativa pronosticada, según la ecuación de Horwitz:

$$
\operatorname{RSD}_{r, \text { pronosica }} d a(\%)=2 / 3\left(2^{1-0,5 \log C}\right)
$$

Donde "C" es la concentración del analito. Este valor puede servir como indicador de la aceptabilidad de un método de análisis en lo que respecta a su precisión. En otras palabras, es el mayor error relativo experimental que se puede cometer a un nivel de concentración dado, para aceptar que un método cuantitativo es el más indicado, en cuanto a precisión, para realizar una determinación.

Una vez obtenida las desviaciones estándar relativas, se calcularon los valores HORRATr, a través de la siguiente expresión:

$$
\text { HORRATr }=\frac{R S D(\%)_{r, \text { observada }}}{R S D(\%)_{r, \text { pronositica da }}}
$$

Para evaluar la precisión de las medidas de repetibilidad de un mismo laboratorio, estos valores deben mantenerse dentro de un intervalo comprendido entre 0,3 y 1,3. En la Tabla 3.4 se muestran los resultados obtenidos para los distintos isómeros CLA encontrados en la grasa láctea ovina. Se puede observar que, a excepción del isómero trans-8,cis-10, todos los isómeros se mantienen dentro de este intervalo, 
cumpliendo con los criterios especificados por la Association of Analytical Communities (AOAC, 2002). Por tanto, se considera que el método propuesto posee una buena precisión.

Tabla 3.4. Comparación de las desviaciones estándar relativas y los valores HORRATr para los diferentes isómeros CLA encontrados en la grasa de leche de oveja $(n=12)$

\begin{tabular}{cccc}
\hline Isómero & RSDr, obs $(\%)$ & RSDr, pron $(\%)$ & HORRATr \\
\hline trans-12,trans-14 & 2,47 & 5,50 & 0,46 \\
trans-11,trans-13 & 2,60 & 5,55 & 0,46 \\
trans-10,trans-12 & 2,56 & 6,15 & 0,46 \\
trans-9,trans-11 & 2,65 & 5,24 & 0,44 \\
12,14 (cis-trans/trans-cis) & 4,65 & 6,05 & 0,89 \\
trans-11,cis-13 & 2,08 & 5,96 & 0,46 \\
trans-10,cis-12 & 3,57 & 6,03 & 0,50 \\
cis-9,trans-11 & 2,14 & 3,01 & 0,71 \\
trans-8,cis-10 & 7,50 & 5,11 & 1,43 \\
trans- 7, cis-9 & 2,11 & 4,36 & 0,47 \\
\hline
\end{tabular}

Parámetros de precisión similares a los que hemos obtenido en nuestro ensayo han sido publicados por Moltó Puigmartí et al. (2007); dichos valores se muestran en la Tabla 3.5. La diferencia con respecto a nuestro ensayo es que estos autores llevan a cabo ensayos intradía e interdía, utilizando muestras de leche humana y de rata; además, la determinación de los isómeros CLA se realizó por cromatografía de gases. Observando estos valores, podríamos admitir que la precisión obtenida por estos investigadores es similar a la que hemos encontrado en nuestro método de trabajo.

Tabla 3.5. Valores de desviación estándar relativa (RSD) obtenidos en los ensayos realizados por Moltó-Puigmartí et al. (2007) en muestras de leche de rata y leche humana

\begin{tabular}{c|cc}
\hline \multirow{2}{*}{ Isómero } & \multicolumn{2}{|c}{ RSD (\%) } \\
\cline { 2 - 3 } & Leche de Rata & Leche Humana \\
\hline trans-trans, intradía & 7,78 & 6,50 \\
trans-trans, interdía & 3,46 & 7,75 \\
trans-10,cis-12, intradía & n.d. & 6,56 \\
trans-10,cis-12, interdía & n.d. & 7,51 \\
cis-9,trans-11, intradía & 1,53 & 2,51 \\
cis-9,trans-11, interdía & 3,08 & 3,27 \\
\hline
\end{tabular}




\subsubsection{Exactitud}

Este ensayo se llevó a cabo añadiendo a una muestra de grasa láctea un patrón de cis-9,trans-11 $\mathrm{C}_{18: 2}$ en forma de triglicérido (Larodan Fine Chemical, Suecia) de una pureza del 90\%, determinada por cromatografía de gases. Se pesó una cantidad exacta (200 mg) de triglicérido y se disolvió en 10 mL de hexano. A partir de esta disolución se hicieron las diluciones necesarias para añadir distintas cantidades a la muestra. La determinación se realizó cuatro veces para cada cantidad añadida y los resultados encontrados se presentan en la Tabla 3.6. La muestra utilizada en este ensayo se analizó en distintos días, obteniéndose un valor medio de cis-9,trans-11 de 4,511 $\pm \mathbf{0 , 0 9 4} \mathrm{mg}$ cis-9,trans $-11 / \mathrm{g}_{\text {Grasa }}(\mathrm{n}=12)$; dicho valor se consideró la cantidad inicial presente en la muestra.

Tabla 3.6. Ensayo de recuperación de cis-9,trans-11 CLA, añadido como triglicérido cis-9,trans-11 $\mathrm{C}_{18: 2}$ a la grasa de leche de oveja

\begin{tabular}{|c|c|c|c|c|c|c|c|c|}
\hline \multicolumn{4}{|c|}{ Cantidad añadida* (mg/g $\left.\mathbf{g}_{\text {Grasa }}\right)^{(a)}$} & \multicolumn{4}{|c|}{$\begin{array}{c}\text { Cantidad encontrada después } \\
\text { de la adición }\left(\mathrm{mg} / \mathrm{g}_{\mathrm{Grasa}}\right) \text { (a) }\end{array}$} & \multirow{2}{*}{$\begin{array}{c}\begin{array}{c}\text { Recuperación } \\
(\boldsymbol{\%})\end{array} \\
97 \pm 2,7\end{array}$} \\
\hline 2,562 & 2,355 & 2,543 & 2,477 & 6,894 & 6,814 & 7,016 & 6,884 & \\
\hline 4,032 & 3,869 & 4,316 & 3,734 & 8,341 & 8,249 & 8,976 & 8,286 & $99 \pm 3,7$ \\
\hline \multirow[t]{2}{*}{9,041} & 9,000 & 9,209 & 9,124 & 12,919 & 12,695 & 12,891 & 12,742 & $91 \pm 1,3$ \\
\hline & & & & & & & Media: & $96 \pm 4,2$ \\
\hline
\end{tabular}

* Se añadieron tres cantidades distintas a cuatro muestras de la misma grasa láctea, cuyo contenido de CLA inicial (o sin adición) era de 4,511 \pm 0,094 miligramos de cis-9,trans-11 CLA/g de grasa láctea.

(a) Valores expresados en miligramos de cis-9,trans-11 CLA / $\mathrm{g}_{\text {Grasa }}$.

(b) Media \pm desviación estándar.

Las recuperaciones oscilaron entre el 91 y el 97\% (con un valor medio de 96\%). Estos porcentajes de recuperación se consideran buenos según los intervalos establecidos, en función de las concentraciones que se determinan (AOAC, 2002).

Estos resultados también nos confirman que la metilación con $\mathrm{KOH} /$ metanol del triglicérido cis-9,trans-11 $\mathrm{C}_{18: 2}$ es completa; algo que permite garantizar una adecuada metilación de la grasa láctea, compuesta casi en su totalidad por triglicéridos. Elegir la metilación en medio alcalino $(\mathrm{KOH} / \mathrm{metanol})$ tiene la gran ventaja de que con ella se evitan posibles isomerizaciones indeseadas. Este procedimiento de metilación no es adecuado para matrices con altas cantidades de fosfolípidos y ácidos grasos libres. Sin 
embargo, este inconveniente no supuso ningún problema en el análisis de la grasa de leche, ya que en dicha matriz, estos componentes se encuentran como una fracción minoritaria (menos de un $2 \%$ ). La leche con baja calidad bacteriológica puede contener mayores niveles de ácidos grasos libres, por lo que para garantizar la efectividad de la metilación alcalina, es necesario que la muestra de leche se mantenga en buenas condiciones de conservación (De la Fuente et al., 2006; Lee y Tweed, 2008).

En lo que respecta al análisis de CLA, debemos comentar la escasa disponibilidad de trabajos en los que se publiquen estudios de recuperación de estos isómeros. Nuernberg et al. (2007) encontraron porcentajes de recuperación similares (entre 89 y 93\%) cuando estudiaban diferentes métodos de metilación para la determinación de isómeros CLA en grasa de carne de vacuno. Para ello, utilizan un material de referencia (BCR-163 grasa de carne porcina), al que añaden cis-9,trans-11 en estado libre. Si tenemos en cuenta la cantidad de cis-9,trans-11 utilizada (100,05 $\mu \mathrm{g})$ y las condiciones experimentales en las que se realizó dicho estudio, la cantidad añadida por estos investigadores estaría próxima al nivel intermedio que se empleó en nuestros ensayos de recuperación. Aldai et al. (2006), añadiendo diversos ácidos grasos libres a la carne de vacuno, obtienen una recuperación de 93,67\% para el isómero cis-9,trans11 , determinado por cromatografía de gases.

\subsection{CONSIDERACIONES FINALES}

El método que proponemos permite la determinación cuantitativa de los diferentes isómeros CLA en leche. Teniendo en cuenta los parámetros de validación establecidos, este método podría ser una buena alternativa a la determinación convencional de estos isómeros, la cual combina dos técnicas, GC y $\mathrm{Ag}^{+}-\mathrm{HPLC}$. Su aplicación como único método de análisis permitiría un ahorro importante de tiempo y de medios. Desde el punto de vista práctico, estas ventajas pueden ser de gran interés, sobre todo en la valoración de las ingestas de los distintos isómeros y en aquellos estudios que buscan relacionar las actividades biológicas con cantidades concretas de isómeros individuales.

La validación del método incluye el estudio de la linealidad, límite de cuantificación, ensayos de recuperación y de precisión. Otros autores (Fritsche et al., 2000) han descrito un procedimiento similar para la determinación de CLA en grasa de 
carne de vacuno y en la validación estudiaron la linealidad y el límite de cuantificación, pero no establecieron la precisión ni la exactitud. Por ello, pensamos que la validación del método aporta datos nuevos que generan confianza en los resultados desde el punto de vista cuantitativo. Unos de los aspectos más innovadores es la utilización de un patrón en forma de triglicérido de cis-9,trans-11 $\mathrm{C}_{18: 2}$ para los ensayos de recuperación. Esta forma de trabajar garantiza que el proceso de metilación es completo y permite cuantificar recurriendo a estándares externos.

El método, puesto a punto y validado, es una herramienta que consigue determinar isómeros CLA de forma relativamente rápida y fiable en leche y derivados lácteos. También puede utilizarse para el análisis de rutina de mezclas comerciales obtenidas por síntesis, las cuales son empleadas actualmente como complementos dietéticos. En los ensayos de valoración de actividad biológica, debe conocerse el contenido de cada uno de los isómeros en las mezclas que se están utilizando. En ambos casos, es imprescindible establecer la composición exacta de isómeros y por ello el método puede interesar a sectores relacionados con la elaboración de complementos dietéticos o bien a investigadores cuyo objetivo sea relacionar las actividades biológicas con contenidos de isómeros individuales. 


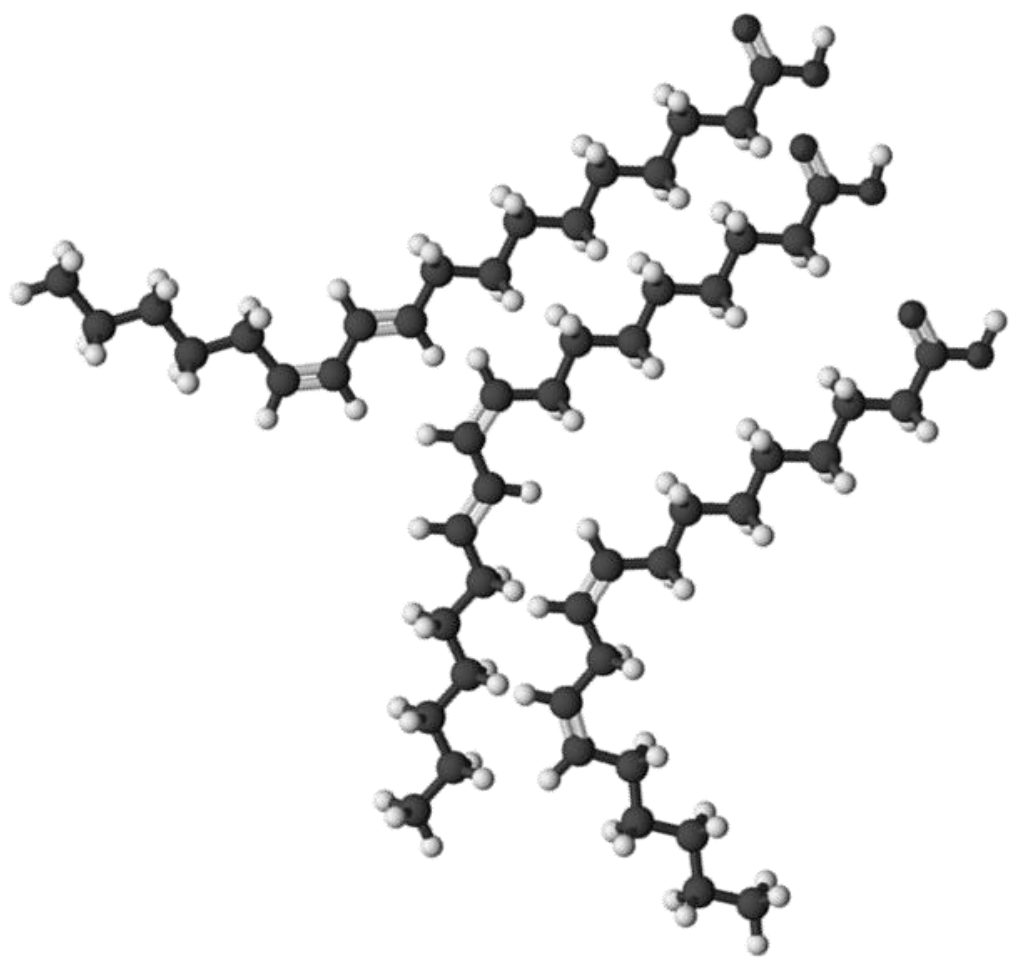

4. ISÓMEROS CLA EN LECHE DE OVEJA PARCIALMENTE DESNATADA Y TRATADA TÉRMICAMENTE (UHT) 



\section{ISÓMEROS CLA EN LECHE DE OVEJA PARCIALMENTE DESNATADA Y TRATADA TÉRMICAMENTE}

Una vez validado el método de análisis, el siguiente objetivo fue conocer el contenido de los diferentes isómeros CLA en leche de oveja UHT semidesnatada, así como estudiar la influencia que sobre los mismos pueden tener el procesado y el almacenamiento. Para ello, se han analizado muestras correspondientes a leche cruda, recién procesada y al final del periodo de vida útil. También se valorarán las variaciones en los isómeros, atribuibles a la época del año, puesto que condiciona, en gran medida, la alimentación de los animales.

\subsection{MUESTRAS}

Las muestras de leche de oveja fueron suministradas por la empresa Leche GAZA, S.L.; esta empresa dispone de 22 rebaños de ovejas, todos pertenecientes y controlados por la misma. Los rebaños incluyen cerca de 10000 ovejas reproductoras adultas, de las cuales 8300 son de raza Assaf y 1700 proceden de razas autóctonas (como la Churra y la Castellana). Los animales se alimentaron mediante dos sistemas productivos: semi-extensivo y semi-intensivo (Tabla 4.1).

Con el sistema semi-extensivo, los animales permanecieron estabulados de octubre a febrero, alimentándose de piensos comerciales y forrajes, mientras que de marzo a septiembre, pastorearon 6 horas al día, consumiendo las especies vegetales disponibles. Con el sistema semi-intensivo, la alimentación se basó casi exclusivamente en piensos y forrajes, complementándose con cortos períodos de pastoreo de 3 horas al día entre los meses de abril y agosto. En ninguno de los casos se modificó la dieta animal de manera intencionada, con el fin de aumentar los niveles de CLA en la leche.

La frecuencia de muestreo estuvo condicionada por la planificación de la empresa, impuesta a su vez por las necesidades del mercado. Desde octubre de 2007 hasta diciembre de 2008 (15 meses), Leche GAZA, S.L. nos suministró un total de 24 muestras de leche de oveja semidesnatada UHT, además de sus correspondientes muestras de leche cruda. 
Tabla 4.1. Régimen de alimentación de las ovejas, según el sistema de producción empleado

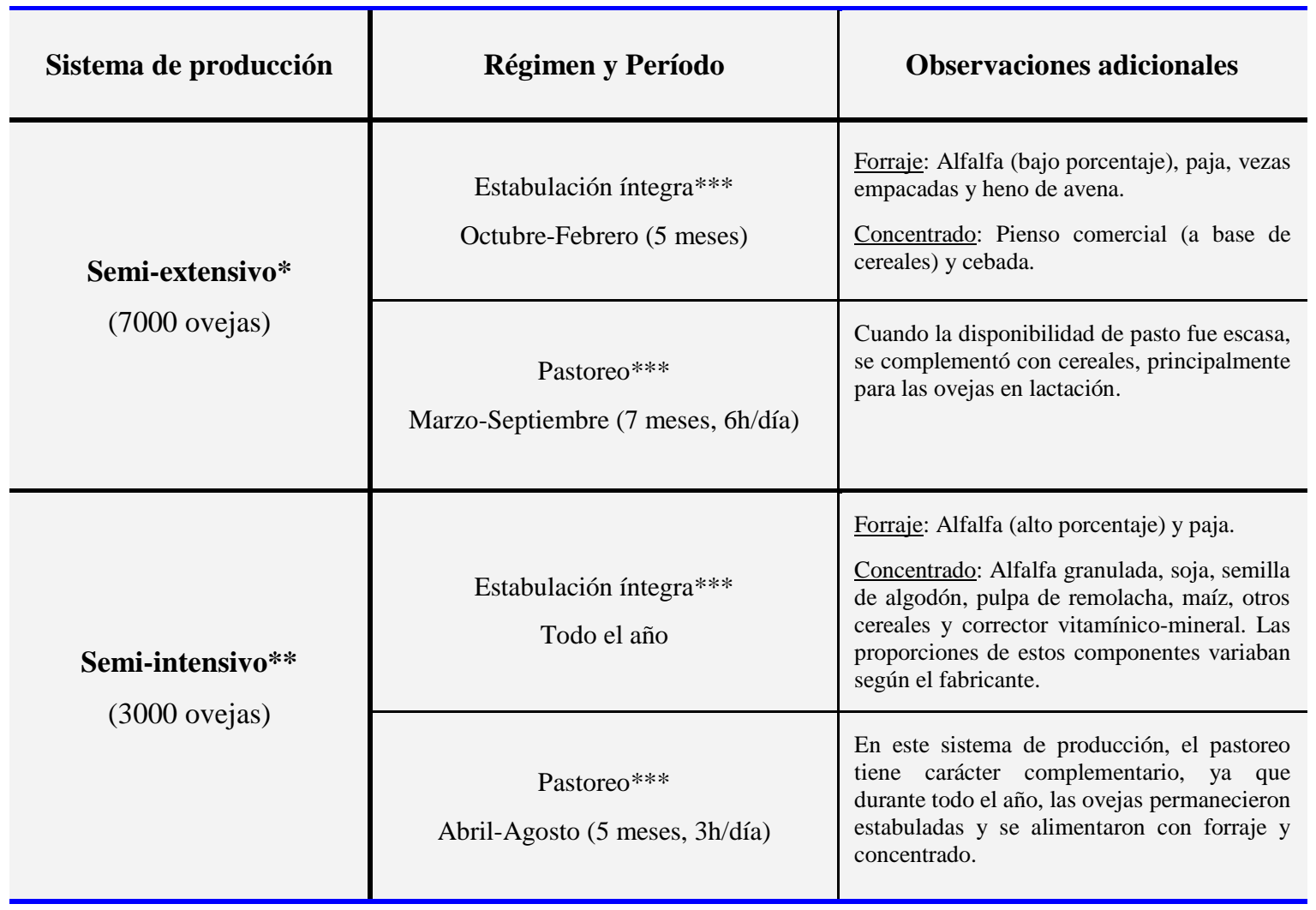

La información plasmada en esta tabla fue suministrada por la empresa GAZA, S.L.

*De las 7000 ovejas de este grupo, 5300 eran de raza Assaf; mientras que las restantes (1700) pertenecían a otras razas autóctonas (como la churra o la castellana).

** Todas las ovejas (3000 cabezas) pertenecían a la raza Assaf.

*** En la estabulación íntegra, la alimentación de las ovejas consistió en suministrarles forraje y concentrado, aunque no se especifica la proporción de los mismos, mientras que en el pastoreo, las ovejas consumían las distintas especies vegetales disponibles, según la zona geográfica (alfalfa, pastizal, etc.).

Las muestras de leche cruda se recogían del conjunto total de la mezcla de leche recién ordeñada. La leche se mantenía refrigerada, se depositaba en envases esterilizados y se trasladaba al laboratorio lo más rápidamente posible el mismo día de su ordeño, para evitar la lipólisis. La extracción de la grasa se realizó en el momento de recibir la muestra en el laboratorio (ver apartado 3.1.1) y se guardó a $-20^{\circ} \mathrm{C}$ hasta el día en que se procedió con su análisis.

Las correspondientes muestras de leche de oveja semidesnatada llegaron uno o dos días después de recibir la leche cruda. Se recibía un pack de 6 envases "Tetra Brik" de 1 litro, cuya vida útil era de aproximadamente 3 meses. Se extrajo la grasa de la misma forma que para la leche cruda. Uno de los envases se dejó cerrado y se almacenó en el laboratorio (temperatura ambiente aproximada de $22 \pm 2{ }^{\circ} \mathrm{C}$ ) para una posterior 
extracción próxima a la fecha de caducidad. En el etiquetado se recoge la información nutricional que se detalla a continuación:

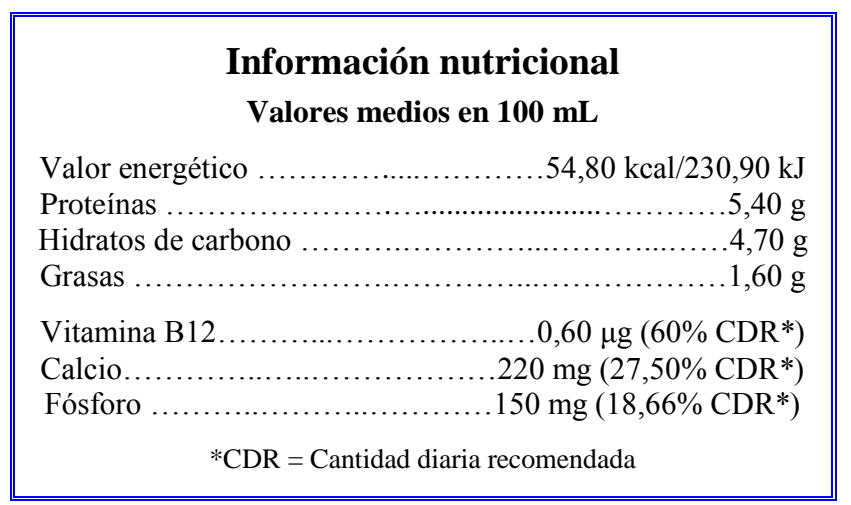

\subsection{TRATAMIENTO ESTADÍSTICO}

Los contenidos de isómeros CLA en los tres tipos de leche, y según la época del año, se compararon con un análisis de varianza de dos factores independientes con interacción (tipo de leche y variación estacional). Para el análisis de detección de las diferencias de medias entre los niveles de los factores, se ha utilizado la penalización de Bonferroni. Los niveles de significación elegidos han sido los habituales del $5 \%$ y el 1\%. Para la realización de análisis estadístico, se ha utilizado el software XLSTAT 2007.

\subsection{RESULTADOS Y DISCUSIÓN}

En la Tabla 4.2 se recogen los contenidos de isómeros CLA encontrados en las distintas muestras de leche cruda, así como en sus correspondientes muestras de leche semidesnatada UHT, tanto las recién procesadas como las que se almacenaron hasta su caducidad. Los valores medios obtenidos para todos los isómeros durante los 15 meses de estudio se agruparon en intervalos de tres meses, para valorar la influencia estacional en los diferentes isómeros. Estos resultados se expresan en miligramos por gramo de grasa $\left(\mathrm{mg}_{\mathrm{CLA}} / \mathrm{g}_{\text {Grasa }}\right)$, por lo que para compararlos con aquellas publicaciones en las que el CLA se expresa de otra forma ( $\mathrm{g}_{\mathrm{CLA}} / 100 \mathrm{~g}$ de ácidos grasos totales o $\mathrm{g}_{\mathrm{CLA}-\mathrm{FAME}} / 100 \mathrm{~g}$ de FAME's), hemos optado por convertir los datos de otros autores a esta misma unidad ( $\left.\mathrm{mg} / \mathrm{g}_{\text {Grasa }}\right)$, empleando para ello los factores de conversión que se recogen en el Anexo 1. Pensamos que la aplicación de estos factores resulta útil a efectos comparativos, aunque debemos asumir que los valores calculados pueden incluir errores derivados del número y cantidad concreta de ácidos grasos determinados en cada trabajo. 
Tabla 4.2. Contenido de isómeros CLA (mg/g $/ \mathrm{g}_{\text {Grasa }}$ en leche de oveja

\begin{tabular}{|c|c|c|c|c|c|c|}
\hline \multirow[b]{2}{*}{ Isómero CLA } & \multirow[b]{2}{*}{$\begin{array}{l}\text { Tipo de } \\
\text { Leche }^{(a)}\end{array}$} & \multicolumn{5}{|c|}{$\tilde{\boldsymbol{x}} \pm s_{D}$} \\
\hline & & 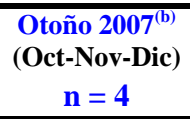 & $\begin{array}{c}\text { Invierno 2008 }^{(\mathrm{b})} \\
\text { (Ene-Feb-Mar) } \\
\mathbf{n}=\mathbf{4}\end{array}$ & $\begin{array}{c}\text { Primavera 2008 }^{(\mathbf{b})} \\
\text { (Abr-May-Jun) } \\
n=6\end{array}$ & $\begin{array}{c}\text { Verano 2008 }^{(b)} \\
\text { (Jul-Ago-Sep) } \\
\quad n=5\end{array}$ & $\begin{array}{c}\text { Otoño 2008 }^{(\mathbf{b})} \\
\text { (Oct-Nov-Dic) }^{\text {Oct- }} \\
\mathrm{n}=5\end{array}$ \\
\hline trans-12,trans-14 & $\begin{array}{c}\text { Cruda } \\
\text { Procesada } \\
\text { Almacenada }\end{array}$ & $\begin{array}{l}0,125 \pm 0,017 \\
0,119 \pm 0,018 \\
0,120 \pm 0,017\end{array}$ & $\begin{array}{r}\mathbf{0 , 1 2 7} \pm \mathbf{0 , 0 1 1} \\
\mathbf{0 , 1 1 5} \pm \mathbf{0 , 0 0 9} \\
0,118 \pm \mathbf{0 , 0 0 8}\end{array}$ & $\begin{array}{l}0,225 \pm 0,040 \\
0,219 \pm 0,037 \\
0,210 \pm 0,039\end{array}$ & $\begin{array}{r}\mathbf{0 , 1 3 2} \pm \mathbf{0 , 0 2 4} \\
\mathbf{0 , 1 3 4} \pm \mathbf{0 , 0 1 9} \\
\mathbf{0 , 1 3 7} \pm \mathbf{0 , 0 1 9}\end{array}$ & $\begin{array}{l}0,127 \pm 0,006 \\
0,120 \pm 0,010 \\
0,124 \pm 0,010\end{array}$ \\
\hline trans-11,trans-13 & $\begin{array}{c}\text { Cruda } \\
\text { Procesada } \\
\text { Almacenada }\end{array}$ & $\begin{array}{l}0,121 \pm 0,016 \\
0,115 \pm 0,016 \\
0,114 \pm 0,018\end{array}$ & $\begin{array}{l}0,117 \pm 0,014 \\
0,106 \pm 0,007 \\
0,107 \pm 0,005\end{array}$ & $\begin{array}{l}0,327 \pm 0,065 \\
0,326 \pm 0,068 \\
0,311 \pm 0,071\end{array}$ & $\begin{array}{l}0,130 \pm 0,038 \\
0,137 \pm 0,047 \\
0,140 \pm 0,047\end{array}$ & $\begin{array}{l}0,128 \pm 0,015 \\
0,123 \pm 0,016 \\
0,126 \pm 0,015\end{array}$ \\
\hline trans -10, trans -12 & $\begin{array}{c}\text { Cruda } \\
\text { Procesada } \\
\text { Almacenada }\end{array}$ & $\begin{array}{l}0,070 \pm 0,008 \\
0,071 \pm 0,008 \\
0,070 \pm 0,008\end{array}$ & $\begin{array}{l}0,071 \pm 0,009 \\
0,069 \pm 0,011 \\
0,065 \pm 0,007\end{array}$ & $\begin{array}{l}0,066 \pm 0,013 \\
0,068 \pm 0,015 \\
0,069 \pm 0,012\end{array}$ & $\begin{array}{l}0,074 \pm 0,009 \\
0,074 \pm 0,007 \\
0,064 \pm 0,006\end{array}$ & $\begin{array}{l}0,063 \pm 0,006 \\
0,067 \pm 0,009 \\
0,059 \pm 0,008\end{array}$ \\
\hline trans-9,trans-11 & $\begin{array}{c}\text { Cruda } \\
\text { Procesada } \\
\text { Almacenada }\end{array}$ & $\begin{array}{l}0,140 \pm 0,017 \\
0,140 \pm 0,017 \\
0,133 \pm 0,015\end{array}$ & $\begin{array}{l}0,137 \pm 0,005 \\
0,149 \pm 0,007 \\
0,137 \pm 0,006\end{array}$ & $\begin{array}{l}0,208 \pm 0,026 \\
0,216 \pm 0,022 \\
0,209 \pm 0,022\end{array}$ & $\begin{array}{l}0,154 \pm 0,018 \\
0,161 \pm 0,018 \\
0,156 \pm 0,023\end{array}$ & $\begin{array}{l}0,146 \pm 0,018 \\
0,141 \pm 0,012 \\
0,138 \pm 0,015\end{array}$ \\
\hline trans -8, trans -10 & $\begin{array}{c}\text { Cruda } \\
\text { Procesada } \\
\text { Almacenada }\end{array}$ & $\begin{array}{l}0,052 \pm 0,007 \\
0,052 \pm 0,004 \\
0,055 \pm 0,009\end{array}$ & $\begin{array}{l}0,060 \pm 0,005 \\
0,061 \pm 0,008 \\
0,057 \pm 0,004\end{array}$ & $\begin{array}{l}0,066 \pm 0,010 \\
0,060 \pm 0,007 \\
0,061 \pm 0,007\end{array}$ & $\begin{array}{l}0,059 \pm 0,006 \\
0,061 \pm 0,004 \\
0,061 \pm 0,007\end{array}$ & $\begin{array}{l}0,060 \pm 0,007 \\
0,058 \pm 0,005 \\
0,058 \pm 0,004\end{array}$ \\
\hline trans-7,trans-9 & $\begin{array}{c}\text { Cruda } \\
\text { Procesada } \\
\text { Almacenada }\end{array}$ & $\begin{array}{l}0,048 \pm 0,004 \\
0,051 \pm 0,006 \\
0,051 \pm 0,007\end{array}$ & $\begin{array}{l}0,055 \pm 0,004 \\
0,056 \pm 0,006 \\
0,048 \pm 0,004\end{array}$ & $\begin{array}{l}0,065 \pm 0,005 \\
0,065 \pm 0,004 \\
0,065 \pm 0,006\end{array}$ & $\begin{array}{l}0,057 \pm 0,005 \\
0,058 \pm 0,005 \\
0,061 \pm 0,003\end{array}$ & $\begin{array}{l}0,052 \pm 0,005 \\
0,051 \pm 0,003 \\
0,052 \pm 0,004\end{array}$ \\
\hline trans-6,trans -8 & $\begin{array}{c}\text { Cruda } \\
\text { Procesada } \\
\text { Almacenada }\end{array}$ & $\begin{array}{l}0,012 \pm 0,002 \\
0,013 \pm 0,002 \\
0,013 \pm 0,003\end{array}$ & $\begin{array}{l}0,014 \pm 0,002 \\
0,013 \pm 0,003 \\
0,013 \pm 0,002\end{array}$ & $\begin{array}{l}0,013 \pm 0,002 \\
0,016 \pm 0,005 \\
0,014 \pm 0,004\end{array}$ & $\begin{array}{l}\mathbf{0 , 0 1 7} \pm \mathbf{0 , 0 0 2} \\
\mathbf{0 , 0 1 7} \pm \mathbf{0 , 0 0 3} \\
\mathbf{0 , 0 1 8} \pm \mathbf{0 , 0 0 4}\end{array}$ & $\begin{array}{l}0,017 \pm 0,001 \\
0,017 \pm 0,002 \\
0,017 \pm 0,003\end{array}$ \\
\hline
\end{tabular}

\footnotetext{
(a) Tipo de leche: No se han encontrado diferencias significativas, $\mathrm{P}>0,05$.

(b) Tiempo de muestreo: Se han encontrado diferencias significativas, $\mathrm{P}<0,05$.

(ax b) Interacción: Sólo se da para el isómero trans-7,trans-9.

“n” = Número de muestras, analizadas por triplicado.
} 
Tabla 4.2 (cont.). Contenido de isómeros CLA (mg/g $\mathrm{g}_{\text {Grasa }}$ ) en leche de oveja

\begin{tabular}{|c|c|c|c|c|c|c|}
\hline \multirow[b]{2}{*}{ Isómero CLA } & \multirow[b]{2}{*}{$\begin{array}{l}\text { Tipo de } \\
\text { Leche }^{(a)}\end{array}$} & \multicolumn{5}{|c|}{$\tilde{\boldsymbol{x}} \pm s_{D}$} \\
\hline & & $\begin{array}{c}{\text { Otoño } 2007^{(\mathrm{b})}} \\
\text { (Oct-Nov-Dic) } \\
\mathbf{n}=4\end{array}$ & $\begin{array}{c}\text { Invierno 2008 } \\
\text { (Ene-Feb-Mar) }^{(\mathrm{b})} \\
\mathrm{n}=\mathbf{4}\end{array}$ & $\begin{array}{c}\text { Primavera 2008 }^{(\mathrm{b})} \\
\text { (Abr-May-Jun) } \\
\text { n }=6\end{array}$ & $\begin{array}{c}\text { Verano 2008 } \\
\text { (Jul-Ago-Sep) } \\
n=5\end{array}$ & $\begin{array}{c}\text { Otoño 2008 } \\
\text { (Oct-Nov-Dic) } \\
n=5\end{array}$ \\
\hline $12,14-(c-t / t-c)$ & $\begin{array}{c}\text { Cruda } \\
\text { Procesada } \\
\text { Almacenada }\end{array}$ & $\begin{array}{l}0,057 \pm 0,005 \\
0,055 \pm 0,004 \\
0,052 \pm 0,005\end{array}$ & $\begin{array}{l}0,058 \pm 0,005 \\
0,056 \pm 0,002 \\
0,059 \pm 0,009\end{array}$ & $\begin{array}{l}0,152 \pm 0,035 \\
0,152 \pm 0,035 \\
0,147 \pm 0,039\end{array}$ & $\begin{array}{l}0,068 \pm 0,011 \\
0,071 \pm 0,018 \\
0,071 \pm 0,014\end{array}$ & $\begin{array}{l}0,060 \pm 0,007 \\
0,061 \pm 0,006 \\
0,061 \pm 0,007\end{array}$ \\
\hline trans-11,cis-13 & $\begin{array}{c}\text { Cruda } \\
\text { Procesada } \\
\text { Almacenada }\end{array}$ & $\begin{array}{l}0,061 \pm 0,007 \\
0,057 \pm 0,005 \\
0,056 \pm 0,009\end{array}$ & $\begin{array}{l}0,068 \pm 0,016 \\
0,065 \pm 0,009 \\
0,064 \pm 0,010\end{array}$ & $\begin{array}{l}0,223 \pm 0,046 \\
0,232 \pm 0,055 \\
0,230 \pm 0,067\end{array}$ & $\begin{array}{l}\mathbf{0 , 0 6 9} \pm \mathbf{0 , 0 2 2} \\
0,073 \pm \mathbf{0 , 0 3 0} \\
0,075 \pm \mathbf{0 , 0 2 7}\end{array}$ & $\begin{array}{l}0,064 \pm 0,005 \\
0,063 \pm 0,005 \\
0,069 \pm 0,009\end{array}$ \\
\hline trans-10,cis-12 & $\begin{array}{c}\text { Cruda } \\
\text { Procesada } \\
\text { Almacenada }\end{array}$ & $\begin{array}{l}0,044 \pm 0,005 \\
0,043 \pm 0,005 \\
0,043 \pm 0,006\end{array}$ & $\begin{array}{l}0,042 \pm 0,002 \\
0,046 \pm 0,003 \\
0,046 \pm 0,003\end{array}$ & $\begin{array}{l}0,062 \pm 0,010 \\
0,060 \pm 0,012 \\
0,060 \pm 0,009\end{array}$ & $\begin{array}{l}0,050 \pm 0,009 \\
0,050 \pm 0,009 \\
0,050 \pm 0,006\end{array}$ & $\begin{array}{l}0,046 \pm 0,004 \\
0,045 \pm 0,004 \\
0,045 \pm 0,002\end{array}$ \\
\hline cis-9,trans-11 & $\begin{array}{c}\text { Cruda } \\
\text { Procesada } \\
\text { Almacenada }\end{array}$ & $\begin{array}{l}4,446 \pm 0,292 \\
4,364 \pm 0,274 \\
4,295 \pm 0,275\end{array}$ & $\begin{array}{l}4,400 \pm 0,254 \\
4,225 \pm 0,189 \\
4,242 \pm 0,121\end{array}$ & $\begin{array}{l}6,737 \pm 0,657 \\
6,507 \pm 0,717 \\
6,486 \pm 0,726\end{array}$ & $\begin{array}{l}4,725 \pm 0,651 \\
4,666 \pm 0,704 \\
4,685 \pm 0,674\end{array}$ & $\begin{array}{l}4,605 \pm 0,324 \\
4,556 \pm 0,469 \\
4,617 \pm 0,459\end{array}$ \\
\hline trans -8, cis -10 & $\begin{array}{c}\text { Cruda } \\
\text { Procesada } \\
\text { Almacenada }\end{array}$ & $\begin{array}{l}0,064 \pm 0,009 \\
0,068 \pm 0,017 \\
0,072 \pm 0,007\end{array}$ & $\begin{array}{l}0,075 \pm 0,017 \\
0,067 \pm 0,013 \\
0,062 \pm 0,013\end{array}$ & $\begin{array}{l}0,093 \pm 0,014 \\
0,086 \pm 0,009 \\
0,090 \pm 0,012\end{array}$ & $\begin{array}{l}0,098 \pm 0,007 \\
0,096 \pm 0,008 \\
0,096 \pm 0,006\end{array}$ & $\begin{array}{l}0,088 \pm 0,006 \\
0,086 \pm 0,009 \\
0,087 \pm 0,008\end{array}$ \\
\hline trans -7, cis -9 & $\begin{array}{c}\text { Cruda } \\
\text { Procesada } \\
\text { Almacenada }\end{array}$ & $\begin{array}{l}0,385 \pm 0,022 \\
0,381 \pm 0,029 \\
0,373 \pm 0,029\end{array}$ & $\begin{array}{l}0,393 \pm 0,044 \\
0,369 \pm 0,031 \\
0,360 \pm 0,026\end{array}$ & $\begin{array}{l}0,442 \pm 0,028 \\
0,428 \pm 0,024 \\
0,436 \pm 0,026\end{array}$ & $\begin{array}{l}0,398 \pm 0,038 \\
0,393 \pm 0,027 \\
0,395 \pm 0,018\end{array}$ & $\begin{array}{l}0,389 \pm 0,031 \\
0,386 \pm 0,036 \\
0,392 \pm 0,033\end{array}$ \\
\hline CLA TOTAL & $\begin{array}{c}\text { Cruda } \\
\text { Procesada } \\
\text { Almacenada }\end{array}$ & $\begin{array}{l}5,624 \pm 0,383 \\
5,530 \pm 0,375 \\
5,448 \pm 0,366\end{array}$ & $\begin{array}{l}5,617 \pm 0,290 \\
5,395 \pm 0,185 \\
5,378 \pm 0,112\end{array}$ & $\begin{array}{l}8,679 \pm 0,868 \\
8,435 \pm 0,922 \\
8,388 \pm 0,950\end{array}$ & $\begin{array}{l}6,031 \pm 0,815 \\
5,992 \pm 0,871 \\
6,009 \pm 0,805\end{array}$ & $\begin{array}{l}5,845 \pm 0,353 \\
5,775 \pm 0,531 \\
5,846 \pm 0,518\end{array}$ \\
\hline
\end{tabular}

\footnotetext{
(a) Tipo de leche: No se han encontrado diferencias significativas, $\mathrm{P}>0,05$.

(b) Tiempo de muestreo: Se han encontrado diferencias significativas, $\mathrm{P}<0,05$.

(a x b) Interacción: No se encontró

"n” = Número de muestras, analizadas por triplicado.
} 


\subsubsection{Influencia del procesado y del almacenamiento}

Para observar la influencia del procesado y del almacenamiento, se compararon entre sí los contenidos de isómeros CLA encontrados en las diferentes muestras de leche semidesnatada con la correspondiente leche cruda (ver Tabla 4.2). En la Figura 4.1 se esquematiza el proceso de fabricación de la leche UHT, facilitada por la empresa GAZA, S.L. En ella puede observarse que la temperatura más elevada $\left(150^{\circ} \mathrm{C}\right)$ se mantiene durante un tiempo muy corto (2,4 segundos).

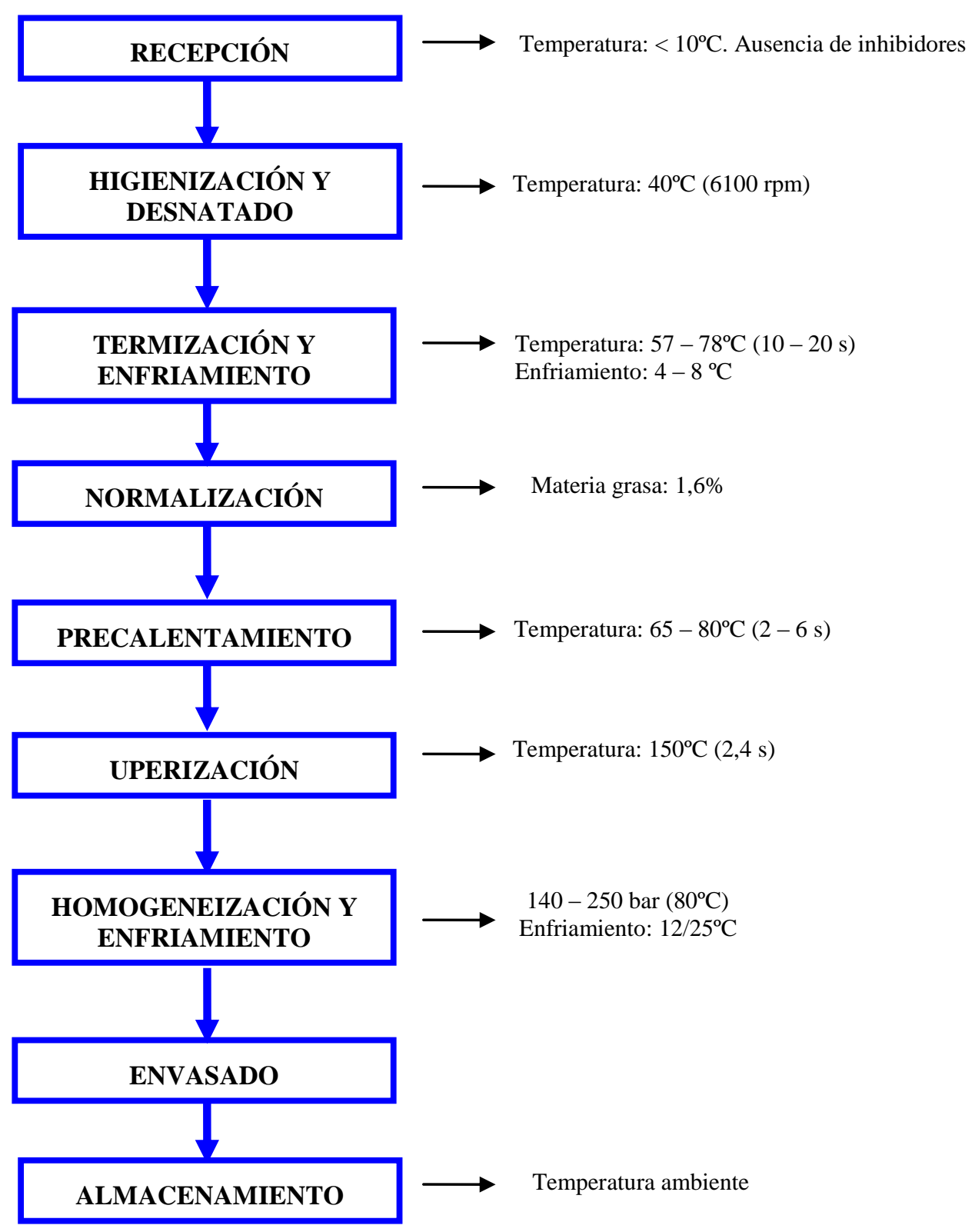

Figura 4.1. Esquema del procesado de la leche de oveja UHT, según la empresa GAZA. 


\subsubsection{Efecto del procesado y el almacenamiento en el contenido de CLA total}

Para casi todas las épocas del año, el contenido total de CLA fue ligeramente mayor en la leche cruda que en sus respectivas muestras de leche procesada o almacenada. Sin embargo, hay que decir que estas diferencias no fueron significativas ( $\mathrm{P}>0,05)$, ni en leche recién tratada, ni cuando el producto final se almacenó durante tres meses (período correspondiente a su vida útil). Estas observaciones coinciden con las encontradas en algunos trabajos relacionados con los efectos del procesado de la leche para obtener distintos derivados lácteos, en las que no se observan variaciones de CLA o, de producirse, son muy pequeñas (Luna et al., 2005c y 2007; Partidario et al., 2008; Prandini et al., 2009).

Sin embargo, las publicaciones más antiguas contradicen estas afirmaciones (Ha et al., 1989; Shantha et al., 1992; García-López et al., 1994), creando cierta controversia en lo que se refiere a la influencia del procesado sobre el contenido total e individual de isómeros CLA en leche y derivados lácteos. Los primeros estudios indicaban que el incremento del CLA en los productos lácteos se debía a los diversos procesos térmicos que se aplicaban a la leche cruda durante la fabricación de los mismos, sobre todo aquellos que utilizaban temperaturas moderadas (inferiores a $100^{\circ} \mathrm{C}$ ). Otros consideraron que este aumento se debía a una posible conversión del ácido linoleico en CLA, influenciado por factores como la temperatura de calentamiento, el oxígeno y la presencia de moléculas donadoras de hidrógeno (como las proteínas). Estos trabajos están hechos en quesos y por ello, en este apartado, no hemos considerado necesario entrar en detalles respecto a los mismos (ver apartado 1.3.2).

Los estudios más recientes sostienen la idea de que los distintos procesos térmicos no tienen influencia en el contenido de CLA en leche y sus derivados. Los procesos de fabricación de leche líquida (Herzallah et al., 2005; Buccioni et al., 2010), leche fermentada (Luna et al., 2004) y quesos (Gnädig et al., 2004; Luna et al., 2005c y 2007; Partidario et al., 2008; Prandini et al., 2009) no parecen alterar la cantidad de CLA.

En leche de oveja, después de un tratamiento de pasteurización $\left(73^{\circ} \mathrm{C}, 15\right.$ segundos), se mantuvo el contenido de CLA total $\left(17,4 \mathrm{mg} / \mathrm{g}_{\text {Grasa }}\right)$, aunque se modificó la distribución de isómeros (Buccioni et al., 2010). Herzallah et al. (2005) no observan 
diferencias entre los contenidos de CLA en leche cruda de vaca $\left(5,67 \mathrm{mg} / \mathrm{g}_{\text {Grasa }}\right)$ y los encontrados en la correspondiente leche pasteurizada a $63^{\circ} \mathrm{C}$ durante 30 min $(5,34$ $\left.\mathrm{mg} / \mathrm{g}_{\text {Grasa }}\right)$ y a $95^{\circ} \mathrm{C}$ durante $5 \mathrm{~min}\left(5,37 \mathrm{mg} / \mathrm{g}_{\text {Grasa }}\right)$, aunque sí determinan descensos en los niveles de CLA $\left(4,82 \mathrm{mg} / \mathrm{g}_{\text {Grasa }}\right.$, aproximadamente un $\left.15 \%\right)$ cuando la leche se sometió a tratamiento UHT $\left(140^{\circ} \mathrm{C}\right.$, durante 4 segundos). Estas variaciones están bastante alejadas de los resultados que hemos obtenido con la leche de oveja UHT, en la que el descenso más destacado del contenido de CLA total se dio en invierno. En esta época, los niveles de CLA en la leche procesada $\left(5,395 \pm 0,185 \mathrm{mg} / \mathrm{g}_{\text {Grasa }}\right)$ o almacenada $\left(5,378 \pm 0,112 \mathrm{mg} / \mathrm{g}_{\text {Grasa }}\right)$ fueron apenas un $4 \%$ menores que en su correspondiente leche de partida $\left(5,617 \pm 0,290 \mathrm{mg} / \mathrm{g}_{\text {Grasa }}\right)$. Las diferencias en las temperaturas y tiempos de calentamiento no explican la falta de concordancia entre los resultados encontrados en nuestro trabajo y las publicadas para la leche UHT de vaca.

En leche pasteurizada $\left(85^{\circ} \mathrm{C}, 16\right.$ segundos), el tratamiento térmico no supuso ninguna variación en los niveles de CLA. Sin embargo, el almacenamiento en refrigeración $\left(5^{\circ} \mathrm{C}\right)$ durante tres días, hizo descender dichas cantidades (de 5,53 a 4,71 $\left.\mathrm{mg} / \mathrm{g}_{\text {Grasa }}\right)$. Este mismo efecto no se observó en la leche UHT, después de mantenerla en refrigeración durante cinco días (Herzallah et al. 2005).

\subsubsection{Efecto del procesado y el almacenamiento en los isómeros individuales}

No hemos observado cambios importantes en los contenidos individuales de isómeros CLA, como consecuencia del procesado de la leche o por el almacenamiento, y las ligeras diferencias encontradas en los niveles de CLA total se deben principalmente al isómero mayoritario, el cis-9,trans-11, pero no fueron estadísticamente significativas $(\mathrm{P}>0,05)$.

Como ya hemos recogido previamente, la leche de oveja, después de un tratamiento de pasteurización $\left(73^{\circ} \mathrm{C}, 15\right.$ segundos $)$, conservó el contenido de CLA total pero se modificó la distribución de isómeros. El cis-9,trans-11 y el trans-10,trans-12 aumentaron ( 1,3 y $0,7 \%$ respectivamente), mientras que en el cis-10,cis-12 y en otros isómeros no especificados, se observó una reducción ( 0,3 y 1,4\% respectivamente). En el perfil no se han considerado los isómeros trans-10, cis-12 y trans-6,trans-8, porque se encuentran en cantidades muy pequeñas, tanto en la leche cruda como en la pasteurizada (Buccioni et al., 2010). 
Los contenidos de cis-9,trans-11 y de trans-10,cis-12, determinados por Zengin et al. (2011) en leche de vaca pasteurizada a diferentes temperaturas ( 70 a $\left.90^{\circ} \mathrm{C}, 5 \mathrm{~min}\right)$, fueron iguales a los que presentaba su correspondiente leche sin tratar.

Estos resultados estarían en la misma línea de los recogidos por RodríguezAlcalá y Fontecha (2007), que trabajaron con 6 productos lácteos enriquecidos con CLA (leche, leche fermentada, queso fresco, yogur, zumo y leche en polvo) y evaluaron el efecto del procesado y almacenamiento (durante 1, 5 y 10 semanas) sobre el contenido de CLA en estos productos. En leche desnatada, enriquecida con CLA y tratada térmicamente $\left(142^{\circ} \mathrm{C}, 6\right.$ segundos) no encontraron diferencias en la cantidad de los isómeros mayoritarios (cis-9,trans-11 y trans-10,cis-12) ni tampoco en la de los minoritarios (trans-11,trans-13; trans-10,trans-12; cis-11,trans-13; trans-8,cis-10; cis9,cis-11 y cis-10,cis-12) después de 10 semanas almacenada a $4^{\circ} \mathrm{C}$. Sólo en las muestras de queso fresco llegaron a encontrar pérdidas significativas de los mayoritarios cis9,trans-11 y trans-10,cis-12.

Otros estudios ponen de manifiesto cambios significativos en los contenidos de cis-9,trans-11, así como de otros isómeros minoritarios. Campbell et al. (2003) detectan un descenso significativo del contenido de cis-9,trans-11 y de otros isómeros minoritarios como consecuencia de la pasteurización HTST (alta temperatura y corto tiempo) en muestras de leche desnatada enriquecida con un $2 \%$ de CLA. Los mismos autores llegan a determinar descensos significativos del ácido ruménico después de 3 semanas de almacenamiento en refrigeración. Estos cambios en el contenido de cis9,trans-11 los atribuyen al proceso térmico que se empleó en la elaboración de los productos y a un excesivo crecimiento microbiológico durante el almacenamiento de las muestras.

Se han publicado descensos de hasta un $20 \%$ (de 15,0 hasta $12,0 \mathrm{mg} / \mathrm{g}_{\text {Grasa }}$ ) en el contenido de cis-9,trans-11 en la leche UHT $\left(138^{\circ} \mathrm{C}\right.$, durante 3 segundos). Esta reducción fue comparativamente más baja (de 15,0 hasta 13,4 mg/g $\mathrm{g}_{\text {Grasa }}$, un 10\% menos) cuando utilizaron la pasteurización a $60^{\circ} \mathrm{C}$ durante 20 minutos. El almacenamiento de la leche UHT durante dos meses a temperatura de refrigeración $\left(6-7^{\circ} \mathrm{C}\right)$ produjo una reducción muy pequeña $(1,2 \%)$ del ácido ruménico. Esta disminución se puede 
considerar despreciable frente al efecto producido por el tratamiento térmico (Leite $e t$ al., 2007).

Pensamos que la discrepancia entre los resultados de distintos autores, no puede deberse a las diferencias en el tiempo y temperatura de tratamiento, sino que podría estar condicionada por otros factores no contemplados en los trabajos publicados.

\subsubsection{Contenido de CLA total y variación estacional}

En la Tabla 4.2 se puede observar que, para las distintas muestras de leche, el contenido de CLA total se mantiene entre 5,378 y 8,679 $\mathrm{mg} / \mathrm{g}_{\text {Grasa }}$. Dichos datos se representan en la Figura 4.2. Los mayores niveles se encontraron durante la época primaveral $\left(8,501 \pm 0,906 \mathrm{mg} / \mathrm{g}_{\text {Grasa }}\right)$, mientras que en el resto de épocas estacionales, las cantidades de CLA total apenas llegaron a alcanzar $\operatorname{los} 6,00 \mathrm{mg} / \mathrm{g}_{\text {Grasa. Hay que }}$ precisar que, en muestras correspondientes al mes de mayo, se determinaron cantidades más altas $\left(10 \mathrm{mg} / \mathrm{g}_{\text {Grasa }}\right)$.

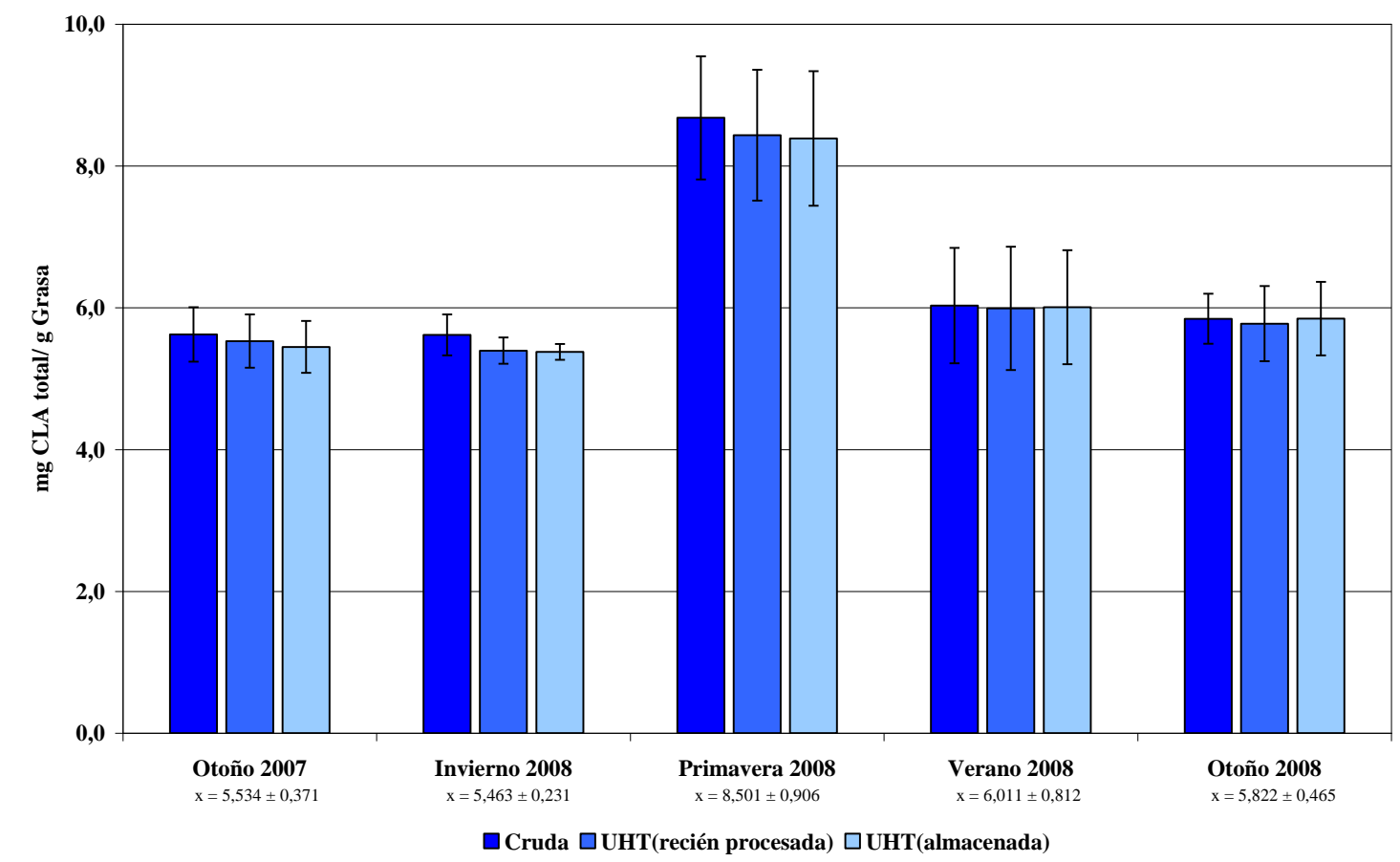

Figura 4.2. Variación del contenido de CLA total en las muestras de leche de oveja UHT.

Los contenidos de CLA total determinados en primavera presentan diferencias significativas $(\mathrm{P}<0,01)$ con respecto a los contenidos encontrados en el resto del año. En la Tabla 4.3 se recogen de forma esquemática los resultados del tratamiento 
estadístico, con el fin de facilitar su visualización y la comparación global de las variaciones estacionales entre isómeros.

El análisis estadístico califica como significativas variaciones mínimas que se dan en los isómeros que se encuentran en concentraciones más bajas. En estos casos concretos, no se ha tenido en cuenta la significación si la diferencia de las medias era inferior al límite de cuantificación referido a las muestras y determinado en la validación del método de análisis.

Tabla 4.3. Diferencias estacionales: resultados del tratamiento estadístico en leche de oveja UHT

\begin{tabular}{|c|c|c|c|c|c|c|c|c|c|c|c|c|c|c|}
\hline \multirow[b]{2}{*}{ Tiempo de muestreo } & \multicolumn{14}{|c|}{ Isómeros } \\
\hline & 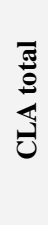 & 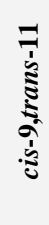 & 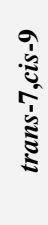 & 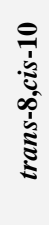 & 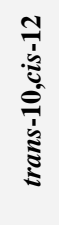 & $\begin{array}{l}m \\
\vdots \\
\vdots \\
\vdots \\
\Xi \\
\vdots \\
\vdots \\
\vdots \\
\vdots\end{array}$ & 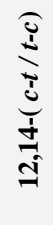 & 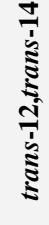 & 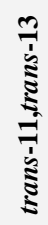 & 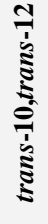 & 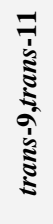 & 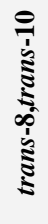 & $\begin{array}{l}0 \\
\vdots \\
\vdots \\
\vdots \\
\vdots \\
\vdots \\
\vdots \\
\vdots \\
\vdots \\
\vdots\end{array}$ & $\begin{array}{l}\infty \\
1 \\
\vdots \\
\vdots \\
\vdots \\
0 \\
0 \\
1 \\
\vdots \\
\vdots \\
\vdots \\
\vdots\end{array}$ \\
\hline \multicolumn{15}{|l|}{ Otoño 2007 - Invierno 2008} \\
\hline Otoño 2007 - Primavera 2008 & $* *$ & $* *$ & $* *$ & $* *$ & $* *$ & $* *$ & $* *$ & $* *$ & $* *$ & & $* *$ & & & \\
\hline Otoño 2007 - Verano 2008 & $* *$ & & & $* *$ & & & $* *$ & & & & $* *$ & & & \\
\hline Otoño 2007 - Otoño 2008 & & & & $* *$ & & & & & & & & & & \\
\hline Invierno 2008 - Primavera 2008 & $* *$ & $* *$ & $* *$ & $* *$ & $* *$ & $* *$ & $* *$ & $* *$ & $* *$ & & $* *$ & & & \\
\hline Invierno 2008 - Verano 2008 & $* *$ & $* *$ & $* *$ & $* *$ & & & & & & & $* *$ & & & \\
\hline Invierno 2008 - Otoño 2008 & & & & $* *$ & & & & & & & & & & \\
\hline Primavera 2008 - Verano 2008 & $* *$ & $* *$ & $* *$ & & $* *$ & $* *$ & $* *$ & $* *$ & $* *$ & & $* *$ & & & \\
\hline Primavera 2008 - Otoño 2008 & $* *$ & $* *$ & $* *$ & & $* *$ & $* *$ & $* *$ & $* *$ & $* *$ & & $* *$ & & & \\
\hline Verano 2008 - Otoño 2008 & & & & $* *$ & & & & & & & & & & \\
\hline
\end{tabular}

$* * \ll \mathrm{P} »<0,01 ; * \ll \mathrm{P} »<0,05 ;$ No significativo $>0,05$.

Si tenemos en cuenta estos contenidos y la alimentación que han recibido los animales, podemos decir que nuestros resultados son bastante parecidos a los que se han obtenido en algunos trabajos publicados previamente. Los valores de CLA total encontrados por Luna et al. (2005a) en leche de ovejas de distintas razas, son muy similares a los que hemos obtenido en este ensayo $\left(5,43-9,25 \mathrm{mg} / \mathrm{g}_{\text {Grasa }}\right)$. En otro estudio realizado por los mismos autores (Luna et al., 2005b), el contenido de CLA total en leche de ovejas Assaf alimentadas con una dieta control fue de 7,6 mg/g $\mathrm{g}_{\text {Grasa }}$; dicho valor no superó los $10,0 \mathrm{mg} / \mathrm{g}_{\text {Grasa }}$ cuando la dieta se suplementó con semillas de lino. Atti et al. (2006) obtuvieron un intervalo de variación más amplio (2,40 - 10,30 $\mathrm{mg} / \mathrm{g}_{\text {Grasa }}$ ) en ovejas alimentadas con tres dietas distintas. Según los resultados de Castro 
et al. (2009), los niveles de CLA en leche de oveja no superan $\operatorname{los} 7,5 \mathrm{mg} / \mathrm{g}_{\text {Grasa }}$ en ovejas alimentadas con suplementos enriquecidos con pequeñas cantidades de aceites vegetales. Luna et al. (2007) determinaron cantidades similares a las obtenidas en este estudio en leche cruda de oveja utilizada para elaborar quesos manchegos $(5,70-6,50$ $\mathrm{mg} / \mathrm{g}_{\text {Grasa }}$ ), mientras que Partidario et al. (2008) obtuvieron valores algo mayores en la leche de partida empleada en la fabricación de tres tipos de quesos ovinos portugueses $\left(8,00-11,00 \mathrm{mg} / \mathrm{g}_{\text {Grasa }}\right)$. En leche de oveja destinada a la elaboración de queso Pecorino, se han recogido contenidos mas altos $\left(17,4 \mathrm{mg} / \mathrm{g}_{\text {Grasa }}\right.$, Buccioni et al., 2010).

En algunos de los estudios en los que las ovejas se alimentaron con dietas básicas (aquéllas que no contenían ningún tipo de suplemento), los niveles de CLA se mantuvieron cercanos a los valores que hemos determinado en nuestros ensayos: 4,98 $7,07 \mathrm{mg} / \mathrm{g}_{\text {Grasa }}$ (Mele et al., 2006), 2,45 - 8,38 mg/g $\mathrm{g}_{\text {Grasa }}$ (Reynolds et al., 2006), 6,06 9,71 mg/g $\mathrm{g}_{\text {Grasa }}$ (Gómez-Cortés et al., 2008b), 7,34 - 8,19 mg/g $\mathrm{g}_{\text {Grasa }}$ (Gómez-Cortés et al., 2009a), 4,28 - 9,41 mg/g $\mathrm{g}_{\text {Grasa }}$ (Bodas et al., 2010), 3,86 - 6,59 mg/g $\mathrm{g}_{\text {Grasa }}$ (Lurueña, 2010), y 7,72-9,41 mg/g $\mathrm{g}_{\text {Grasa }}$ (Martini et al., 2010).

Otros estudios relacionados con el contenido de CLA en leche de vaca comercial, también publican datos muy similares. En leche entera de vaca, el intervalo de variación del contenido de CLA es relativamente amplio, estos valores oscilan entre

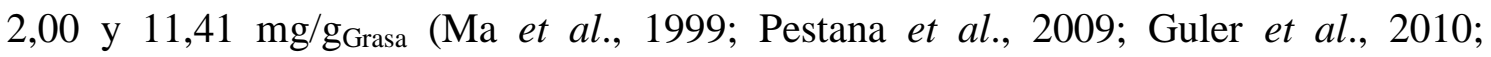
Mushtaq et al., 2010; Nunes y Torres, 2010). En leche UHT, se han determinado concentraciones de CLA entre 5,08 y 7,63 mg/g $/ \mathrm{g}_{\text {Grasa }}$ (Chin et al., 1992; Fritsche et al., 1998a; Jones et al., 2005; Laloux et al., 2007; Park et al., 2008). En los trabajos llevados a cabo con leche baja en grasa, el contenido de CLA también se mantuvo dentro de los valores que hemos encontrado en nuestro estudio. Martins et al. (2007) analizaron diferentes tipos de productos derivados de la leche y encontraron que el contenido de CLA en leche semidesnatada fue de $7,22 \mathrm{mg} / \mathrm{g}_{\text {Grasa }}$, valor relativamente alto si se compara con los $2,10 \mathrm{mg} / \mathrm{g}_{\text {Grasa }}$ determinado por Mushtaq et al. (2010). En este último trabajo no se encontró CLA en leche desnatada, resultado que debería esperarse si se tiene en cuenta que el contenido de grasa es muy pequeño. Sin embargo, llaman la atención los resultados publicados por Guler et al. (2010), que recogen contenidos medios de CLA de $9,20 \mathrm{mg} / \mathrm{g}_{\text {Grasa }}$ en leche desnatada. 
En trabajos publicados recientemente, se insiste en la necesidad de asignar contenidos de ácidos grasos a la leche destinada al consumo, y que incluyan variables estacionales, geográficas y de producción (Butler et al., 2011; O’Donnell-Megaro et al., 2011). En muestras comerciales de leche de vaca de diferentes estados de Estados Unidos recogidas durante un año, con una frecuencia de tres meses y procesadas en distintas empresas, se llega a la conclusión de que se puede considerar un valor medio de $5,22 \mathrm{mg} / \mathrm{g}_{\text {Grasa }}$ para el isómero cis-9,trans-11 y que el trans-10,cis-12 se encontraría por debajo de $0,09 \mathrm{mg} / \mathrm{g}_{\text {Grasa }}$. También se llama la atención respecto a que muchos de los contenidos publicados se han obtenido en condiciones de alimentación experimental, y no deberían utilizarse para asignar valores a la leche comercial.

Después de lo que se acaba de exponer, debe admitirse que las cantidades de CLA en leche, tanto de oveja como de vaca, son menores de lo que se había recogido en la bibliografía hace unos años. Además, el intervalo de variación es tan amplio que resulta difícil asignar un valor medio.

Ya hemos comentado previamente (véase el apartado 4.1) que la alimentación de los animales se llevó a cabo siguiendo dos sistemas productivos (semiextensivo y semiintensivo) y que dicha alimentación no se modificó intencionalmente con el fín de aumentar los niveles de CLA. Puede observarse que el mayor contenido de CLA corresponde a los meses en los que hay una mayor disponibilidad de pastos verdes frescos. También es probable que los descensos registrados en las muestras correspondientes a épocas distintas a la primavera, tengan relación con la ingesta de dietas básicas junto con un pasto de menor calidad, con bajos contenidos de ácido linoleico y $\alpha$-linolénico, ambos precursores del CLA.

Resultados similares en los que se relaciona la ingesta de pasto fresco con niveles más altos de CLA en leche de oveja han sido encontrados por varios autores (Cabiddu et al., 2005; Nudda et al., 2005; Tsiplakou et al., 2006a; Mel'uchova et al., 2008; Gómez-Cortés et al., 2009a; Ostrovsky et al., 2009). Nudda et al. (2005) determinan los mayores contenidos de CLA (expresados como cis-9,trans-11) en leche y lácteos de ovejas alimentadas con pasto fresco, y relacionan los descensos significativos del CLA en estos productos entre los meses de marzo $\left(20,0 \mathrm{mg} / \mathrm{g}_{\text {Grasa }}\right)$ y junio (menos de $12,0 \mathrm{mg} / \mathrm{g}_{\text {Grasa }}$ ) con la ingesta por parte de los animales de un pasto 
cada vez más maduro. En un estudio realizado entre los meses de enero y junio por Tsiplakou et al. (2006a), se encontró que los valores más elevados de CLA total en leche de oveja cruda correspondieron a los meses de abril $\left(19,48 \mathrm{mg} / \mathrm{g}_{\text {Grasa }}\right)$ y mayo $\left(16,38 \mathrm{mg} / \mathrm{g}_{\text {Grasa }}\right)$; mientras que en enero $\left(7,44 \mathrm{mg} / \mathrm{g}_{\text {Grasa }}\right)$, marzo $\left(9,22 \mathrm{mg} / \mathrm{g}_{\text {Grasa }}\right)$ y junio $\left(12,71 \mathrm{mg} / \mathrm{g}_{\text {Grasa }}\right)$ su contenido fue menor.

Gómez-Cortés et al. (2009a) determinan que el contenido de CLA en leche de ovejas alimentadas con pasto supera los $15 \mathrm{mg} / \mathrm{g}_{\text {Grasa, }}$ valores que se pueden ver reducidos a casi la mitad cuando se utilizan dietas TMR $\left(8,20 \mathrm{mg} / \mathrm{g}_{\text {Grasa }}\right)$ o cuando el pasto se combina con suplementos ricos en granos de avena $\left(7,30 \mathrm{mg} / \mathrm{g}_{\text {Grasa }}\right)$. Los resultados publicados por Ostrovsky et al. (2009) muestran que durante los meses de mayo y septiembre, las ovejas que consumieron pasto fresco produjeron una leche cuyo contenido de CLA fue tres veces superior $\left(21,0 \mathrm{mg} / \mathrm{g}_{\text {Grasa }}\right)$ al que se encontró en leche de ovejas alimentadas con dietas básicas (TMR, 7,0 mg/g $\mathrm{g}_{\text {Grasa }}$ ). Estos valores primaverales se reducen durante los meses de julio y agosto $\left(12,7 \mathrm{mg} / \mathrm{g}_{\text {Grasa }}\right)$, probablemente por el descenso de ácido $\alpha$-linolénico en el pasto y la escasa disponibilidad del mismo durante esos períodos. Justifican los incrementos que se encontraron en septiembre con un cambio en la composición botánica del pasto, más rico en ácido $\alpha$-linolénico. En un estudio previo, Mel'uchova et al. (2008) obtuvieron resultados similares entre los meses de abril y septiembre, período en el que las ovejas fueron alimentadas con el pasto disponible. Se encontraron aumentos de hasta cuatro veces en el contenido de CLA en leche de mayo $\left(22,6 \mathrm{mg} / \mathrm{g}_{\text {Grasa }}\right)$ y septiembre $\left(25,0 \mathrm{mg} / \mathrm{g}_{\text {Grasa }}\right)$, respecto a los niveles encontrados en las muestras obtenidas de ovejas alimentadas con dietas básicas $(6,70$ $\left.\mathrm{mg} / \mathrm{g}_{\text {Grasa }}\right)$ y con descensos importantes durante los meses de verano $\left(14,8 \mathrm{mg} / \mathrm{g}_{\text {Grasa }}\right)$.

Los valores de CLA que se han mencionado anteriormente son más altos que los encontrados en nuestro estudio con leche de oveja. No obstante, nos permiten constatar que, al igual que en nuestros resultados, los mayores niveles de CLA pueden encontrarse en primavera, época en la que se dispone de pastos frescos, ricos en ácido $\alpha$ linolénico. El contenido de este ácido graso disminuye progresivamente cuando el pasto madura, por lo que la ingesta de pastos maduros o la combinación de los mismos con dietas deficientes en ácido $\alpha$-linolénico trae como consecuencia un descenso en los niveles de TVA, intermediario generado durante la biohidrogenación en el rumen. Esto se traduce en una reducción del CLA sintetizado a partir de TVA en la glándula 
mamaria (Nudda et al., 2005). Otros trabajos destacan la posible asociación que existe entre la variación del contenido de CLA en leche y la relación $\alpha$-linolénico/linoleico en el pasto, ya que cuanto mayor sea dicha relación, mayor será el contenido de CLA en la leche (Dhiman et al., 2000; Mel'uchova et al., 2008). En cualquier caso, todos sugieren que el ácido $\alpha$-linolénico es el principal responsable del aumento de CLA en leche de ovejas alimentadas con pasto.

El tipo de pasto proporcionado al animal (especie vegetal, etapa fenológica) y la frecuencia de pastoreo son dos de las posibles causas a las que pueden atribuirse las diferencias importantes entre los contenidos de CLA de este trabajo con los encontrados en las distintas publicaciones.

\subsubsection{Contenido individual de los isómeros CLA y variación estacional}

A continuación, pasaremos a describir las variaciones estacionales que experimentan los diferentes isómeros CLA presentes en las muestras que hemos analizado. En la Tabla 4.2, los isómeros se han ordenado según el tiempo de retención observado en el cromatograma, sin embargo, en esta parte de la discusión trataremos primero los isómeros cis-trans/trans-cis para continuar después con los trans-trans. Dentro de los cis-trans/trans-cis, empezaremos con los dos isómeros mayoritarios: cis9,trans-11 y trans-7,cis-9.

\subsubsection{Isómeros cis-trans/trans-cis}

\section{cis-9,trans-11 $\mathrm{C}_{18: 2}$}

Como ya se dijo previamente, la mayor parte del CLA determinado en las muestras de leche corresponde al isómero cis-9,trans-11. Los niveles encontrados se mantuvieron entre 4,289 y 6,577 mg/g $\mathrm{g}_{\text {Grasa }}$ (Figura 4.3). Dicho isómero experimenta una variación estacional significativa durante la primavera $(\mathrm{P}<0,05$; Tabla 4.3), época en la que se registraron los mayores contenidos de cis-9,trans-11. Respecto a otras épocas estacionales, el aumento de este isómero en leche de primavera equivale a un 50\%.

Resultados similares a los obtenidos en las muestras que analizamos han sido publicados por diversos autores, que encontraron los siguientes niveles (en $\mathrm{mg} / \mathrm{g}_{\text {Grasa }}$ ) de cis-9,trans-11: 3,86 - 5,82 (Mele et al., 2006); 2,54 - 7,72 (Reynolds et al., 2006); 3,29 
- 4,33 (Tsiplakou et al., 2006b); 4,48 - 7,07 (Luna et al., 2005a y 2007); 5,77 - 6,62 (Partidario et al., 2008); 5,18 - 6,68 (Castro et al., 2009); 5,41 - 6,78 (Gómez-Cortés et al., 2009a). Otros autores han determinado mayores concentraciones de este isómero mayoritario, utilizando dietas específicas cuyo fin era aumentar el contenido de CLA: pasto fresco (Addis et al., 2005; Cabiddu et al., 2006a y 2006b; Biondi et al., 2008; Mel'uchova et al., 2008; Tsiplakou et al., 2010), suplementos de origen vegetal (Luna et al., 2005b y 2008b; Zhang et al., 2006a y 2006b; Gómez-Cortés et al., 2008a, 2009b y 2011; Hervás et al., 2008b; Addis et al., 2009; Bodas et al., 2010; Mele et al., 2011) o alimentos de origen marino (Toral et al., 2010a y 2010b). Este tipo de dietas son estrategias útiles para incrementar de forma importante los niveles de cis-9,trans-11, ya que pueden llegar a triplicar el contenido de este isómero en la leche, alcanzando valores máximos superiores a $\operatorname{los} 30 \mathrm{mg} / \mathrm{g}_{\text {Grasa }}$.

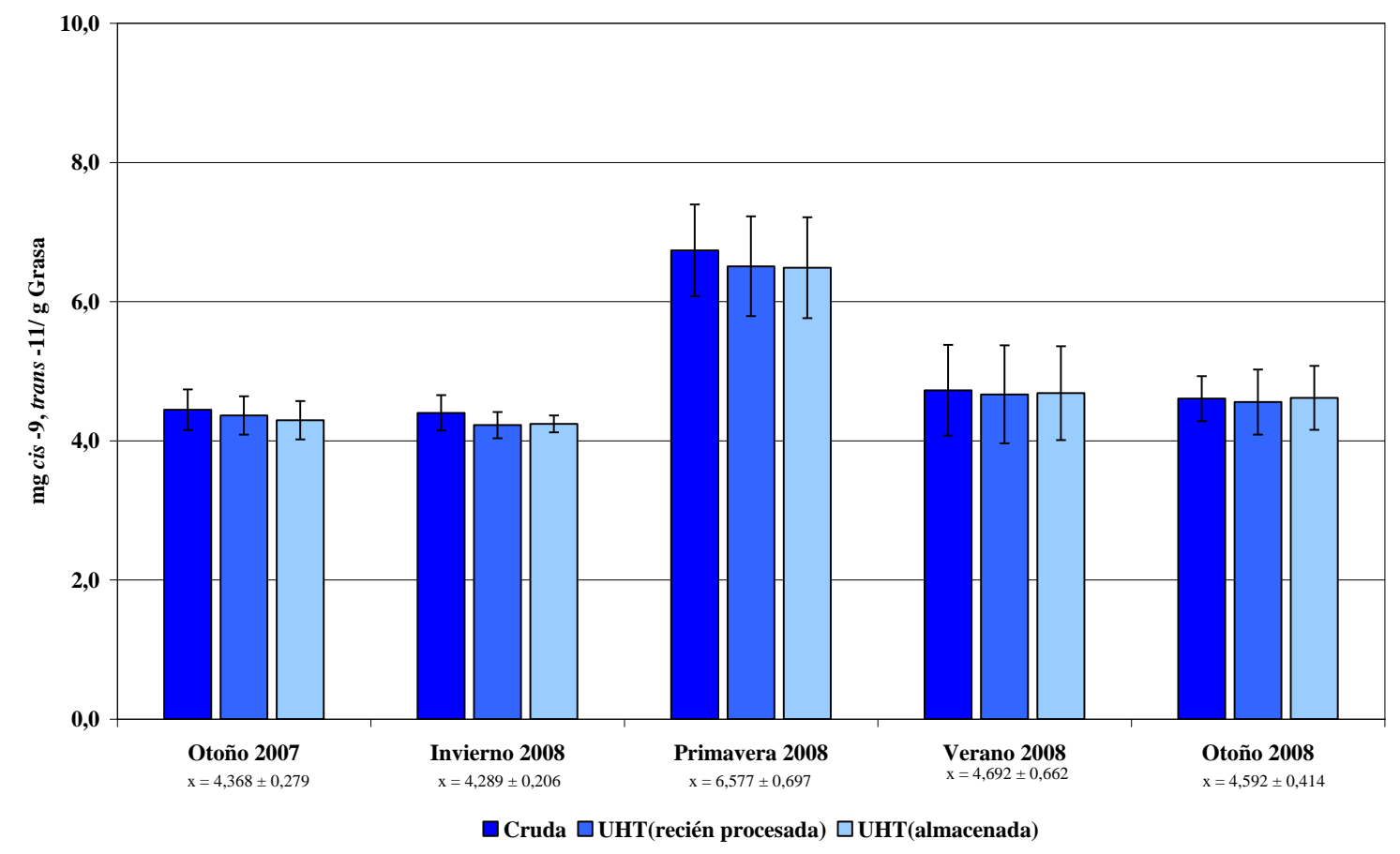

Figura 4.3. Variación del contenido de cis-9,trans-11 en las muestras de leche de oveja UHT.

También se detectaron diferencias significativas entre los contenidos de ácido ruménico correspondientes al invierno y verano. Esto se debe a que la primera muestra del verano, que se recibió en el mes de julio, tenía un contenido muy próximo a los que se encontraron en primavera, y es posible que la disponibilidad de pasto fresco se mantuviese durante este período. 


\section{trans-7,cis-9 $\mathrm{C}_{18: 2}$}

El contenido de trans-7,cis-9 en la leche se mantuvo entre 0,374 y 0,435 $\mathrm{mg} / \mathrm{g}_{\text {Grasa }}$, siendo el segundo isómero más abundante (Figura 4.4). Según nuestros resultados, el efecto estacional que experimenta este isómero es poco relevante, ya que los niveles encontrados en primavera apenas aumentan un $16 \%$, si se comparan con las muestras de otras épocas del año. Aunque las variaciones sean menores, existen diferencias significativas entre los contenidos medios determinados en primavera y el resto del año. También se encontraron diferencias entre el invierno y el verano, pero con menor significación (Tabla 4.3).

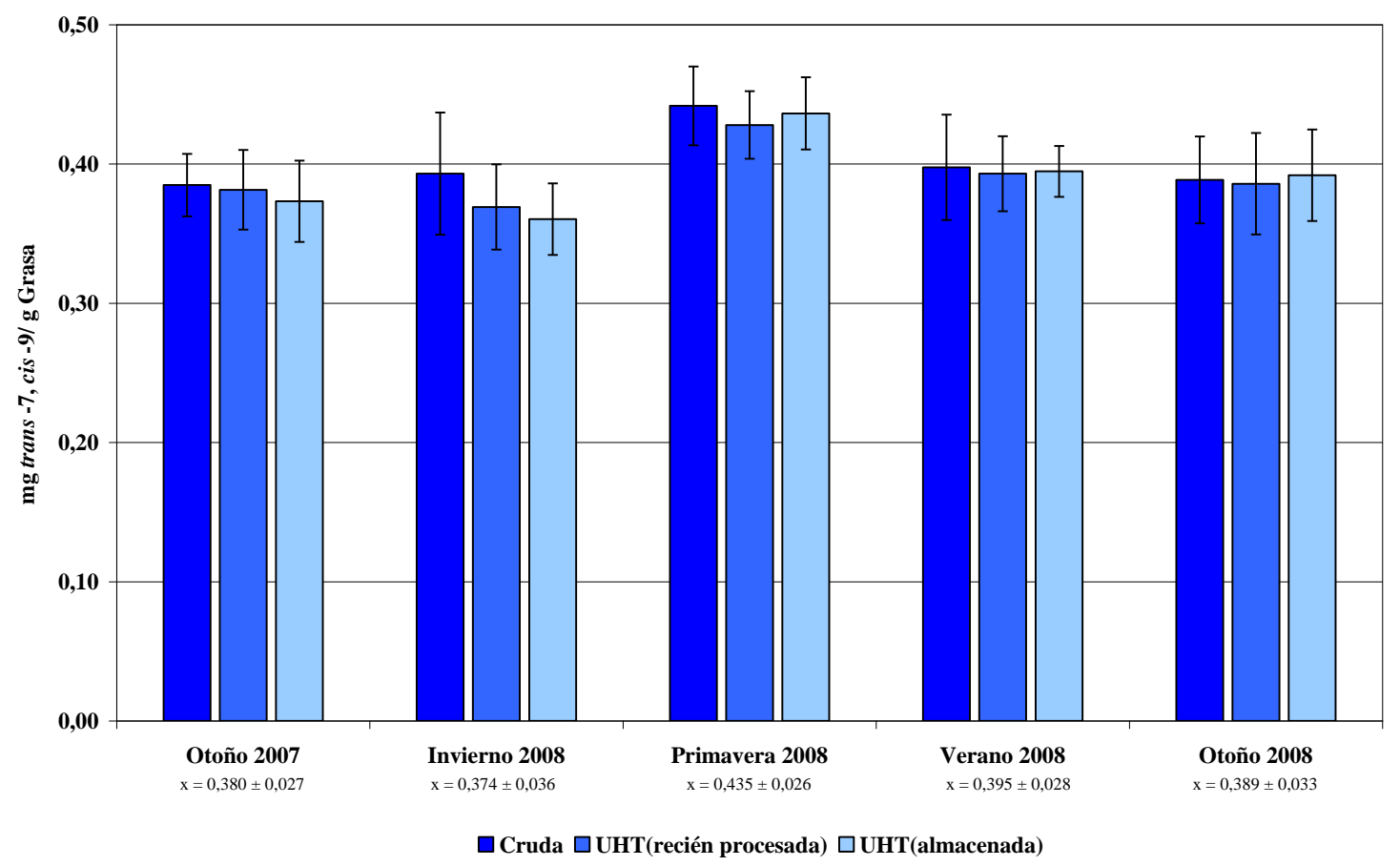

Figura 4.4. Variación del contenido de trans-7,cis-9 en las muestras de leche de oveja UHT.

Estos valores son muy parecidos a los encontrados por Luna et al. (2005a) en distintas razas de ovino (variaban entre 0,300 y 0,570), o incluso cercanos a los publicados por Abilleira et al. (2009) en dos épocas distintas del año (0,260 en invierno y 0,430 en primavera). Gómez-Cortés et al. (2009a y 2011) y Luna et al. (2007), también determinan la presencia de trans-7,cis-9 en leche de oveja, cuyos niveles se aproximan a los $0,460 \mathrm{mg} / \mathrm{g}_{\text {Grasa }}$. Ostrovsky et al. (2009) encuentran que los contenidos de este isómero en leche no sobrepasa los $0,380 \mathrm{mg} / \mathrm{g}_{\text {Grasa }}$. La suplementación con aceite de oliva puede producir un aumento significativo de trans-7,cis-9, ya que se llegan a 
alcanzar valores de hasta 1,90 mg/g $\mathrm{g}_{\text {Grasa }}$ (Gómez-Cortés et al., 2008b). En otros trabajos, se observaron aumentos importantes cuando se suministraron dietas ricas en aceite de girasol (Gómez-Cortés et al., 2011; Hervás et al., 2008b), semillas de lino (Mele et al., 2011) o ácidos grasos de origen marino (Toral et al., 2010a y 2010b).

\section{trans-8,cis-10 $\mathrm{C}_{18: 2}$}

Como se observa en la Figura 4.5, los niveles de trans-8,cis-10 encontrados en las distintas estaciones muestran una tendencia algo distinta a la de otros isómeros. A diferencia de los máximos valores primaverales que hemos recogido para el resto de los isómeros, las muestras de leche presentaban el mayor contenido de trans-8,cis-10 durante la época de verano $\left(0,097 \mathrm{mg} / \mathrm{g}_{\text {Grasa }}\right)$. Los niveles encontrados en primavera $\left(0,089 \mathrm{mg} / \mathrm{g}_{\text {Grasa }}\right)$, otoño $\left(0,068\right.$ y $\left.0,087 \mathrm{mg} / \mathrm{g}_{\text {Grasa }}\right)$ o invierno $\left(0,068 \mathrm{mg} / \mathrm{g}_{\text {Grasa }}\right)$ fueron relativamente menores. Se detectaron diferencias significativas para casi todas las épocas del año (Tabla 4.3).

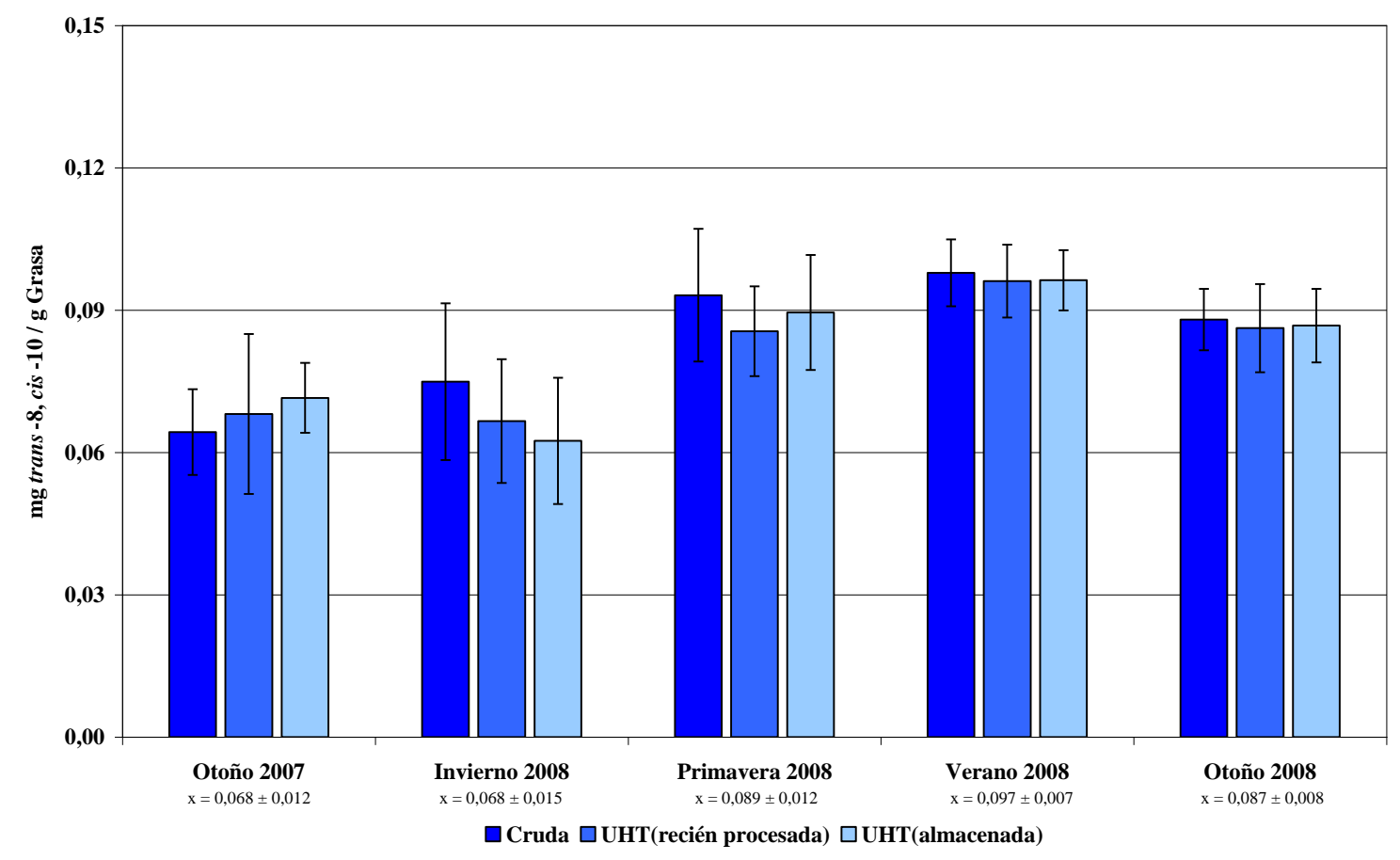

Figura 4.5. Variación del contenido de trans-8,cis-10 en las muestras de leche de oveja UHT.

En algunos trabajos se publican valores de trans-8,cis-10 que suelen ser más elevados que los encontrados en las muestras que hemos analizado. Sin embargo, es posible que estos altos contenidos se deban a que, con el mismo, coexistan pequeñas 
cantidades de otros isómeros, como el cis-9,trans-11 y sobre todo el trans-7,cis-9 (Martins et al., 2007; Mel'uchova et al., 2008; Partidario et al., 2008), ya que, como habíamos comentado antes (apartado 3.2.1), este isómero presenta una pobre resolución cromatográfica. Si comparamos nuestros resultados con los determinados por Luna et al. (2005a), los contenidos de trans-8,cis-10 son relativamente mayores que los encontrados en leche de ovejas de distintas razas (entre 0,010 y $0,040 \mathrm{mg} / \mathrm{g}_{\text {Grasa }}$ ). En las muestras de leche analizadas por Mele et al. (2006), también se observan niveles de trans-8,cis-10 bastante próximos a los nuestros $(0,060-0,120)$, aunque estas cantidades pueden llegar a aumentar considerablemente (entre 0,230 y $0,300 \mathrm{mg} / \mathrm{g}_{\text {Grasa }}$ ) cuando la dieta contiene suplementos vegetales, como el aceite de soja.

Luna et al. (2008b) determinan que una dieta suplementada con semillas de lino y aceite de girasol, duplica el contenido de este isómero en leche de oveja (de 0,090 hasta $0,190 \mathrm{mg} / \mathrm{g}_{\text {Grasa }}$ ). Valores bastante similares a los anteriores fueron obtenidos por Gómez-Cortés et al. (2009a) en muestras de leche de oveja alimentadas con pasto fresco $\left(0,070-0,130 \mathrm{mg} / \mathrm{g}_{\text {Grasa }}\right)$, mientras que los resultados publicados por Ostrovsky et al. (2009) muestran contenidos de trans-8,cis-10 (de 0,070 hasta $0,200 \mathrm{mg} / \mathrm{g}_{\text {Grasa }}$ ), en el que las cantidades más altas se encontraron en leche de ovejas alimentadas con pasto veraniego, es decir, en la misma época en la que determinamos el máximo contenido de dicho isómero.

\section{trans-10,cis-12 $\mathrm{C}_{18: 2}$}

Los contenidos de trans-10,cis-12 en las muestras de leche de oveja oscilaron entre 0,043 y $0,061 \mathrm{mg} / \mathrm{g}_{\text {Grasa }}$ (Figura 4.6). Este isómero tiene una variación estacional significativa respecto a la primavera (ver Tabla 4.3), pero al tratarse de cantidades muy bajas, no tendría importancia desde el punto de vista práctico.

Estos resultados estarían en la línea de los publicados por Nudda et al. (2005), Ovstrovsky et al. (2009) y Gómez-Cortés et al. (2009a), en los que el pasto que se suministró a los animales no supuso cambios en el contenido de trans-10,cis-12, cuyos niveles en la leche no superaron los $0,050 \mathrm{mg} / \mathrm{g}_{\text {Grasa }}$. Estos valores contrastan con las concentraciones de este isómero, determinadas por Cabiddu et al. (2009) en leche de ovejas alimentadas con Hedysarum coronarium L., y que oscilaron entre 0,95 y 1,24 $\mathrm{mg} / \mathrm{g}_{\text {Grasa }}$. 
Los contenidos determinados en nuestro estudio son ligeramente superiores a los encontrados por Luna et al. (2005a, 2007) y Abilleira et al. (2009), cuyos niveles de trans-10,cis-12 se mantuvieron entre 0,020 y $0,040 \mathrm{mg} / \mathrm{g}_{\text {Grasa. }}$. En cambio, los valores encontrados por Partidario et al. (2008), se asemejan a los detectados en las muestras que hemos analizado $\left(0,030-0,070 \mathrm{mg} / \mathrm{g}_{\text {Grasa }}\right)$. Martins et al. (2007) también determinan concentraciones de este isómero en leche de vaca, cuyos contenidos permanecieron por debajo de $0,050 \mathrm{mg} / \mathrm{g}_{\text {Grasa }}$.

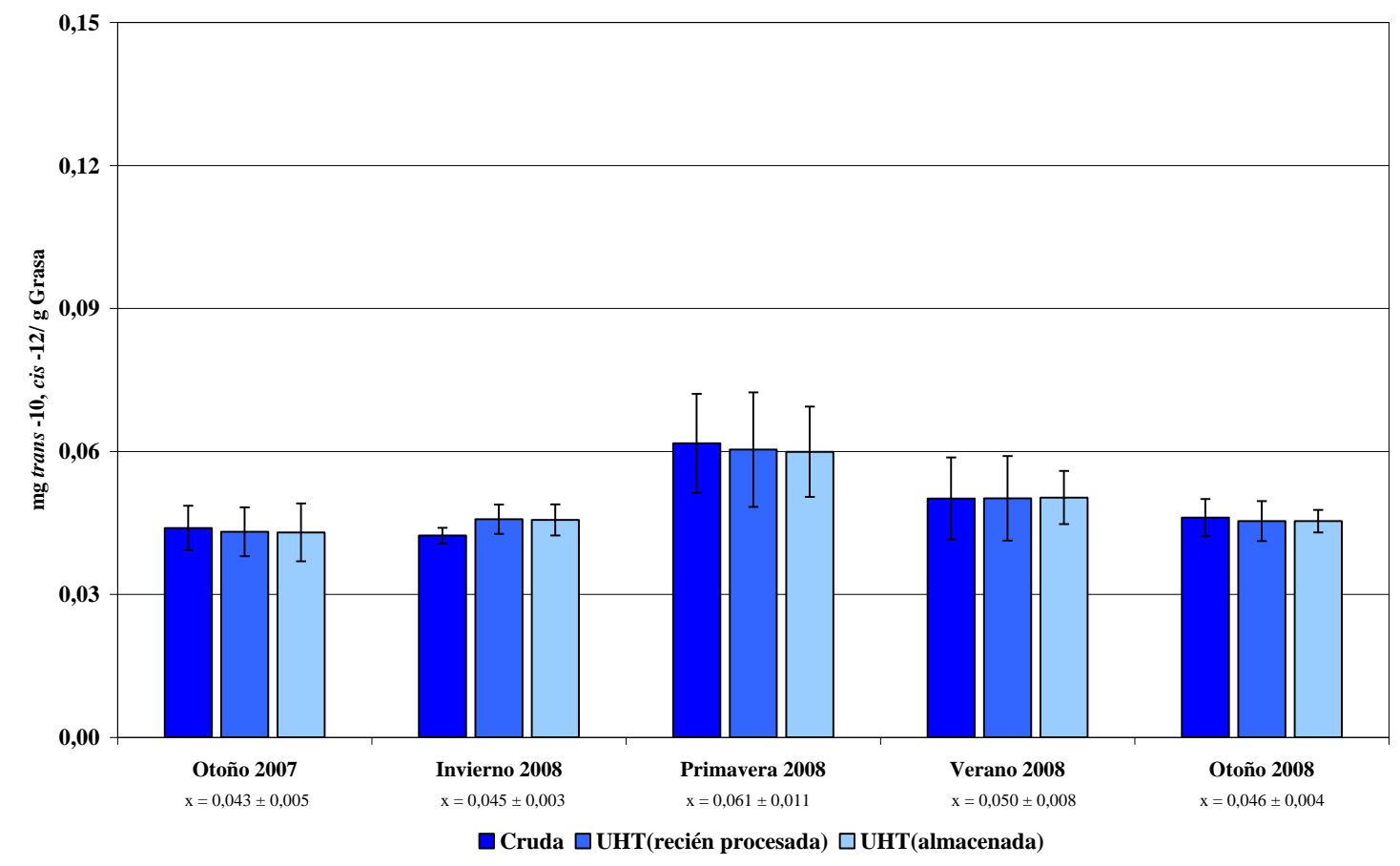

Figura 4.6. Variación del contenido de trans-10,cis-12 en las muestras de leche de oveja UHT.

La suplementación con ciertos aceites vegetales no parece incrementar de manera importante los niveles de este isómero en leche, ya que según algunos estudios, la concentración de trans-10,cis-12 se mantiene entre 0,010 y $0,110 \mathrm{mg} / \mathrm{g}_{\text {Grasa }}$ (Mele et al., 2006; Gómez-Cortés et al., 2008a y 2008b; Luna et al., 2008b; Bodas et al., 2010). Se encontraron contenidos similares $\left(0,090 \mathrm{mg} / \mathrm{g}_{\text {Grasa }}\right)$ en leche de ovejas que fueron alimentadas con semillas de lino extrusionadas (Gómez-Cortés et al., 2009b). Sin embargo, se han observado cantidades relativamente altas de trans-10,cis-12 cuando la dieta se enriquece con distintos porcentajes de aceite de girasol, cuyas concentraciones varían desde 0,050 hasta 0,670 mg/g $\mathrm{g}_{\text {Grasa }}$ (Hervás et al., 2008b; Gómez-Cortés et al., 2011). El empleo de suplementos de origen marino tampoco supone cambios 
importantes en los niveles de este isómero en la leche ovina (Toral et al., 2010a y 2010b).

Si tenemos en cuenta el mecanismo de formación que se muestra en la Figura 1.4 (ver apartado 1.2.2.3), el trans-10,cis-12 sólo podría formarse en el rumen y a partir del ácido linoleico (no del ácido $\alpha$-linolénico), descartándose así la formación endógena del mismo a partir de trans-10 $\mathrm{C}_{18: 1}$. Se cree que el incremento en leche de este isómero está relacionado con el empleo de dietas básicas con un bajo porcentaje de forrajes, ya que en el rumen, dichas dietas podrían provocar cambios en las rutas de biohidrogenación e inhibir la síntesis de la grasa de leche en la glándula mamaria (Gómez-Cortés et al., 2008b y 2009a; Bodas et al., 2010).

\section{trans-11,cis-13 $\mathrm{C}_{18: 2}$}

El trans-11,cis-13 es uno de los isómeros que experimenta mayor variación estacional (Figura 4.7 y Tabla 4.3). Su contenido en leche primaveral fue hasta cuatro veces superior respecto al que se encontró en otras épocas del año $(0,058-0,228$ $\left.\mathrm{mg} / \mathrm{g}_{\text {Grasa }}\right)$. Dicho aumento se relaciona con los niveles de ácido $\alpha$-linolénico presente en el pasto (Addis et al., 2009; Gómez-Cortés et al., 2009a).

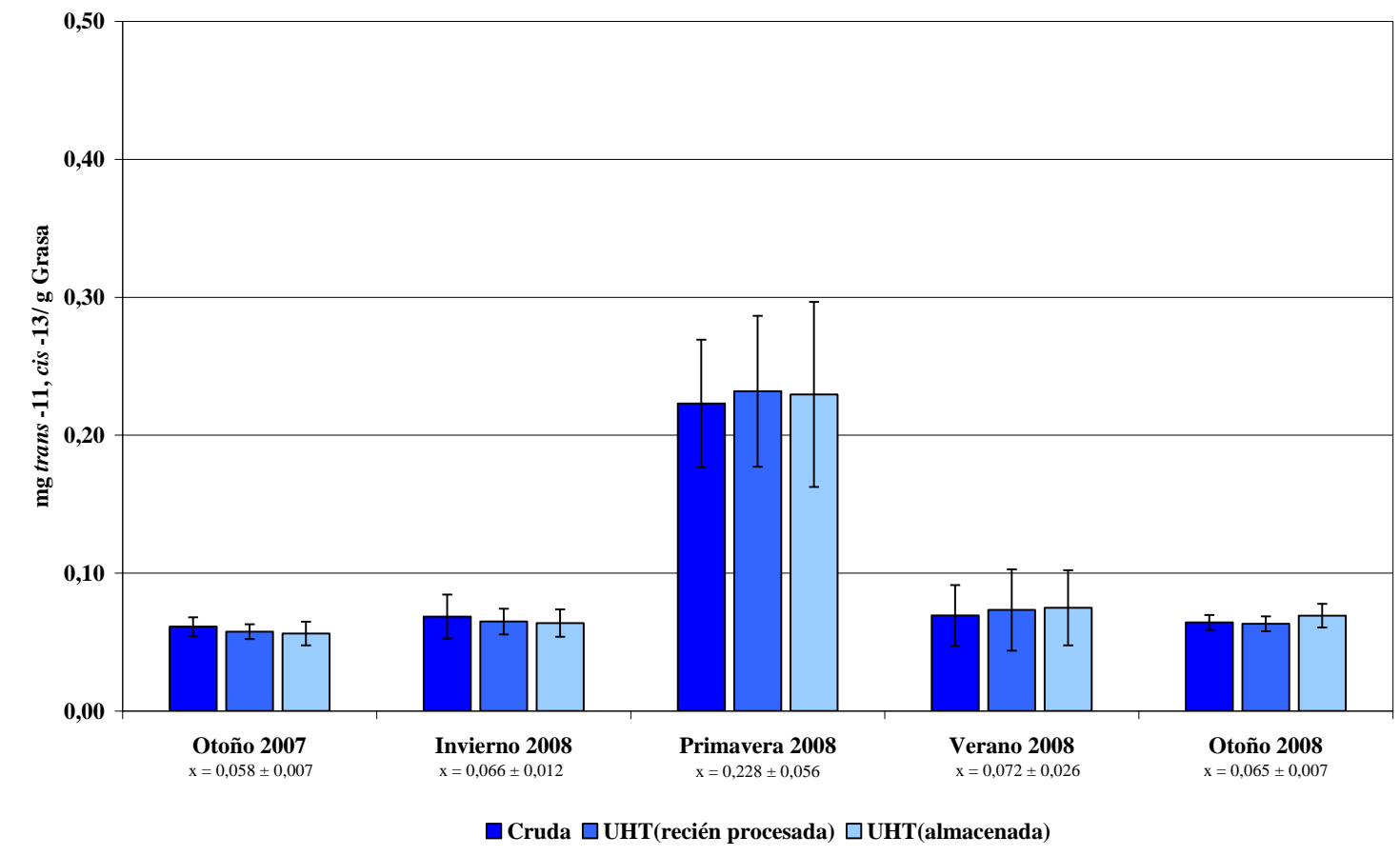

Figura 4.7. Variación del contenido de trans-11,cis-13 en las muestras de leche de oveja UHT. 
Las muestras de leche de oveja analizadas por Luna et al. (2005a) contienen cantidades de trans-11,cis-13 similares a los que hemos obtenido, cuyos valores oscilaron entre 0,060 y $0,390 \mathrm{mg} / \mathrm{g}_{\text {Grasa. }}$ Ovstrovsky et al. (2009) también determinaron concentraciones cercanas a estas $\left(0,020-0,380 \mathrm{mg} / \mathrm{g}_{\text {Grasa }}\right)$, cuando las ovejas se alimentaron con pasto. Abilleira et al. (2009) encontraron que los niveles de trans$11, c i s-13$ en quesos Idiazábal invernales $\left(0,090 \quad \mathrm{mg} / \mathrm{g}_{\text {Grasa }}\right)$ aumentaban significativamente cuando su leche de partida se obtenía en primavera $\left(0,320 \mathrm{mg} / \mathrm{g}_{\text {Grasa }}\right)$. Mele et al. (2006) cuantifican este mismo isómero en leche de ovejas alimentadas con suplementos de aceite de soja $\left(0,120-0,280 \mathrm{mg} / \mathrm{g}_{\text {Grasa }}\right)$. Las concentraciones de trans11,cis-13 que se encontraron en la leche de partida de determinados tipos de quesos ovinos (Luna et al., 2007; Partidario et al., 2008) se mantuvieron en un intervalo similar $\left(0,120-0,350 \mathrm{mg} / \mathrm{g}_{\text {Grasa }}\right)$.

Sin embargo, en otros trabajos se recogen valores más altos para este isómero. El suministro de determinadas especies botánicas, como la Lolium multiflorium Lam. o la Hedysarum coronarium L., pueden incrementar el trans-11,cis-13 en leche hasta llegar a alcanzar niveles superiores a los $1,10 \mathrm{mg} / \mathrm{g}_{\text {Grasa }}$ (Addis et al., 2009; Cabiddu et al., 2009). Además, en algunas ocasiones, el trans-11,cis-13 ha llegado a ser el segundo isómero más abundante, según los resultados publicados por Gómez-Cortés et al. (2009a) y por Ostrovsky et al. (2009) en leche de ovejas alimentadas con determinados tipos de pasto.

Los aceites y semillas de lino, con altas cantidades de ácido $\alpha$-linolénico, también suponen incrementos importantes cuando se combinan con dietas básicas, alcanzándose en la leche de oveja niveles de trans-11,cis-13 de hasta 2,00mg/g $\mathrm{g}_{\text {Grasa }}$ (Gómez-Cortés et al., 2009b; Bodas et al., 2010). El complementar las dietas con otros tipos de aceites vegetales (como soja, girasol u oliva) no se tradujo en aumentos relevantes de este isómero en leche (Gómez-Cortés et al., 2008a, 2008b y 2011; Hervás et al., 2008b; Luna et al., 2008b). Tampoco se observaron cambios en las concentraciones de trans-11,cis-13 cuando la dieta se modificó añadiendo suplementos de origen marino (Toral et al., 2010a y 2010b).

El incremento en leche de este isómero se ha relacionado, como habíamos comentado antes, con la presencia de altas concentraciones de ácido $\alpha$-linolénico en la 
dieta de los animales. El mecanismo de formación del trans-11,cis-13 sugiere que proviene de la isomerización del trans-11,cis-15 $\mathrm{C}_{18: 2}$, siguiendo una ruta metabólica aún desconocida (ver Figura 1.3, apartado 1.2.2). Se cree que el ácido $\alpha$-linolénico sufre una isomerización inicial en el rumen, transfiriendo el doble enlace del carbono 12 al carbono 11, formándose así un trieno (cis-9,trans-11,cis-15 $\mathrm{C}_{18: 3}$ ). Uno de los dobles enlaces "cis" de dicho trieno se reduce para formar el trans-11,cis-15 $\mathrm{C}_{18: 2}$, intermediario que se necesita para formar el ácido vacénico (trans-11 $\mathrm{C}_{18: 1}$ ). Algunas referencias señalan la posibilidad de que, a través de este mecanismo, se formen otros isómeros CLA como el trans-11,trans-13, trans-12,trans-14, 12,14-(cis-trans/trans-cis) y cis-9,trans-11 (Kraft et al., 2003; Luna et al., 2005b; Gómez-Cortés et al., 2009a).

\section{2,14-C $\mathrm{C}_{18: 2}$ (cis-trans/trans-cis)}

En las muestras de leche de oveja que hemos analizado, el contenido de 12,14-

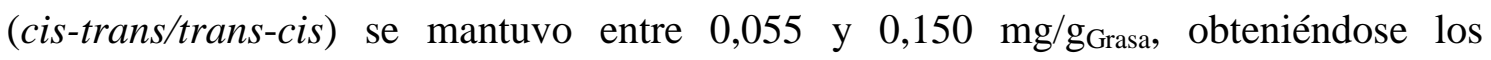
mayores niveles en la primavera, época en la que se duplica su contenido (Figura 4.8). Las cantidades encontradas en primavera se diferencian significativamente de las correspondientes al resto del año (Tabla 4.3).

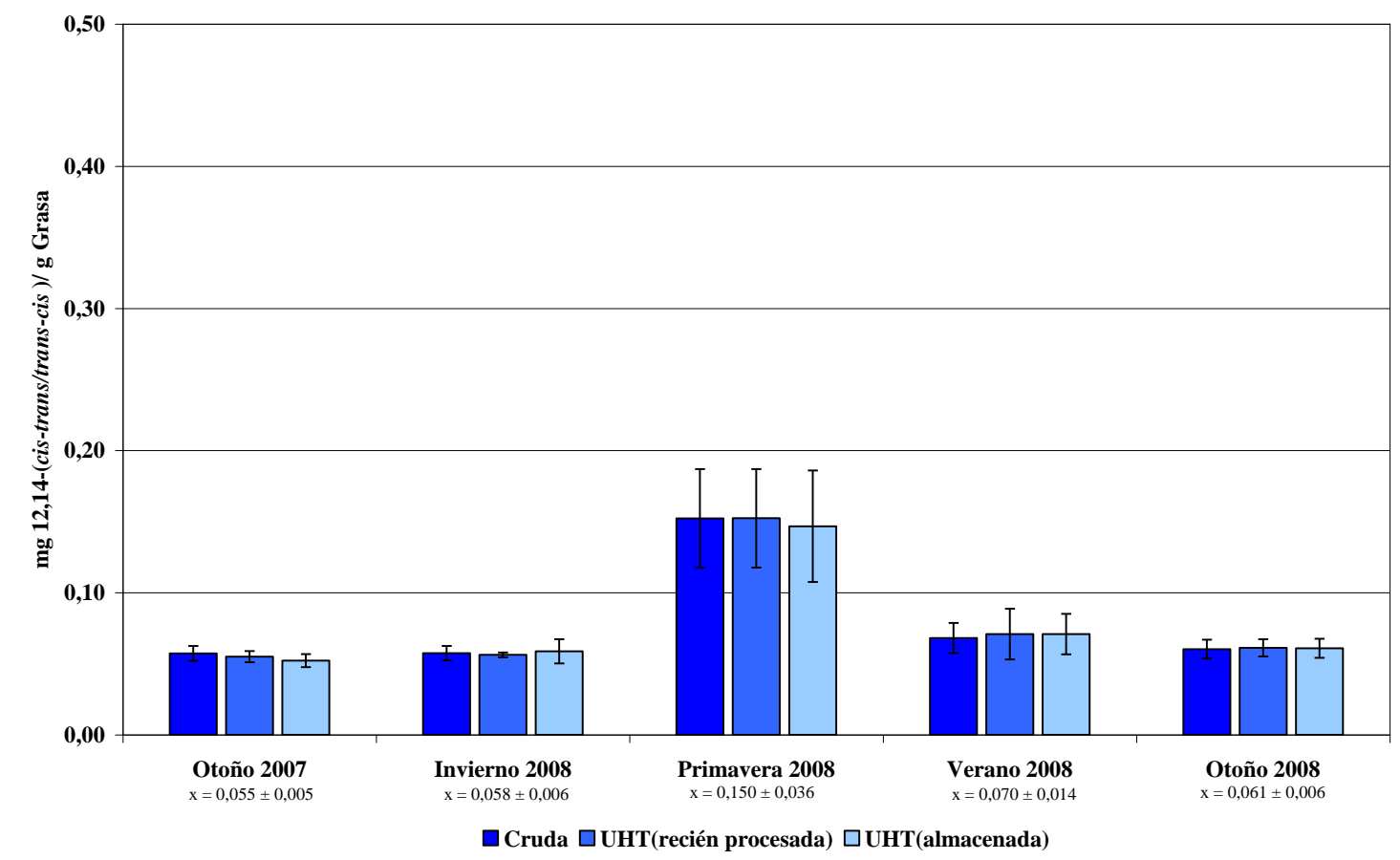

Figura 4.8. Variación del contenido de 12,14- (cis-trans/trans-cis) en las muestras de leche de oveja UHT. 
En cualquier caso, podríamos decir que los niveles encontrados en la leche analizada son bastante semejantes a los que determinaron algunos autores en muestras de leche de oveja, con intervalos de concentración (expresados en $\mathrm{mg} / \mathrm{g}_{\text {Grasa }}$ ) bastante similares entre sí: 0,030-0,170 (Luna et al., 2005a); 0,060-0,120 (Partidario et al., 2008) y 0,030 - 0,130 (Gómez-Cortés et al., 2009a). En el resto de los trabajos encontrados, el contenido de 12,14-(cis-trans/trans-cis) apenas alcanzan los 0,070 mg/g $\mathrm{g}_{\text {Grasa }}$ (Mele et al., 2006; Luna et al., 2007 y 2008b; Gómez-Cortés et al., 2008a, 2008b y 2011; Hervás et al., 2008b).

Al igual que sucede con el trans-11,cis-13, este isómero aumenta su contenido en leche debido a la presencia en la dieta de altas cantidades de ácido $\alpha$-linolénico, y aunque no se ha establecido con seguridad el mecanismo de formación, se cree que se generaría por la misma ruta propuesta para el trans-11,cis-13.

\subsubsection{Isómeros trans-trans}

\section{trans-12,trans-14 $\mathrm{C}_{18: 2}$}

El contenido de trans-12,trans-14 en las muestras de leche de oveja que hemos analizado se mantuvo entre 0,121 y $0,218 \mathrm{mg} / \mathrm{g}_{\text {Grasa }}$ (Figura 4.9); registrándose los valores más elevados durante la primavera, que difieren significativamente del resto (Tabla 4.3). Estas concentraciones fueron ligeramente superiores a las que se encontró para su correspondiente isómero geométrico 12,14-(cis-trans/trans-cis) (Figura 4.8).

Estos resultados se corresponden con los que se han publicado para el trans12,trans-14, en los que se muestran contenidos, expresados en $\mathrm{mg} / \mathrm{g}_{\text {Grasa }}$, con un intervalo de variación bastante parecido: 0,070 a 0,320 (Luna et al., 2005a y 2007); 0,150 a 0,220 (Partidario et al., 2008); 0,090 a 0,200 (Abilleira et al., 2009); 0,090 a 0,230 (Gómez-Cortés et al., 2009b); 0,090 a 0,190 (Bodas et al., 2010). En otros trabajos se determinan valores de trans-12,trans-14 ligeramente menores: 0,010 a 0,180 (Gómez-Cortés et al., 2009a); 0,020 a 0,111 (Ostrovsky et al., 2009).

Las dietas enriquecidas con aceite de girasol (Hervás et al., 2008b; GómezCortés et al., 2011), aceite de soja (Gómez-Cortés et al., 2008a), aceite de oliva (Gómez-Cortés et al., 2008b) o algas marinas (Toral et al., 2010b) no parecen influir en 
el contenido de este isómero en leche, ya que las concentraciones de trans-12,trans-14 que se han encontrado no sobrepasaron los $0,100 \mathrm{mg} / \mathrm{g}_{\text {Grasa }}$.

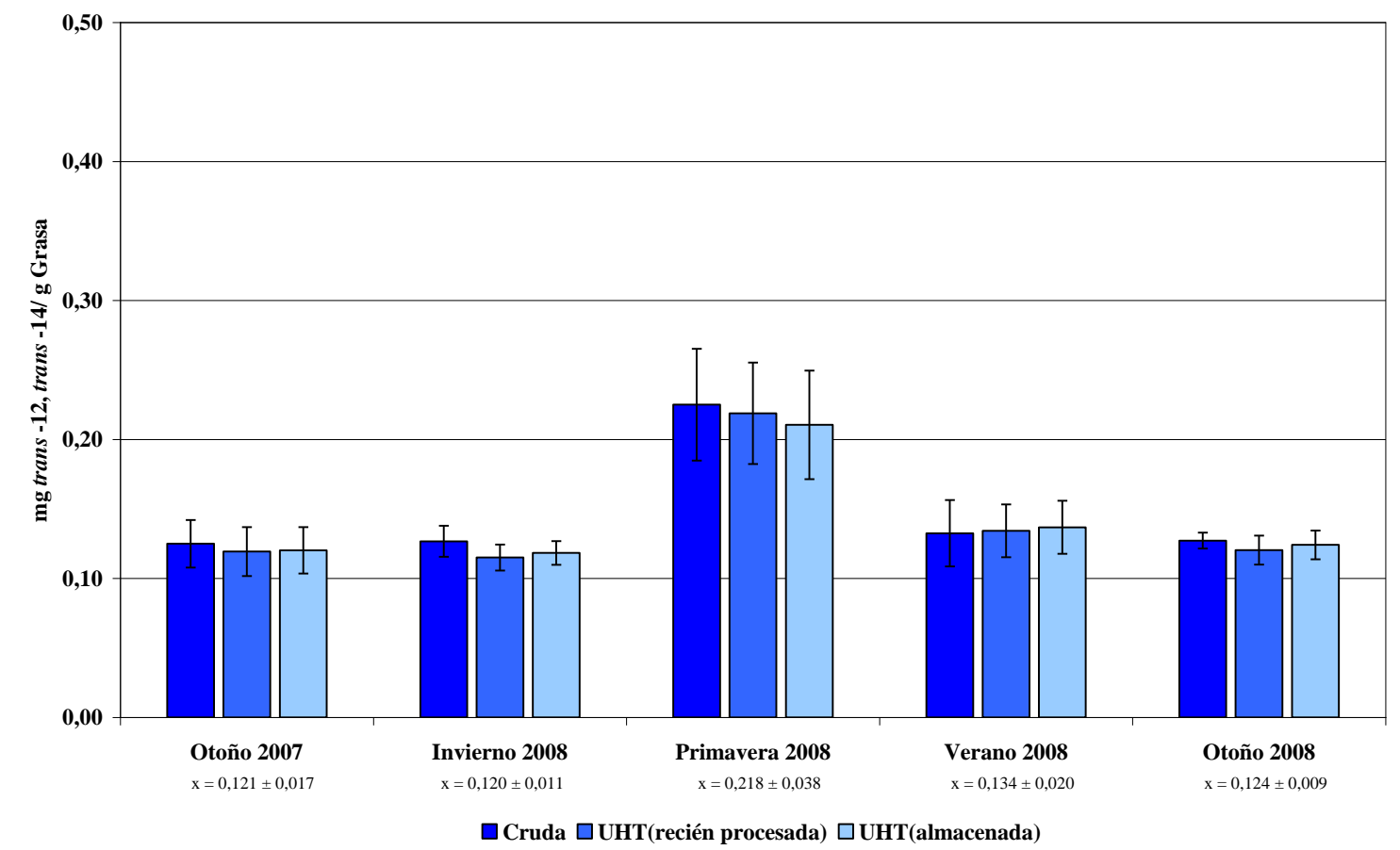

Figura 4.9. Variación del contenido de trans-12,trans-14 en las muestras de leche de oveja UHT.

Las dietas ricas en ácido $\alpha$-linolénico son las que incrementan de manera importante el contenido de este isómero. Según los datos publicados por Bodas et al. (2010), el uso de aceite de lino en la dieta de las ovejas supuso un aumento considerable del contenido de trans-12,trans-14 en leche de oveja $\left(0,090-0,660 \mathrm{mg} / \mathrm{g}_{\text {Grasa }}\right)$. La alimentación con determinados pastos, como Hedysarum coronarium L., también elevó el contenido de este isómero en leche (entre 0,380 y 0,570 mg/Grasa) (Cabiddu et al., 2009). Al igual que el 12,14-(cis-trans/trans-cis), es posible que el mecanismo de formación de este isómero esté bastante relacionado con el mencionado previamente para el trans-11,cis-13.

\section{trans-11,trans-13 $\mathrm{C}_{18: 2}$}

Según nuestros resultados, este isómero sufre una variación estacional significativa durante la primavera $(\mathrm{P}<0,01$, Tabla 4.3). Es en este período donde llega a ser el tercer isómero más abundante en las muestras analizadas, triplicándose su contenido respecto al de otras épocas estacionales (Figura 4.10). Los valores que hemos 


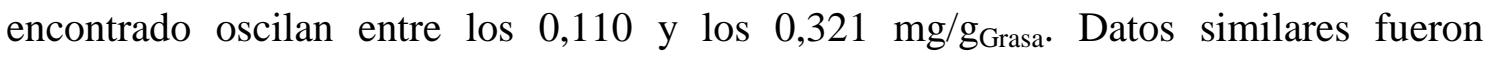
determinados en diferentes estudios llevados a cabo previamente: 0,090 - 0,470 (Luna et al., 2005a); 0,130 - 0,270 (Mele et al., 2006); 0,100 - 0,350 (Abilleira et al., 2009); 0,060 - 0,140 (Ovstrovsky et al., 2009).

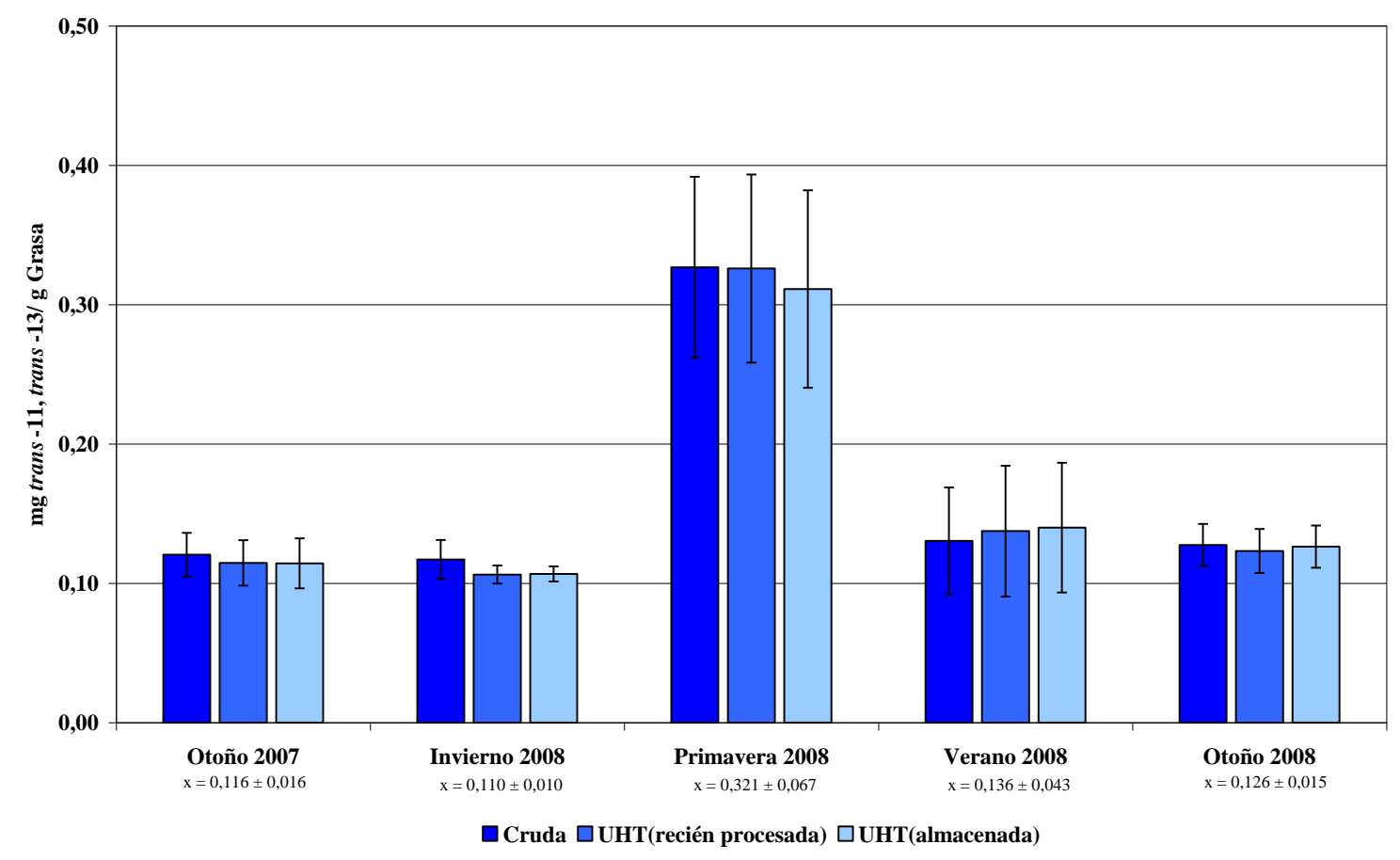

Figura 4.10. Variación del contenido de trans-11,trans-13 en las muestras de leche de oveja UHT.

El marcado efecto estacional que hemos observado para el trans-11,trans-13 concuerda con muchos de los resultados publicados respecto a dicho isómero. Abilleira et al. (2009) determinaron aumentos de hasta 3 veces en el contenido de este isómero en quesos Idiazábal fabricados con leche de primavera e invierno. Gómez-Cortés et al. (2009a) determinan que los niveles de trans-11,trans-13, en la leche de ovejas alimentadas con pasto fresco, fueron diez veces más altos $\left(0,600 \mathrm{mg} / \mathrm{g}_{\text {Grasa }}\right)$ que $\mathrm{los}$ encontrados en muestras obtenidas de ovejas alimentadas con dietas básicas $(0,060$ $\left.\mathrm{mg} / \mathrm{g}_{\text {Grasa }}\right)$. Algunas especies botánicas pueden llegar a incrementar el contenido de trans-11,trans-13 hasta niveles superiores a los $1,5 \mathrm{mg} / \mathrm{g}_{\text {Grasa }}$ (Cabiddu et al., 2009).

También se han encontrado niveles relativamente altos en leche de oveja $(0,470$ - 0,750), cuando su dieta ha sido suplementada con aceite o semilla de lino (GómezCortés et al., 2009b; Bodas et al., 2010). Otros suplementos vegetales, como los aceites de girasol, oliva o soja, no incrementan este isómero en leche de ovejas suplementadas 
con dichos aceites (Gómez-Cortés et al., 2008a, 2008b y 2011; Hervás et al., 2008b). Los suplementos marinos parecen tener un efecto reductor en los niveles de trans11,trans-13 encontrados en leche de oveja alimentadas con aceites de pescado o algas marinas (Toral et al., 2010a y 2010b).

\section{trans-10,trans-12 $\mathrm{C}_{18: 2}$}

Respecto al trans-10,trans-12, no se observan variaciones estacionales $(\mathrm{P}>0,05$, Tabla 4.3); los niveles de este isómero en la leche se mantuvieron durante todo el período de estudio entre 0,063 y $0,071 \mathrm{mg} / \mathrm{g}_{\text {Grasa }}$ (Figura 4.11 ). Estos datos son ligeramente superiores a los que hemos determinado para su homólogo geométrico, el trans-10,cis-12 (ver Figura 4.6).

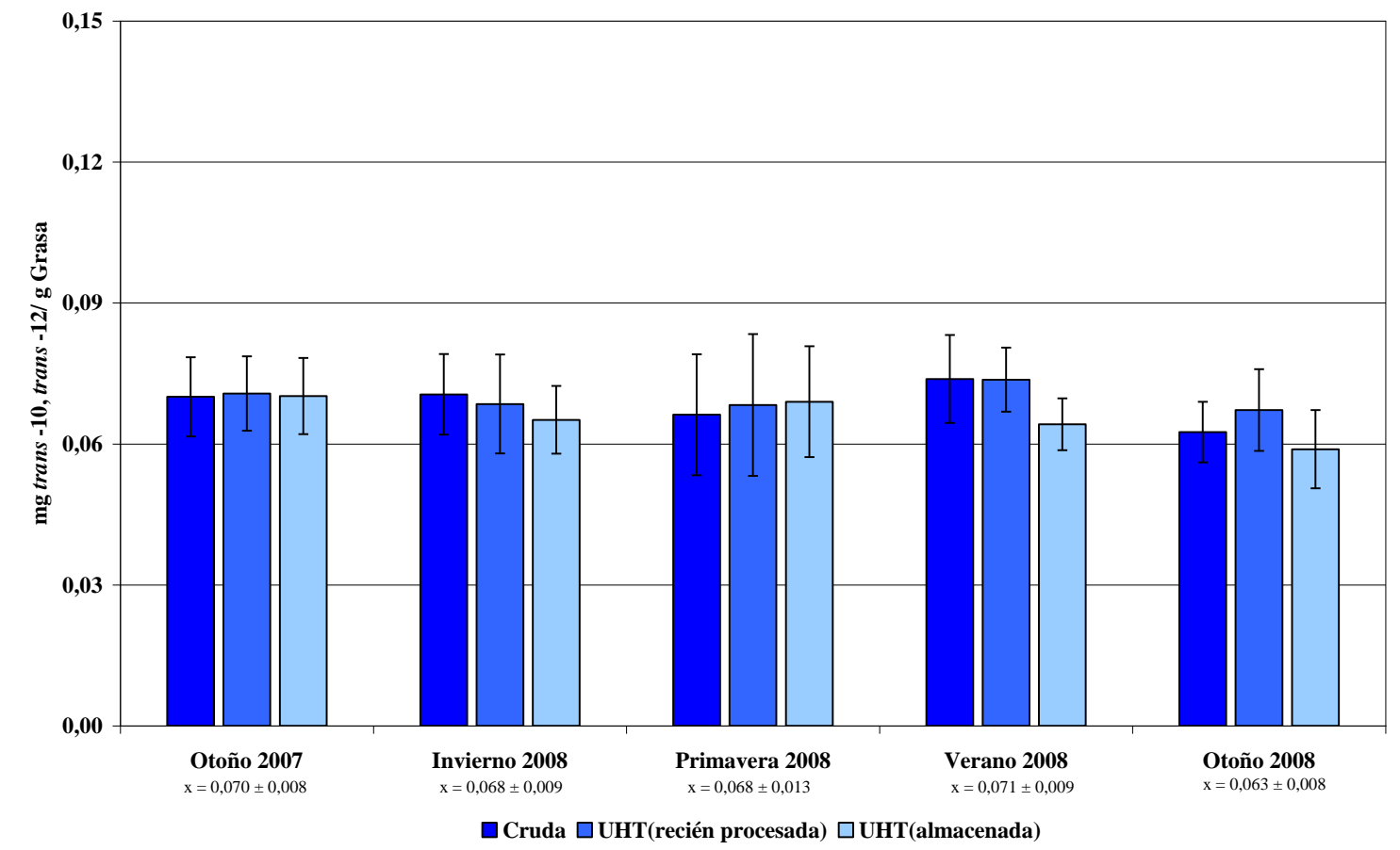

Figura 4.11. Variación del contenido de trans-10,trans-12 en las muestras de leche de oveja UHT.

Luna et al. (2005a), en leche de ovejas de distintas razas, encuentran valores de trans-10,trans-12 ligeramente más altos (entre 0,100 y $0,130 \mathrm{mg} / \mathrm{g}_{\text {Grasa }}$ ). En muestras de leche utilizadas para elaborar queso manchego, se determinaron contenidos de trans10,trans-12 que no sobrepasaron los 0,070 mg/g $\mathrm{g}_{\text {Grasa }}$ (Luna et al., 2007), mientras que en la leche de partida que se empleó para elaborar quesos portugueses, las cantidades de trans-10,trans-12 se mantuvieron entre 0,070 y 0,140 mg/g $\mathrm{g}_{\text {Grasa }}$ (Partidario et al., 2008). 
Contenidos de trans-10,trans-12 más bajos de los que hemos determinado $(<0,040$ $\mathrm{mg} / \mathrm{g}_{\text {Grasa }}$ ) han sido recogidos por algunos investigadores en leche de ovejas alimentadas con pasto fresco (Abilleira et al., 2009; Gómez-Cortés et al., 2009a) o determinados suplementos de origen vegetal (Luna et al., 2008b; Gómez-Cortés et al., 2008b)

Se han registrado aumentos importantes de este isómero en leche cuando se empleó, junto con la dieta básica suministrada a los animales, aceite de girasol (0,030 0,190 mg/g $\mathrm{g}_{\text {Grasa }}$; Hervás et al., 2008b; Gómez-Cortés et al., 2011) o aceite de soja (0,050 - 0,220; Mele et al., 2006; Gómez-Cortés et al., 2008a).

\section{trans-9,trans-11 $\mathrm{C}_{18: 2}$}

El trans-9,trans-11 fue el isómero trans-trans más importante desde el punto de vista cuantitativo, excepto en la primavera, época en la que el trans-11,trans-13 registró un mayor contenido. La variación estacional de este isómero en las muestras analizadas (Figura 4.12) fue similar a la que se observó para el cis-9,trans-11 (Figura 4.3), encontrándose diferencias significativas entre las mismas épocas estacionales, aunque se encontró una diferencia adicional entre el verano y el otoño 2007 (Tabla 4.3).

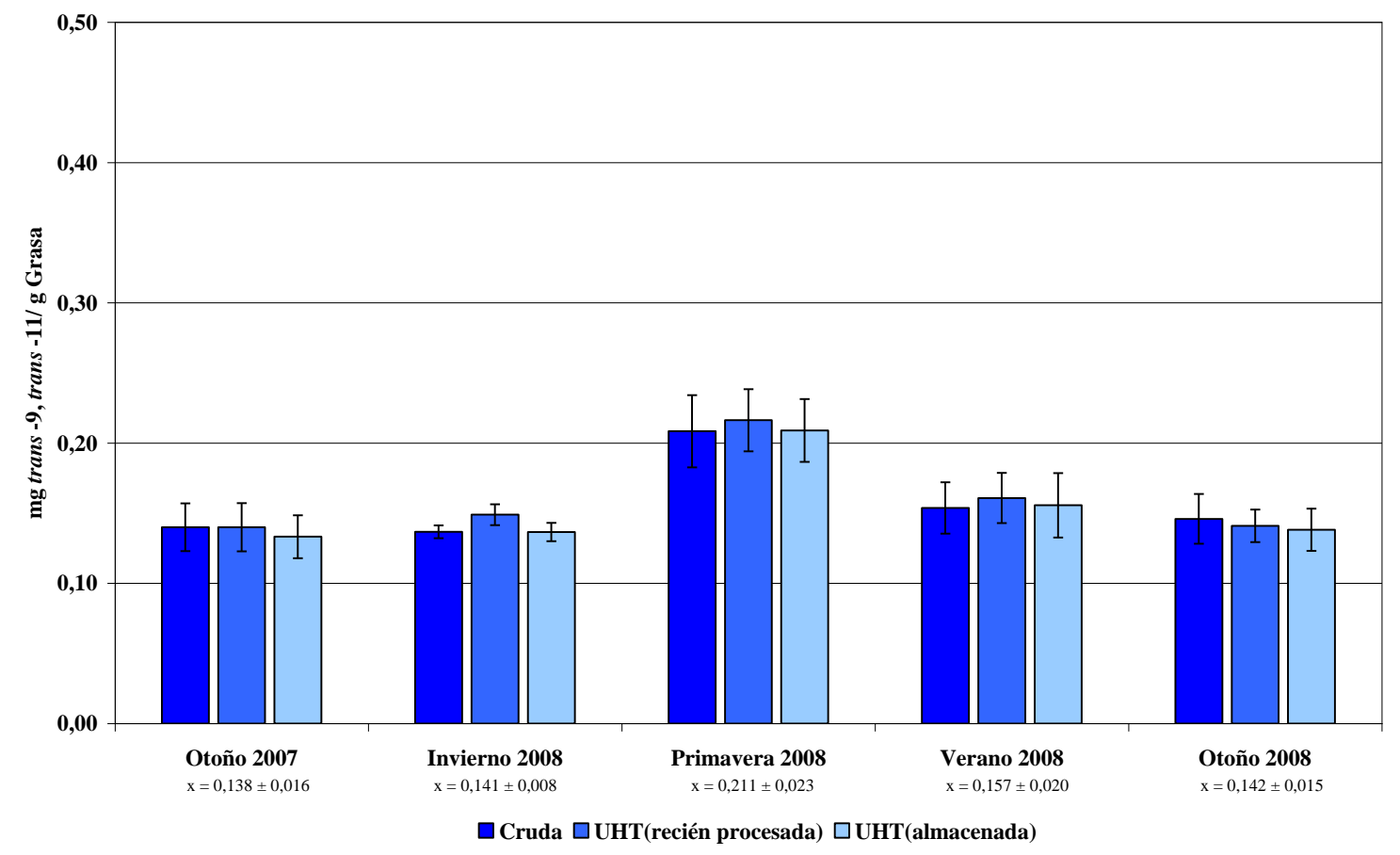

Figura 4.12. Variación del contenido de trans-9,trans-11 en las muestras de leche de oveja UHT. 
Los valores determinados para este isómero varían entre 0,138 y $0,211 \mathrm{mg} / \mathrm{g}_{\text {Grasa }}$ (Figura 4.12) y se aproximan a los encontrados en algunos de los trabajos publicados previamente. Por ejemplo, Cabiddu et al. (2009) observaron que el contenido de trans9,trans-11 en leche de ovejas alimentadas con pasto fresco (Hedysarum coronarium), varía entre 0,190 - 0,290. Los niveles de trans-9,trans-11 encontrados por Luna et al. (2005a) son ligeramente más bajos $\left(0,060-0,180 \mathrm{mg} / \mathrm{g}_{\text {Grasa }}\right)$. Otros valores encontrados en leche de ovejas alimentadas con pasto fueron los siguientes: 0,130-0,210 (Abilleira et al., 2009) y 0,120 - 0,240 (Gómez-Cortés et al., 2009a). Los contenidos de este isómero determinados en la leche de partida de ciertos quesos mostraron los siguientes intervalos $\left(\mathrm{mg} / \mathrm{g}_{\text {Grasa }}\right): 0,080-0,100$ (Luna et al., 2007) y 0,050 - 0,130 (Partidario et al., 2008).

En cuanto a la influencia de suministrar determinados suplementos grasos sobre el contenido de trans-9,trans-11, se ha observado que, al igual que sucede con el cis9,trans-11, las dietas que contienen aceite de girasol (Hervás et al., 2008b; GómezCortés et al., 2011) o aceite de soja (Mele et al., 2006; Gómez-Cortés et al., 2008a) pueden incrementar los niveles de trans-9,trans-11 en leche hasta triplicar el contenido, respecto a la leche de ovejas alimentadas con dietas básicas.

\section{trans-8,trans-10 $\mathrm{C}_{18: 2}$}

En las muestras de leche de oveja UHT analizadas, hemos determinado que los contenidos de trans-8,trans-10 se mantuvieron entre 0,053 y $0,062 \mathrm{mg} / \mathrm{g}_{\text {Grasa }}$ (Figura 4.13); estos valores no varían durante las distintas estaciones (ver Tabla 4.3).

Concentraciones similares $\left(0,040-0,080 \mathrm{mg} / \mathrm{g}_{\text {Grasa }}\right)$ se encontraron en muestras de leche de oveja alimentadas con pasto fresco (Gómez-Cortés et al., 2009a). Los niveles de trans-8,trans-10 en las muestras analizadas por Luna et al. (2005a, $2007 \mathrm{y}$ 2008b) oscilaron entre los 0,040 y 0,100 mg/g $\mathrm{g}_{\text {Grasa }}$. Gómez Cortés et al. (2011) determinaron contenidos de trans-8,trans-10 en ovejas alimentadas con suplementos de aceite de girasol (de 0,030 a $0,110 \mathrm{mg} / \mathrm{g}_{\text {Grasa }}$ ). En otro de los estudios que utilizan aceite de girasol (Hervás et al., 2008b) se observó que estos suplementos parecen aumentar el contenido de este isómero en leche (de 0,050 a $0,230 \mathrm{mg} / \mathrm{g}_{\text {Grasa }}$ ). A diferencia de lo que sucede con el aceite de girasol, las dietas complementadas con aceite de soja (Mele et al., 2006; Gómez-Cortés et al., 2008a) no parece que incrementen de manera destacada los contenidos de trans-8,trans-10. 


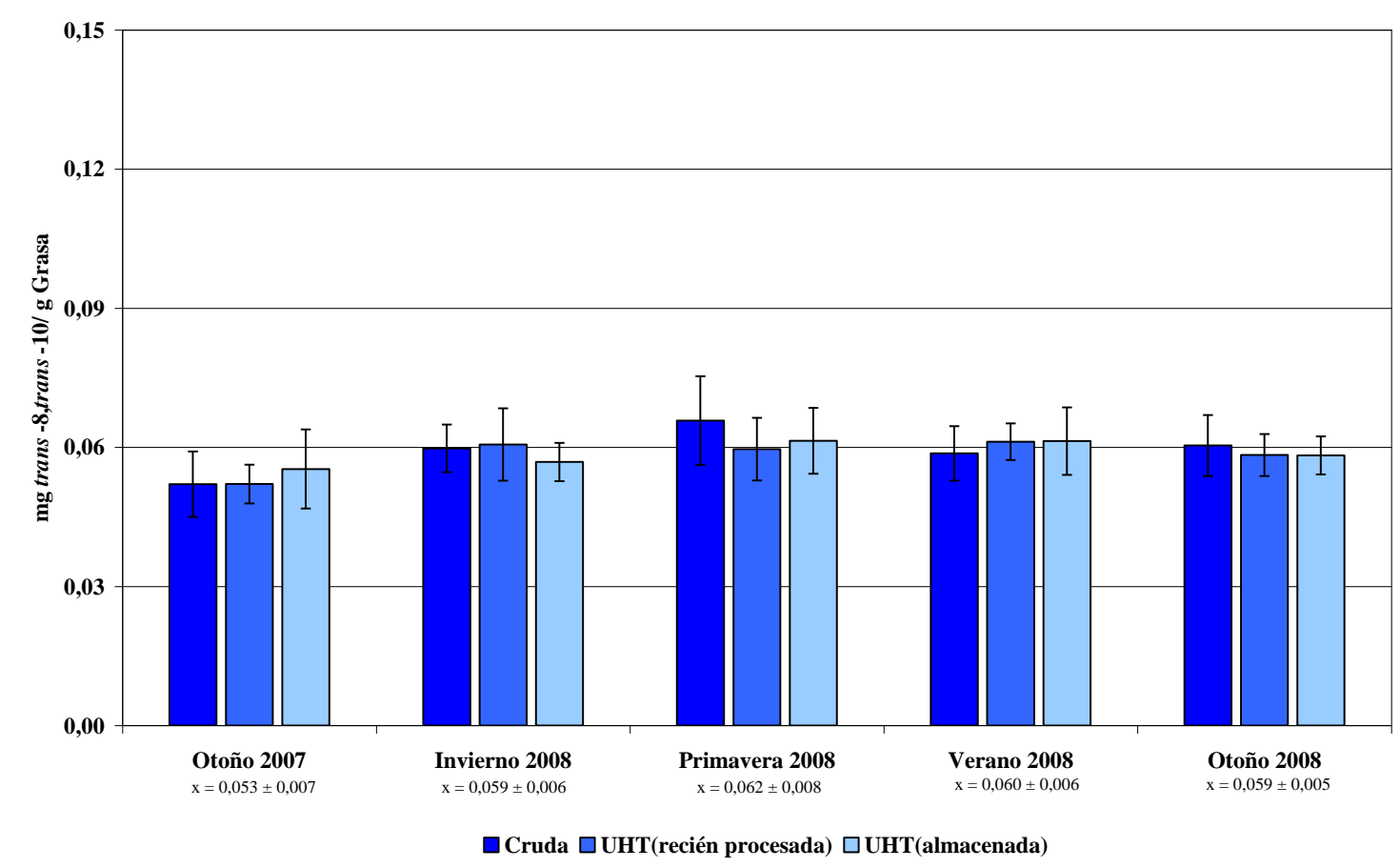

Figura 4.13. Variación del contenido de trans-8,trans-10 en las muestras de leche de oveja UHT.

\section{trans-7,trans-9 $\mathrm{C}_{18: 2}$}

El contenido de trans-7,trans-9 que se encontró en nuestro estudio se mantuvo dentro de los 0,050 y $0,065 \mathrm{mg} / \mathrm{g}_{\text {Grasa }}$ (Figura 4.14), no detectándose variaciones relacionadas con el tiempo de muestreo ( $\mathrm{P}>0,05$; Tabla 4.3).

Estos valores son muy parecidos a los $0,060 \mathrm{mg} / \mathrm{g}_{\text {Grasa }}$ que determinaron Abilleira et al. (2009) en quesos fabricados en primavera e invierno. Se obtuvieron concentraciones ligeramente más bajas en los ensayos realizados por Luna et al. (2005a, 2007 y 2008b) y Gómez-Cortés et al. (2008b, 2009a y 2011), cuyos valores oscilaron entre 0,020 y $0,050 \mathrm{mg} / \mathrm{g}_{\text {Grasa }}$. Se observaron aumentos significativos en el contenido de este isómero $\left(0,060-0,160 \mathrm{mg} / \mathrm{g}_{\text {Grasa }}\right)$ cuando las dietas se suplementaron con aceite de girasol (Hervás et al., 2008b); o cuando se alimentó a las ovejas con dietas ricas en aceite de soja (0,080 - 0,140 mg/g $\mathrm{g}_{\text {Grasa }}$; Mele et al., 2006; Gómez-Cortés et al., 2008a).

Para este isómero se han encontrado interacciones entre el procesado y el tiempo de muestreo, con significación estadística $(\mathrm{P}<0,05)$. Pensamos que este resultado está condicionado por una mayor variabilidad en el comportamiento de los diferentes tipos de leche que a su vez puede estar influida por las dificultades de cuantificación, puesto 
que se encuentra solapado al trans-8,trans-10, y además, ambos están presentes en cantidades pequeñas.

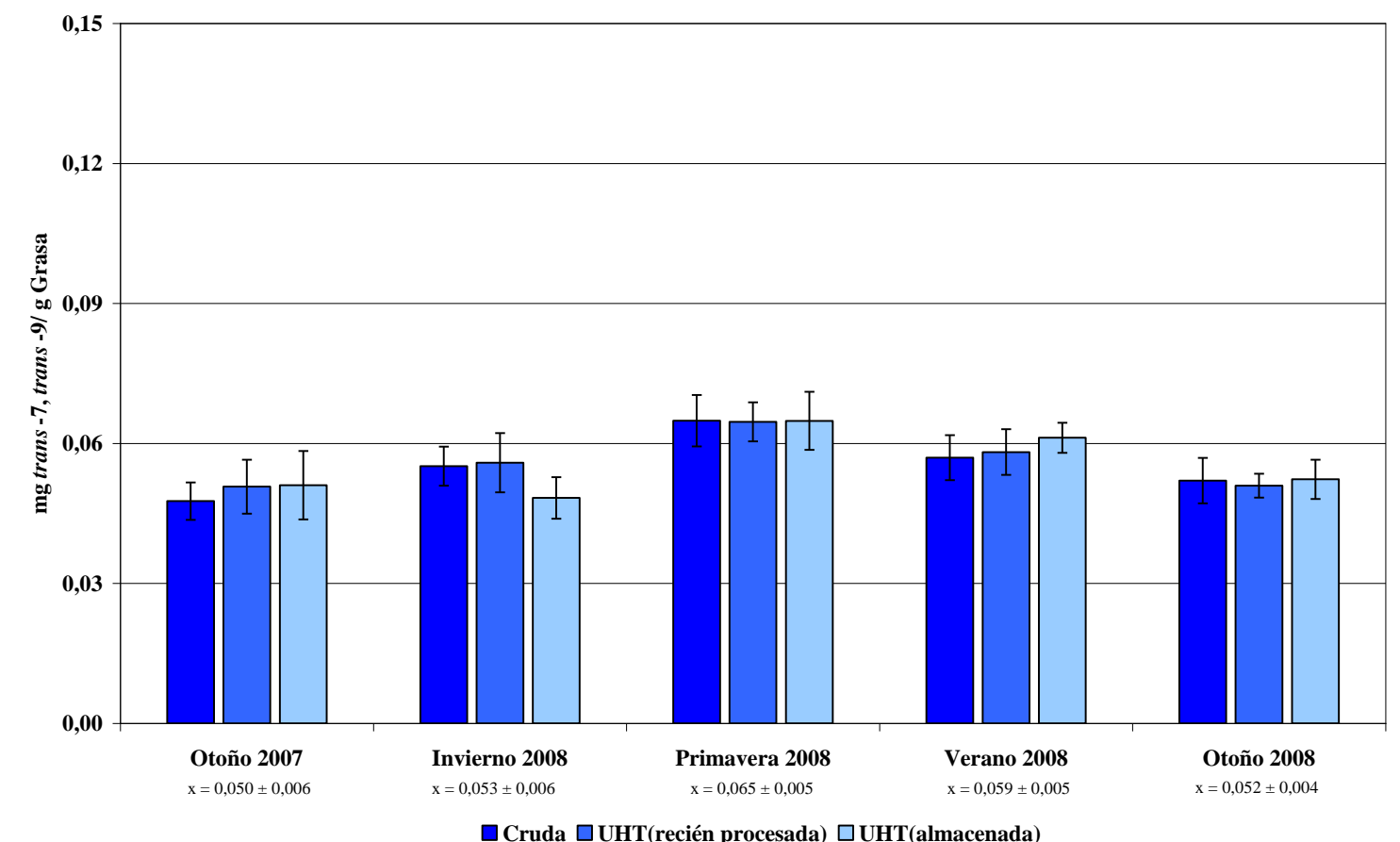

Figura 4.14. Variación del contenido de trans-7,trans-9 en las muestras de leche de oveja UHT.

\section{trans-6,trans-8 $\mathrm{C}_{18: 2}$}

El trans-6,trans-8 es el isómero que se encuentra en menor cantidad; su contenido osciló entre 0,013 y 0,017 mg/g $\mathrm{g}_{\text {Grasa }}$ (Figura 4.15) y no se observan diferencias estacionales (Tabla 4.3). Son pocas las referencias bibliográficas en las que se menciona la presencia en la leche ovina del trans-6,trans-8, posiblemente porque su bajo contenido no permite que se determine en muchos casos.

Gómez Cortés et al. (2011) encuentran dicho isómero en leche de ovejas alimentadas con distintas dosis de aceite de girasol (0,040 y 0,090 mg/g $\left.\mathrm{g}_{\text {Grasa }}\right)$. Abilleira et al. (2009) determinan concentraciones cercanas a los $0,040 \mathrm{mg} / \mathrm{g}_{\mathrm{Grasa}}$ en quesos de primavera y de invierno. Partidario et al. (2008) también cuantifican este mismo isómero en la leche de oveja utilizada para fabricar quesos portugueses $(0,040$ y 0,050 $\left.\mathrm{mg} / \mathrm{g}_{\text {Grasa }}\right)$. Como se puede observar, los valores encontrados en nuestro trabajo no llegan a alcanzar estos niveles de trans-6,trans-8. Los escasos datos no permiten hacer una valoración más objetiva de la influencia estacional o de la dieta animal en el 
contenido de este isómero en leche. Sin embargo, se podría llegar a pensar que dichos suplementos no parecen influir en el aumento del trans-6,trans-8 en la leche, ya que ni el aceite de girasol $(0,040$ hasta 0,090) ni el pasto primaveral (valor constante de 0,040 tanto en invierno como en verano) hacen que aumente su contenido de manera significativa.

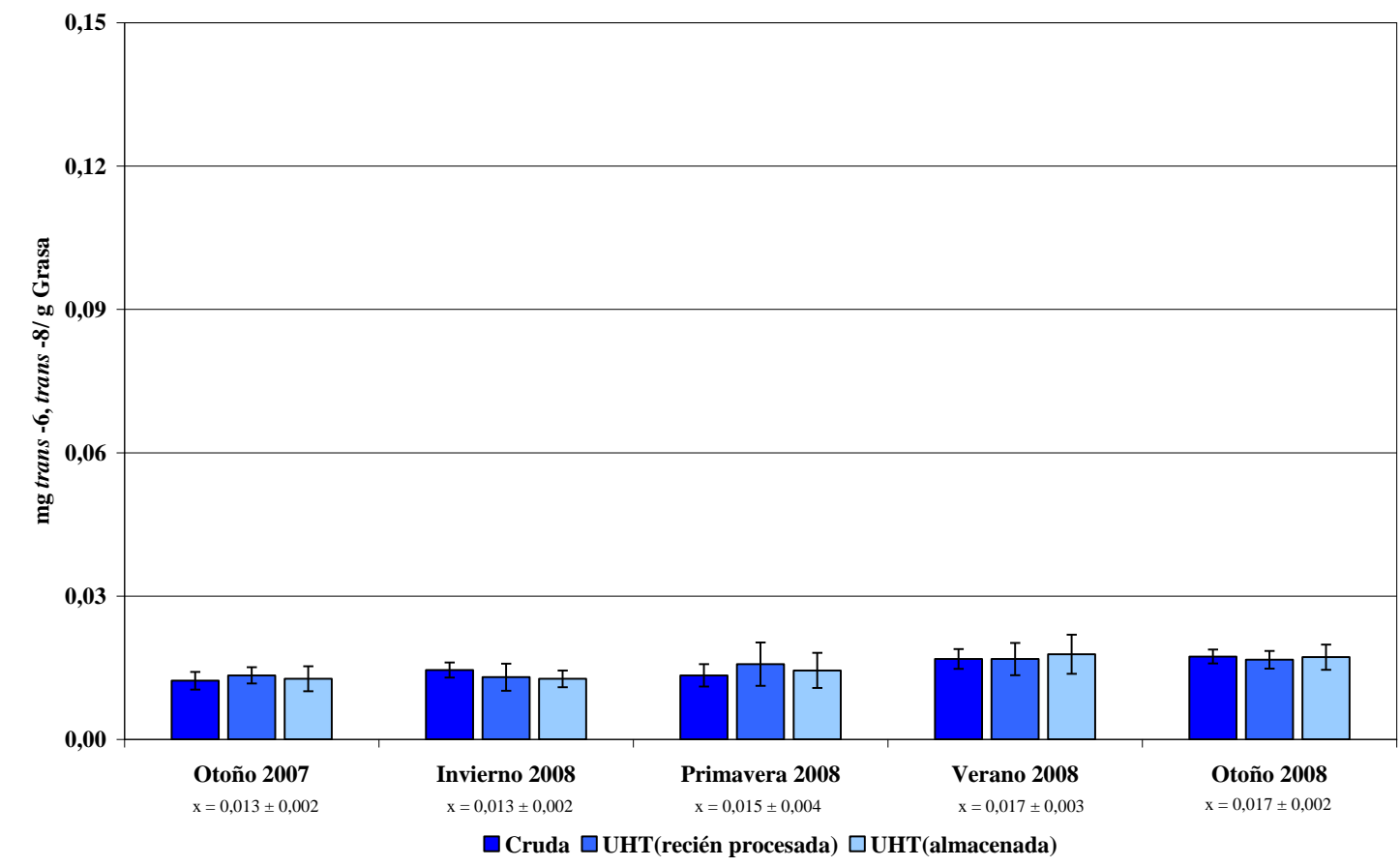

Figura 4.15. Variación del contenido de trans-6,trans-8 en las muestras de leche de oveja UHT.

\subsubsection{Distribución de los isómeros CLA}

En la Tabla 4.4 se recoge el perfil de isómeros presentes en leche de oveja UHT semidesnatada. El isómero cis-9,trans-11 varía entre el 77 y el $79 \%$ respecto al total de isómeros CLA. El trans-7,cis-9 se mantuvo como el segundo isómero en todas las épocas estacionales (entre 5 y $7 \%$ ), aunque su contenido porcentual durante la primavera experimentó un descenso relativo de aproximadamente un 1\%. El tercer isómero más abundante es el trans-9,trans-11, excepto en la época primaveral, en la que es superado por el isómero trans-11,trans-13. Durante la primavera, los isómeros trans12,trans-14 y trans-11,cis-13 llegan a igualar en porcentaje al trans-9,trans-11, pero para el resto del año, la contribución de estos al total de CLA es menor. Del resto de isómeros, sólo los ya mencionados trans-11,trans-13 y trans-12,trans-14 superan el 2\% del total de CLA en leche; los demás no llegan a alcanzar este porcentaje, entre los que 
se incluyen el trans-10,cis-12 (0,70 - 0,90\%). La suma de todos los isómeros transtrans superó el $10 \%$ en todas las épocas del año, y si se excluye el ruménico, el resto de los isómeros cis-trans/trans-cis contribuyen con aproximadamente un $10 \%$.

Tabla 4.4. Contenido porcentual de isómeros CLA presentes en las distintas muestras de leche de oveja UHT, según la época estacional

\begin{tabular}{|c|c|c|c|c|c|}
\hline \multirow[b]{2}{*}{ Isómero CLA } & \multicolumn{5}{|c|}{ \% sobre el CLA total } \\
\hline & $\begin{array}{c}\text { Otoño } \\
2007 \\
\end{array}$ & $\begin{array}{c}\text { Invierno } \\
2008 \\
\end{array}$ & $\begin{array}{c}\text { Primavera } \\
2008 \\
\end{array}$ & $\begin{array}{c}\text { Verano } \\
2008 \\
\end{array}$ & $\begin{array}{c}\text { Otoño } \\
2008 \\
\end{array}$ \\
\hline trans-trans CLA & $10,20 \pm 0,43$ & $10,42 \pm 0,53$ & $11,33 \pm 0,58$ & $10,63 \pm 0,56$ & $10,11 \pm 0,69$ \\
\hline trans -12, trans -14 & $2,19 \pm 0,17$ & $2,20 \pm 0,19$ & $2,55 \pm 0,24$ & $2,23 \pm 0,11$ & $2,13 \pm 0,11$ \\
\hline trans -11, trans -13 & $2,09 \pm 0,17$ & $2,01 \pm 0,17$ & $3,74 \pm 0,41$ & $2,21 \pm 0,39$ & $2,16 \pm 0,22$ \\
\hline trans -10, trans -12 & $1,27 \pm 0,16$ & $1,24 \pm 0,15$ & $0,81 \pm 0,19$ & $1,19 \pm 0,15$ & $1,08 \pm 0,15$ \\
\hline trans -9, trans -11 & $2,55 \pm 0,22$ & $2,67 \pm 0,21$ & $2,55 \pm 0,21$ & $2,70 \pm 0,18$ & $2,53 \pm 0,27$ \\
\hline trans -8, trans -10 & $0,96 \pm 0,15$ & $1,08 \pm 0,12$ & $0,74 \pm 0,15$ & $1,02 \pm 0,18$ & $1,02 \pm 0,12$ \\
\hline trans -7, trans -9 & $0,90 \pm 0,10$ & $0,97 \pm 0,12$ & $0,77 \pm 0,07$ & $0,99 \pm 0,12$ & $0,89 \pm 0,11$ \\
\hline trans -6, trans -8 & $0,23 \pm 0,03$ & $0,25 \pm 0,04$ & $0,18 \pm 0,06$ & $0,29 \pm 0,09$ & $0,30 \pm 0,05$ \\
\hline cis-trans + trans-cis & $89,80 \pm 0,43$ & $89,58 \pm 0,53$ & $88,67 \pm 0,58$ & $89,37 \pm 0,56$ & $89,89 \pm 0,69$ \\
\hline $12,14-(c-t / t-c)$ & $0,99 \pm 0,09$ & $1,05 \pm 0,11$ & $1,75 \pm 0,26$ & $1,16 \pm 0,10$ & $1,05 \pm 0,11$ \\
\hline trans -11, cis -13 & $1,05 \pm 0,09$ & $1,20 \pm 0,22$ & $2,66 \pm 0,44$ & $1,17 \pm 0,25$ & $1,12 \pm 0,08$ \\
\hline trans -10, cis -12 & $0,78 \pm 0,05$ & $0,82 \pm 0,07$ & $0,72 \pm 0,16$ & $0,83 \pm 0,06$ & $0,78 \pm 0,05$ \\
\hline cis-9,trans-11 & $78,89 \pm 0,53$ & $78,42 \pm 1,05$ & $77,33 \pm 0,93$ & $77,94 \pm 0,93$ & $78,76 \pm 1,24$ \\
\hline trans -8, cis -10 & $1,22 \pm 0,17$ & $1,25 \pm 0,29$ & $1,06 \pm 0,14$ & $1,63 \pm 0,23$ & $1,50 \pm 0,16$ \\
\hline trans -7, cis -9 & $6,86 \pm 0,17$ & $6,83 \pm 0,49$ & $5,15 \pm 0,41$ & $6,63 \pm 0,49$ & $6,68 \pm 0,39$ \\
\hline
\end{tabular}

Nota: Estos datos corresponden al promedio global de los porcentajes de cada isómero encontrado en las distintas muestras de leche.

La distribución de isómeros presente en estas muestras es similar a la publicada por otros autores (Luna et al., 2005a, 2005b y 2007; Martins et al., 2007; Park et al., 2007). Luna et al. (2007) trabajaron con leche de oveja cruda para elaborar quesos manchegos y determinaron que, de los isómeros cis-trans/trans-cis $(89,88 \%)$, el cis9,trans-11 $(79,15 \pm 0,49 \%)$ y el trans-7,cis-9 $(7,12 \pm 0,10 \%)$ son los más importantes; mientras que de los trans-trans (7,86\%), los más abundantes fueron el trans-11,trans-13 $(2,55 \pm 0,05 \%)$ y el trans-12,trans-14 $(2,10 \pm 0,07 \%)$. Los porcentajes de isómeros CLA determinados en la leche de distintas razas de ovinos son muy distintos, aunque podemos recoger los intervalos de variación para los siguientes isómeros: cis-9,trans-11 (76,5 - 82,4\%); trans-7,cis-9 (3,31 - 9,69\%); trans-11,trans-13 (1,21 - 5,08\%); trans11, cis-13 (0,76-4,23\%) y trans-12,trans-14 (1,26 - 3,47\%) (Luna et al. 2005a).

Valores porcentuales muy diferentes a los que hemos obtenido fueron publicados por Partidario et al. (2008) en leche cruda de oveja, aunque también 
consideraron al cis-9,trans-11 (67,2 - 69,7\%) y trans-7,cis-9 (12,6 - 15,8\%) como los dos isómeros mayoritarios; el porcentaje de trans-trans encontrado por dichos autores se mantuvo entre el 7,9 y 12,1\%. No podemos explicar los bajos porcentajes de cis9,trans-11 encontrados por estos autores, sobre todo teniendo en cuenta que en ninguna de las referencias consultadas se ha observado estos niveles tan bajos. Rodríguez-Alcalá et al. (2009) determinan en la leche de oveja cruda porcentajes relativamente cercanos a los obtenidos en nuestro trabajo, sobre todo para los isómeros cis-9,trans-11 (85,53 \pm $0,18 \%)$ y trans-7,cis-9 (7,98 $\pm 0,34 \%)$, aunque el contenido de trans-trans $(5,62 \pm 0,26$ $\%)$ es relativamente menor.

Respecto al trans-10,cis-12, los porcentajes que se han publicado de este isómero, no superan los valores que hemos determinado en este trabajo: 0,28-0,41\% (Luna et al., 2005a); 0,56 \pm 0,01\% (Luna et al., 2005b); 0,40 \pm 0,05\% (Luna et al., 2007); 0,68-0,77\% (Partidario et al., 2008).

\subsection{CONSIDERACIONES FINALES}

El desarrollo de este objetivo ha permitido disponer de contenidos de CLA total y de 13 isómeros en muestras comerciales de leche de oveja. Las cantidades más altas corresponden a los meses de abril a junio, con un valor medio para el CLA total de $8,501 \pm 0,906 \mathrm{mg} / \mathrm{g}_{\text {Grasa }}$, mientras que el resto del año, varían entre $5,463 \pm 0,231$ (invierno de 2008) y 6,011 $\pm 0,812$ (verano de 2008). Los datos bibliográficos en leche de oveja son escasos, se refieren a leche cruda y generalmente sólo se recoge el contenido de CLA total o del isómero mayoritario. Estos resultados pueden utilizarse para valorar la contribución de la leche de oveja a la ingesta de CLA total y de los diferentes isómeros.

El tratamiento térmico y el almacenamiento durante el tiempo de vida útil de la leche de oveja no tienen influencia en la cantidad de CLA ni tampoco en la distribución de isómeros. Se debe resaltar que al realizarse el estudio durante 15 meses, se incluye la variabilidad estacional, aspecto a considerar cuando se quieren asignar cantidades de CLA a un alimento. 


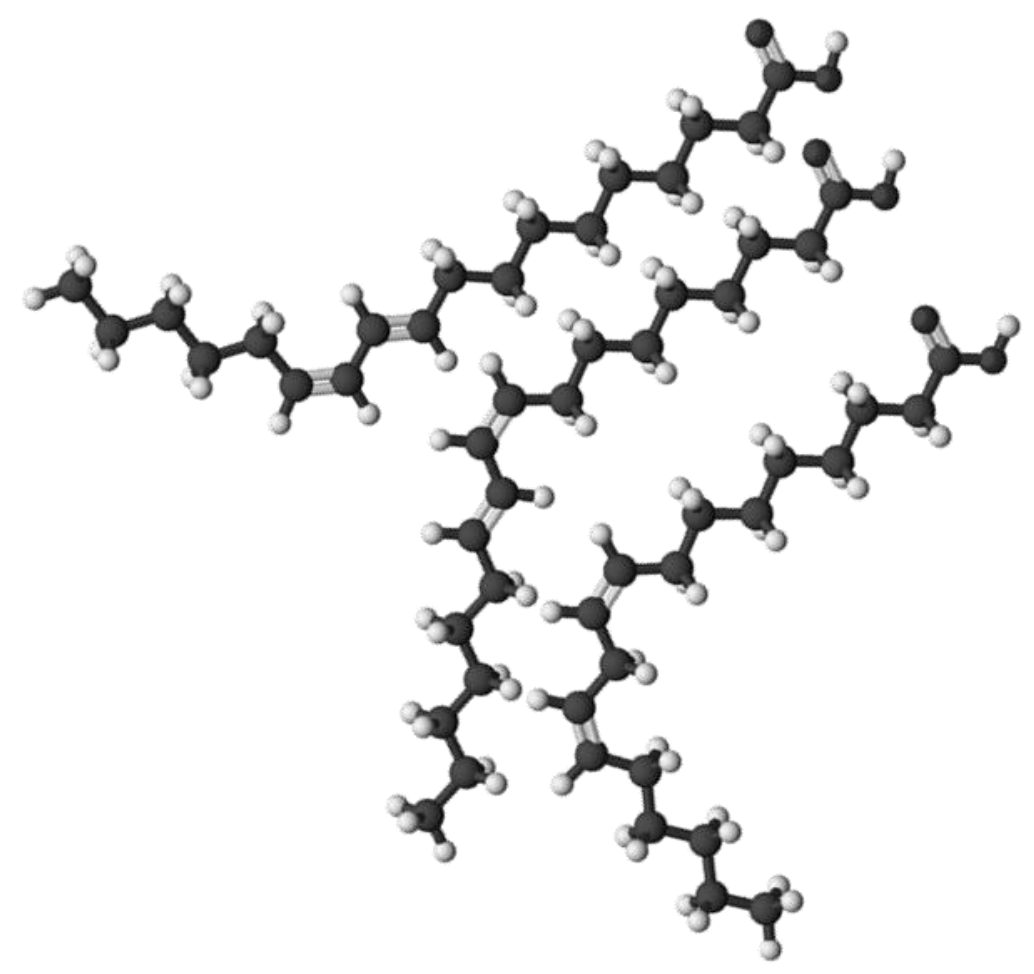

5. ISÓMEROS CLA EN CUAJADAS Y YOGURES ELABORADOS CON LECHE DE OVEJA 



\section{ISÓMEROS CLA EN CUAJADAS Y YOGURES ELABORADOS CON LECHE DE OVEJA}

Se determinó el contenido total e individual de los isómeros CLA en yogures y cuajadas elaboradas con leche de oveja. Para evaluar la influencia del proceso de fabricación y el almacenamiento, se compararán entre sí los valores de CLA encontrados en las diferentes muestras de leche cruda con su correspondiente yogur o cuajada recién procesada y después de almacenarse durante aproximadamente un mes. Sólo se estudiarán las variaciones estacionales del CLA en las cuajadas, ya que no se dispuso de un número suficiente de muestras de yogur que nos permitiera observar el efecto estacional en dicho producto; debido a que la demanda del mismo fue limitada, según nos informó la empresa suministradora.

\subsection{MUESTRAS}

Los yogures (7 muestras) y las cuajadas (12 muestras) fueron suministrados por Leche Gaza, S.L.; estos productos comerciales se elaboraron con leche de oveja, procedente de los 22 rebaños anteriormente descritos (ver apartado 4.1). El régimen de alimentación de las ovejas es el mismo que se recoge en la Tabla 4.1; además, cabe recordar que la dieta no se modificó para aumentar el contenido de CLA. La frecuencia del muestreo estuvo condicionada por la planificación de la empresa, impuesta a su vez por las necesidades del mercado. La leche de partida se recogía del conjunto total de la mezcla de leche recién ordeñada y se trasladaba refrigerada al laboratorio el mismo día de su ordeño, contenida en envases esterilizados. Los yogures venían envasados en tarros de cristal (140g), mientras que las cuajadas estaban contenidas en tarros de cerámica (140g). Ambos productos se transportaban refrigerados al día siguiente de su fabricación. La vida útil del yogur y la cuajada es de 28 y 20 días, respectivamente, tiempo en el que se almacenaban $\left(\right.$ a $5^{\circ} \mathrm{C}$ ) hasta su análisis, un día antes de la fecha de caducidad. La extracción de la grasa, la metilación de los ácidos grasos y la determinación de CLA se llevaron a cabo siguiendo los procedimientos descritos en el apartado 3.1. En el etiquetado de estos productos, se recoge la información nutricional que se detalla a continuación: 


\begin{tabular}{|c|c|}
\hline $\begin{array}{c}\text { Información nutricional (cuajada) } \\
\text { Valores medios en } 100 \mathrm{~mL}\end{array}$ & $\begin{array}{c}\text { Información nutricional (yogur) } \\
\text { Valores medios en } 100 \mathrm{~mL}\end{array}$ \\
\hline 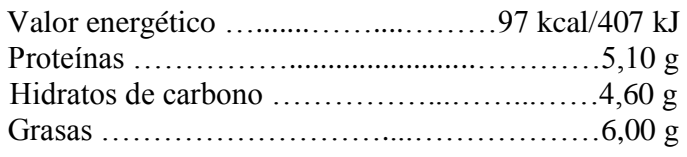 & 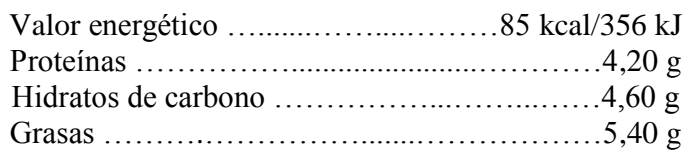 \\
\hline Calcio..........................130 mg (15\% CDR*) & Calcio..........................155 mg (19\% CDR*) \\
\hline$* \mathbf{C D R}=$ Cantidad diaria recomendada & $* \mathbf{C D R}=$ Cantidad diaria recomendada \\
\hline
\end{tabular}

\subsection{TRATAMIENTO ESTADÍSTICO}

Se ha realizado un análisis de la varianza de un factor en el caso de los yogures y un análisis de dos factores independientes con interacción en el caso de la cuajada (leche cruda o tipo de cuajada y variación estacional). Para el análisis de detección de las diferencias de medias entre los niveles de los factores, se ha utilizado la penalización de Tukey. Los niveles de significación elegidos han sido los habituales del 5\% y el $1 \%$. Para la realización del análisis estadístico, se ha utilizado el software XLSTAT 2007.

\subsection{RESULTADOS Y DISCUSIÓN}

\subsubsection{Estudio de isómeros CLA en cuajada}

Los resultados encontrados en las muestras comerciales de cuajada como en su correspondiente leche de partida se recogen en la Tabla 5.1. Estos datos están agrupados en intervalos de tres meses, distribuyéndose las 12 muestras en 4 épocas estacionales. Hay que decir que la bibliografía relacionada con la determinación de CLA en este producto es bastante escasa, por lo que para la discusión de los resultados, nos basaremos en dichas referencias, además de las observaciones que previamente hicimos con la leche semidesnatada (UHT).

\subsubsection{Influencia del procesado y del almacenamiento}

Para observar la influencia del procesado y del almacenamiento, se compararon los resultados obtenidos en las diferentes muestras de cuajada con su correspondiente leche de partida (Tabla 5.1). En la Figura 5.1 se resume el proceso de fabricación de la cuajada elaborada por la empresa GAZA. La etapa más drástica en este proceso es la pasteurización, donde se alcanzan temperaturas cercanas a los $90^{\circ} \mathrm{C}$ durante un tiempo prolongado (25 - 35min). 


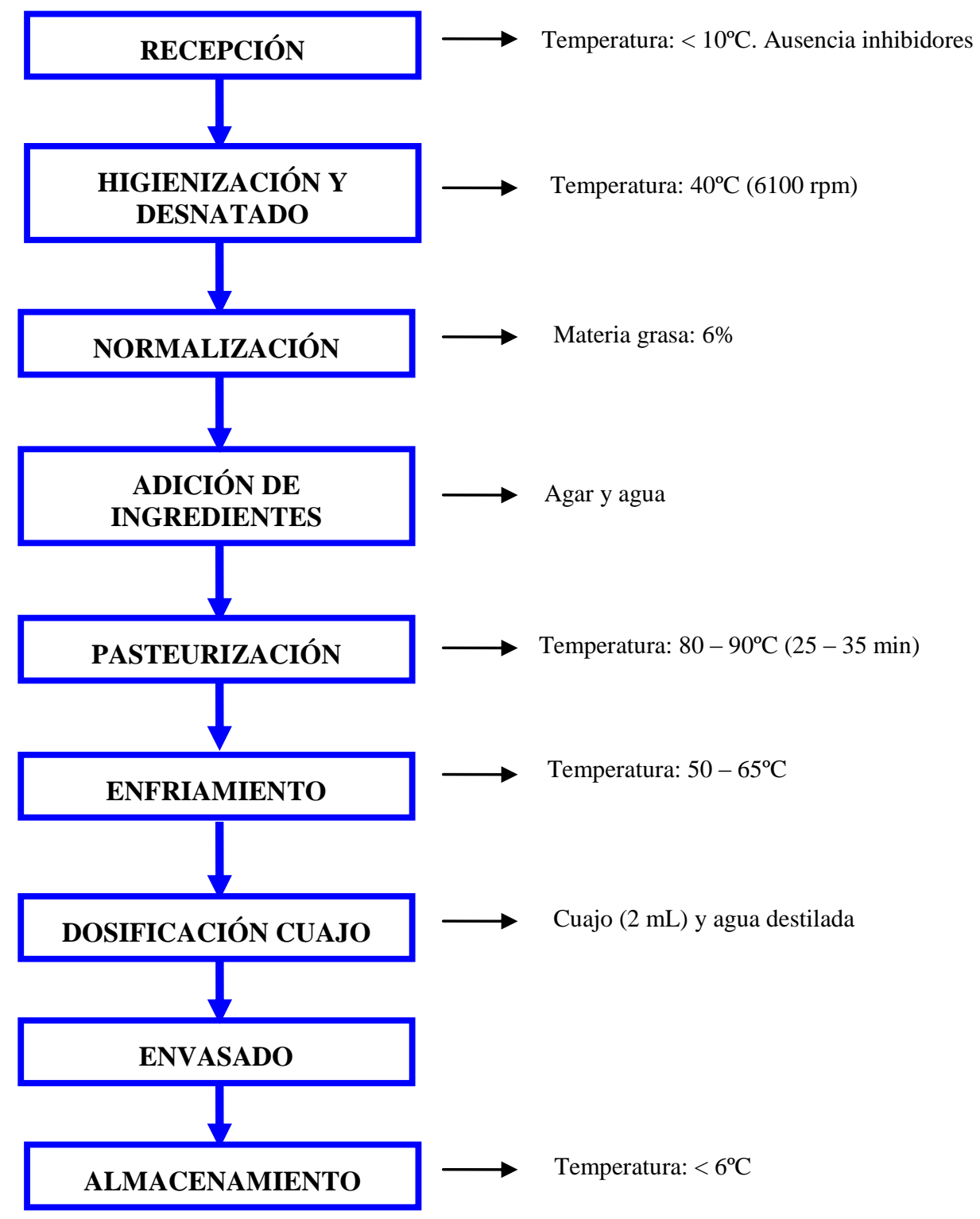

Figura 5.1. Esquema del procesado de la cuajada elaborada con leche de oveja, según la empresa GAZA.

Los resultados obtenidos en las cuajadas no muestran una influencia significativa del proceso de elaboración sobre el contenido de CLA total y de isómeros individuales. Tampoco se encontraron grandes variaciones en el contenido de estos isómeros cuando el producto elaborado se almacenó hasta su caducidad. En general, los resultados muestran una tendencia a presentar contenidos ligeramente más altos en la leche de partida, pero dichas diferencias no presentaron significación estadística ( $\mathrm{P}>$ $0,05)$ ni en las cuajadas recién procesadas ni cuando las mismas se almacenaron hasta su caducidad. 
Tabla 5.1. Contenido de isómeros CLA (mg/g $\left.\mathrm{g}_{\text {Grasa }}\right)$ en cuajada

\begin{tabular}{|c|c|c|c|c|c|}
\hline \multirow[b]{2}{*}{ Isómero CLA } & \multirow[b]{2}{*}{ Muestra $^{(a)}$} & \multicolumn{4}{|c|}{$\tilde{\boldsymbol{x}} \pm s_{D}$} \\
\hline & & $\begin{array}{c}\text { Invierno 2008 } \\
\text { (Ene-Feb-Mar) } \\
\mathbf{n}=\mathbf{3}\end{array}$ & $\begin{array}{c}\text { Primavera 2008 }^{(\mathbf{b})} \\
\text { (Abr-May-Jun) }^{\text {n }=3}\end{array}$ & $\begin{array}{c}\text { Verano 2008 }^{(\mathbf{b})} \\
\text { (Jul-Ago-Sep) } \\
\mathbf{n}=\mathbf{3}\end{array}$ & $\begin{array}{c}\text { Otoño 2008 } \\
\text { (Oct-Nov-Dic) } \\
\mathbf{n}=\mathbf{3}\end{array}$ \\
\hline \multirow[t]{3}{*}{ trans-12,trans-14 } & Leche Cruda & $0,140 \pm 0,008$ & $0,266 \pm 0,047$ & $0,149 \pm 0,010$ & $0,136 \pm 0,018$ \\
\hline & Cuajada Proc. & $0,140 \pm 0,015$ & $0,270 \pm 0,047$ & $\mathbf{0 , 1 4 7} \pm \mathbf{0 , 0 1 1}$ & $\mathbf{0 , 1 3 6} \pm \mathbf{0 , 0 1 5}$ \\
\hline & Cuajada Almac. & $0,137 \pm 0,014$ & $0,275 \pm 0,046$ & $0,149 \pm 0,013$ & $\mathbf{0 , 1 3 6} \pm \mathbf{0 , 0 1 7}$ \\
\hline \multirow[t]{3}{*}{ trans-11,trans-13 } & Leche Cruda & $0,112 \pm 0,018$ & $\mathbf{0 , 3 3 7} \pm \mathbf{0 , 0 8 8}$ & $\mathbf{0 , 1 5 1} \pm \mathbf{0 , 0 3 2}$ & $0,131 \pm 0,014$ \\
\hline & Cuajada Proc. & $0,110 \pm 0,020$ & $0,335 \pm 0,080$ & $0,148 \pm 0,032$ & $0,132 \pm 0,012$ \\
\hline & Cuajada Almac. & $0,108 \pm 0,021$ & $0,348 \pm 0,092$ & $\mathbf{0 , 1 5 0} \pm \mathbf{0 , 0 3 3}$ & $0,134 \pm 0,012$ \\
\hline \multirow[t]{3}{*}{ trans-10,trans-12 } & Leche Cruda & $0,082 \pm 0,011$ & $0,070 \pm 0,015$ & $0,065 \pm 0,004$ & $0,054 \pm 0,011$ \\
\hline & Cuajada Proc. & $0,078 \pm 0,012$ & $0,070 \pm 0,013$ & $0,071 \pm 0,004$ & $0,060 \pm 0,013$ \\
\hline & Cuajada Almac. & $0,076 \pm 0,017$ & $0,064 \pm 0,003$ & $0,066 \pm 0,005$ & $\mathbf{0 , 0 5 4} \pm \mathbf{0 , 0 1 3}$ \\
\hline \multirow[t]{3}{*}{ trans -9, trans -11} & Leche Cruda & $0,142 \pm 0,016$ & $0,230 \pm 0,016$ & $\mathbf{0 , 1 5 5} \pm \mathbf{0 , 0 0 7}$ & $0,148 \pm 0,030$ \\
\hline & Cuajada Proc. & $0,140 \pm 0,007$ & $0,232 \pm 0,015$ & $0,162 \pm 0,011$ & $0,141 \pm 0,023$ \\
\hline & Cuajada Almac. & $0,141 \pm 0,005$ & $0,244 \pm 0,019$ & $0,162 \pm 0,009$ & $0,147 \pm 0,030$ \\
\hline \multirow[t]{3}{*}{ trans -8, trans -10} & Leche Cruda & $\mathbf{0 , 0 5 5} \pm \mathbf{0 , 0 0 7}$ & $0,068 \pm 0,007$ & $0,053 \pm 0,003$ & $0,056 \pm 0,008$ \\
\hline & Cuajada Proc. & $0,056 \pm 0,006$ & $0,074 \pm 0,005$ & $0,056 \pm 0,003$ & $0,052 \pm 0,007$ \\
\hline & Cuajada Almac. & $0,054 \pm 0,005$ & $0,070 \pm 0,010$ & $0,055 \pm 0,002$ & $\mathbf{0 , 0 5 8} \pm \mathbf{0 , 0 0 7}$ \\
\hline \multirow[t]{3}{*}{ trans -7, trans -9} & Leche Cruda & $0,051 \pm 0,007$ & $0,066 \pm 0,006$ & $0,055 \pm 0,002$ & $0,051 \pm 0,004$ \\
\hline & Cuajada Proc. & $0,053 \pm 0,006$ & $0,067 \pm 0,003$ & $0,056 \pm 0,002$ & $\mathbf{0 , 0 5 0} \pm \mathbf{0 , 0 0 4}$ \\
\hline & Cuajada Almac. & $\mathbf{0 , 0 5 5} \pm \mathbf{0 , 0 0 7}$ & $0,070 \pm 0,009$ & $0,057 \pm 0,002$ & $0,055 \pm 0,004$ \\
\hline \multirow[t]{3}{*}{ trans -6, trans -8} & Leche Cruda & $0,011 \pm 0,002$ & $0,017 \pm 0,001$ & $0,015 \pm 0,003$ & $0,016 \pm 0,001$ \\
\hline & Cuajada Proc. & $0,012 \pm 0,003$ & $0,016 \pm 0,002$ & $0,016 \pm 0,002$ & $0,015 \pm 0,002$ \\
\hline & Cuajada Almac. & $0,012 \pm 0,002$ & $0,016 \pm 0,002$ & $0,018 \pm 0,001$ & $\mathbf{0 , 0 1 7} \pm \mathbf{0 , 0 0 1}$ \\
\hline
\end{tabular}

(a) Leche cruda, cuajada recién procesada, cuajada almacenada: No se han encontrado diferencias significativas, $\mathrm{P}>0,05$.

(b) Tiempo de muestreo: Se han encontrado diferencias significativas, $\mathrm{P}<0,05$.

(a x b) Interacción: No se encontró.

"n" = Número de muestras, analizadas por triplicado. 
Tabla 5.1 (cont.). Contenido de isómeros CLA (mg/g $\mathrm{g}_{\text {Grasa }}$ ) en cuajada

\begin{tabular}{|c|c|c|c|c|c|}
\hline \multirow[b]{2}{*}{ Isómero CLA } & \multirow[b]{2}{*}{ Muestra $^{(a)}$} & \multicolumn{4}{|c|}{$\tilde{x} \pm s_{D}$} \\
\hline & & $\begin{array}{c}\text { Invierno 2008 } \\
\text { (Ene-Feb-Mar) } \\
\mathbf{n}=\mathbf{3}\end{array}$ & $\begin{array}{c}\text { Primavera 2008 }^{(\mathbf{b})} \\
\text { (Abr-May-Jun) } \\
\mathbf{n}=\mathbf{3}\end{array}$ & $\begin{array}{c}\text { Verano 2008 }^{(\mathrm{b})} \\
\text { (Jul-Ago-Sep) } \\
\mathbf{n}=\mathbf{3}\end{array}$ & $\begin{array}{c}\text { Otoño 2008 }^{(\mathbf{b})} \\
\text { (Oct-Nov-Dic) } \\
\mathbf{n}=\mathbf{3}\end{array}$ \\
\hline $12,14-(c-t / t-c)$ & $\begin{array}{l}\text { Leche Cruda } \\
\text { Cuajada Proc. } \\
\text { Cuajada Almac. }\end{array}$ & $\begin{array}{l}\mathbf{0 , 0 7 2} \pm \mathbf{0 , 0 0 7} \\
0,072 \pm \mathbf{0 , 0 0 7} \\
0,066 \pm \mathbf{0 , 0 1 2}\end{array}$ & $\begin{array}{r}0,156 \pm 0,038 \\
0,155 \pm 0,039 \\
0,156 \pm 0,043\end{array}$ & $\begin{array}{l}\mathbf{0 , 0 7 1} \pm \mathbf{0 , 0 1 5} \\
0,071 \pm \mathbf{0 , 0 1 8} \\
0,070 \pm \mathbf{0 , 0 1 6}\end{array}$ & $\begin{array}{l}0,065 \pm 0,006 \\
0,066 \pm 0,008 \\
0,069 \pm 0,011\end{array}$ \\
\hline trans-11,cis-13 & $\begin{array}{l}\text { Leche Cruda } \\
\text { Cuajada Proc. } \\
\text { Cuajada Almac. }\end{array}$ & $\begin{array}{r}0,067 \pm 0,018 \\
0,063 \pm 0,019 \\
0,066 \pm 0,018\end{array}$ & $\begin{array}{l}0,267 \pm 0,052 \\
0,266 \pm 0,046 \\
0,270 \pm 0,052\end{array}$ & $\begin{array}{r}\mathbf{0 , 0 8 5} \pm 0,026 \\
0,085 \pm 0,028 \\
0,084 \pm 0,027\end{array}$ & $\begin{array}{l}0,067 \pm 0,004 \\
0,066 \pm 0,003 \\
0,069 \pm 0,003\end{array}$ \\
\hline trans-10,cis-12 & $\begin{array}{l}\text { Leche Cruda } \\
\text { Cuajada Proc. } \\
\text { Cuajada Almac. }\end{array}$ & $\begin{array}{r}0,041 \pm 0,009 \\
0,041 \pm 0,009 \\
0,043 \pm 0,013\end{array}$ & $\begin{array}{r}\mathbf{0 , 0 7 6} \pm \mathbf{0 , 0 0 7} \\
\mathbf{0 , 0 7 3} \pm \mathbf{0 , 0 0 9} \\
0,073 \pm \mathbf{0 , 0 0 7}\end{array}$ & $\begin{array}{r}0,041 \pm 0,004 \\
0,040 \pm 0,003 \\
0,040 \pm 0,003\end{array}$ & $\begin{array}{l}0,040 \pm 0,007 \\
0,042 \pm 0,006 \\
0,045 \pm 0,006\end{array}$ \\
\hline cis-9,trans -11 & $\begin{array}{l}\text { Leche Cruda } \\
\text { Cuajada Proc. } \\
\text { Cuajada Almac. }\end{array}$ & $\begin{array}{l}4,625 \pm 0,257 \\
4,602 \pm 0,251 \\
4,552 \pm 0,336\end{array}$ & $\begin{array}{l}6,998 \pm 0,375 \\
6,930 \pm 0,289 \\
6,977 \pm 0,391\end{array}$ & $\begin{array}{l}4,772 \pm 0,427 \\
4,762 \pm 0,497 \\
4,733 \pm 0,437\end{array}$ & $\begin{array}{l}4,475 \pm 0,131 \\
4,450 \pm 0,107 \\
4,461 \pm 0,132\end{array}$ \\
\hline trans -8, cis -10 & $\begin{array}{l}\text { Leche Cruda } \\
\text { Cuajada Proc. } \\
\text { Cuajada Almac. }\end{array}$ & $\begin{array}{r}0,070 \pm 0,008 \\
0,071 \pm 0,003 \\
0,069 \pm 0,006\end{array}$ & $\begin{array}{l}0,107 \pm 0,013 \\
0,105 \pm 0,009 \\
0,104 \pm 0,012\end{array}$ & $\begin{array}{l}0,082 \pm 0,002 \\
0,081 \pm 0,004 \\
0,083 \pm 0,002\end{array}$ & $\begin{array}{l}0,081 \pm 0,016 \\
0,080 \pm 0,015 \\
0,078 \pm 0,012\end{array}$ \\
\hline trans -7, cis -9 & $\begin{array}{l}\text { Leche Cruda } \\
\text { Cuajada Proc. } \\
\text { Cuajada Almac. }\end{array}$ & $\begin{array}{l}\mathbf{0 , 4 0 3} \pm \mathbf{0 , 0 5 5} \\
0,397 \pm 0,049 \\
0,394 \pm 0,056\end{array}$ & $\begin{array}{l}\mathbf{0 , 4 5 6} \pm \mathbf{0 , 0 2 4} \\
\mathbf{0 , 4 5 8} \pm \mathbf{0 , 0 2 5} \\
0,443 \pm \mathbf{0 , 0 3 0}\end{array}$ & $\begin{array}{l}0,379 \pm 0,005 \\
0,370 \pm 0,013 \\
0,369 \pm 0,012\end{array}$ & $\begin{array}{l}0,383 \pm 0,022 \\
0,384 \pm 0,022 \\
0,389 \pm 0,021\end{array}$ \\
\hline CLA TOTAL & $\begin{array}{l}\text { Leche Cruda } \\
\text { Cuajada Proc. } \\
\text { Cuajada Almac. }\end{array}$ & $\begin{array}{r}5,871 \pm 0,389 \\
5,834 \pm 0,390 \\
5,772 \pm 0,466\end{array}$ & $\begin{array}{l}9,113 \pm 0,621 \\
9,051 \pm 0,515 \\
9,110 \pm 0,618\end{array}$ & $\begin{array}{r}6,071 \pm 0,509 \\
6,066 \pm 0,599 \\
6,036 \pm 0,536\end{array}$ & $\begin{array}{l}5,703 \pm 0,214 \\
5,674 \pm 0,181 \\
5,712 \pm 0,207\end{array}$ \\
\hline
\end{tabular}

(a) Leche cruda, cuajada recién procesada, cuajada almacenada: No se han encontrado diferencias significativas, $\mathrm{P}>0,05$.

(b) Tiempo de muestreo: Se han encontrado diferencias significativas, $\mathrm{P}<0,05$.

(a x b) Interacción: No se encontró.

"n" = Número de muestras, analizadas por triplicado. 
Estas observaciones se corresponden con las que hemos encontrado en las muestras de leche UHT analizadas previamente, en las que no se detectaron cambios significativos en el contenido de CLA cuando la leche se sometió a una temperatura más alta pero durante un tiempo más corto $\left(150^{\circ} \mathrm{C}, 2,4\right.$ segundos $)$.

En cuanto a los contenidos, nuestros resultados son similares a los publicados por Prandini et al. (2009) en muestras de cuajadas convencionales y orgánicas de leche de vaca. Según estos autores, el contenido de CLA (cis-9,trans-11) en las cuajadas convencionales $\left(5,4 \mathrm{mg} / \mathrm{g}_{\text {Grasa }}\right)$, comparadas con su leche de partida $\left(4,9 \mathrm{mg} / \mathrm{g}_{\text {Grasa }}\right)$, experimentan un aumento de aproximadamente un 10\%. Para las cuajadas procedentes de un régimen de alimentación orgánico, los niveles de cis-9,trans-11 son mayores (7,1 $\mathrm{mg} / \mathrm{g}_{\text {Grasa }}$ ), aunque se observa una ligera disminución (de aproximadamente un $8 \%$ ) con respecto a su leche de partida $\left(7,7 \mathrm{mg} / \mathrm{g}_{\text {Grasa }}\right)$. En ambos casos, los cambios no eran estadísticamente significativos $(\mathrm{P}>0,05)$. Estas cuajadas también se sometieron a un posterior calentamiento $\left(53-56^{\circ} \mathrm{C}\right)$, pero tampoco se observaron variaciones importantes en el contenido de CLA.

\subsubsection{Contenido y variación estacional del CLA total e isómeros individuales}

Según los resultados de la Tabla 5.1, puede observarse que los contenidos más elevados de CLA total, tanto para la leche de partida como para la cuajada ya procesada, se encuentran en las muestras correspondientes a los meses de primavera, con valores que superan los 9,0 mg/g $\mathrm{g}_{\text {Grasa }}$ (Figura 5.2). En los meses correspondientes a la época veraniega, los valores se mantienen por encima de los $6,0 \mathrm{mg} / \mathrm{g}_{\text {Grasa }}$, mientras que en invierno y en otoño, el contenido de CLA total es inferior. Las cantidades de cis9,trans-11 determinadas en las cuajadas de leche de oveja se mantuvieron entre 4,462 y $6,968 \mathrm{mg} / \mathrm{g}_{\text {Grasa }}$ (Figura 5.3).

Estos valores son ligeramente superiores a los determinados en la leche UHT, aunque hay que tener en cuenta que para la cuajada, se dispuso de 3 muestras por época, mientras que para la leche UHT, el número de muestras fue mayor. En cualquier caso, hay que decir que la influencia estacional en este producto lácteo es muy similar a la observada en leche UHT. 


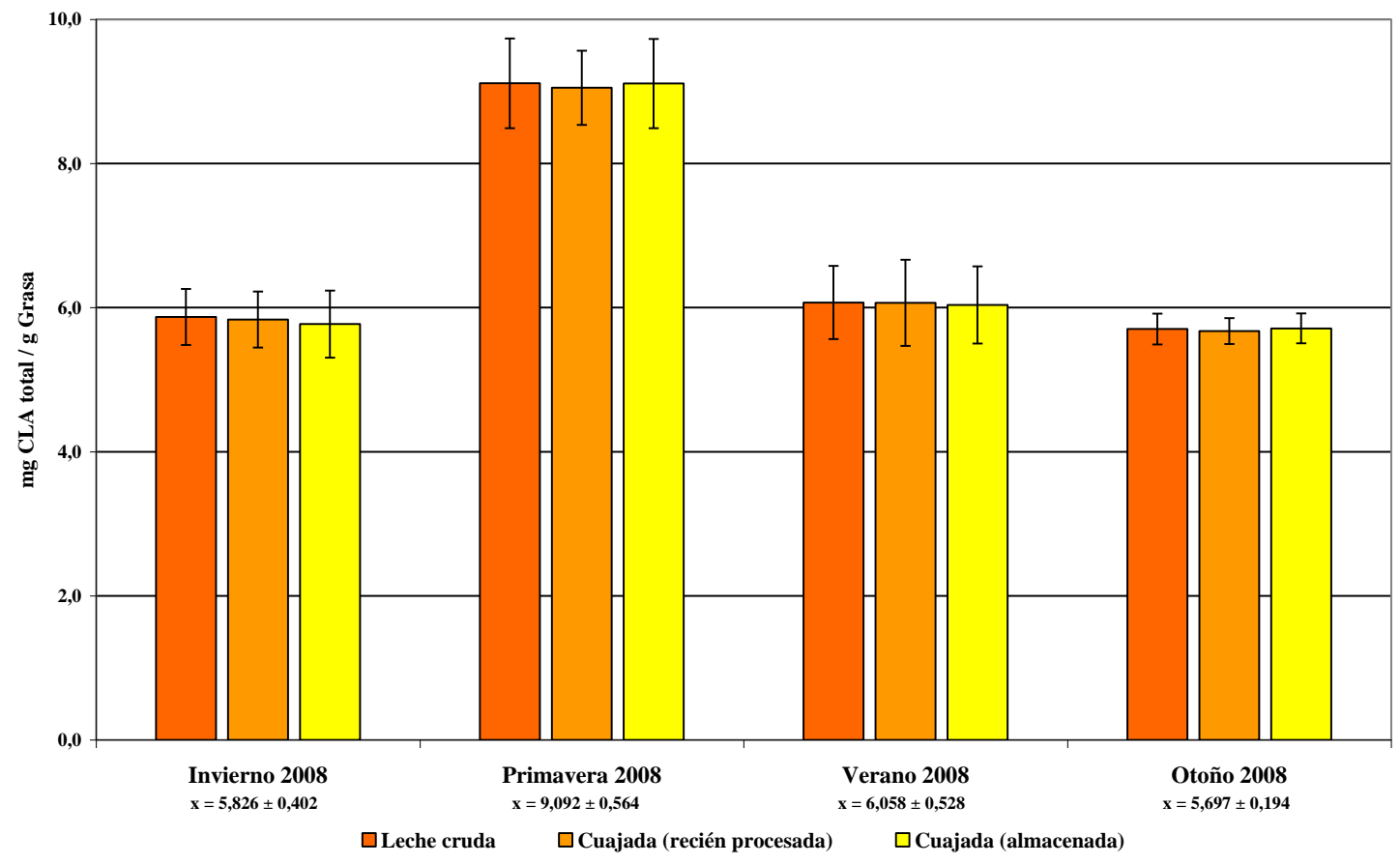

Figura 5.2. Variación del contenido de CLA total en las muestras de cuajada.

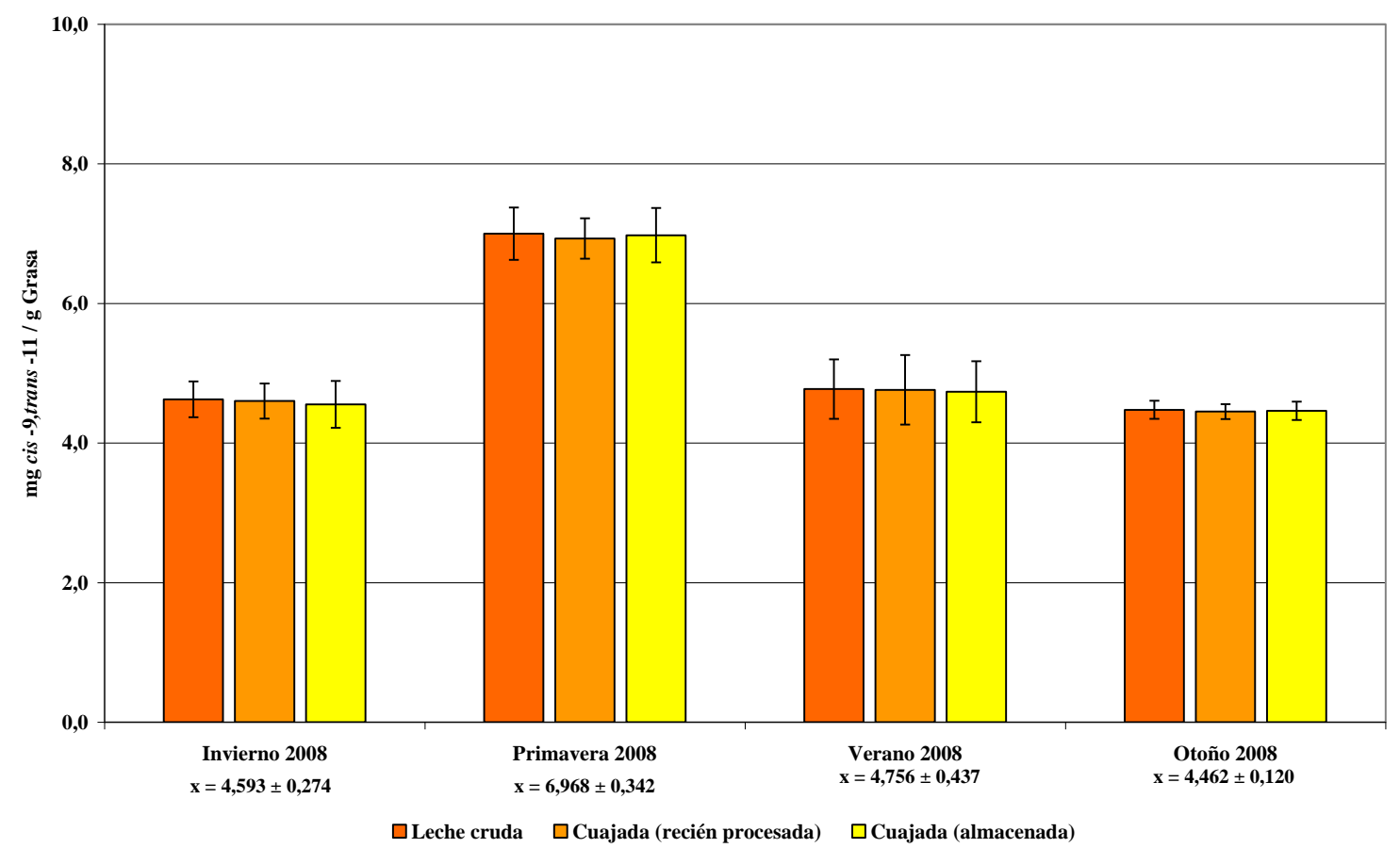

Figura 5.3. Variación del contenido de $c$ is-9,trans-11 en las muestras de cuajada. 
En la bibliografía sólo hemos encontrado una referencia en la que se cuantifica el contenido de CLA total en cuajada elaborada con leche de oveja (Herzallah et al., 2005). Estos autores determinan una concentración de $5,85 \mathrm{mg} / \mathrm{g}_{\text {Grasa }}$, un valor que se aproxima mucho a los niveles de CLA encontrados en las muestras de cuajada que hemos analizado durante los meses anteriores y posteriores a la primavera.

La Tabla 5.2 recoge de forma esquemática los resultados del tratamiento estadístico, con el fin de facilitar la comparación de las variaciones estacionales entre isómeros. En la misma se puede observar que las cantidades de CLA total y de cis9,trans-11, determinados en primavera, presentan diferencias significativas $(\mathrm{P}<0,01)$ con el resto de épocas estacionales; aunque también se encontró significación entre el verano y el otoño, tanto para el CLA total $(\mathrm{P}<0,05)$ como para el cis-9,trans-11 $(\mathrm{P}<$ $0,01)$.

Tabla 5.2. Diferencias estacionales: resultados del tratamiento estadístico en cuajada

\begin{tabular}{|c|c|c|c|c|c|c|c|c|c|c|c|c|c|c|}
\hline \multirow[b]{2}{*}{ Tiempo de muestreo } & \multicolumn{14}{|c|}{ Isómeros } \\
\hline & 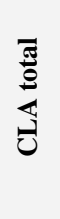 & 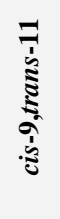 & 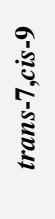 & 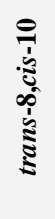 & 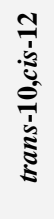 & 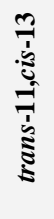 & 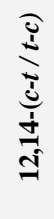 & 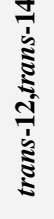 & 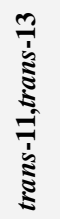 & 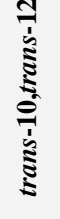 & 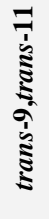 & 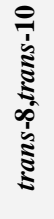 & 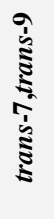 & 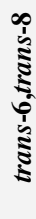 \\
\hline Invierno 2008 - Primavera 2008 & ** & ** & ** & ** & ** & ** & ** & ** & ** & ** & ** & ** & ** & \\
\hline Invierno 2008 - Verano 2008 & & & $*$ & $* *$ & & & & & $*$ & ** & ** & & & \\
\hline Invierno 2008 - Otoño 2008 & & & & ** & & & & & & ** & & & & \\
\hline Primavera 2008 - Verano 2008 & ** & $* *$ & $* *$ & $* *$ & $* *$ & $* *$ & ** & $* *$ & $* *$ & & $* *$ & ** & $* *$ & \\
\hline Primavera 2008 - Otoño 2008 & $* *$ & ** & $* *$ & ** & ** & ** & ** & ** & $* *$ & ** & ** & ** & ** & \\
\hline Verano 2008 - Otoño 2008 & $*$ & ** & & & & & & & & ** & $*$ & & & \\
\hline
\end{tabular}

Respecto a los cambios estacionales experimentados por otros isómeros en las cuajadas, hay que decir que muchos de ellos presentan un comportamiento bastante similar al encontrado en la leche UHT. Se detectaron diferencias con significación estadística entre los contenidos de primavera y el resto del año, para todos los isómeros $(\mathrm{P}<0,01)$, excepto para el trans-6,trans-8. 
El aumento del contenido de CLA total durante la primavera se debe al incremento de los siguientes isómeros, que claramente experimentan un mayor efecto estacional: trans-11,cis-13, trans-11,trans-13, 12,14-(cis-trans/trans-cis) y trans12,trans-14 (Figuras 5.5 a 5.8). De todos ellos, se observó la mayor repercusión estacional en los isómeros posicionales 11-13-CLA (trans-11,trans-13, trans-11,cis-13), ya que ambos isómeros triplicaron su contenido en primavera (Figura 5.5 y 5.6), aunque para el trans-11,trans-13 se encontró una significación adicional entre el invierno y el verano $(\mathrm{P}<0,05)$. Esta misma significación estadística se observó para el trans-7,cis-9 (Figura 5.4), segundo isómero mayoritario en las cuajadas, después del cis-9,trans-11. Respecto al trans-9,trans-11 (Figura 5.9), se encontraron diferencias estadísticas en todas las épocas, excepto entre el invierno y el otoño $(\mathrm{P}>0,05)$.

Para el resto de isómeros (ver Figuras 5.10 hasta 5.15), existe un pequeño aumento de su contenido en la cuajada durante la primavera, y al igual que en los demás isómeros mencionados previamente, los contenidos determinados en esta época presentan variaciones significativas $(\mathrm{P}<0,01)$ respecto a los encontrados en otras épocas del año. En cualquier caso, cabe decir que los aumentos observados no son tan importantes si se comparan con los encontrados en los isómeros que claramente experimentan mayor variación estacional. Salvo en el trans-8,cis-10 primaveral (Figura 5.10), ninguno de estos isómeros superó, en las distintas épocas del año, los 0,100 $\mathrm{mg} / \mathrm{g}_{\text {Grasa }}$ (ver Tabla 5.1). Este último isómero presenta diferencias entre todas las épocas $(\mathrm{P}<0,01)$, excepto entre el verano y el otoño (Tabla 5.2). Al igual que con la leche UHT, el trans-6,trans-8 (Figura 5.15) es el isómero minoritario cuyos contenidos fueron los más bajos de todos los isómeros presentes (entre 0,012 y $0,017 \mathrm{mg} / \mathrm{g}_{\text {Grasa }}$ ).

El incremento estacional del CLA observado en las cuajadas durante los meses correspondientes a la época primaveral es consecuencia de una mayor disponibilidad de pasto fresco, rico en ácido $\alpha$-linolénico. En la discusión de los resultados realizados para la leche UHT, se comentó que cuando se ingiere pasto, el aumento del CLA en la leche dependerá de la especie botánica del pasto, de su calidad y de la cantidad ingerida. Estas mismas observaciones pueden aplicarse a los resultados obtenidos en las cuajadas, aunque no hemos encontrado estudios relacionados con las variaciones estacionales en este tipo de productos. 


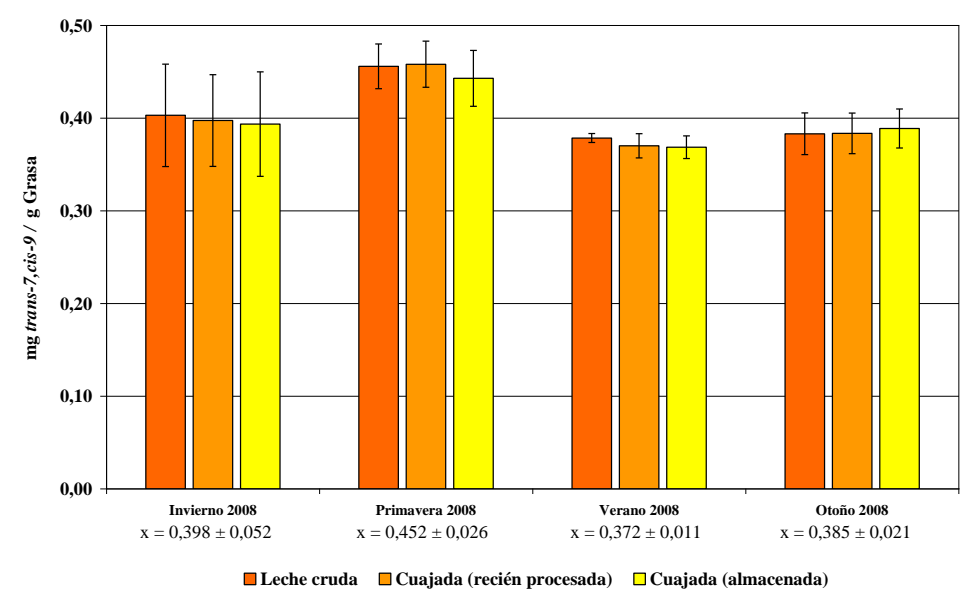

Figura 5.4. Variación del contenido de trans-7,cis-9 en las muestras de cuajada.

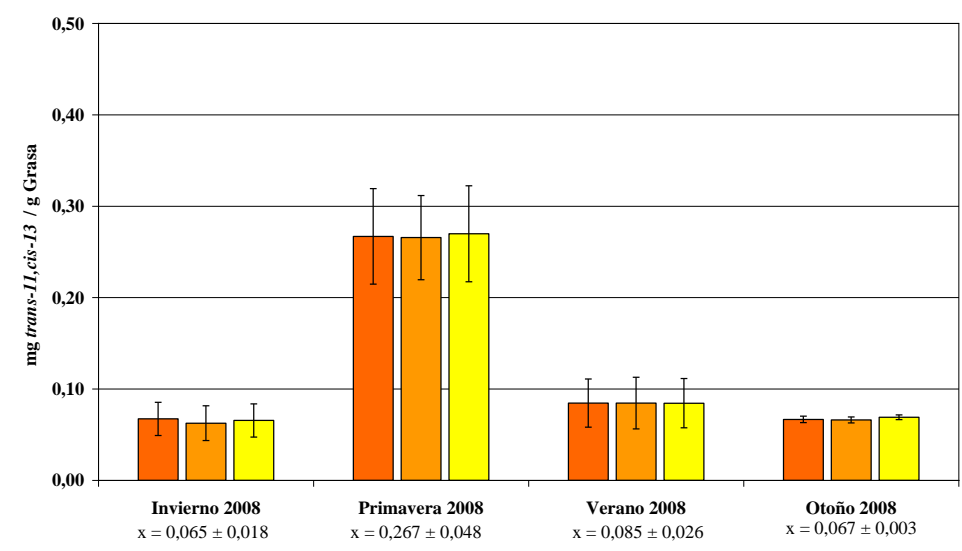

$\square$ Leche cruda $\square$ Cuajada (recién procesada) $\quad \square$ Cuajada (almacenada)

Figura 5.5. Variación del contenido de trans-11,cis-13 en las muestras de cuajada.

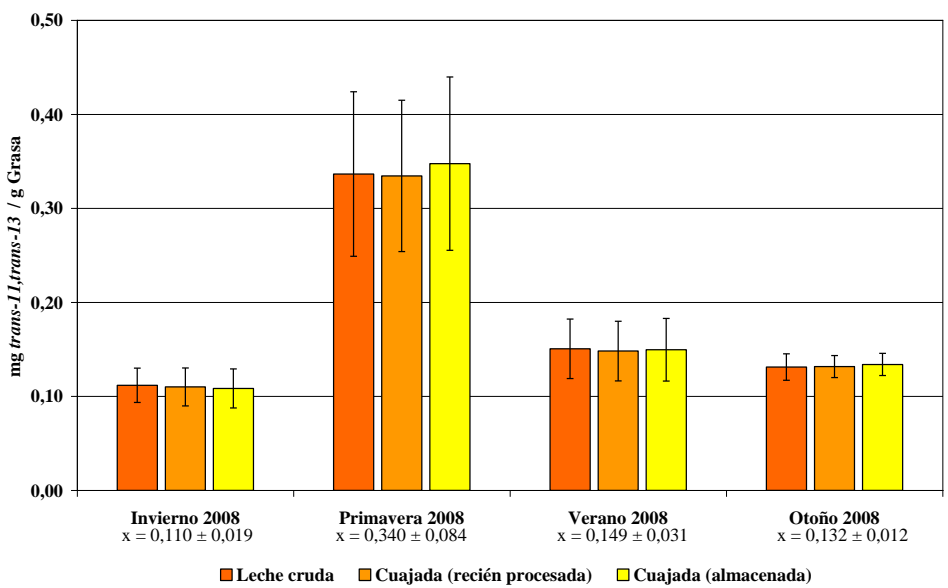

Figura 5.6. Variación del contenido de trans-11,trans-13 en las muestras de cuajada. 


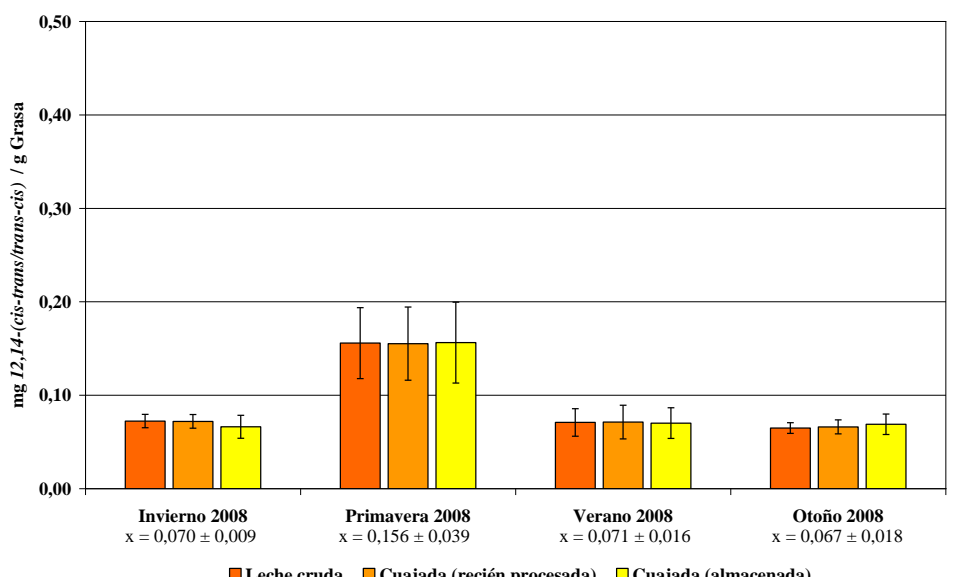

Figura 5.7. Variación del contenido de 12,14-(cis-trans/trans-cis) en las muestras de cuajada.

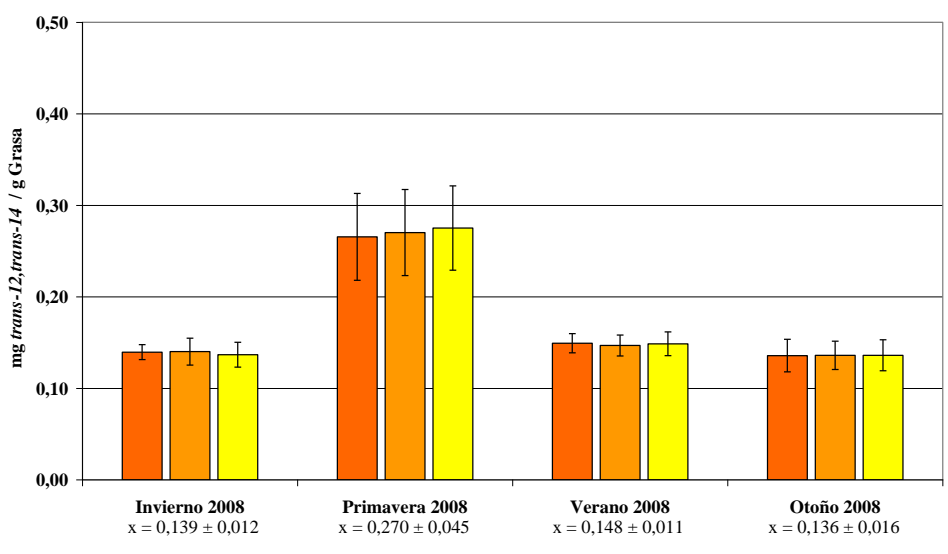

$\square$ Leche cruda $\square$ Cuajada (recién procesada) $\square$ Cuajada (almacenada)

Figura 5.8. Variación del contenido de trans-12,trans-14 en las muestras de cuajada.

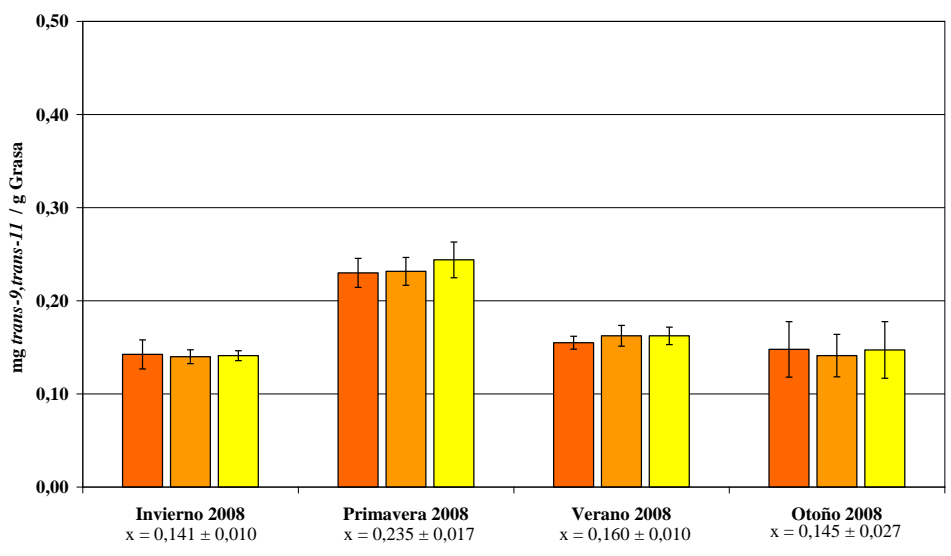

$\square$ Leche cruda $\square$ Cuajada (recién procesada) $\square$ Cuajada (almacenada)

Figura 5.9. Variación del contenido de trans-9,trans-11 en las muestras de cuajada. 


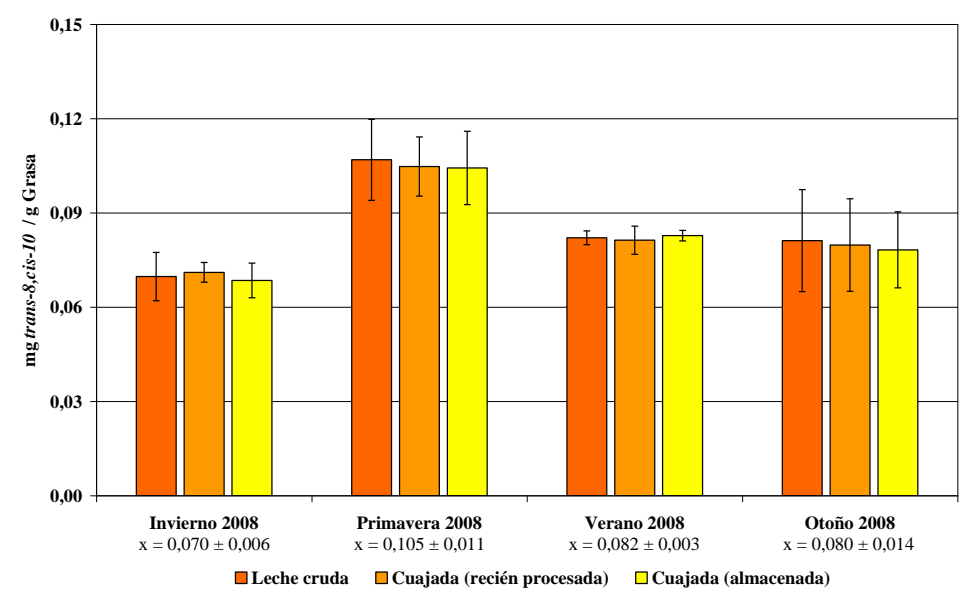

Figura 5.10. Variación del contenido de trans-8,cis-10 en las muestras de cuajada.

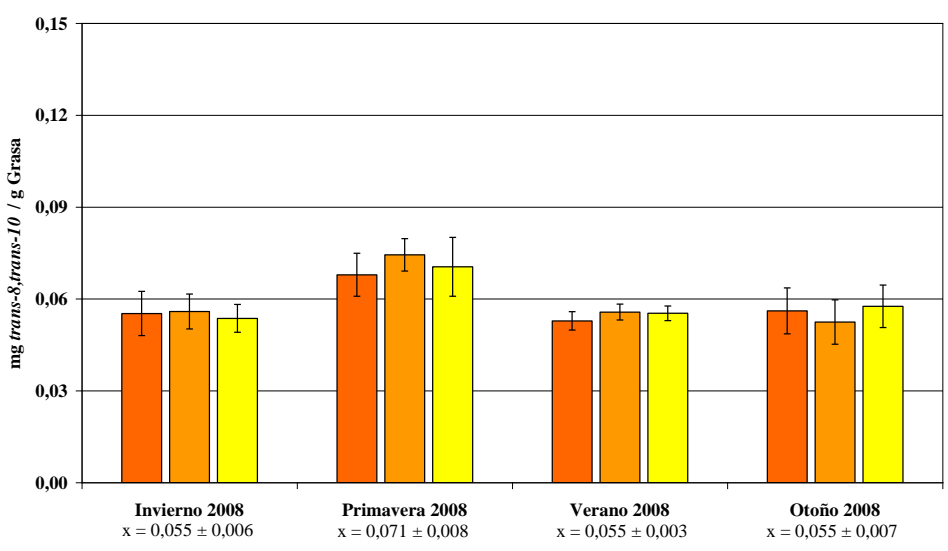

$\square$ Leche cruda $\square$ Cuajada (recién procesada) $\square$ Cuajada (almacenada)

Figura 5.11. Variación del contenido de trans-8,trans-10 en las muestras de cuajada.

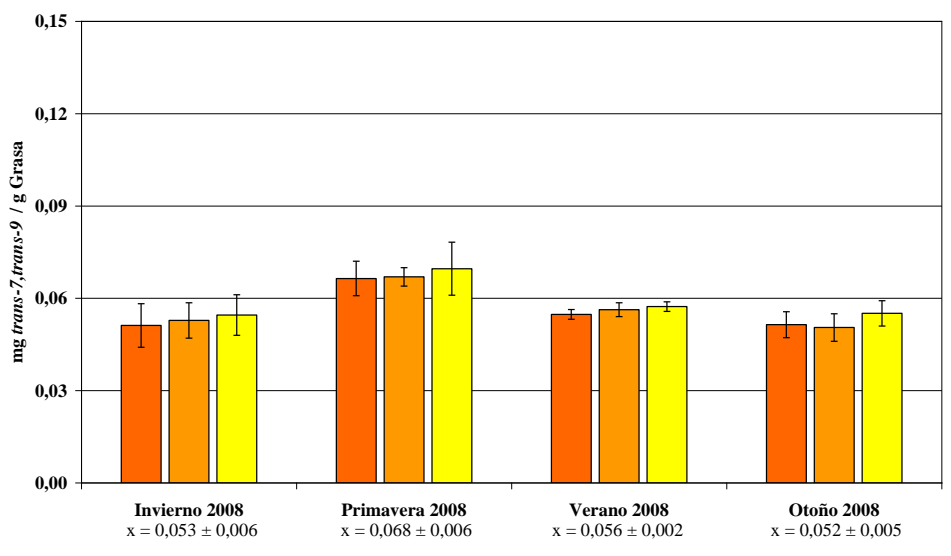

$\square$ Leche cruda $\square$ Cuajada (recién procesada) $\square$ Cuajada (almacenada)

Figura 5.12. Variación del contenido de trans-7,trans-9 en las muestras de cuajada. 


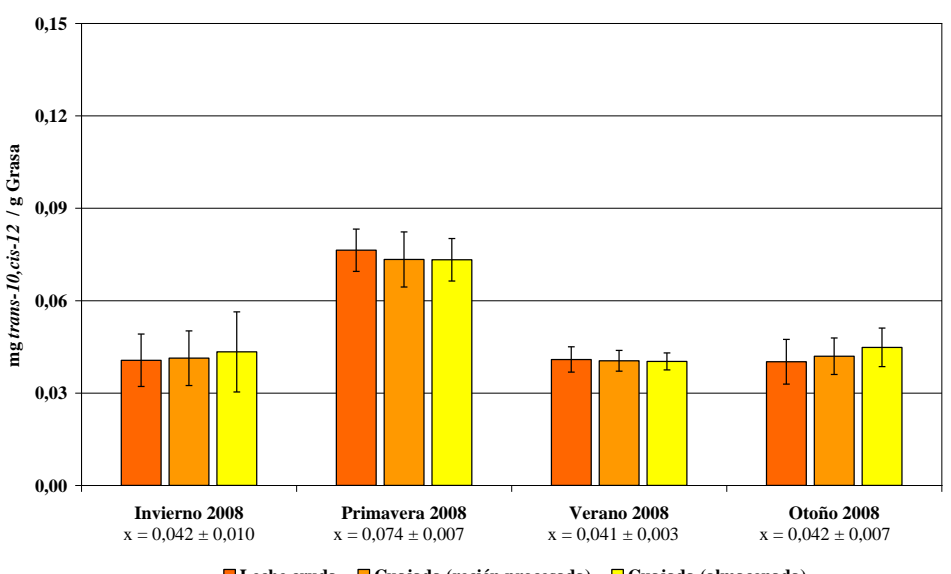

Figura 5.13. Variación del contenido de trans-10,cis-12 en las muestras de cuajada.

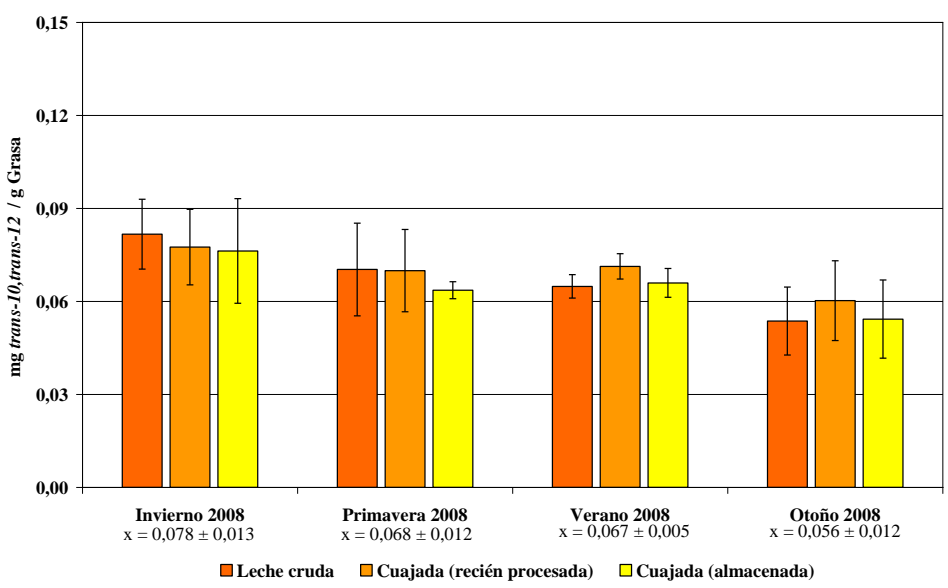

Figura 5.14. Variación del contenido de trans-10,trans-12 en las muestras de cuajada.

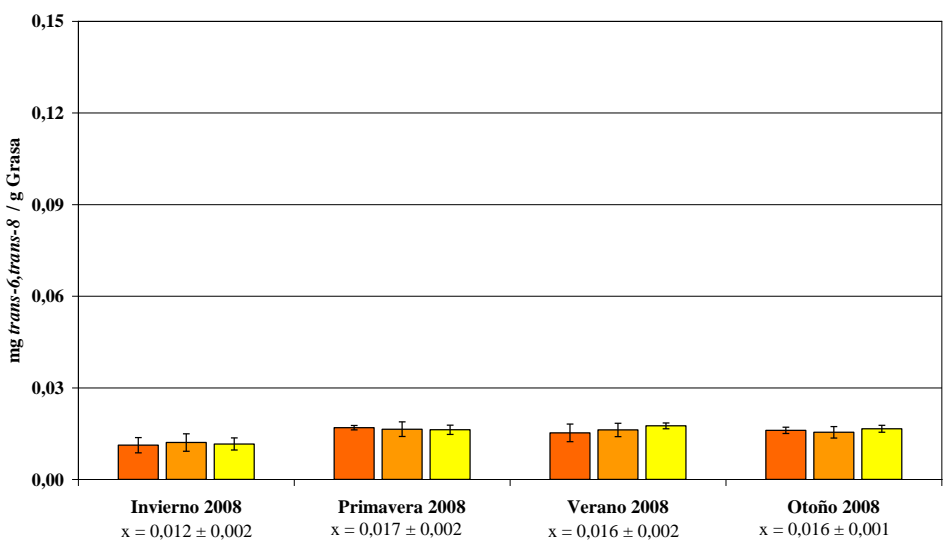

$\square$ Leche cruda $\square$ Cuajada (recién procesada) $\square$ Cuajada (almacenada)

Figura 5.15. Variación del contenido de trans-6,trans-8 en las muestras de cuajada. 
En el estudio realizado por Prandini et al. (2009), se observaron que los contenidos de CLA (cis-9,trans-11), en cuajadas elaboradas con leche de vaca alimentadas con un régimen "orgánico", aumentaron hasta $7,15 \mathrm{mg} / \mathrm{g}_{\text {Grasa }}$. Este valor es prácticamente igual al que hemos determinado para este mismo isómero en nuestras cuajadas primaverales $\left(6,968 \mathrm{mg} / \mathrm{g}_{\text {Grasa }}\right)$, aunque cabe destacar que estos autores también encuentran cambios estadísticamente significativos $(\mathrm{P}<0,05)$ respecto a las cuajadas convencionales $\left(5,00 \mathrm{mg} / \mathrm{g}_{\text {Grasa }}\right)$.

\subsubsection{Distribución de los isómeros CLA en cuajadas}

En general, los porcentajes de los isómeros CLA son bastante similares a los que encontramos en la leche de oveja UHT (Tabla 5.3). El isómero mayoritario, como era de esperar, fue el cis-9,trans-11 y su contenido en cuajada (entre 4,40 y 7,00 mg/g $\mathrm{g}_{\text {Grasa }}$, según la época estacional) supone entre el 77 y el 79\% del CLA total, mientras que el trans-7,cis-9 (entre 5 y 7\%) fue el segundo isómero más abundante.

Tabla 5.3. Contenido porcentual de isómeros CLA presentes en las distintas muestras de cuajadas, según la época estacional

\begin{tabular}{|c|c|c|c|c|}
\hline \multirow[b]{2}{*}{ Isómero CLA } & \multicolumn{4}{|c|}{ \% sobre el CLA total } \\
\hline & $\begin{array}{c}\text { Invierno } \\
\mathbf{2 0 0 8} \\
\end{array}$ & $\begin{array}{c}\text { Primavera } \\
2008 \\
\end{array}$ & $\begin{array}{c}\text { Verano } \\
2008 \\
\end{array}$ & $\begin{array}{c}\text { Otoño } \\
2008 \\
\end{array}$ \\
\hline trans-trans $C L A$ & $10,08 \pm 0,58$ & $11,69 \pm 0,98$ & $10,78 \pm 0,35$ & $10,40 \pm 0,74$ \\
\hline trans-12,trans-14 & $2,38 \pm 0,11$ & $2,96 \pm 0,33$ & $2,45 \pm 0,10$ & $2,38 \pm 0,22$ \\
\hline trans -11 ,trans -13 & $1,88 \pm 0,20$ & $3,69 \pm 0,70$ & $2,44 \pm 0,29$ & $2,32 \pm 0,15$ \\
\hline trans -10, trans -12 & $1,34 \pm 0,17$ & $0,74 \pm 0,10$ & $1,12 \pm 0,15$ & $0,99 \pm 0,23$ \\
\hline trans-9,trans-11 & $2,43 \pm 0,17$ & $2,59 \pm 0,17$ & $2,65 \pm 0,17$ & $2,54 \pm 0,41$ \\
\hline trans -8, trans -10 & $0,94 \pm 0,09$ & $0,78 \pm 0,06$ & $0,91 \pm 0,08$ & $0,97 \pm 0,11$ \\
\hline trans-7,trans-9 & $0,91 \pm 0,08$ & $0,75 \pm 0,08$ & $0,93 \pm 0,09$ & $0,92 \pm 0,07$ \\
\hline trans-6,trans -8 & $0,20 \pm 0,03$ & $0,18 \pm 0,02$ & $0,27 \pm 0,05$ & $0,28 \pm 0,02$ \\
\hline cis-trans + trans-cis & $89,92 \pm 0,58$ & $88,31 \pm 0,98$ & $89,22 \pm 0,35$ & $89,60 \pm 0,74$ \\
\hline $12,14-(c-t / t-c)$ & $1,21 \pm 0,17$ & $1,69 \pm 0,32$ & $1,16 \pm 0,15$ & $1,17 \pm 0,18$ \\
\hline trans -11, cis-13 & $1,10 \pm 0,23$ & $2,92 \pm 0,35$ & $1,37 \pm 0,30$ & $1,18 \pm 0,04$ \\
\hline trans -10, cis -12 & $0,71 \pm 0,13$ & $0,82 \pm 0,06$ & $0,68 \pm 0,11$ & $0,74 \pm 0,10$ \\
\hline cis-9,trans-11 & $78,89 \pm 1,14$ & $76,71 \pm 1,09$ & $78,47 \pm 0,46$ & $78,35 \pm 0,95$ \\
\hline trans $-8, c i s-10$ & $1,20 \pm 0,12$ & $1,16 \pm 0,11$ & $1,36 \pm 0,10$ & $1,39 \pm 0,21$ \\
\hline trans -7, cis -9 & $6,81 \pm 0,42$ & $5,01 \pm 0,56$ & $6,18 \pm 0,42$ & $6,76 \pm 0,16$ \\
\hline
\end{tabular}

Nota: Estos datos corresponden al promedio global de los porcentajes de cada isómero encontrado en las distintas muestras de cuajada. 
Durante la primavera, aumenta de forma considerable el porcentaje de los isómeros trans-11,trans-13 y trans-11,cis-13, y en menor proporción los correspondientes al trans-9,trans-11, trans-12,trans-14 y 12,14-(cis-trans/trans-cis). Este aumento conlleva una modificación en la distribución que hace que el porcentaje de isómeros mayoritarios disminuya en esta estación, efecto que también se manifiesta en algunos de los isómeros minoritarios (trans-10,trans-12, trans-8,trans-10, trans7,trans-9). Para el isómero trans-10,cis-12, la distribución se mantiene sin variaciones a lo largo del año de estudio.

\subsubsection{Estudio de isómeros CLA en yogur}

Los yogures se elaboraron con leche de oveja, siguiendo un procedimiento habitual para la fabricación de este tipo de productos (Figura 5.16).

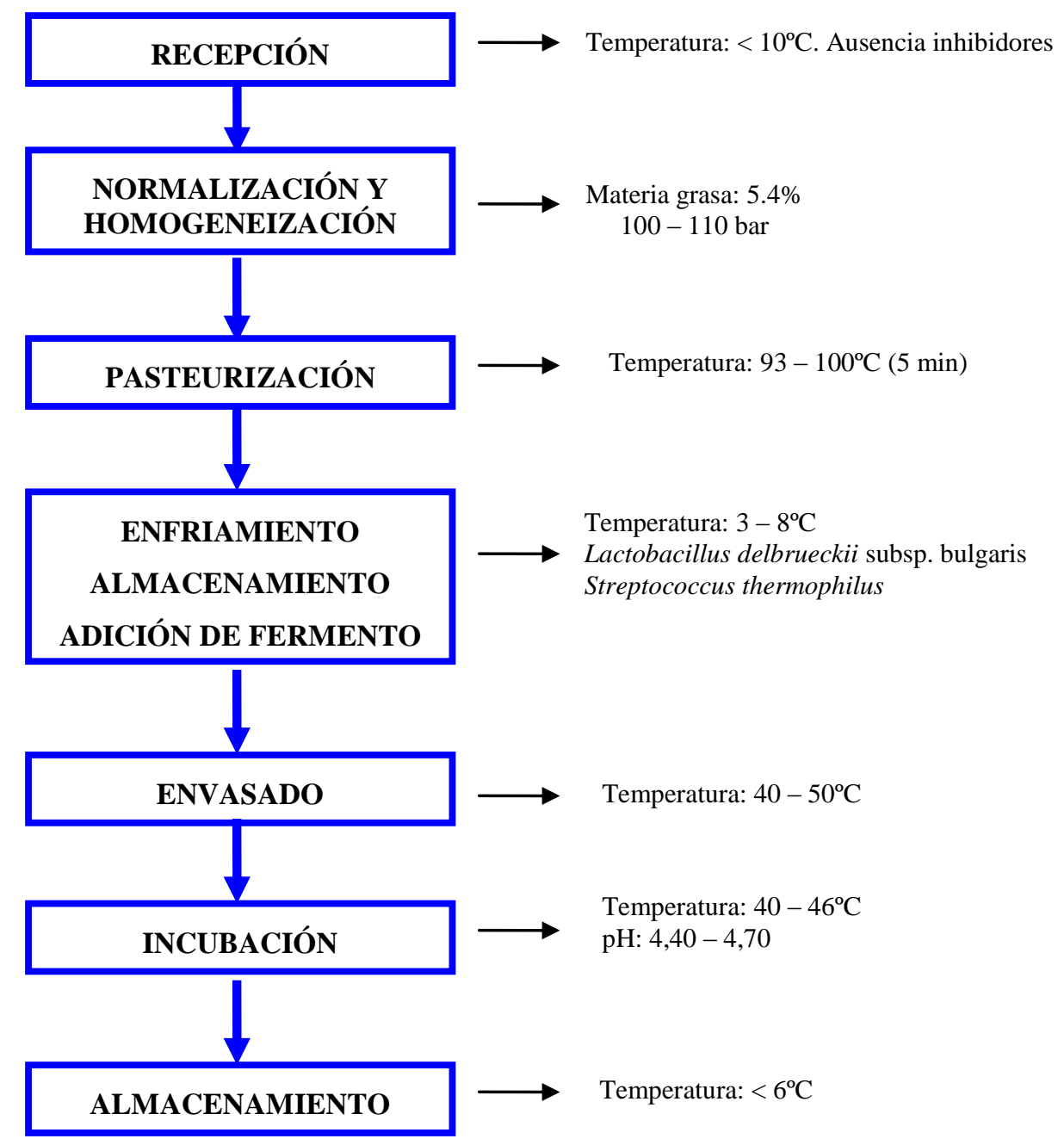

Figura 5.16. Esquema del procesado del yogur elaborado con leche de oveja, según la empresa GAZA. 
Durante la normalización, sólo se ajusta el contenido de grasa para que el producto final tenga un $5,40 \%$ de este componente, mientras que en los yogures que se fabrican con leche de vaca, se suele partir de leche semidesnatada, a la que se le añade nata y leche el polvo. Como ya hemos comentado previamente, no se dispuso de un número suficiente de muestras de yogur para estudiar la influencia estacional, por lo que para estas muestras, sólo se estudiará la influencia del procesado y almacenamiento.

\subsubsection{Contenido y variación del CLA total e isómeros individuales}

En la Tabla 5.4 se recogen los contenidos de los 13 isómeros y de CLA total, correspondientes a yogur recién elaborado y almacenado así como a la leche de partida.

Tabla 5.4. Contenido de isómeros CLA (mg/g $\left.\mathrm{g}_{\text {Grasa }}\right)$ en yogures

\begin{tabular}{|c|c|c|c|c|c|c|c|c|}
\hline \multirow[t]{2}{*}{ Isómero CLA } & \multirow[t]{2}{*}{ Muestra $^{(a)}$} & \multicolumn{7}{|c|}{$\tilde{\boldsymbol{x}} \pm s_{D}$} \\
\hline & & $\begin{array}{c}\text { Ene. } 08 \\
n=1\end{array}$ & $\begin{array}{c}\text { Abr. } 08 \\
\text { n }=1\end{array}$ & $\begin{array}{c}\text { May. } 08 \\
\text { n = } 1\end{array}$ & $\begin{array}{c}\text { Jul. } 08 \\
\text { n = } 1\end{array}$ & $\begin{array}{c}\text { Sep. } 08 \\
\mathrm{~N}=1\end{array}$ & $\begin{array}{c}\text { Nov. } 08 \\
n=1\end{array}$ & $\begin{array}{c}\text { Dic. } 08 \\
n=1\end{array}$ \\
\hline \multirow[t]{3}{*}{ trans-12,trans-14 } & Leche Cruda & $0,140 \pm 0,002$ & $0,240 \pm 0,008$ & $0,292 \pm 0,007$ & $0,142 \pm 0,006$ & $0,137 \pm 0,006$ & $0,146 \pm 0,002$ & $0,112 \pm 0,004$ \\
\hline & Yogur Proc. & $0,139 \pm 0,001$ & $0,255 \pm 0,004$ & $0,297 \pm 0,003$ & $0,150 \pm 0,003$ & $0,134 \pm 0,002$ & $0,146 \pm 0,003$ & $0,114 \pm 0,010$ \\
\hline & Yogur Almac. & $0,144 \pm 0,002$ & $0,264 \pm 0,004$ & $0,297 \pm 0,007$ & $0,152 \pm 0,004$ & $0,138 \pm 0,002$ & $0,147 \pm 0,007$ & $0,109 \pm 0,001$ \\
\hline \multirow[t]{3}{*}{ trans-11,trans-13 } & Leche Cruda & $0,093 \pm 0,001$ & $0,309 \pm 0,010$ & $0,399 \pm 0,007$ & $0,193 \pm 0,006$ & $0,135 \pm 0,011$ & $0,129 \pm 0,001$ & $0,110 \pm 0,006$ \\
\hline & Yogur Proc. & $0,094 \pm 0,004$ & $0,315 \pm 0,008$ & $0,400 \pm 0,002$ & $0,189 \pm 0,003$ & $0,130 \pm 0,002$ & $0,130 \pm 0,004$ & $0,119 \pm 0,005$ \\
\hline & Yogur Almac. & $0,088 \pm 0,002$ & $0,313 \pm 0,013$ & $0,419 \pm 0,008$ & $0,195 \pm 0,006$ & $0,132 \pm 0,002$ & $0,127 \pm 0,002$ & $0,119 \pm 0,004$ \\
\hline \multirow[t]{3}{*}{ trans -10, trans -12} & Leche Cruda & $0,066 \pm 0,001$ & $0,052 \pm 0,002$ & $0,076 \pm 0,003$ & $0,064 \pm 0,004$ & $0,064 \pm 0,003$ & $0,039 \pm 0,002$ & $0,065 \pm 0,004$ \\
\hline & Yogur Proc. & $0,066 \pm 0,001$ & $0,058 \pm 0,002$ & $0,063 \pm 0,001$ & $0,071 \pm 0,001$ & $0,064 \pm 0,002$ & $0,041 \pm 0,004$ & $0,063 \pm 0,003$ \\
\hline & Yogur Almac. & $0,064 \pm 0,003$ & $\mathbf{0 , 0 6 1 \pm 0 , 0 0 7}$ & $0,064 \pm 0,001$ & $0,065 \pm 0,001$ & $0,068 \pm 0,001$ & $0,039 \pm 0,002$ & $0,061 \pm 0,003$ \\
\hline \multirow[t]{3}{*}{ trans -9, trans -11} & Leche Cruda & $0,147 \pm 0,003$ & $0,219 \pm 0,007$ & $0,230 \pm 0,003$ & $0,164 \pm 0,002$ & $0,147 \pm 0,003$ & $0,133 \pm 0,002$ & $0,122 \pm 0,003$ \\
\hline & Yogur Proc. & $0,149 \pm 0,003$ & $0,229 \pm 0,005$ & $0,240 \pm 0,005$ & $0,164 \pm 0,006$ & $0,153 \pm 0,003$ & $0,130 \pm 0,007$ & $0,135 \pm 0,003$ \\
\hline & Yogur Almac. & $0,154 \pm 0,009$ & $0,222 \pm 0,020$ & $0,233 \pm 0,001$ & $0,169 \pm 0,002$ & $0,152 \pm 0,007$ & $0,135 \pm 0,002$ & $0,129 \pm 0,007$ \\
\hline \multirow[t]{3}{*}{ trans -8, trans -10} & Leche Cruda & $0,055 \pm 0,001$ & $0,068 \pm 0,010$ & $0,053 \pm 0,002$ & $0,056 \pm 0,004$ & $0,055 \pm 0,001$ & $0,052 \pm 0,001$ & $0,047 \pm 0,001$ \\
\hline & Yogur Proc. & $0,055 \pm 0,002$ & $0,063 \pm 0,001$ & $0,059 \pm 0,001$ & $0,050 \pm 0,001$ & $0,055 \pm 0,001$ & $0,054 \pm 0,002$ & $0,051 \pm 0,004$ \\
\hline & Yogur Almac. & $0,057 \pm 0,002$ & $0,064 \pm 0,004$ & $0,055 \pm 0,002$ & $0,050 \pm 0,002$ & $0,056 \pm 0,002$ & $0,053 \pm 0,001$ & $0,052 \pm 0,005$ \\
\hline \multirow[t]{3}{*}{ trans -7, trans -9} & Leche Cruda & $0,048 \pm 0,002$ & $0,064 \pm 0,008$ & $0,062 \pm 0,001$ & $0,053 \pm 0,002$ & $0,049 \pm 0,002$ & $0,055 \pm 0,001$ & $0,048 \pm 0,002$ \\
\hline & Yogur Proc. & $0,049 \pm 0,003$ & $0,060 \pm 0,006$ & $0,060 \pm 0,002$ & $0,051 \pm 0,002$ & $0,049 \pm 0,001$ & $0,057 \pm 0,002$ & $0,047 \pm 0,003$ \\
\hline & Yogur Almac. & $0,048 \pm 0,001$ & $0,056 \pm 0,004$ & $0,061 \pm 0,001$ & $0,048 \pm 0,002$ & $0,050 \pm 0,002$ & $0,055 \pm 0,003$ & $0,052 \pm 0,003$ \\
\hline \multirow[t]{3}{*}{ trans -6, trans -8} & Leche Cruda & $0,012 \pm 0,003$ & $0,019 \pm 0,006$ & $0,016 \pm 0,001$ & $0,013 \pm 0,002$ & $0,018 \pm 0,001$ & $0,014 \pm 0,002$ & $0,015 \pm 0,001$ \\
\hline & Yogur Proc. & $0,011 \pm 0,001$ & $0,016 \pm 0,007$ & $0,014 \pm 0,001$ & $0,013 \pm 0,002$ & $0,016 \pm 0,001$ & $0,015 \pm 0,001$ & $0,012 \pm 0,001$ \\
\hline & Yogur Almac. & $0,010 \pm 0,001$ & $0,016 \pm 0,001$ & $0,016 \pm 0,001$ & $0,011 \pm 0,001$ & $0,019 \pm 0,001$ & $0,014 \pm 0,001$ & $0,015 \pm 0,002$ \\
\hline
\end{tabular}

(a) Leche cruda, yogur recién procesado, yogur almacenado: No se han encontrado diferencias significativas, $\mathrm{P}>0,05$.

"n" = Número de muestras, analizadas por triplicado. 
Cada una de las muestras se analizó por triplicado, y los resultados se registraron según el mes al que corresponde. En el yogur recién fabricado, el contenido de CLA total varía entre 5,556 y $8,796 \mathrm{mg} / \mathrm{g}_{\text {Grasa }}$, con un valor medio de $6,617 \pm 1,308 \mathrm{mg} / \mathrm{g}_{\text {Grasa }}$. Los niveles más elevados corresponden a los meses de abril y mayo $\left(>8,00 \mathrm{mg} / \mathrm{g}_{\text {Grasa }}\right.$ ), mientras que el más bajo se encontró en diciembre $\left(5,556 \pm 0,246 \mathrm{mg} / \mathrm{g}_{\text {Grasa }}\right)$. El isómero mayoritario cis-9,trans-11 (Figura 5.18) presenta un comportamiento similar, como no podría ser de otra forma, puesto que es el que prácticamente condiciona el contenido de CLA total (Figura 5.17).

Tabla 5.4 (cont.). Contenido de isómeros CLA ( $\left.\mathrm{mg} / \mathrm{g}_{\text {Grasa }}\right)$ en yogures

\begin{tabular}{|c|c|c|c|c|c|c|c|c|}
\hline \multirow[t]{2}{*}{ Isómero CLA } & \multirow[t]{2}{*}{ Muestra $^{(\mathbf{a})}$} & \multicolumn{7}{|c|}{$\tilde{\boldsymbol{x}} \pm \boldsymbol{s}_{\boldsymbol{D}}$} \\
\hline & & $\begin{array}{c}\text { Ene. } 08 \\
n=1\end{array}$ & $\begin{array}{c}\text { Abr. } 08 \\
n=1\end{array}$ & $\begin{array}{c}\text { May. } 08 \\
n=1\end{array}$ & $\begin{array}{c}\text { Jul. 08 } \\
\text { n = 1 }\end{array}$ & $\begin{array}{c}\text { Sep. } 08 \\
n=1\end{array}$ & $\begin{array}{c}\text { Nov. } 08 \\
n=1\end{array}$ & $\begin{array}{c}\text { Dic. } 08 \\
n=1\end{array}$ \\
\hline \multirow[t]{3}{*}{$12,14-(c-t / t-c)$} & Leche Cruda & $0,061 \pm 0,002$ & $0,144 \pm 0,003$ & $0,180 \pm 0,002$ & $0,090 \pm 0,004$ & $0,067 \pm 0,005$ & $0,063 \pm 0,002$ & $0,073 \pm 0,001$ \\
\hline & Yogur Proc. & $0,061 \pm 0,001$ & $0,145 \pm 0,013$ & $0,176 \pm 0,002$ & $0,083 \pm 0,001$ & $0,062 \pm 0,005$ & $0,063 \pm 0,007$ & $0,073 \pm 0,002$ \\
\hline & Yogur Almac. & $0,058 \pm 0,001$ & $0,139 \pm 0,015$ & $0,177 \pm 0,001$ & $0,082 \pm 0,004$ & $0,061 \pm 0,006$ & $0,060 \pm 0,004$ & $0,084 \pm 0,005$ \\
\hline \multirow[t]{3}{*}{ trans -11, cis -13} & Leche Cruda & $0,049 \pm 0,002$ & $0,245 \pm 0,005$ & $0,310 \pm 0,002$ & $0,109 \pm 0,005$ & $0,068 \pm 0,005$ & $0,071 \pm 0,001$ & $0,056 \pm 0,002$ \\
\hline & Yogur Proc. & $0,048 \pm 0,001$ & $0,242 \pm 0,001$ & $0,308 \pm 0,005$ & $0,114 \pm 0,001$ & $0,068 \pm 0,001$ & $0,072 \pm 0,006$ & $0,058 \pm 0,002$ \\
\hline & Yogur Almac. & $0,047 \pm 0,002$ & $0,226 \pm 0,005$ & $0,309 \pm 0,004$ & $0,116 \pm 0,004$ & $0,070 \pm 0,003$ & $0,069 \pm 0,004$ & $0,055 \pm 0,001$ \\
\hline \multirow[t]{3}{*}{ trans -10, cis -12} & Leche Cruda & $0,050 \pm 0,001$ & $0,063 \pm 0,002$ & $0,072 \pm 0,004$ & $0,035 \pm 0,002$ & $0,042 \pm 0,005$ & $0,042 \pm 0,002$ & $0,038 \pm 0,003$ \\
\hline & Yogur Proc. & $0,049 \pm 0,003$ & $0,063 \pm 0,002$ & $0,070 \pm 0,004$ & $0,034 \pm 0,002$ & $0,036 \pm 0,002$ & $0,043 \pm 0,003$ & $0,038 \pm 0,001$ \\
\hline & Yogur Almac. & $0,050 \pm 0,001$ & $0,072 \pm 0,002$ & $0,070 \pm 0,004$ & $0,032 \pm 0,002$ & $0,038 \pm 0,003$ & $0,042 \pm 0,002$ & $0,042 \pm 0,002$ \\
\hline \multirow[t]{3}{*}{ cis -9, trans -11} & Leche Cruda & $4,662 \pm 0,071$ & $6,403 \pm 0,102$ & $6,662 \pm 0,071$ & $4,940 \pm 0,034$ & $4,694 \pm 0,057$ & $4,583 \pm 0,087$ & $4,320 \pm 0,025$ \\
\hline & Yogur Proc. & $4,607 \pm 0,017$ & $6,445 \pm 0,203$ & $6,640 \pm 0,045$ & $4,882 \pm 0,046$ & $4,521 \pm 0,084$ & $4,601 \pm 0,074$ & $4,415 \pm 0,188$ \\
\hline & Yogur Almac. & $4,616 \pm 0,072$ & $6,441 \pm 0,214$ & $6,666 \pm 0,063$ & $4,910 \pm 0,039$ & $4,582 \pm 0,042$ & $4,523 \pm 0,055$ & $4,280 \pm 0,097$ \\
\hline \multirow[t]{3}{*}{ trans -8, cis -10} & Leche Cruda & $0,066 \pm 0,006$ & $0,096 \pm 0,005$ & $0,093 \pm 0,008$ & $0,074 \pm 0,003$ & $0,086 \pm 0,010$ & $0,090 \pm 0,011$ & $0,054 \pm 0,008$ \\
\hline & Yogur Proc. & $0,064 \pm 0,003$ & $0,094 \pm 0,003$ & $0,090 \pm 0,005$ & $0,075 \pm 0,002$ & $0,075 \pm 0,006$ & $0,095 \pm 0,003$ & $0,063 \pm 0,010$ \\
\hline & Yogur Almac. & $0,064 \pm 0,003$ & $0,096 \pm 0,004$ & $0,090 \pm 0,006$ & $0,072 \pm 0,002$ & $0,078 \pm 0,004$ & $0,087 \pm 0,013$ & $0,062 \pm 0,011$ \\
\hline \multirow[t]{3}{*}{ trans -7, cis -9} & Leche Cruda & $0,379 \pm 0,013$ & $0,417 \pm 0,017$ & $0,365 \pm 0,004$ & $0,349 \pm 0,004$ & $0,380 \pm 0,017$ & $0,386 \pm 0,007$ & $0,355 \pm 0,008$ \\
\hline & Yogur Proc. & $0,378 \pm 0,010$ & $0,416 \pm 0,015$ & $0,380 \pm 0,006$ & $0,344 \pm 0,002$ & $0,364 \pm 0,009$ & $0,398 \pm 0,004$ & $0,366 \pm 0,022$ \\
\hline & Yogur Almac. & $0,379 \pm 0,010$ & $0,410 \pm 0,014$ & $0,366 \pm 0,007$ & $0,340 \pm 0,007$ & $0,364 \pm 0,013$ & $0,382 \pm 0,005$ & $0,361 \pm 0,013$ \\
\hline \multirow[t]{3}{*}{ CLA TOTAL } & Leche Cruda & $5,828 \pm 0,072$ & $8,341 \pm 0,174$ & $8,812 \pm 0,074$ & $6,282 \pm 0,055$ & $5,942 \pm 0,065$ & $5,801 \pm 0,061$ & $5,415 \pm 0,045$ \\
\hline & Yogur Proc. & $5,770 \pm 0,027$ & $8,399 \pm 0,251$ & $8,796 \pm 0,067$ & $6,221 \pm 0,051$ & $5,728 \pm 0,107$ & $5,847 \pm 0073$ & $5,556 \pm 0,246$ \\
\hline & Yogur Almac. & $5,779 \pm 0,066$ & $8,380 \pm 0,286$ & $8,824 \pm 0,090$ & $6,241 \pm 0,054$ & $5,808 \pm 0,068$ & $5,735 \pm 0,093$ & $5,420 \pm 0,130$ \\
\hline
\end{tabular}

(a) Leche cruda, yogur recién procesado, yogur almacenado: No se han encontrado diferencias significativas, $\mathrm{P}>0,05$.

"n" = Número de muestras, analizadas por triplicado. 


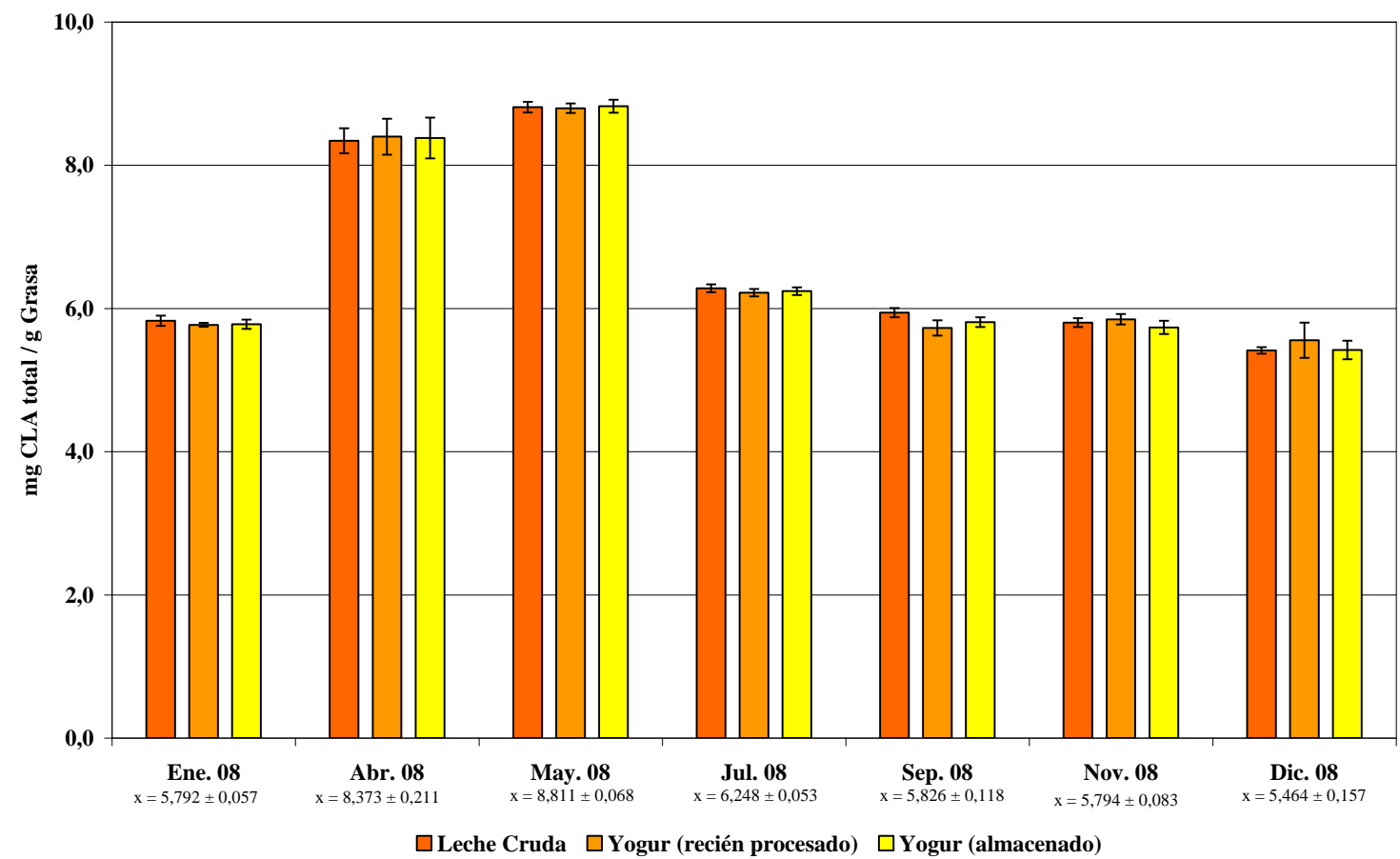

Figura 5.17. Variación del contenido de CLA total en las muestras de yogur.

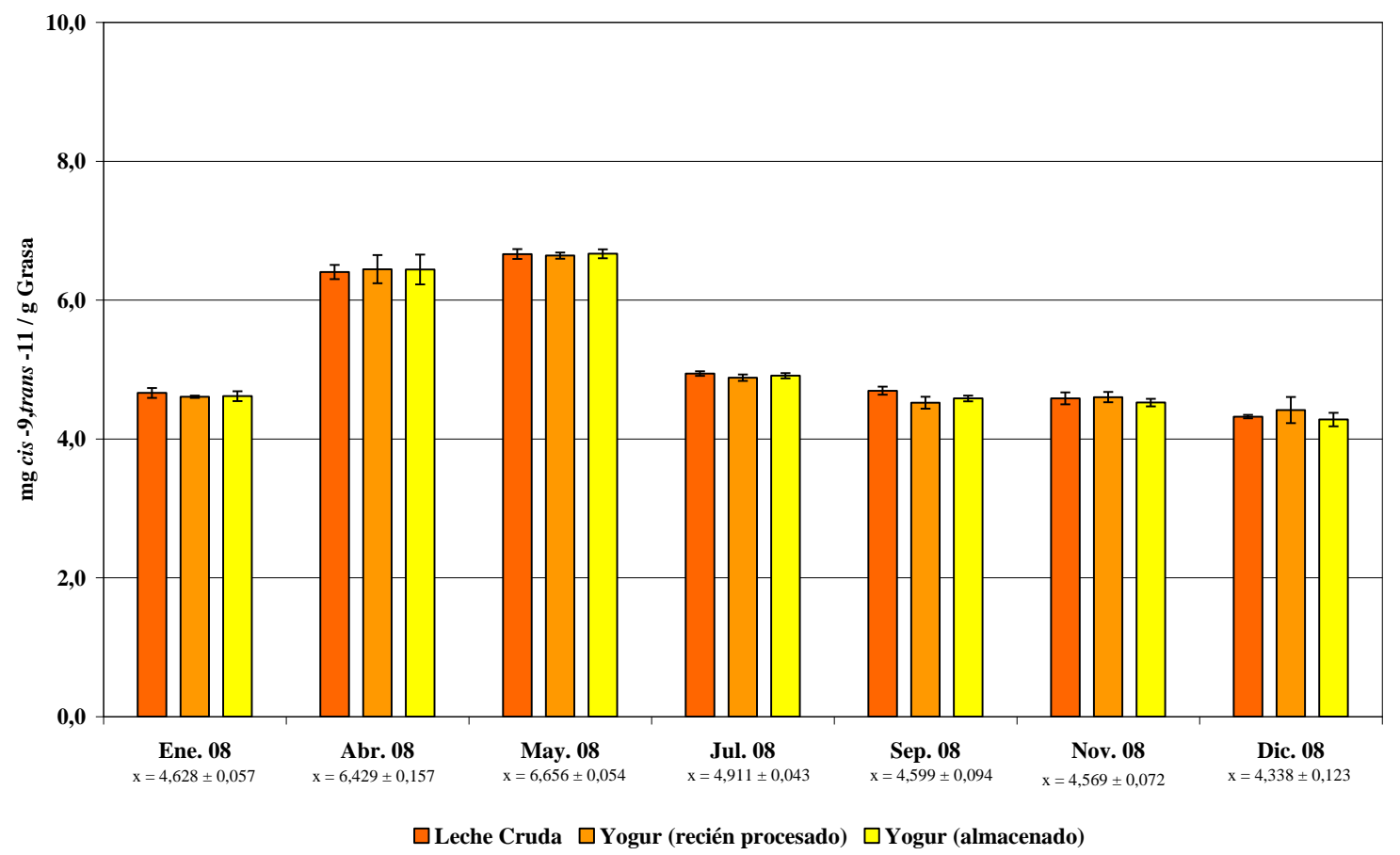

Figura 5.18. Variación del contenido de cis-9,trans-11 en las muestras de yogur. 
En la bibliografía se dispone de muy pocos resultados respecto a la presencia de CLA en yogur de oveja. Prandini et al. (2007) recogen un contenido medio de cis9,trans-11 de 6,92 $\pm 1,48 \mathrm{mg} / \mathrm{g}_{\text {Grasa }}$ para 5 muestras de yogures comerciales y encuentran diferencias significativas respecto a los elaborados con leche de vaca, en este caso con concentraciones inferiores. Las cantidades de este isómero presentes en las muestras analizadas en nuestro trabajo se encuentran en un intervalo de 4,41 a 6,64 $\mathrm{mg} / \mathrm{g}_{\text {Grasa }}$ (Tabla 5.4) con un contenido medio, para los meses de enero a abril, de 5,526 $\pm 1,105$, evidentemente más bajo que el determinado en la publicación que se acaba de citar. Se ha calculado el valor medio para esos meses concretos porque se corresponden con los de adquisición de las muestras en el estudio anterior.

Las cantidades encontradas en yogures de leche de vaca, varían en intervalos muy amplios. Así, en 6 muestras de yogures comerciales adquiridas en Québec (Park et $a l ., 2008)$, se determinaron contenidos de cis-9,trans-11 de $12,98 \pm 4,7 \mathrm{mg} / \mathrm{g}_{\text {Grasa }}$ con un intervalo de 5,45 a 19,40. Sin embargo, en 45 muestras de yogures comerciales comprados en Portugal (Martins et al., 2007), la cantidad de CLA total correspondió a un valor mucho más bajo $\left(4,00 \pm 1,031 \mathrm{mg} / \mathrm{g}_{\text {Grasa }}\right)$. El contenido medio de cis-9,trans-11 que se encontró en 30 muestras de Italia fue de $5,20 \pm 1,33 \mathrm{mg} / \mathrm{g}_{\text {Grasa }}$ (Prandini et al., 2007). Para estimar la ingesta de CLA en Francia, se ha considerado un contenido de $0,02 \mathrm{~g} / 100 \mathrm{~g}$ de yogur, que correspondería a $5,464 \mathrm{mg} / \mathrm{g}_{\text {Grasa }}$ (Laloux et al., 2007). En la última estimación realizada en Reino Unido (Mushtaq et al., 2010), se asignó al yogur un contenido medio de $2,3 \pm 0,3 \mathrm{mg} / \mathrm{g}_{\text {Grasa }}$ para el cis-9,trans-11 y de $0,069 \mathrm{mg} / \mathrm{g}_{\text {Grasa }}$ para el trans-10,cis-12, este último valor es bastante parecido a los niveles de trans10,cis-12 que hemos determinado en las muestras de yogur analizadas en nuestro trabajo para los meses de abril y mayo y algo más alto si se compara con el resto de meses.

En esta parte de la discusión, sólo hacemos mención a aquellas publicaciones que recogen resultados en yogures comerciales, debido a que pensamos que es con los que se debe hacer la comparación, puesto que en el caso de los yogures experimentales, se introducen cambios con el fin de aumentar el contenido de CLA. Aunque se ha afirmado que los productos lácteos derivados de oveja tienen contenidos de CLA mayores que los correspondientes de vaca, los resultados que acabamos de comentar no nos permiten apoyar dicha afirmación puesto que la variabilidad es muy grande. 


\subsubsection{Influencia del procesado y del almacenamiento}

En nuestros resultados no se observan diferencias con significación estadística entre las cantidades de los distintos isómeros en el yogur y en la leche utilizada para su elaboración. Este es un aspecto que presenta controversia en la bibliografía, puesto que algunos autores han encontrado aumentos atribuibles a la fermentación y otros no. Parece que, el incremento estaría condicionado por el tipo de microorganismos, presencia de sustratos, tiempo y condiciones de incubación (Sieber et al., 2004).

Se dispone de bastantes evidencias en sistemas modelo, que apoyan la síntesis microbiana de CLA a partir de ácido linoleico libre. Lin et al., (1999) utilizaron un sistema con leche desnatada esterilizada más ácido linoleico libre (1.000 ó 5.000 $\mu \mathrm{g} / \mathrm{mL}$ ) y a este sistema añadieron diferentes bacterias, demostrándose que aquellas que se emplean comúnmente en la elaboración del yogur (Lactobacillus delbrueckii subsp. bulgaricus y Streptococcus thermophilus) son capaces de producir CLA, aunque bajo las mismas condiciones, otros microorganismos resultaron ser más eficaces. Sin embargo, este y otros efectos comprobados en sistemas modelo, no están totalmente contrastados en yogures (Xu et al., 2005; Xu et al., 2006). Las publicaciones más recientes indican que es necesaria la combinación de otras bacterias con las propias del yogur y/o la presencia de ácido linoleico libre para que se produzcan aumentos de CLA (Sieber et al., 2004; Yadav et al., 2007; Florence et al., 2009). Sin embargo, respecto al ácido linoleico hay que matizar que la adición del mismo en forma de triglicérido (aceite de girasol, $1 \mathrm{mg} / \mathrm{mL}$ ) también provocó un aumento en el contenido de CLA. Dicho aumento fue menor que al utilizar linoleico libre y además fue necesario un tiempo mayor de incubación (Rodríguez-Alcalá et al., 2011).

En yogur desnatado, se produjo un pequeño aumento de CLA atribuible al procesado, pero este efecto resulta difícil de explicar, puesto que no se observó en yogures con un contenido de grasa de 1 y 3,25\% (Shantha et al., 1995). En otros estudios, no se detectaron diferencias entre la leche de partida y el yogur, destacándose que la variabilidad observada entre los contenidos de las distintas muestras se relaciona con las diferencias en la leche de partida (Boylston y Beitz, 2002; Lin et al., 1995).

Los resultados encontrados en las muestras analizadas en este trabajo estarían de acuerdo con la afirmación de Prandini et al., (2007), respecto a que el isómero cis- 
9,trans-11 no depende de la presencia microorganismos, sino de la cantidad originalmente presente en leche.

En algún trabajo se recoge que las cantidades de CLA presentes en yogur son dos veces más elevadas que la encontradas en leche (Park et al., 2008) o al contrario que son bastante más bajas, aproximadamente la mitad (Martins et al., 2007). Dichas afirmaciones hay que matizarlas, puesto que, en estos casos concretos, se analizan muestras adquiridas en el mercado, y la leche analizada no corresponde a la que se utilizó para la elaboración del yogur.

Se admite que la leche tiene un contenido medio de ácido linoleico (cis-9,cis-12 $\mathrm{C}_{18: 2}$ ) de $10 \mathrm{mg} / \mathrm{g}_{\text {Grasa }}$, y su presencia como ácido graso libre no supera $\operatorname{los} 0,1 \mathrm{mg} / \mathrm{g}_{\text {Grasa }}$ (Sieber et al., 2004). Aunque toda la fracción libre se hubiese transformado en CLA, supondría un aumento muy pequeño que, con los contenidos determinados en las muestras analizadas en este trabajo, no representarían una modificación significativa, salvo que la transformación afectase a algunos de los isómeros minoritarios. Además, el CLA que se pudiera llegar a formar estaría presente como ácido libre y no sería posible determinarlo con el método de análisis utilizado.

El almacenamiento de los yogures en refrigeración hasta el final de su vida útil, no produjo modificaciones en el contenido de CLA total ni en los isómeros individuales. Estos resultados coinciden con los encontrados por otros autores en yogures experimentales fabricados con leche de vaca. No se encontraron variaciones en el contenido de cis-9,trans-11, trans-10,cis-12 y cis-11,trans-13 en yogures almacenados a $4^{\circ} \mathrm{C}$ durante siete días (Boylston y Beitz, 2002). Tampoco se observaron cambios en el contenido del isómero cis-9,trans-11 en yogur almacenado a la misma temperatura durante 28 días, pero sí hubo diferencias a los 35 días de almacenamiento (Akalin et al., 2007), aunque hay que tener presente que este último periodo supera la vida útil del yogur. Según estos últimos autores, no se llegó a detectar la presencia de trans-10,cis-12 después de una semana de almacenamiento, pero como los contenidos iniciales del mismo fueron muy bajos $(0,05 \mu \mathrm{g} / \mathrm{g})$, es posible que una pequeña disminución provoque que la cantidad residual sea inferior al límite de detección.

Herzallah et al. (2005) recogen un descenso del CLA total en yogur almacenado 7 días en refrigeración y lo atribuyen a la captación de radicales libres formados durante 
la oxidación lipídica. En cualquier caso, se trata de pequeñas variaciones del orden de 0,22 a $0,35 \mathrm{mg} / \mathrm{g}_{\text {Grasa }}$, para valores iniciales de $5 \mathrm{mg} / \mathrm{g}_{\text {Grasa }}$.

Al no disponer de datos relacionados con la variación del contenido de CLA en yogures fabricados con leche de oveja, no podemos realizar una comparación con nuestros resultados. Sin embargo, y según lo que acabamos de exponer, tendríamos que admitir que no deberían producirse variaciones atribuibles al almacenamiento.

\subsubsection{Distribución de los isómeros CLA en yogures}

En cuanto al perfil de isómeros en yogur (Tabla 5.5), el mayoritario continúa siendo el cis-9,trans-11 (75 - 80\%) y le sigue en abundancia el trans-7,cis-9 (4-7\%). En los isómeros trans-12,trans-14; 12,14- (cis-trans/trans-cis); trans-11,trans-13; trans-11,cis-13, se observa un aumento porcentual en el mes de mayo, lo que produce una disminución relativa en el porcentaje de otros isómeros. El aumento que se acaba de mencionar, coincide con la época de mayor disponibilidad de pasto.

Tabla 5.5. Contenido porcentual de isómeros CLA presentes en las distintas muestras de yogur, según el mes de muestreo

\begin{tabular}{c|c|c|c|c|c|c|c}
\hline \multirow{2}{*}{ Isómero CLA } & \multicolumn{7}{c}{ \% sobre el CLA total } \\
\cline { 2 - 8 } & $\begin{array}{c}\text { Enero } \\
\mathbf{2 0 0 8}\end{array}$ & $\begin{array}{c}\text { Abril } \\
\mathbf{2 0 0 8}\end{array}$ & $\begin{array}{c}\text { Mayo } \\
\mathbf{2 0 0 8}\end{array}$ & $\begin{array}{c}\text { Julio } \\
\mathbf{2 0 0 8}\end{array}$ & $\begin{array}{c}\text { Septiembre } \\
\mathbf{2 0 0 8}\end{array}$ & $\begin{array}{c}\text { Noviembre } \\
\mathbf{2 0 0 8}\end{array}$ & $\begin{array}{c}\text { Diciembre } \\
\mathbf{2 0 0 8}\end{array}$ \\
\hline trans-trans $\boldsymbol{C L A}$ & $9,73 \pm 0,18$ & $11,80 \pm 0,26$ & $12,89 \pm 0,13$ & $11,00 \pm 0,15$ & $10,44 \pm 0,21$ & $9,85 \pm 0,15$ & $9,74 \pm 0,18$ \\
\hline trans-12,trans-14 & $2,43 \pm 0,05$ & $3,02 \pm 0,14$ & $3,35 \pm 0,06$ & $2,37 \pm 0,09$ & $2,35 \pm 0,07$ & $2,53 \pm 0,07$ & $2,04 \pm 0,08$ \\
trans-11,trans-13 & $1,58 \pm 0,06$ & $3,73 \pm 0,06$ & $4,61 \pm 0,11$ & $3,08 \pm 0,06$ & $2,28 \pm 0,09$ & $2,22 \pm 0,04$ & $2,12 \pm 0,10$ \\
trans-10,trans-12 & $1,13 \pm 0,03$ & $0,68 \pm 0,06$ & $0,77 \pm 0,07$ & $1,06 \pm 0,06$ & $1,12 \pm 0,05$ & $0,69 \pm 0,05$ & $1,15 \pm 0,07$ \\
trans-9,trans-11 & $2,60 \pm 0,11$ & $2,66 \pm 0,12$ & $2,66 \pm 0,05$ & $2,65 \pm 0,07$ & $2,59 \pm 0,11$ & $2,29 \pm 0,09$ & $2,35 \pm 0,10$ \\
trans-8,trans-10 & $0,96 \pm 0,03$ & $0,78 \pm 0,07$ & $0,63 \pm 0,03$ & $0,83 \pm 0,06$ & $0,95 \pm 0,02$ & $0,92 \pm 0,03$ & $0,92 \pm 0,05$ \\
trans-7,trans-9 & $0,84 \pm 0,04$ & $0,71 \pm 0,07$ & $0,70 \pm 0,01$ & $0,81 \pm 0,04$ & $0,85 \pm 0,02$ & $0,96 \pm 0,03$ & $0,90 \pm 0,07$ \\
trans-6,trans-8 & $0,19 \pm 0,03$ & $0,20 \pm 0,05$ & $0,17 \pm 0,01$ & $0,20 \pm 0,03$ & $0,31 \pm 0,02$ & $0,25 \pm 0,02$ & $0,26 \pm 0,04$ \\
\hline cis-trans + trans-cis & $90,27 \pm 0,18$ & $88,20 \pm 0,26$ & $87,11 \pm 0,13$ & $89,00 \pm 0,15$ & $89,56 \pm 0,21$ & $90,15 \pm 0,15$ & $90,26 \pm 0,18$ \\
\hline 12,14- $($ c- / $/$ t-c) & $1,04 \pm 0,03$ & $1,70 \pm 0,09$ & $2,02 \pm 0,03$ & $1,35 \pm 0,07$ & $1,08 \pm 0,08$ & $1,07 \pm 0,07$ & $1,41 \pm 0,12$ \\
trans-11,cis-13 & $0,83 \pm 0,02$ & $2,84 \pm 0,12$ & $3,51 \pm 0,03$ & $1,81 \pm 0,08$ & $1,18 \pm 0,06$ & $1,22 \pm 0,06$ & $1,03 \pm 0,03$ \\
trans-10,cis-12 & $0,86 \pm 0,03$ & $0,79 \pm 0,06$ & $0,80 \pm 0,05$ & $0,54 \pm 0,03$ & $0,66 \pm 0,06$ & $0,73 \pm 0,04$ & $0,73 \pm 0,06$ \\
cis-9,trans-11 & $79,90 \pm 0,26$ & $76,79 \pm 0,23$ & $75,55 \pm 0,18$ & $78,60 \pm 0,22$ & $78,94 \pm 0,21$ & $78,85 \pm 0,47$ & $79,41 \pm 0,44$ \\
trans-8,cis-10 & $1,11 \pm 0,07$ & $1,14 \pm 0,05$ & $1,03 \pm 0,06$ & $1,18 \pm 0,04$ & $1,37 \pm 0,12$ & $1,56 \pm 0,16$ & $1,09 \pm 0,15$ \\
trans-7,cis-9 & $6,53 \pm 0,16$ & $4,95 \pm 0,08$ & $4,21 \pm 0,10$ & $5,51 \pm 0,08$ & $6,34 \pm 0,17$ & $6,71 \pm 0,12$ & $6,60 \pm 0,11$ \\
\hline
\end{tabular}

Nota: Estos datos corresponden al promedio global de los porcentajes de cada isómero encontrado en las distintas muestras de yogur. 
La distribución de isómeros es diferente a la publicada por Martins et al. (2007), que recogen un valor de 69,74\% para el ácido ruménico (cis-9,trans-11) presente en yogur de leche de vaca; evidentemente, este porcentaje es bastante inferior al calculado en las muestras analizadas en este trabajo. Sin embargo, los mismos autores encuentran para este isómero un $79,21 \%$ y un $73,7 \%$ en leche y queso, respectivamente; dichos valores estarían dentro de los intervalos que habitualmente se determinan para estos alimentos.

Respecto al isómero trans-7,cis-9, parece suceder lo contrario, ya que obtienen un 20,2\%, muy por encima del que se suele encontrar. Llama la atención que, en yogur, no detectan algunos isómeros como el trans-10,cis-12, el trans-12,trans-14 y el cis11,trans-13, mientras que en leche si los encuentran, y los autores no dan ninguna explicación a este hecho. Al conjunto de isómeros trans-trans le asignan un 9\% como valor medio; valor bastante próximo al calculado en los yogures que hemos analizado en enero, noviembre y diciembre, aunque más bajo que los determinados en abril, julio, septiembre y sobre todo en mayo (cercano al 13\%). El porcentaje total de isómeros cistrans/trans-cis $(90,99 \%)$ es muy similar a los determinados en este trabajo (Tabla 5.5).

\subsection{CONSIDERACIONES FINALES}

El desarrollo de este objetivo ha permitido conocer los contenidos de 13 isómeros CLA en muestras comerciales de yogur y cuajada elaborados con leche de oveja. En la bibliografía sólo hemos encontrado un trabajo referido a cuajada de oveja y los datos existentes para yogur de la misma especie son escasos. Al hacerse el estudio durante un año (en el caso de la cuajada) se incluye la variación estacional, correspondiendo las cantidades mayores a la primavera. Los resultados indican que la concentración de los diferentes isómeros CLA en cuajada y yogur depende del contenido de los mismos en la leche de partida y que no se observan variaciones que puedan atribuirse al proceso de elaboración y/o al de almacenamiento. 



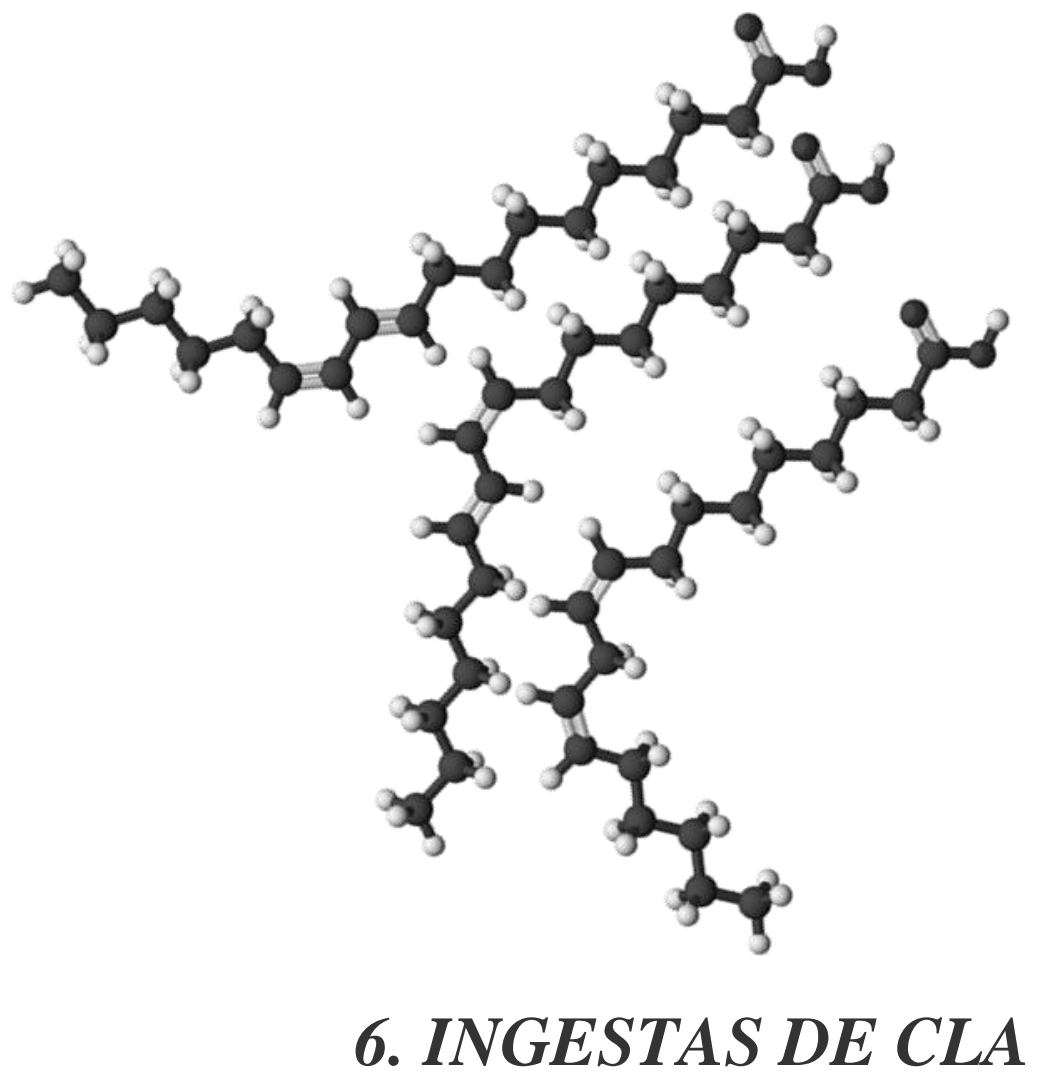





\section{INGESTAS DE CLA}

El desarrollo de los objetivos permite disponer de datos sobre contenidos de CLA en productos lácteos de oveja comerciales, de los que no se disponía hasta el momento. A partir de los mismos, hemos estimado la contribución a la ingesta de CLA de una ración de leche semidesnatada UHT, o de cuajada o de yogur (Tabla 6.1). Pueden observarse diferencias importantes entre las posibles ingestas por consumo de estos productos en primavera y en el resto del año y también la mayor contribución a la ingesta de la cuajada y el yogur, por tener un contenido de grasa más elevado.

Tabla 6.1. Contenidos medios e ingesta de CLA

\begin{tabular}{|c|c|c|c|c|}
\hline & \multicolumn{2}{|c|}{ Primavera } & \multicolumn{2}{|c|}{ Resto del año } \\
\hline Contenido & $\begin{array}{l}\text { CLA total } \\
\left(\mathrm{mg} / \mathrm{g}_{\text {Grasa }}\right)\end{array}$ & $\begin{array}{c}\text { cis-9,trans-11 } \\
\left(\mathrm{mg} / \mathrm{g}_{\text {Grasa }}\right)\end{array}$ & $\begin{array}{l}\text { CLA total } \\
\left(\mathrm{mg} / \mathrm{g}_{\text {Grasa }}\right)\end{array}$ & $\begin{array}{c}\text { cis-9,trans-11 } \\
\left(\mathrm{mg} / \mathrm{g}_{\text {Grasa }}\right)\end{array}$ \\
\hline Leche de oveja UHT & 8,50 & 6,58 & 5,71 & 4,49 \\
\hline Cuajada & 9,09 & 6,97 & 5,86 & 4,60 \\
\hline Yogur & 8,59 & 6,54 & 5,82 & 4,61 \\
\hline Ingesta & $\begin{array}{c}\text { CLA total } \\
\text { (mg) }\end{array}$ & $\begin{array}{c}\text { cis-9,trans-11 } \\
(\mathrm{mg})\end{array}$ & $\begin{array}{c}\text { CLA total } \\
(\mathrm{mg})\end{array}$ & $\begin{array}{c}\text { cis-9,trans-11 } \\
(\mathrm{mg})\end{array}$ \\
\hline 1 vaso de leche & 34 & 26 & 23 & 18 \\
\hline 1 cuajada & 76 & 59 & 49 & 39 \\
\hline 1 yogur & 65 & 49 & 44 & 35 \\
\hline Total & 175 & 134 & 116 & 92 \\
\hline
\end{tabular}

La ingesta derivada del consumo de estos alimentos resulta significativa si se compara el aporte de CLA de una ración de los mismos con las ingestas publicadas en los últimos años. Así para la población catalana se ha estimado una ingesta media de 72 mg/día del isómero cis-9,trans-11 (Mayneris-Perxachs et al., 2010), valor que se alcanzaría con el consumo de un vaso de leche y un yogur o una cuajada, en primavera. En el resto del año serían necesarios dos vasos de leche y un derivado lácteo o bien, una cuajada y un yogur de oveja, al día.

En Portugal las ingestas estimadas de ácido ruménico y de CLA total son de 56 y $73 \mathrm{mg} /$ día respectivamente, valores muy próximos a los de la población catalana. En España, al igual que en la mayoría de los países, hace unos años se han publicado 
ingestas más altas que las que se reflejan en trabajos más actuales (apartado 1.2.5). En estos últimos, el país para el que se recoge una ingesta más elevada es Francia, con unos valores de CLA total de $213 \mathrm{mg}$ en varones y $178 \mathrm{mg}$ en mujeres. Si en España se incluyen en la dieta diaria leche, yogur y cuajada de oveja sería posible alcanzar e incluso superar las ingestas estimadas en Francia.

Aunque no se conocen con seguridad las cantidades necesarias de cis-9,trans-11 para ejercer efectos beneficiosos para la salud, la inclusión en la dieta de yogur o cuajada de oveja contribuirán a aumentar la ingesta de ácido ruménico de forma importante.

Además, hay que recordar que los contenidos determinados en este trabajo incluyen, en gran medida, la variación debida a diferentes factores que condicionan la presencia de CLA en alimentos y por ello serían valores representativos de las cantidades reales presentes en productos comerciales. 


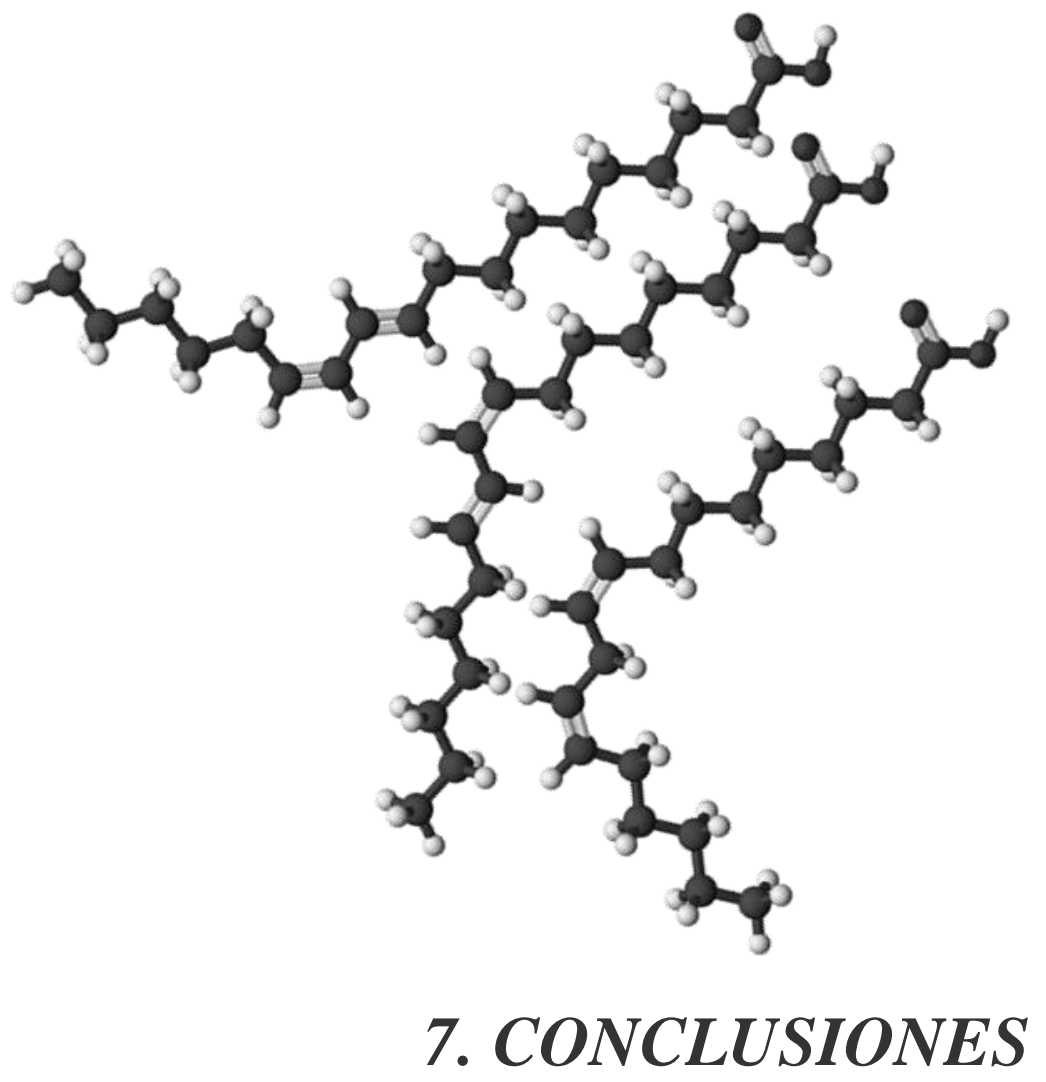



1. El método que se propone permite la determinación cuantitativa de 13 isómeros CLA en leche y derivados lácteos. Si se tienen presentes los parámetros de validación establecidos, este método puede ser una buena alternativa a la determinación convencional de estos isómeros, que combina dos técnicas, GC y $\mathrm{Ag}^{+}$-HPLC. Además, su aplicación como único procedimiento de análisis supondrá un ahorro de tiempo y de medios.

2. La validación del método incluye el estudio de linealidad, límite de cuantificación, ensayos de recuperación y de precisión. Los resultados de los ensayos de validación cumplen con los criterios especificados por organismos internacionales, lo que garantiza que es un método preciso y exacto y que genera confianza en los resultados obtenidos con su aplicación.

3. La utilización de un patrón en forma de triglicérido de cis-9,trans-11 en los ensayos de recuperación asegura que el proceso de metilación es completo y permite cuantificar recurriendo a patrones externos, que a su vez han demostrado unas características adecuadas de linealidad.

4. El método puesto a punto también puede emplearse para el análisis de mezclas de isómeros CLA obtenidas por síntesis o de complementos dietéticos. Por ello, es una herramienta útil que puede interesar a sectores relacionados con la elaboración de suplementos, o bien, a investigadores cuyo objetivo sea relacionar actividades biológicas con contenidos de isómeros concretos.

5. Se dispone del contenido de 13 isómeros CLA en muestras comerciales de leche de oveja UHT semidesnatada, correspondientes a un periodo de 15 meses. Las cantidades más altas de CLA total y de algunos isómeros se encontraron en los meses de primavera. El resto del año, los contenidos medios son más bajos y relativamente similares entre sí.

6. Entre los isómeros que muestran un aumento estacional relativo más importante, se encuentran: trans-11,cis-13, 12,14-(cis-trans/trans-cis), trans-11,trans-13 y trans-12,trans-14, que al menos duplican su contenido durante la primavera y, en el caso del isómero trans-11,cis-13, la cantidad determinada en esta época es cuatro veces mayor a la encontrada en otoño. En valores absolutos, los mayores aumentos 
corresponden al isómero mayoritario cis-9,trans-11, mientras que los isómeros trans-10,trans-12, trans-8,trans-10 y trans-6,trans-8 no se modifican durante el periodo de estudio.

7. En lo que se refiere al isómero trans-10,cis-12, se encuentran variaciones significativas en todas las estaciones, respecto a la primavera, pero al tratarse de cantidades muy pequeñas, pensamos que no tiene relevancia desde un punto de vista práctico.

8. El tratamiento térmico y posterior almacenamiento no modifica los contenidos de CLA presentes en leche de oveja ni la distribución de isómeros. Estos resultados, unidos a las variaciones estacionales observadas, nos permiten confirmar que el contenido de CLA está condicionado fundamentalmente por la dieta que se suministra a los animales.

9. En leche de oveja UHT comercial, las cantidades de CLA total y de la mayoría de los isómeros analizados, son del mismo orden que las publicadas por autores españoles en leche sin tratar de ovejas alimentadas con dietas básicas o dietas control.

10. Las variaciones estacionales observadas en los distintos isómeros en cuajadas de oveja, son semejantes a las encontradas en leche UHT y los mayores aumentos relativos correspondieron a los mismos isómeros.

11. El contenido de CLA total en las muestras de primavera es mayor al único resultado recogido en la bibliografía para cuajada elaborada con leche de oveja, aunque hay que mencionar que este último valor se aproxima bastante a los niveles encontrados en las cuajadas que hemos analizado en otras estaciones.

12. En yogures de oveja, el isómero cis-9,trans-11 se encuentra en cantidades inferiores a las recogidas en la bibliografía, sin embargo, son similares a las publicadas en algunos yogures de leche de vaca. En cuanto al isómero trans-10,cis12, los contenidos determinados en nuestro trabajo son parecidos a los publicados para yogur de vaca. 
13. El proceso de elaboración y almacenamiento no cambian los contenidos de CLA en cuajadas y yogures de leche de oveja, en los que se encuentran las mismas concentraciones y perfil de isómeros que en la leche utilizada para su fabricación. Los resultados de este estudio permiten afirmar que los niveles de CLA en yogur y cuajada dependen únicamente de las cantidades inicialmente presentes en leche.

14. Los resultados pueden utilizarse para valorar la contribución de leche, cuajada y yogur de oveja a la ingesta de CLA total y de los diferentes isómeros. La ingesta de cis-9,trans-11 derivada del consumo de un yogur o de una cuajada puede considerarse relativamente alta al compararla con las recogidas en los estudios de estimación de ingestas y aunque no se conocen con seguridad las cantidades necesarias para que el ácido ruménico pueda ejercer efectos positivos para la salud, la inclusión de estos derivados lácteos en la dieta contribuirá a aumentar la ingesta del mismo, de manera significativa. 



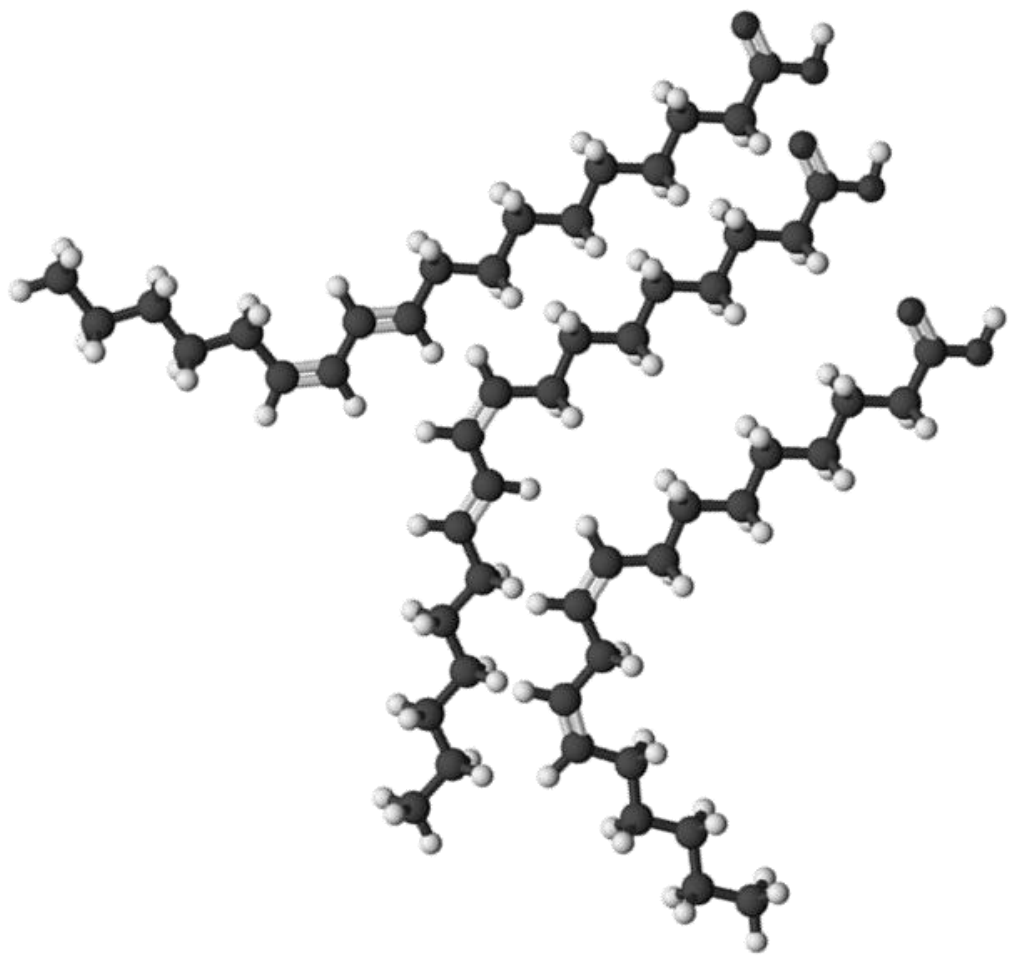

8. BIBLIOGRAFÍA 

Abilleira E., Collomb M., Schlichtherle-Cerny H., Virto M., de Renobales M., Barron L.J.R. (2009). Winter/spring changes in fatty acid composition of farmhouse Idiazabal cheese due to different flock management systems. Journal of Agricultural and Food Chemistry 57(11): 4746-4753.

AbuGhazaleh A.A., Schingoethe D.J., Hippen A.R., Whitlock L.A. (2002). Feeding fish meal and extruded soybeans enhances the conjugated linoleic acid (CLA) content of milk. Journal of Dairy Science 85: 624-631.

AbuGhazaleh A.A., Schingoethe D.J., Hippen A.R., Kalscheur K.F. (2004). Conjugated linoleic acid increases in milk when cows fed fish meal and extruded soybeans for an extended period of time. Journal of Dairy Science 87(6): 1758-1766.

Addis M., Cabiddu A., Pinna G., Decandia M., Piredda G., Pirisi A., Molle G. (2005). Milk and cheese fatty acid composition in sheep fed mediterranean forages with reference to conjugated linoleic acid cis-9,trans-11. Journal of Dairy Science 88: 3443-3454.

Addis M., Cabiddu A., Decandia M., Spada S., Acciaro M., Pirisi A., Sitzia M., Costa E., Cannas A., Molle G. (2009). Effects of different fat-enriched concentrates on fatty acid profile of cheese from grazing dairy sheep. Italian Journal of Animal Science 8: 378-380 (Suppl. 2).

Adlof R.O., Menzer A., Dorovska-Taran V. (2002). Analysis of CLA-enriched triacylglycerol mixtures by silver-ion HPLC. Journal of Chromatography A 953: 293-297.

Adlof R.O. (2003). Application of silver-ion chromatography to the separation of conjugated linoleic acid isomers. En: Advances in Conjugated Linoleic Acid Research (Volume 2): pp. 37-55. Editores: J.L. Sebedio, W.W. Christie, R.O. Adlof. AOCSS Press, Champaign IL (USA).

Adlof R.O. (2004). Separation of conjugated linoleic acid methyl esters by silver-ion high performance liquid chromatography in semi-preparative mode. Journal of. Chromatography A 1033: $369-371$.

Adlof R.O. (2007). Analysis of triacylglycerol and fatty acid isomers by low-temperature silver-ion high performance liquid chromatography with acetonitrile in hexane as solvent: Limitations of the methodology. Journal of Chromatograohy A 1148: 256-259.

Akalin A.S., Tokusoglu O., Gonc S., Aycan S. (2007). Occurrence of conjugated linoleic acid in probiotic yoghurts supplemented with fructooligosaccharide. International Dairy Journal 17(9): 1089-1095.

Albers R., Jutzeler van der Wielen R.P., Brink E.J., Hendriks H.F.J., Dorovska-Taran V.N., Mohede I.C.M. (2003). Effects of cis-9,trans-11 and trans-10,cis-12 conjugated linoleic acid (CLA) isomers on immune function in healthy men. European Journal of Clinical Nutrition 57: 595-603.

Aldai N., Osoro K., Barron L.J.R., Nájera A.I. (2006). Gas-liquid chromatographic metod for analysing complex mixtures of fatty acids including conjugated linoleic acids (cis9trans11 and trans10cis12 isomers) and long-chain (n-3 or n-6) polyunsaturated fatty acids. Aplication to the intramuscular fat of beef meat. Journal of Chromatography A 1110: 133-139.

Alfaia C.M.M., Ribeiro V.S.S., Lourenço M.R.A., Quaresma M.A.G., Martins S.I.V., Portugal A.P.V., Fontes C.M.G.A., Bessa R.J.B., Castro M.L.F., Prates J.A.M. (2006). Fatty acid composition, conjugated linoleic acid isomers and cholesterol in beef from crossbred bullocks intensively produced and from Alentejana purebred bullocks reared according to Carnalentejana-PDO specifications. Meat Science 72: 425-436.

Alonso L., Fontecha J., Lozada L., Fraga M.J., Juárez M. (1999). Fatty acid composition of caprine milk: major, branched-chain, and trans fatty acids. Journal of Dairy Science 82: 878-884.

Aneja R.P., Murthy T.N. (1990). Conjugated linoleic acid contents of Indian curds and ghee. Indian Journal of Dairy Science 43: 231-238. 
Antongiovanni M., Mele M., Buccioni A., Petacchi F., Serra A., Melis M.P., Cordeddu L., Banni S., Secchiari P. (2004). Effect of forage/concentrate ratio and oil supplementation on C18:1 and CLA isomers in milk fat from Sarda ewes. Journal of Animal and Feed Sciences 13: 669-672.

AOAC (2002). Guidelines for Single Laboratory Validation of Chemical Methods for Dietary Supplements and Botanicals. Association of Analytical Communities, p. 38 http://www.aoac.org/dietsupp6/Dieatary-Supplement-web-site/slv_guidelines.pdf.

Aro A., Mannisto S., Salminen I., Ovaskainen M.L., Kataja V., Uusitupa M. (2000). Inverse association between dietary and serum conjugated linoleic acid and risk of breast cancer in postmenopausal women. Nutrition and Cancer 38: 151-157.

Atti N., Rouissi H., Othmane M.H. (2006). Milk production, milk fatty acid composition and conjugated linoleic acid (CLA) content in dairy ewes raised on feedlot or grazing pasture. Livestock Science 104(1-2): 121-127.

Badui Dergal, S. (2006). Química de los Alimentos. $4^{a}$ edición. Director: S. Badui Dergal. Revisión Técnica: H. Cejudo Gómez. Editorial Pearson Educación. México. 603-631.

Barbosa E., Oliveira C., Casal S., Soares L., Vale A.P., Lopes J.C., Oliveira B., Brito N.V. (2003). Quantification and variability of conjugated linoleic acids level in sheep milk of two autochtonous portuguese breeds. Electronic Journal of Environmental, Agricultural and Food Chemistry 2(4): 493-497.

Bauman D.E., Baumgard L.H., Corl B.A., Griinari J.M. (1999). Biosynthesis of conjugated linoleic acid in ruminants. Proceedings of the American Society of Animal Science (15 páginas). Disponible en: http://jas.fass.org/cgi/reprint/77/E-Suppl/1-ae.pdf.

Bauman D.E., Corl B.A., Peterson D.G. (2003). The biology of conjugated linoleic acids in ruminants. En: Advances in Conjugated Linoleic Acid Research, Volumen 2: pp. 146-173. Editores: J.L. Sebedio, W.W. Christie, R. Adlof. AOCS Press, Estados Unidos.

Benjamin S., Spener F. (2009). Conjugated linoleic acids as functional food: An insight into their health benefits. Nutrition \& Metabolism 6:36 (13 páginas).

Bhattacharya A., Banu J., Rahman M., Causey J., Fernandes G. (2006). Biological effects of conjugated linoleic acids in health and disease (Review). Journal of Nutritional Biochemistry 17(12): 789-810.

Biondi L., Valvo M.A., Di Gloria M., Scinardo Tenghi E., Galofaro V., Priolo A. (2008). Changes in ewe milk fatty acids following turning out to pasture. Small Ruminant Research 75: 17-23.

Bisig W., Eberhard P., Collomb M., Rehberger B. (2007). Influence of processing on the fatty acid composition and the content of conjugated linoleic acid in organic and conventional dairy products A review. Le Lait 87(1): 1-19.

Bodas R., Manso T., Mantecón A.R., Juárez M., De la Fuente M.A., Gómez-Cortés P. (2010). Comparison of the fatty acid profiles in cheeses from ewes fed diets supplemented with different plant oils. Journal of Agricultural and Food Chemistry 58(19): 10493-10502.

Bos C., Gaudichon C., Tomé D. (2000). Nutritional and physiologycal criteria in the assessment of milk protein quality for humans. Journal of the American College of Nutrition 19 (2): 191S-205S.

Boylston T.D., Beitz D.C. (2002). Conjugated linoleic acid and fatty acid composition of yogurt produced from milk of cows fed soy oil and conjugated linoleic acid. Journal of Food Science 67 (5): 1973-1978.

Brown A.W., Trenkle A.H., Beitz D.C. (2011). Diets high in conjugated linoleic acid from pasturefed cattle did not alter markers of health in young women. Nutrition Research 31: 33-41. 
Buccioni A., Rapaccini S., Antongiovanni M., Minieri S., Conte G., Mele M. (2010). Conjugated linoleic acid and C18:1 isomers content in milk fat of sheep and their transfer to Pecorino Toscano cheese. International Dairy Journal 20: 190-194.

Butler G., Stergiadis S., Seal C., Eyre M., Leifert C. (2011). Fat composition of organic and conventional retail milk in northeast England. Journal of Dairy Science 94: 24-36.

Cabiddu A., Decandia M., Addis M., Piredda G., Pirisi A., Molle G. (2005). Managing mediterranean pastures in order to enhance the level of beneficial fatty acid in sheep milk. Small Ruminant Research 59: 169-180.

Cabiddu A., Addis M., Pinna G., Decandia M., Sitzia M., Piredda G., Pirisi A., Molle G. (2006a). Effect of corn and beet pulp based concentrates on sheep milk and cheese fatty acid composition when fed Mediterranean fresh forages with particular reference to conjugated linoleic acid cis-9, trans-11. Animal Feed Science and Technology 131(3-4): 292-311.

Cabiddu A., Addis M., Pinna G., Spada S., Fiori M., Sitzia M., Pirisi A., Piredda G., Molle G. (2006b). The inclusion of a daisy plant (Chrysanthemum coronarium) in dairy sheep diet. 1: Effect on milk and cheese fatty acid composition with particular reference to C18:2 cis-9, trans-11. Livestock Science 101(1-3): 57-67.

Cabiddu A., Molle G., Decandia M., Spada S., Fiori M., Piredda G., Addis M. (2009). Responses to condensed tannins of flowering sulla (Hedysarum coronarium L.) grazed by dairy sheep, Part 2: Effects on milk fatty acid profile. Livestock Science 123(2-3): 230-240.

Campbell W., Drake M.A., Larick D.K. (2003). The impact of fortification with conjugated linoleic acid (CLA) on the quality of fluid milk. Journal of Dairy Science 86: 43-51.

Capper J.L., Wilkinson R.G., Mackenzie A.M., Sinclair L.A. (2007). The effect of fish oil supplementation of pregnant and lactating ewes on milk production and lamb performance. Animal 1(6): 889-898.

Castro T., Manso T., Jimeno V., Del Álamo M., Mantecón A.R. (2009). Effects of dietary sources of vegetable fats on performance of dairy ewes and conjugated linoleic acid (CLA) in milk. Small Ruminant Research 84(1-3): 47-53.

Cervera P., Clapés J., Rigolfas R. (2004). Alimentación y dietoterapia. $4^{a}$ Ed. McGraw-Hill Interamericana.

Chajes V., Lavillonniere F., Ferrari P., Jourdan M.L., Pinault M., Maillard V., Sebedio J.L., Bougnoux P. (2002). Conjugated linoleic acid content in breast adipose tissue is not associated with the relative risk of breast cancer in a population of French patients. Cancer Epidemiology, Biomarkers \& Prevention 11: 672-673.

Chajes V., Lavillonniere F., Maillard V., Giraudeau B., Jourdan M.L., Sebedio J.L., Bougnoux P. (2003). Conjugated linoleic acid content in breast adipose tissue of breast cancer patients and the risk of metastasis. Nutrition and Cancer 45: 17-23.

Chilliard Y., Glasser F., Ferlay A., Bernard L., Rouel J., Doreau M. (2007). Diet, rumen biohydrogenation and nutritional quality of cow and goat milk fat. European Journal of Lipid Science and Technology 109: 828-855.

Chin S.F., Liu W., Storkson J.M., Ha Y.L., Pariza M.W. (1992). Dietary sources of conjugated dienoic isomers of linoleic acid, a newly recognized class of anticarcinogens. Journal of Food Composition and Analysis 5: 185-197.

Chouinard P.Y., Corneau L., Butler W.R., Chilliard Y., Drackley J.K., Bauman D.E. (2001). Effect of dietary lipid source on conjugated linoleic acid concentrations in milk fat. Journal of Dairy Science 84: 680-690. 
Christie W.W., Dobson G., Adlof R. (2007). A practical guide to the isolation, analysis and identification of conjugated linoleic acid. Lipids 42(12): 1073-1084.

Churruca I., Fernández-Quintela A., Puy Portillo M. (2009). Conjugated linoleic acid isomers: Diferences in metabolism and biological effects. Biofactors 35 (1): 105-111.

Collomb M., Sieber R., Bütikofer U. (2004). CLA isomers in milk fat from cows fed diets with high levels of unsaturated fatty acids. Lipids 39(4): 355-364.

Collomb M., Schmid A., Sieber R., Wechsler D., Ryhanen E.L. (2006). Conjugated linoleic acids in milk fat: Variation and physiological effects (Review). International Dairy Journal 16(11): 13471361.

Contarini G., Pelizzola V., Povolo M. (2009). Content of conjugated linoleic acid in neutral and polar lipid fractions of milk of different ruminant species. International Dairy Journal 19: 342-344.

Corl B.A., Baumgard L.H., Griinari J.M., Delmonte P., Morehouse K.M., Yurawecz M.P., Bauman D.E. (2002). Trans-7, cis-9 CLA is synthesized endogenously by $\triangle 9$ desaturase in dairy cows Lipids 37: 681-688.

Cruz-Hernandez C., Deng Z., Zhou J., Hill A., Yurawecs M., Delmonte P., Mossoba M., Dugan M., Kramer J.K.G. (2004). Methods of analysis of conjugated linoleic acids and trans 18:1 isomers in dairy fats by using combination of gas chromatography, silver-ion thin layer chromatography and silver-ion liquid chromatography. Journal of AOAC International 87(2): 545-562.

Czauderna M., Kowalczyk J., Marounek M., Michalski J.P., Rozbicka-Wieczorek A.J., Krajewska K.A. (2011). A new internal standard for HPLC assay of conjugated linoleic acid in animal tissues and milk. Czech Journal of Animal Science 56(1): 23-29.

Dance L.J.E., Doran O., Hallett K., Dannenberg D., Nuernberg G., Nuernberg K. (2010). Comparison of two derivatisation methods for conjugated linoleic acid isomer analysis by $\mathrm{Ag}^{+}-$ HPLC/DAD in beef fat. European Journal of Lipid Science and Technology 112: 188-194.

De Blas C., Mateos G.G., Rebollar P.G. (2003). Tablas FEDNA de composición y valor nutritivo de alimentos para la fabricación de piensos compuestos (2 ${ }^{a}$ edición). Fundación Española para el Desarrollo de la Nutrición Animal (FEDNA). Madrid, España. 423 pp. Disponible en: http://www1.etsia.upm.es/fedna/tablas.htm

De la Fuente L.F., Barbosa E., Carriedo J.A., Gonzalo C., Arenas R., Fresno J.M., Primitivo F.S. (2009). Factors influencing variation of fatty acid content in ovine milk. Journal of Dairy Science 92(8): 3791-3799.

De la Fuente M.A., Juárez M. (2004). El ácido linoleico conjugado en la leche y los productos lácteos. Alimentación, Nutrición y Salud 11: 100-112.

De la Fuente M.A., Luna P., Juárez M. (2006). Chromatographic techniques to determine conjugated linoleic acid isomers. Trends in Analytical Chemistry 25(9): 917-926.

Delmonte P., Roach J.A.G., Mossoba M.M., Morehouse K.M., Lehmann L., Yurawecs M.P. (2003). Synthesis and isolation of trans-7, cis-9 octadecadienoic acid and other CLA isomers by base conjugation of partially hydrogenated $\gamma$-linolenic acid. Lipids 38: 579-583.

Delmonte P., Roach J.A.G., Mossoba M.M., Losi G., Yurawecs M.P. (2004a). Synthesis, isolation and GC analysis of all the 6,8- to 13,15-cis/trans conjugated linoleic acid isomers. Lipids 39: 185191.

Delmonte P., Yurawecs M.P., Mossoba M.M. (2004b). Improved identification of conjugated linoleic acid isomers using silver-ion HPLC separations. Journal of AOAC International 87(2): 563-568. 
Delmonte P., Kataoka K., Corl B.A., Bauman D.E., Yurawecs M.P. (2005). Relative retention order of all isomers of cis/trans conjugated linoleic acid FAME from the 6,8- to 13,15-positions using silver ion HPLC with two elution systems. Lipids 40: 509-514.

Demir A., Talpur F. (2010). Chemoenzimatic conversion of linoleic acid into conjugated linoleic acid. Journal of Agricultural and Food Chemistry 58: 1646-1652.

Desroches S., Chouinard P.Y., Galibois I., Corneau L., Delisle J., Lamarche B., Couture P., Bergeron N. (2005). Lack of effect of dietary conjugated linoleic acids naturally incorporated into butter on the lipid profile and body composition of overweight and obese men. American Journal of Clinical Nutrition 82: 309-319.

Destaillats F., Angers P. (2003). Direct sequential synthesis of conjugated linoleic acid isomers from $\Delta^{7,9}$ to $\Delta^{12,14}$. European Journal of Lipid Science and Technology 105: 3-8.

Destaillats F., Japiot C., Chouinard P.Y., Arul J., Angers P. (2005). Rearrangement of rumenic acid in ruminant fats: A marker of thermal treatment (Short Communication). Journal of Dairy Science 88: $1631-1635$.

Dewhurst R.J., Shingfield K.J., Lee M.R.F., Scollan N.D. (2006). Increasing the concentrations of beneficial polyunsaturated fatty acids in milk produced by dairy cows in high-forage systems. (Review). Animal Feed Science and Technology 131(3-4): 168-206.

Dhiman T.R., Satter L.D., Pariza M.W., Galli M.P., Allbright K., Tolosa M.X. (2000). Conjugated linoleic acid (CLA) content of milk from cows offered diets rich in linoleic and linolenic acid. Journal of Dairy Science 83: 1016-1027.

Dhiman T.R., Nam S.H., Ure A.L. (2005). Factors affecting conjugated linoleic acid content in milk and meat. Critical Reviews in Food Science and Nutrition 45: 463-482.

Dierking R.M., Kallenbach R.L., Grun I.U. (2010). Effect of forage species on fatty acid content and performance of pasture-finished steers. Meat Science 85(4): 597-605.

Dobson G. (2003). Gas chromatography - mass spectrometry of conjugated linoleic acids and metabolites. En: Advances in Conjugated Linoleic Acid Research (Volume 2): pp. 13-36. Editores: J.L. Sebedio, W.W. Christie, R.O. Adlof. AOCSS Press, Champaign IL (USA).

Dolan J.W. (2009). Calibration curves 2: What are the limits? LC GC Europe 22: 244-247.

Domagala J., Sady M.. Grega T., Pustkowiak H., Florkiewics A. (2010). The influence of cheese type and fat extraction method on the content of conjugated linoleic acid. Journal of Food Composition and Analysis 23: 238-243.

Dubois V., Breton S., Linder M., Fanni J., Parmentier M. (2007). Fatty acid profiles of 80 vegetable oils with regard to their nutritional potential. European Journal of Lipid Science and Technology 109: 710-732.

EFSA (European Food Safety Autority). (2010a). EFSA Panel on Dietetic Products, Nutrition and Allergies (NDA). Scientific opinion on the safety of "conjugated linoleic acid (CLA)-rich oil" (Clarinol $^{\circledR}$ ) as a novel food ingredient. EFSA Journal 2010, 8(5): 1601 (41páginas). Disponible "on line": www.efsa.europa.eu.

EFSA (European Food Safety Autority). (2010b). EFSA Panel on Dietetic Products, Nutrition and Allergies (NDA). Scientific opinion on the safety of "conjugated linoleic acid (CLA)-rich oil" (Tonalin $^{\circledR}$ TG 80) as a novel food ingredient. EFSA Journal 2010, 8(5): 1600 (43páginas). Disponible “on line”: www.efsa.europa.eu. 
EFSA (European Food Safety Autority). (2010c). Panel on Dietetic Products, Nutrition and Allergies (NDA). Scientific Opinion on the substantiation of health claims related to conjugated linoleic acid (CLA) isomers and contribution to the maintenance or achievement of a normal body weight (ID 686, 726, 1516, 1518, 2892, 3165), increase in lean body mass (ID 498, 731), increase in insulin sensitivity (ID 1517), protection of DNA, proteins and lipids from oxidative damage (ID 564, 1937), and contribution to immune defences by stimulation of production of protective antibodies in response to vaccination (ID 687, 1519) pursuant to Article 13(1) of Regulation (EC) No 1924/2006. EFSA Journal 8 (10): 1794-1820.

Ens J.G., Ma D.W.L., Cole K.S. (2001). An assessment of c9,t11 linoleic acid intake in a small group of young Canadians. Nutrition Research 21: 955-960.

Espírito Santo A.P., Silva R.C., Soares F.A.S.M., Anjos D., Gioielli L.A., Oliveira M.N. (2010). Açai pulp addition improves fatty acid profile and probiotic viability in yoghurt. International Dairy Journal 20(6): 415-422.

Eulitz K., Yurawecs M., Sehat N., Fritsche J., Roach J.A.G., Mossoba M.M., Kramer J.K.G., Adlof R.O., Ки Y. (1999). Preparation, separation and confirmation of the eight geometrical cis/trans conjugated linoleic acid isomers 8,10-through 11,13-18:2. Lipids 34: 873-877.

FAOSTAT (2009). Base de datos FAOSTAT de la Organización de las Naciones Unidas para la Alimentación y la Agricultura (http://faostat.fao.org/site/569/default.aspx\#ancor).

Farran A., Zamora R., Cervera P. (2004). Tablas de composición de alimentos del CESNID (Centre d'Enseyanment Superior de Nutrició i Dietética); pp. 68-69. McGraw-Hill Interamericana, Barcelona (España).

FDA (U.S. Food and Drug Administration). (2008). Agency response letter GRAS notice No. GRN 000232. CFSAN/Office of Food Additive Safety. July 11, 2008. Washington D.C. (http://www.fda.gov/Food/FoodIngredientsPackaging/GenerallyRecognizedasSafeGRAS/GRASListi ngs/ucm153908.htm).

Feng S., Lock A.L., Garnsworthy P.C. (2004). A rapid method for determining fatty acid composition of milk. Journal of Dairy Science 87: 3785-3788.

Ferlay A., Martin B., Pradel P., Coulon J.B., Chilliard Y. (2006). Influence of grass-based diets on milk fatty acid composition and milk lipolytic system in tarentaise and Montbeliarde cow breeds. Journal of Dairy Science 89(10): 4026-4041.

Fernández-Quintela A., Rodríguez V.M., Portillo M.P. (2004). Ácido linoleico conjugado y grasa corporal. Revista Española de Obesidad 2: 71-79.

Florence A.C.R., da Silva R.C., do Espírito Santo A.P., Gioielli L.A., Tamine A.Y., de Oliveira M.N. (2009). Increased CLA content in organic milk fermented by bifidobacteria or yoghurt cultures. Dairy Science and Technology, 89: 541-553.

Fontecha J., Goudjil H., Ríos J.J., Fraga M.J., Juárez M. (2005). Identity of the major triacylglycerols in ovine milk fat. International Dairy Journal 15: 1217-1224.

Fremann D., Linseisen J., Wolfram G. (2002). Dietary conjugated linoleic acid (CLA) intake assessment and possible biomarkers of CLA intake in young women. Public Health Nutrition 5: 7380.

Fritsche J., Steinhart H. (1998a). Analysis, occurrence, and physiological properties of trans fatty acids (TFA) with particular emphasis on conjugated linoleic acid isomers (CLA) - A review. Fett/Lipid 100: 190-210. 
Fritsche J., Steinhart H. (1998b). Amounts of conjugated linoleic acid (CLA) in German foods and evaluation of daily intake. Zeitschrift fur Lebensmittel-Untersuchung und-Forschung A 206: 7782.

Fritsche J., Fritsche S., Solomon M.B., Mossoba M.M., Yurawecz M.P., Morehouse K., Ки Y. (2000). Quantitative determination of conjugated linoleic acid isomers in beef fat. European Journal of Lipid Science and Technology 102: 667-672.

Fritsche J., Yurawecz M.P., Pawlosky R., Flanagan V.P., Steinhart H., Ku Y. (2001). Spectroscopic characterization of unusual conjugated linoleic acid (CLA) isomers. Journal of Separation Science 24: 59-61.

García-López S., Echeverría E., Tsui I., Balch B. (1994). Changes in the content of conjugated linoleic acid (CLA) in processed cheese during processing. Food Research International 27: 61-64.

Gaullier J.M., Halse J., Hoye K., Kristiansen K., Fagertun H., Vik H., Gudmundsen O. (2004). Conjugated linoleic acid supplementation for 1 y reduces body fat mass in healthy overweight humans. American Journal of Clinical Nutrition 79: 1118-1125.

Gaullier J.M., Halse J., Hoye K., Kristiansen K., Fagertun H., Vik H., Gudmundsen O. (2005). Supplementation with conjugated linoleic acid for 24 months is well tolerated by and reduces body fat mass in healthy overweight humans. Journal of Nutrition 135: 778-784.

Gnädig S., Chamba J.F., Perreard E., Chappaz S., Chardigny J.M., Rickert R., Steinhart H., Sébédio J.L. (2004). Influence of manufacturing conditions on the conjugated linoleic acid content and the isomer composition in ripened French Emmental cheese. Journal of Dairy Research 71: 367-371.

Gómez-Cortés P., Frutos P., Mantecón A.R., Juárez M., De la Fuente M.A., Hervás G. (2008a). Milk production, conjugated linoleic acid content, and in vitro ruminal fermentation in response to high levels of soybean oil in dairy ewe diet. Journal of Dairy Science 91(4): 1560-1569.

Gómez-Cortés P., Frutos P., Mantecón A.R., Juárez M., De la Fuente M.A., Hervás G. (2008b). Addition of olive oil to dairy ewe diets: Effect on milk fatty acid profile and animal performance. Journal of Dairy Science 91(8): 3119-3127.

Gómez-Cortés P., Frutos P., Mantecón A.R., Juárez M., De la Fuente M.A., Hervás G. (2009a). Effect of supplementation of grazing dairy ewes with a cereal concentrate on animal performance and milk fatty acid profile. Journal of Dairy Science 92(8): 3964-3972.

Gómez-Cortés P., Bach A., Luna P., Juárez M., De la Fuente M.A. (2009b). Effects of extruded linseed supplementation on n-3 fatty acids and conjugated linoleic acid in milk and cheese from ewes. Journal of Dairy Science 92(9): 4122-4134.

Gómez-Cortés P. (2010). Efecto de la suplementación de la dieta ovina con distintas fuentes lipídicas sobre el perfil de ácidos grasos de la leche. Tesis Doctoral. Departamento de Química Física I. Facultad de Ciencias Químicas. Universidad Complutense de Madrid.

Gómez-Cortés P., De la Fuente M.A. (2010). El ácido linoleico conjugado como agente anticancerígeno. Alimentación, Nutrición y Salud 17: 68-78.

Gómez-Cortés P., Toral P.G., Frutos P., Juárez M., De la Fuente M.A., Hervás G. (2011). Effect of the supplementation of dairy sheep diet with incremental amounts of sunflower oil on animal performance and milk fatty acid profile. Food Chemistry 125(2): 644-651.

Goudjil H., Fontecha J., Fraga M.J., Juárez M. (2003). TAG composition of ewe's milk fat. Detection of foreign fats. Journal of the American Oil Chemists'Society 80: 219-222.

Goudjil H., Fontecha J., Luna P., De la Fuente M.A., Alonso L., Juárez M. (2004). Quantitative characterization of unsaturated and trans fatty acids in ewe's milk fat. Le Lait 84: 473-482. 
Griinari J.M., Bauman D.E. (1999). Biosynthesis of conjugated linoleic acid and its incorporation into meat and milk in ruminants. En: Advances in Conjugated Linoleic Acid Research (Volume 1): pp. 180-200. Editores: M.P. Yurawecs, M.M. Mossoba, J.K.G. Kramer, M.W. Pariza, G.J. Nelson. AOCSS Press, Champaign IL (USA).

Guler G.O., Cakmak Y.S., Zengin G., Aktumsek A., Akyildiz K. (2010). Fatty acid composition and conjugated linoleic acid (CLA) content of some commercial milk in Turkey. Kafkas Universitesi Veteriner Fakultesi Dergisi 16 (Suppl. A): S37-S40.

Ha Y.L., Grimm N.K., Pariza M.W. (1989). Newly recognized anticarcinogenic fatty acids: Identification and quantification in natural and processed cheeses. Journal of Agricultural and Food Chemistry 37: 75-81.

Haenlein G.F.W. (2001). Past, present and future perspectives of small ruminant dairy research. Journal of Dairy Science 84: 2097-2115.

Haenlein G.F.W. (2006). The nutritional value of sheep milk. NR International managers for the Livestock Production Programme (LPP). Departament for International Development. http://www.smallstock.info/issues/sheepmilk.htm.

Hampel K., Schöne F., Böhm V., Leiterer M., Jahreis G. (2004). Composition and nutritional importance of ewe's milk and ewe's milk products. Deutsche Lebensmittel-Rundschau 11: 425-430.

Haro A.M., Artacho R., Cabrera-Vique C. (2006). Ácido linoleico conjugado: Interés actual en nutrición humana (Revisión). Medicina Clínica 127(13): 508-515.

Herrmann J. (2009). The effect of conjugated linoleic acids on gene expression and risk markers of atherosclerosis and diabetes in humans. Dissertation (PhD thesis). Referencia citada en la publicación realizada por $\mathbf{E F S A} 2010$ a.

Hervás G., Gómez-Cortés P., Frutos P., Juárez M., Mantecón A.R., De la Fuente M.A. (2008a). Complementación de la dieta de ovejas lecheras con aceite de soja: Efecto sobre el rendimiento productivo y el perfil de ácidos grasos de la leche. ALBEITAR 121 (Diciembre 2008): 52-54.

Hervás G., Luna P., Mantecón A.R., Castañares N., De la Fuente M.A., Juárez M., Frutos P. (2008b). Effect of diet supplementation with sunflower oil on milk production, fatty acid profile and ruminal fermentation in lactating dairy ewes. Journal of Dairy Research 75(4): 399-405.

Herzallah S.M., Humeid M.A., Al-Ismail K.M. (2005). Effect of heating and processing methods of milk and dairy products on conjugated linoleic acid and trans fatty acid isomer content. Journal of Dairy Science 88(4): 1301-1310.

Huang Y., Schoonmaker J.P., Oren S.L., Trenkle A., Beitz D.C. (2009). Calcium salts of CLA improve availability of dietary CLA. Livestock Science 122(1): 1-7.

ISO-IDF. (2001). Milk and milk products - Extraction methods for lipids an liposoluble compounds. International Standard ISO 14156-IDF 172:2001. International Dairy Federation. Brussels, Belgium.

ISO-IDF. (2002). Milk fat - Preparation of fatty acid methyl esters. International Standard ISO 15884-IDF 182:2002. International Dairy Federation. Brussels, Belgium.

Iannone A., Petroni A., Murru E., Cordeddu L., Carta G., Melis M.P., Bergamini S., Della Casa L., Cappiello L., Carissimi R., O'Shea M., Bell D., De Santis E., Banni S. (2009). Impairment of 8-iso$P F_{2 A L P H A}$ isoprostane metabolism by dietary conjugated linoleic acid (CLA). Prostaglandins Leukotrienes Essential Fatty Acids 80: 279-287. 
Ip C., Singh M., Thompson H.J., Scimeca J.A. (1994). Conjugated linoleic acid suppresses mammary carcinogenesis and proliferative activity of the mammary gland in the rat. Cancer Research 54: 1212-1215.

Jaeggi J.J., Wendorff W.L., Romero J., Berger Y.M., Johnson M.E. (2005). Impact of seasonal changes in ovine milk on composition and yield of a hard-pressed cheese. Journal of Dairy Science 88: 1358-1363.

Jaramillo D.P., Zamora A., Guamis B., Rodríguez M., Trujillo A.J. (2008). Cheesemaking aptitude of two Spanish dairy ewe breeds: Changes during lactation and relationship between physicochemical and technological properties. Small Ruminant Research 78: 48-55.

Jenkins T.C., Wallace R.J., Moate P.J., Mosley E.E. (2008). Recent advances in biohydrogenation of unsaturated fatty acids within the rumen microbial ecosystem. Journal of Animal Science 86: 397412.

Jensen, R. G. (2002). Invited review: The composition of bovine milk lipids: January 1995 to December 2000. Journal of Dairy Science 85: 295-350.

Jiang J., Wolk A., Vessby B. (1999). Relation between the intake of milk fat and the occurrence of conjugated linoleic acid in human adipose tissue. American Journal of Clinical Nutrition 70: 2127.

Jones E.L., Shingfield K.J., Konen C., Jones A.K., Lupoli B., Grandison A.S., Beever D.E., Williams C.M., Calder P.C., Yaqoob P. (2005). Chemical, physical, and sensory properties of dairy products enriched with conjugated linoleic acid. Journal of Dairy Science 88: 2923-2937.

Joseph S.V., Jacques H., Plourde M., Mitchell P.L., Mcleod R.S., Jones P.J.H. (2011). Conjugated linoleic acid supplementation for 8 weeks does not affect body composition, lipid profile, or safety biomarkers in overweight, hyperlipidemic men. The Journal of Nutrition 141: 1286-1291.

Juárez M. (1999). Leche y derivados lácteos. En: Tratado de Nutrición. Editores: M. Hernández Rodríguez, A. Sastre Gallego. Ediciones Díaz de Santos. Madrid. 377-381.

Jutzeler van Wijlen R.P., Colombani P.C. (2010). Grass-based ruminant production methods and human bioconversion of vaccenic acid with estimations of maximal dietary intake of conjugated linoleic acids (review). International Dairy Journal 20: 433-448.

Jutzeler van Wijlen R.P. (2011). Long-term conjugated linoleic acid supplementation in humans effects on body composition and safety (review). European Journal of Lipid Science and Technology 113(9): 1077-1094.

Kalac P., Samkova E. (2010). The effects of feeding various forages on fatty acid composition of bovine milk fat: A review. Czech Journal of Animal Science 55(12): 521-537.

Kamphuis M.M.J.W., Lejeune M.G.P.M., Saris W.H.M., Westerterp-Plantenga M.S. (2003). The effect of conjugated linoleic acid supplementation after weight loss on body weight regain, body composition, and resting metabolic rate in overweight subjects. International Journal of Obesity 27: 840-847.

Kelley N.S., Hubbard N.E., Erickson K.L. (2007). Conjugated linoleic acid isomers and cancer. Journal of Nutrition 137(12): 2599-2607.

Khanal R.C., Dhiman T.R. (2004). Biosynthesis of conjugated linoleic acid (CLA): A review. Pakistan Journal of Nutrition 3(2): 72-81.

Khanal R.C., Olson K.C. (2004). Factor affecting conjugatend linoleic acid (CLA) content in milk, meat and egg: A review. Pakistan Journal of Nutrition 3(2): 82-98. 
Kim Y.J., Liu R.H., Rychlik J.L., Russell J.B. (2002). The enrichment of a ruminal bacterium (Megasphaera elsdenii YJ-4) that produces the trans-10, cis-12 isomer of conjugated linoleic acid. Journal of Applied Microbiology 92: 976-982.

Klieve A.V., Hennessy D., Ouwerkerk D., Forster R.J., Mackie R.I, Attwood G.T. (2003). Establishing populations of Megasphaera elsdenii YE 34 and Butyrivibrio fibrisolvens YE 44 in the rumen of cattle fed high grain diets. Journal of Applied Microbiology 95: 621-630.

Kraft J., Collomb M., Möckel P., Sieber R., Jahreis G. (2003). Differences in CLA isomer distribution of cows' milk lipids. Lipids 38: 657-664.

Kramer J.K.G, Sehat N., Fritsche J., Mossoba M., Eulitz K., Yurawecs M., Ku Y. (1999). Separation of conjugated fatty acid isomers. En: Advances in Conjugated Linoleic Acid Research (Volume 1): pp. 83-109. Editores: M.P. Yurawecs, M.M. Mossoba, J.K.G. Kramer, M.W. Pariza, G.J. Nelson. AOCSS Press, Champaign IL (USA).

Kramer J.K.G., Hernández M., Cruz-Hernández C., Kraft J., Dugan M.E.R. (2008). Combinig results of two GC separations partly achieves determination of all cis and trans 16:1, 18:1, 18:2 and 18:3 except CLA isomers of milk fat as demonstrated using Ag-Ion SPE fractionation. Lipids 43: 259-273.

Kuhnt K., Degen C., Jahreis G. (2010). 2-Propanol in the mobile phase reduces the time of analysis of CLA isomers by silver ion-HPLC. Journal of Chromatography B 878: 88-91.

Laloux L., Du Chaffaut L., Razanamahefa L., Lafay L. (2007). Trans fatty acid content of foods and intake levels in France. European Journal of Lipid Science and Technology 109: 918-929.

Larsen T.M., Toubro S., Gudmundsen A., Astrup A. (2006). Conjugated linoleic acid supplementation for 1 y does not prevent weight or body fat regain. The American Journal of Clinical Nutrition 83(3): 606-612.

Larsson S. C., Bergkvist L., Wolk A. (2005). High-fat dairy food and conjugated linoleic acid intakes in relation to colorectal cancer incidence in the Swedish Mammography Cohort. American Journal of Clinical Nutrition 82: 894-900.

Larsson S.C., Bergkvist L., Wolk A. (2009). Conjugated linoleic acid intake and breast cancer risk in a prospective cohort of Swedish women. American Journal of Clinical Nutrition 90(3): 556-560.

Ledoux M., Chardigny J.M., Darbois M., Soustre Y., Sébédio J.L., Laloux L. (2005). Fatty acid composition of French butters, with special emphasis on conjugated linoleic acid (CLA) isomers. Journal of Food Composition and Analysis 18(5): 409-425.

Lee K.W., Lee H.J., Cho H.Y., Kim Y.J., (2005). Role of the conjugated linoleic acid in the prevention of cancer. Critical Reviews of Food Science and Nutrition 45: 135-144.

Lee M., Tweed J. (2008). Isomerisation of cis-9 trans-11 conjugated linoleic acid (CLA) to trans-9 trans-11 CLA during acid methylation can be avoided by a rapid base catalysed methylation of milk fat. Journal of Dairy Research 75: 354-356.

Leite J., Lima E., Baptista J. (2007). Azorean bovine milk conjugated linoleic acid. Effect of green pasture diet, storage and processing temperature. Le Lait 87(1): 167-179.

Lin H., Boylston T.D., Chang M.J., Luedecke L.O., Shultz T.D. (1995). Survey of the conjugated linoleic acid content of dairy products. Journal of Dairy Science 78: 2358-2365.

Lin H., Boylston T.D., Luedecke L.O., Shultz T.D.. (1999). Conjugated linoleic acid content of cheddar - type cheese as affected by processing. Journal of Food Science 64 (5): 874-878. 
Loor J.J., Ueda K., Ferlay A., Chilliard Y., Doreau M. (2004). Biohydrogenation, duodenal flow, and intestinal digestibility of trans fatty acids and conjugated linoleic acids in response to dietary forage: concentrate ratio and linseed oil in dairy cows. Journal of Dairy Science 87: 2472-2485.

Lourenço M., Van Ranst G., Vlaeminck B., De Smet S., Fievez V. (2008). Influence of different dietary forages on the fatty acid composition of rumen digesta as well as ruminant meat and milk. Animal Feed Science and Technology 145(1-4): 418-437.

Luna López M.P. (2006). Ácido linoleico conjugado en productos lácteos. Tesis Doctoral. Departamento de Química-Física Aplicada, Sección Departamental de Ciencias de la Alimentación. Facultad de Ciencias. Universidad Autónoma de Madrid.

Luna P., Martín-Diana A.B., Alonso L., Fontecha J., De la Fuente M.A., Requena T., Juárez M. (2004). Effects of milk fat replacement by PUFA enriched fats on $n$-3 fatty acids, conjugated dienes and volatile compounds of fermented milks. European Journal of Lipid Science and Technology 106: 417-423.

Luna P., Fontecha J., Juárez M., De la Fuente M.A. (2005a). Conjugated linoleic acid in ewe milk fat. Journal of Dairy Research 72: 415-424.

Luna P., Fontecha J., Juárez M., De la Fuente M.A. (2005b). Changes in the milk and cheese fat composition of ewes fed commercial supplements containing lindseed with special reference to the CLA content and isomer composition. Lipids 40: 445-454.

Luna P., De la Fuente M.A., Juárez M. (2005c). Conjugated linoleic acid in processed cheeses during the manufacturing stages. Journal of Agricultural and Food Chemistry 53: 2690-2695.

Luna P., Juárez M., De la Fuente M.A. (2005d). Validation of a rapid milk fat separation method to determine the fatty acid profile by gas chromatography. Journal of Dairy Science 88: 3377-3381.

Luna P., Juárez M., De la Fuente M.A. (2007). Conjugated linoleic acid content and isomer distribution during ripening in three varieties of cheeses protected with designation of origin. Food Chemistry 103: 1465-1472.

Luna P., Juárez M., De la Fuente M.A. (2008a). Gas chromatography and silver-ion high performance liquid chromatography analysis of conjugated linoleic acid isomers in free fatty acid form using sulphuric acid in methanol as catalyst. Journal of Chromatography A 1204(1): 110-113.

Luna P., Bach A., Juárez M., De la Fuente M.A. (2008b). Influence of diets rich in flax seed and sunflower oil on the fatty acid composition of ewe's milk fat especially on the level of conjugated linoleic acid, n-3 and n-6 fatty acids. International Dairy Journal 18(1): 99-107.

Luna P., Rodríguez-Pino V., De la Fuente M.A. (2009). Occurrence of 16:1 isomers in milk fats from ewes fed with different dietary lipid supplements. Food Chemistry 117: 248-253.

Lurueña-Martínez M.A. (2010). Efecto de la raza y del recuento de células somáticas sobre la calidad del queso de oveja. Tesis Doctoral. Departamento de Construcción y Agronomía. Escuela Politécnica de Zamora. Universidad de Salamanca.

Ma D.W.L., Wierzbicki A.A., Field C.J., Clandinin M.T. (1999). Conjugated linoleic acid in Canadian dairy and beef products. Journal of Agricultural and Food Chemistry 47: 1956-1960.

Malpuech-Brugère C., Verboeket - van de Venne W.P.H.G., Mensink R.P., Arnal M.A., Morio B., Brandolini M., Saebo A., Lassel T.S., Chardigny J.M., Sebedio J.L., Beaufrere B. (2004). Effects of two conjugated linoleic acid isomers on body fat mass in overweight humans. Obesity Research 12(4): 591-598.

Marchi I., Rudaz S., Veuthey J-L. (2009). Atmospheric pressure photoionization for coupling liquidchromatography to mass spectrometry: A review. Talanta 78: 1-18. 
Martini M., Liponi G.B., Salari F. (2010). Effect of forage:concentrate ratio on the quality of ewe's milk, especially on milk fat globules characteristics and fatty acids composition. Journal of Dairy Research 77: 239-244.

Martins S., Lopes P., Alfaia C., Ribeiro V., Guerreiro T., Fontes C., Castro M., Soveral G., Prates J. (2007). Contents of conjugated linoleic acid isomers in ruminant-derived foods and estimation of their contribution to daily intake in Portugal. British Journal of Nutrition 98: 1206-1213.

Mataix Verdú J., García Diz L., Mañas Almendros M., Martínez de Victoria E., Llopis González J. (2009). Tablas de composición de alimentos españoles, 5a edición; pp. 169-215 (Editor: J. Mataix Verdú). Instituto de Nutrición y Tecnología de los Alimentos (Universidad de Granada). Editorial Universidad de Granada. Granada, España.

Mayneris-Perxachs J., Bondia-Pons I., Moltó-Puigmartí C., Pairó M., Castellote A.I., López-Sabater M.C. (2010). Diet and plasma evaluation of the main isomers of conjugated linoleic acid and transfatty acids in a population sample from Mediterranean north-east Spain. Food Chemistry 123: 296305.

McCance R.A., Widdowson's E.M. (1992). The composition of foods, 5th. Edition. Royal Society of Chemistry. United Kingdom. 78-81.

McCann S.E., Ip C., Ip M.M., McGuire M.K., Muti P., Edge S.B., Trevisan M., Freudenheim J.L. (2004). Dietary intake of conjugated linoleic acids and risk of premenopausal and postmenopausal breast cancer, Western New York Exposures and Breast Cancer Study (WEB study). Cancer Epidemiology, Biomarkers \& Prevention 13(9): 1480-1484.

Mele M., Buccioni A., Petacchi F., Enjalbert F. (2006). Effect of forage/concentrate ratio and soybean oil supplementation on milk yield, and composition from Sarda ewes. Animal Research 55(4): 273-285.

Mele M., Contarini G., Cercaci L., Serra A., Buccioni A., Povolo M., Conte G., Funaro A., Banni S., Lercker G., Secchiari P. (2011). Enrichment of Pecorino cheese with conjugated linoleic acid by feeding dairy ewes with extruded lindseed: Effect on fatty acid and triglycerides composition and on oxidative stability. International Dairy Journal 21: 365-372.

Mel'uchova B., Blasko J., Kubinec R., Gorova R., Dubravska J., Margetin M., Sojak L. (2008). Seasonal variations in fatty acid composition of pasture forage plants and CLA content in ewe milk fat. Small Ruminant Research 78(1-3): 56-65.

Moloney F., Yeow T.P., Mullen A., Nolan J.J., Roche H.M. (2004). Conjugated linoleic acid supplementation, insulin sensitivity, and lipoprotein metabolism in patients with type 2 diabetes mellitus. The American Journal of Clinical Nutrition 80(4): 887-895.

Moltó-Puigmartí C., Castellote A.I., López-Sabater M.C. (2007). Conjugated linoleic acid determination in human milk by fast gas chromatography. Analytica Chimica Acta 602: 122-130.

Moltó-Puigmartí C., Permanyer M., Castellote A.I., López-Sabater M.C. (2011). Effects of pasteurisation and high-pressure processing on vitamin $C$, tocopherols and fatty acids in mature human milk. Food Chemistry 124: 697-702.

Moreiras O., Carbajal A., Cabrera L., Cuadrado C. (2009). Tablas de composición de alimentos (13a edición): pp. 40-41. Ediciones Pirámide, Madrid (España).

Mozzon M., Frega N.G., Fronte B., Tocchini M. (2002). Effect of dietary fish oil supplements on levels of n-3 polyunsaturated fatty acids, trans acids and conjugated linoleic acid in ewe milk. Food Technology and Biotechnology 40(3): 213-219. 
Müller A., Mickel M., Geyer R., Ringseis R., Eder K., Steinhart H. (2006a). Identification of conjugated linoleic acid elongation and $\beta$-oxidation products by coupled silver-ion HPLC APPI-MS. Journal of Chromatography B 837: 147-152.

Müller A., Düsterloh K., Ringseis R., Eder K., Steinhart H. (2006b). Development of an alternative eluent system for $\mathrm{Ag}^{+}$-HPLC analysis of conjugated linoleic acid isomers. Journal of Separation Science 29: 358-365.

Muñoz Hornillos, M.; Yoldi Bienzobas, G. (2003). Leche y derivados lácteos. En: Alimentos: composición y propiedades. Editores: I. Astiasarán, J.A. Martínez. McGraw - Hill Interamericana. 69-108.

Mushtaq S., Mangiapane E.H., Hunter K.A. (2010). Estimation of cis-9, trans-11 conjugated linoleic acid content in UK foods and assessment of dietary intake in a cohort of healthy adults. British Journal of Nutrition 103: 1366-1374.

Naumann E., Carpentier Y.A., Saebo A., Lassel T.S., Chardigny J.M., Sebedio J.L., Mensink R.P. (2006). Cis-9,trans-11 and trans-10,cis-12 conjugated linoleic acid (CLA) do not affect the plasma lipoprotein profile in moderately overweight subjects with LDL phenotype B. Atherosclerosis 188: 167-174.

Navarro V., Fernández-Quintela A., Churruca I., Portillo M.P. (2006). The body fat-lowering effect of conjugated linoleic acid: a comparison between animal and human studies. Journal of Physiology and Biochemistry 62 (2): 137-148.

Nikolova-Damyanova B. (2009). Retention of lipids in silver ion high performane liquid chromatrography: Facts and assumptions. Journal of Chromatography A 1216: 1815-1824.

Norris L.E., Collene A.L., Asp M.L., Hsu J.C., Liu L.F., Richardson J.R., Li D.M., Bell D., Osei K., Jackson R.D., Belury M.A. (2009). Comparison of dietary conjugated linoleic acid with safflower oil on body composition in obese postmenopausal women with type 2 diabetes mellitus. American Journal of Clinical Nutrition 90(3): 468-476.

Nudda A., Bencini R., Mijatovic S., Pulina G. (2002). The yield and composition of milk in Sarda, Awassi, and Merino sheep milked unilaterally at different frequencies. Journal of Dairy Science 85: 2879-2884.

Nudda A., Battacone G., Bencini R., Pulina G. (2004). Nutrition and milk quality. En: Dairy Sheep Nutrition: pp. $129-149$ (Editores: G. Pulina, R. Bencini). CABI Publishing, London (United Kingdom).

Nudda A., McGuire M.A., Battacone G., Pulina G. (2005). Seasonal variation in conjugated linoleic acid and vaccenic acid in milk fat of sheep and its transfer to cheese and ricotta. Journal of Dairy Science 88: 1311-1319.

Nuernberg K., Dannenberger D., Ender K., Nuernberg G. (2007). Comparison of different methylation methods for the analysis of conjugated linoleic acid isomers by silver ion HPLC in beef lipids. Journal of Agricultural and Food Chemistry 55: 598-602.

Nugent A.P., Roche H.M., Noone E.J., Long A., Kelleher D.K., Gibney M.J. (2005). The effects of conjugated linoleic acid supplementation on immune function in healthy volunteers. European Journal of Clinical Nutrition 59: 742-750.

Nunes J.C., Torres A.G. (2010). Fatty acid and CLA composition of Brazilian dairy products, and contribution to daily intake of CLA. Journal of Food Composition and Analysis 23(8): 782-789.

O'Donnell-Megaro A.M., Barbano D.M., Bauman D.E. (2011). Survey of the fatty acid composition of retail milk in the United States including regional and seasonal variations. Journal of Dairy Science 94: 59-65. 
O'Shea M., Bassaganya-Riera J., Mohede I.C.M. (2004). Immunomodulatory properties of conjugated linoleic acid. The American Journal of Clinical Nutrition 79(6): 1199S-1206S.

Ostrovsky I., Pavlikova E., Blasko J., Gorova R., Kubinec R., Margetin M., Sojak L. (2009). Variation in fatty acid composition of ewes' milk during continuous transition from dry winter to natural pasture diet. International Dairy Journal 19(9): 545-549.

Ostrowska E., Dunshea F.R., Muralitharan M., Cross R.F. (2000). Comparison of silver-ion highperformance liquid chromatographic quantification of free and methylated conjugated linoleic acid. Lipids 35: 1147-1153.

Othmane M.H., Carriedo J.A., De la Fuente L.J., San Primitivo F. (2002). Factors affecting test-day milk composition in dairy ewes, and relationship amongst various milk components. Journal of Dairy Research 69: 53-62.

Palma I., Farran A., Cantós D. (2008). Tablas de composición de alimentos para medidas caseras de consumo habitual en España. Centre d'Enseyanment Superior de Nutrició i Dietética (CESNID); pp. 56-79. McGraw-Hill Interamericana, Barcelona (España).

Palmquist D.L., Lock A.L., Shingfield K.J., Bauman D.E. (2005). Biosynthesis of conjugated linoleic acid in ruminants and humans. Advances in Food and Nutrition Research 50: 179-217.

Pariza M.W., Park Y., Cook M.E. (2001). The biologically active isomers of conjugated linoleic acid. Progress in Lipid Research 40: 283-298.

Park S.Y., Ahn J.E., Kim G.B., Jung M.Y., Lee B.H. (2008). Distribution and content of geometric isomers of conjugated linoleic acid in dairy foods from the Quebec Province of Canada. Food Science and Biotechnology 17: 31-37.

Park Y., Albright K.J., Liu W., Storkson J.M., Cook M.E., Pariza M.W. (1997). Effect of conjugated linoleic acid on body composition in mice. Lipids 32(8): 853-858.

Park Y., Juárez M., Ramos M., Haenlein G.F.W. (2007). Physico-chemical characteristics of goat and sheep milk. Small Ruminant Research 68: 88-113.

Park Y. (2009). Conjugated linoleic acid (CLA): Good or bad trans fat? Journal of Food Composition and Analysis 22: S4-S12.

Parodi P.W. (2003). Conjugated linoleic acid in food. En: Advances in Conjugated Linoleic Acid Research (Volume 2): pp. 101-122. Editores: J.L. Sebedio, W.W. Christie, R.O. Adlof. AOCSS Press, Champaign IL (USA).

Partidario A.M., Ribeiro J.C.S., Prates J.A.M. (2008). Fatty acid composition and nutritional value of fat in three PDO ewe's milk Portuguese cheeses. Dairy Science and Technology 88(6): 683-694.

Pestana J.M., Martins S.I.V., Alfaia C.M.M., Lopes P.A., Bessa R.J., Castro M.L.F., Prates J.A.M. (2009). Contents and distribution of conjugated linoleic acid isomers in bovine milk, cheese and butter from Azores. Dairy Science and Technology, 89 (2): 193-200.

Pfeuffer M., Fielitz K., Laue C., Winkler P., Rubin D., Helwig U., Giller K., Kammann J., Schwedhelm E., Boger R.H., Bub A., Bell D., Schrezenmeir J. (2011). CLA does not impair endothelial function and decreases body weight as compared with safflower oil in overweight and obese male subjects. Journal of the American College of Nutrition 30 (1): 19-28.

Piperova L.S., Sampugna J., Teter B.B., Kalscheur K.F., Yurawecz M.P., Ku Y., Morehouse K.M., Erdman R.A. (2002). Duodenal and milk trans octadecenoic acid and conjugated linoleic acid (CLA) isomers indicate that postabsorptive synthesis is the predominant source of cis-9 containing CLA in lactating dairy cows. Journal of Nutrition 132: 1235-1241. 
Plourde M., Jew S., Cunnane S.C., Jones P.J.H. (2008). Conjugated linoleic acids: why the discrepancy between animal and human studies? Nutrition Reviews 66 (7): 415-421.

Prandini., A., Sigolo S., Tansini G., Brogna N., Piva G. (2007). Different level of conjugated linoleic acid (CLA) in dairy products from Italy. Journal of Food Composition and Analysis 20(6): 472479.

Prandini A., Sigolo S., Piva G. (2009). Conjugated linoleic acid (CLA) and fatty acid composition of milk, curd and Grana Padano cheese in conventional and organic farming systems. Journal of Dairy Research 76: 278-282.

Prandini A., Sigolo S., Piva G. (2011). A comparative study of fatty acid composition and CLA concentration in commercial cheeses. Journal of Food Composition and Analysis 24(1): 55-61.

Precht D., Molkentin J., Vahlendieck M. (1999). Influence of the heating temperature on the fat composition of milk fat with emphasis on cis-/trans-isomerization. Nahrung-Food 43(1): 25-33.

Pulina G., Nudda A. (2004). Milk production. En: Dairy Sheep Nutrition: pp 1-2 (Editores: G. Pulina, R. Bencini). CABI Publishing, London (United Kingdom).

Pulina G., Nudda A., Battacone G., Cannas A. (2006). Effects of nutrition on the contents of fat, protein, somatic cells, aromatic compounds, and undesirable substances in sheep milk. (Review). Animal Feed Science and Technology 131(3-4): 255-291

Racine N.M., Watras A.C., Carrel A.L., Allen D.B., McVean J.J., Clark R.R., O'Brien A.R., O'Shea M., Scott C.E., Schoeller D.A. (2010). Effect of conjugated linoleic acid on body fat accretion in overweight or obese children. American Journal of Clinical Nutrition 91: 1157-1164.

Raff M., Tholstrup T., Sejrsen K., Straarup E.M., Wiinberg N. (2006). Diets rich in conjugated linoleic acids and vaccenic acid have not effect on blood pressure and isobaric arterial elasticity in healthy young men. The Journal of Nutrition 136: 992-997.

Raff M., Tholstrup T., Toubro S., Bruun J.M., Lund P., Straarup E.M., Christensen R., Sandberg B., Mandrup S. (2009). Conjugated linoleic acids reduce body fat in healthy postmenopausal women. The Journal of Nutrition 139: 134-1352.

Raynal-Ljutovac K., Lagriffoul G., Paccard P., Guillet I., Chilliard Y. (2008). Composition of goat and sheep milk products: An update. Small Ruminant Research 79: 57-72.

Reglamento (CE) $N^{o}$. 258/97 de 27 de enero sobre nuevos alimentos y nuevos ingredientes alimentarios. DOCE $N^{\circ}$. L 43/1, 14 de febrero, 1997.

Reynolds C.K., Cannon V.L., Loerch S.C. (2006). Effects of forage source and supplementation with soybean and marine algal oil on milk fatty acid composition of ewes. Animal Feed Science and Technol 131(3-4): 333-357.

Reynolds C.M., Roche H.M. (2010). Conjugated linoleic acid and inflammatory cell signalling. Prostaglandins, Leukotrienes and Essential Fatty Acids 82: 199-204.

Rickert R., Steinhart H., Fritsche J., Sehat N., Yurawecz M.P., Mossoba M.M., Roach J.A.G., Eulitz K., Ки Y., Kramer J.A.G. (1999). Enhanced resolution of conjugated linoleic acid isomers by tandem-column silver-ion high performance liquid chromatography. Journal of High Resolution Chromatography 22: 144-148.

Risérus U., Brismar K., Arner P., Vessby B. (2002a). Treatment with dietary trans10cis12 conjugated linoleic acid causes isomer-specific insulin resistance in obese men with the metabolic syndrome. Diabetes Care 25: 1516-1521. 
Risérus U., Basu S., Jovinge S., Fredrikson G.N., Arnlov J., Vessby B. (2002b). Supplementation with conjugated linoleic acid causes isomer-dependent oxidative stress and elevated C-reactive protein - A potential link to fatty acid-induced insulin resistance. Circulation 106(15): 1925-1929.

Risérus U., Vessby B., Arnlöv J., Basu S. (2004). Effects of cis-9,trans-11 conjugated linoleic acid supplementation on insulin sensitivity, lipid peroxidation, and proinflammatory markers in obese men. American Journal of Clinical Nutrition 80: 279-283.

Ritzenthaler K.L., McGuire M.K., Falen R., Shultz T.D., Dasgupta N., McGuire M.A. (2001). Estimation of conjugated linoleic acid intake by written dietary assessment methodologies underestimates actual intake evaluated by food duplicate methodology. Journal of Nutrition 131: 1548-1554.

Rodríguez-Alcalá L.M., Fontecha J. (2007). Fatty acid and conjugated linoleic acid (CLA) isomer composition of commercial CLA-fortified dairy products: Evaluation after processing and storage. Journal of Dairy Science 90: 2083-2090.

Rodríguez-Alcala L.M., Harte F., Fontecha J. (2009). Fatty acid profile and CLA isomers content of cow, ewe and goat milks processed by high pressure homogenization. Innovative Food Science and Emerging Technologies 10(1): 32-36.

Rodríguez-Alcala L.M., Braga T., Malcata F.X., Gomes A., Fontecha J. (2011). Quantitative and qualitative determination of CLA produced by Bifidobacterium and lactic acid bacteria by combing spectrophotometric and $\mathrm{Ag}^{+}-\mathrm{HPLC}$ techniques. Food Chemistry 125: 1373-1378.

Rosell, M. S., Lloyd-Wright, Z., Appleby, P. N., Sanders, T. A., Allen, N. E., \& Key, T. J. (2005). Long-chain n-3 polyunsaturated fatty acids in plasma in British meateating, vegetarian, and vegan men. American Journal of Clinical Nutrition, 8: 327-334.

Ruiz-Rodríguez A., Reglero G., Ibáñez E. (2010). Recent trends in the advanced analysis of bioactive fatty acids. Journal of Pharmaceutical and Biomedical Analysis 51: 305-326.

Saebo A. (2003). Commercial synthesis of conjugated linoleate. En: Advances in Conjugated Linoleic Acid Research (Volume 2): pp. 71-81. Editores: J.L. Sebedio, W.W. Christie, R.O. Adlof. AOCSS Press, Champaign IL (USA).

Schmid A., Collomb M., Sieber S., Bee G. (2006). Conjugated linoleic acid in meat and meat products: A review. Meat Science 73: 29-41.

Schoeller D.A., Watras A.C., Whigham L.D. (2009). A meta-analysis of the effects of conjugated linoleic acid on fat-free mass in humans. Applied Physiology, Nutrition and Metabolism 34: $975-$ 978.

Sehat N., Yurawecs M.P., Roach J.A.G., Mossoba M.M., Kramer J.K.G., Ku Y. (1998). Silver-ion high-performance liquid chromatographic separation and identification of conjugated linoleic acid isomers. Lipids 33: 217-221.

Sehat N., Rickert R., Mossoba M.M., Kramer J.K.G., Yurawecs M.P., Roach J.A.G., Adlof R.O., Morehouse K.M., Fritsche J., Eluitz K., Steinhart H., Ku Y. (1999). Improved separation of conjugated fatty acid methyl esters by silver ion high performance chromatography. Lipids 34: 407413 .

Sevi A., Albenzio M., Marino R., Santillo A., Muscio A. (2004). Effects of lambing season and stage of lactation on ewe milk quality. Small Ruminant Research 51: 251-259.

Shantha N.C., Decker E.A.., Ustunol Z. (1992). Conjugated linoleic acid concentration in processed cheese. Journal of the American Oil Chemists' Society (JAOCS) 69(5): 425-428. 
Shantha N.C., Ram L.N., O’Leary J., Hicks C.L., Decker E.A. (1995). Conjugated linoleic acid concentration in dairy products as affected by processing and storage. Journal of Food Science 60: 695-697.

Shingfield K.J., Ahvenjarvi S., Toivonen V., Arola A., Nurmela K.V.V., Huhtanen P., Griinari J.M. (2003). Effect of dietary fish oil on biohydrogenation of fatty acids and milk fatty acid content in cows. Animal Science 77: 165-179.

Sieber R., Collomb M., Aeschlimann A., Jelen P., Eyer H. (2004). Impact of microbial cultures on conjugated linoleic acid in dairy products - a review. International Dairy Journal 14: 1-15.

Sluijs I., Plantinga Y., De Roos B., Mennen L.I., Bots M.L. (2010). Dietary supplementation with cis9,trans-11 conjugated linoleic acid and aortic stiffness in overweight and obese adults. The American Journal of Clinical Nutrition 91: 175-183.

Smedman A., Vessby B., Basu S. (2004). Isomer-specific effects of conjugated linoleic acid on lipid peroxidation in humans: regulation by alpha-tocopherol and cyclo-oxygenase-2 inhibitor. Clinical Science 106: 61-73.

Smit LA, Willett WC, Campos H. (2010). trans-Fatty Acid Isomers in Adipose Tissue Have Divergent Associations with Adiposity in Humans. Lipids 45: 693-700.

Song H.J., Grant I., Rotondo D., Mohede I., Sattar N., Heys S.D., Wahle K.W.J. (2005). Effect of CLA supplementation on inmune function in young healthy volunteers. European Journal of Clinical Nutrition 59: 508-517.

Spitzer V. (1999). Gas chromatography /(electron impact) mass spectrometry analysis of conjugated linoleic acid (CLA) using different derivatization techniques. En: Advances in Conjugated Linoleic Acid Research (Volume 1): pp. 110-125. Editores: M.P. Yurawecs, M.M. Mossoba, J.K.G. Kramer, M.W. Pariza, G.J. Nelson. AOCSS Press, Champaign IL (USA).

Stanton C., Murphy J., McGrath E., Devery R. (2003). Animal feeding strategies for conjugated linoleic acid enrichment of milk. En: Advances in Conjugated Linoleic Acid Research (Volume 2): pp. 123-143. Editores: J.L. Sebedio, W.W. Christie, R.O. Adlof. AOCSS Press, Champaign IL (USA).

Suárez López M.M., Kizlansky A., López L.B. (2006). Evaluación de la calidad de las proteínas en los alimentos calculando el escore de aminoácidos corregido por digestibilidad. Nutrición Hospitalaria 21(1): 47-51.

Swaisgood. H. E. (2010). Las características de la leche. En: Fennema Química de los Alimentos. $3^{a}$ edición. Editores: S. Damodaran; K.L. Parkin, O.R. Fennema. Editorial Acribia, S.A. Zaragoza (España). 883-919.

Syvertsen C., Halse J., Hoivik H.O., Gaullier J.M., Nurminiemi M., Kristiansen K., Einerhand A., O'Shea M., Gudmundsen O. (2007). The effect of 6 months supplementation with conjugated linoleic acid on insulin resistance in overweight and obese. International Journal of Obesity 31: 11481154.

Taylor J.S.W., Williams S.R.P., Rhys R., James P., Frenneaux M.P. (2006). Conjugated linoleic acid impairs endothelial function. Arteriosclerosis Thrombosis and Vascular Biology 26: 307-312.

Thijs C., Müller A., Rist L., Kummeling I., Snijders B.E.P., Huber M., van Ree R., Simoes-Wüst A.P., Dagnelie P.C., van den Brandt P.A. (2011). Fatty acids in breast milk and development of atopic eczema and allergic sensitisation in infancy. Allergy 66: 58-67.

Tholstrup T., Raff M., Straarup E.M., Basu S., Bruun J.M. (2008). An oil mixture with trans-10, cis12 conjugated linoleic acid increases markers of inflammation and in vivo lipid peroxidation compared with cis-9, trans-11 conjugated linoleic acid in postmenopausal women. Journal of Nutrition 138: 1445-1451. 
Toral P.G., Frutos P., Hervás G., Gómez-Cortés P., Juárez M., De la Fuente M.A. (2010a). Changes in milk fatty acid profile and animal performance in response to fish oil supplementation, alone or in combination with sunflower oil, in dairy ewes. Journal of Dairy Science 93(4): 1604-1615.

Toral P.G., Hervás G., Gómez-Cortés P., Frutos P., Juárez M., De la Fuente M.A. (2010b). Milk fatty acid profile and dairy sheep performance in response to diet supplementation with sunflower oil plus incremental levels of marine algae. Journal of Dairy Science 93(4): 1655-1667.

Tricon S., Burdge G.C., Kew S., Banerjee T., Russell J.J., Jones E.L., Grimble R.F., Williams C.M., Yaqoob P., Calder P.C. (2004a). Opposing effects of cis-9,trans-11 and trans10,cis-12 conjugated linoleic acid on blood lipids in healthy humans. American Journal of Clinical Nutrition 80: 614620.

Tricon S., Burdge G.C., Kew S., Banerjee T., Russell J.J., Grimble R.F., Williams C.M., Calder P.C., Yaqoob P. (2004b). Effects of cis-9,trans-11 and trans-10,cis-12 conjugated linoleic acid on immune cell function in healthy humans. American Journal of Clinical Nutrition 80(6): 1626-1633.

Tricon S., Burdge G.C., Jones E.L., Russell J.J., El-Khazen S., Moretti E.,Hall W.L., Gerry A.B., Leake D.S., Grimble R.F., Williams C.M., Calder P.C., Yaqoob P.(2006). Effects of dairy products naturally enriched with cis-9,trans-11 conjugated linoleic acid on the blood lipid profile in healthy middle-aged men. American Journal of Clinical Nutrition 83: 744-753.

Tsiplakou E., Mountzouris K.C., Zervas G. (2006a). Concentration of conjugated linoleic acid in grazing sheep and goat milk fat. Livestock Science 103(1-2): 74-84.

Tsiplakou E., Mountzouris K.C., Zervas G. (2006b). The effect of breed, stage of lactation and parity on sheep milk fat CLA content under the same feeding practices. Livestock Science 105: 162-167.

Tsiplakou E., Kominakis A., Zervas G. (2008a). The interaction between breed and diet on CLA and fatty acids content of milk fat of four sheep breeds kept indoors or at grass. Small Ruminant Research 74(1-3): 179-187.

Tsiplakou E., Zervas G. (2008b). Comparative study between sheep and goats on rumenic acid and vaccenic acid in milk fat under the same dietary treatments. Livestock Science 119(1-3): 87-94.

Tsiplakou E., Kotrotsios V., Hadjigeorgiou I., Zervas G. (2010). Differences in sheep and goats milk fatty acid profile between conventional and organic farming systems. Journal of Dairy Research 77: 343-349.

Turpeinen A.M., Ylonen N., Von Willebrand E., Basu S., Aro A. (2008). Immunological and metabolic effects of cis-9, trans-11-conjugated linoleic acid in subjects with birch pollen allergy. British Journal of Nutrition 100: 112-119.

Van Ranst G., Fievez V., Vandewalle M., De Riek J., Van Bockstaele E. (2009). Influence of herbage species, cultivar and cutting date on fatty acid composition of herbage and lipid metabolism during ensiling. Grass and Forage Science 64(2): 196-207.

Venkatramanan S., Joseph S.V., Chouinard P.Y., Jacques H., Farnworth E.R., Jones P.J.H. (2010). Milk enriched with conjugated linoleic acid fails to alter blood lipids or body composition in moderately overweight, borderline hyperlipidemic individuals. Journal of the American College of Nutrition 29 (2): 152-159.

Voorrips L.E., Brants H.A.M., Kardinaal A.F.M., Hiddink G.J., Van den Brandt P.A., Goldbohm R.A. (2002). Intake of conjugated linoleic acid, fat, and other fatty acids in relation to postmenopausal breast cancer: The Netherlands Cohort Study on Diet and Cancer. American Journal of Clinical Nutrition 76(4): 873-882. 
Watras A.C., Buchholz A.C., Close R.N., Zhang Z., Schoeller D.A. (2007). The role of conjugated linoleic acid in reducing body fat and preventing holiday weight gain. International Journal of Obesity 31: 481-487.

Werner S.A., Luedecke L.O., Shultz T.D. (1992). Determination of conjugated linoleic acid content and isomer distribution in three cheddar-type cheeses: Effects of cheese cultures, processing, and aging. Journal of Agricultural and Food Chemistry 40: 1817-1821.

Whigham L.D., O'Shea M., Mohede I.C.M., Walaski H.P., Atkinson R.L. (2004). Safety profile of conjugated linoleic acid in a 12-month trial in obese humans. Food and Chemical Toxicology 42: 1701-1709.

Whigham L.D., Watras A.C., Schoeller D.A. (2007). Efficacy of conjugated linoleic acid for reducing fat mass: a meta-analysis in humans. American Journal of Clinical Nutrition 85(5): 1203-1211.

Wolff R.L., Precht D. (2002). Reassessment of the contribution of bovine milk fats to the trans-18:1 isomeric acid consumption by European populations. Additional data for rumenic acid (c9t11-18:2). Lipids 37: 1149-1150.

Xu S., Boylston T.D., Glatz B.A. (2005). Conjugated linoleic acid content and organoleptic atributes of fermented milk products produced with probiotic bacteria. Journal of Agricultural and Food Chemistry 53: 9064-9072.

Xu S., Boylston T.D., Glatz B.A. (2006). Effect of inoculation level of Lactobacillus rhamnosus and yogurt cultures on conjugated linoleic acid content and quality attributes of fermented milk products. Journal of Food Science 71 (4): 275-280.

Yadav H., Jain S., Sinha P.R. (2007). Production of free fatty acids and conjugated linoleic acid in probiotic dahi containing Lactobacillus acidophilus and Lactobacillus casei during fermentation and storage. International Dairy Journal 17(8): 1006-1010.

Zengin G., Cakmak Y.S., Guler G.O., Aktumsek A., Akim M. (2011). The effect of pasteurisation temperature on the CLA content and fatty acid composition of white pickled cheese. International Journal of Dairy Technology 64(4): 509-516.

Zhang R.H., Mustafa A.F., Zhao X. (2006a). Effects of flaxseed supplementation to lactating ewes on milk composition, cheese yield, and fatty acid composition of milk and cheese. Small Ruminant Research 63(3): 233-241.

Zhang R.H., Mustafa A.F., Zhao X. (2006b). Effects of feeding oilseeds rich in linoleic and linolenic fatty acids to lactating ewes on cheese yield and on fatty acid composition of milk and cheese. Animal Feed Science and Technology 127(3-4): 220-233. 



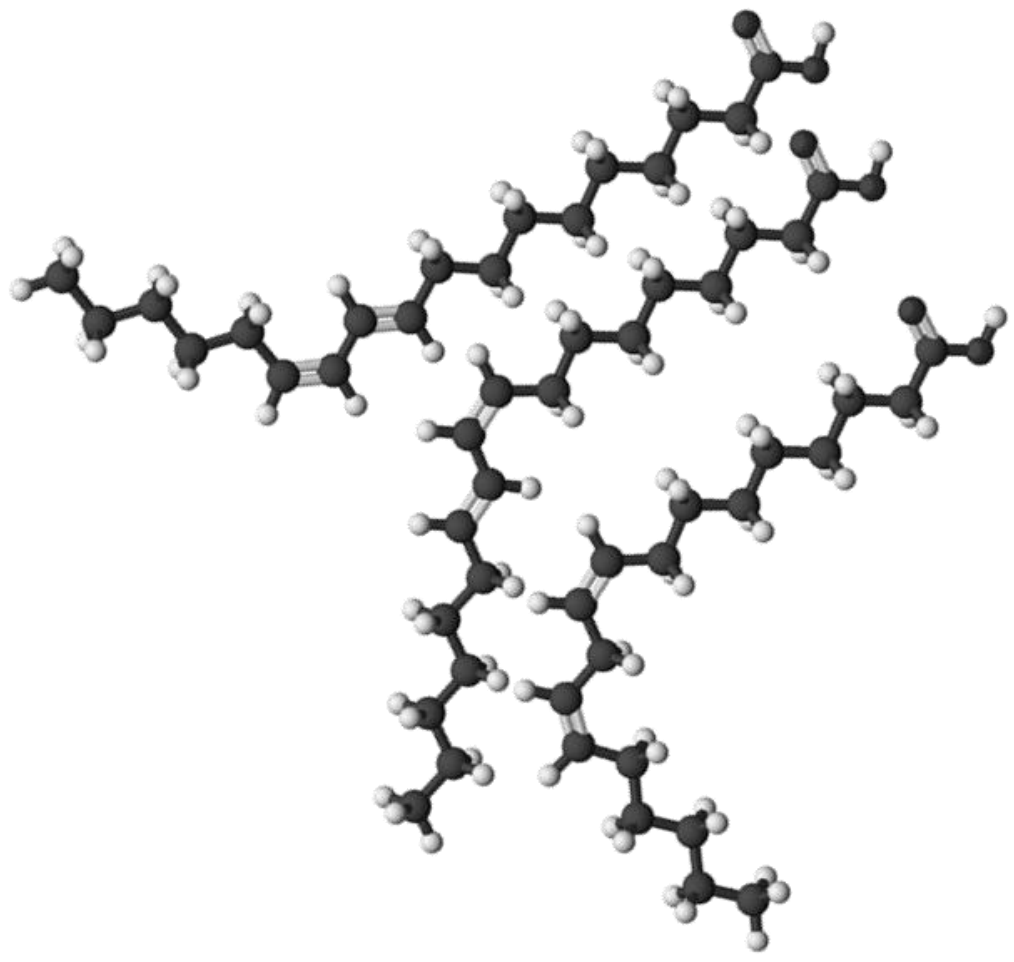

ANEXOS 



\section{Anexo 1: Cálculo de factores de conversión de unidades}

Se trata de transformar las expresiones:

- $\mathrm{g}$ de CLA / $100 \mathrm{~g}$ de ácidos grasos $\rightarrow \mathrm{mg}$ de CLA / g de grasa

- $\mathrm{g}$ de CLA FAME / 100g de FAME $\rightarrow$ mg de CLA / g de grasa

Será necesario:

- Calcular el peso molecular promedio de los triglicéridos de leche de oveja o de vaca, según el caso concreto.

- Conocer el peso molecular promedio de los ácidos grasos y de los FAME's correspondientes.

- Establecer la relación numérica entre gramos de grasa y ácidos grasos totales o FAME's.

\section{Calcular el peso molecular promedio de los triglicéridos de leche de oveja o de vaca}

Se han considerado los diferentes triglicéridos y contenido de los mismo publicados por Goudjil et al. (2003), Fontecha et al. (2005) y Park et al. (2007). Se calculó el peso molecular individual de cada triglicérido y se multiplicó por el porcentaje del mismo en leche de cada especie animal, así se obtiene un valor parcial (peso molecular relativo) para cada triglicérido. La suma de todos estos valores nos dará el peso molecular promedio de los triglicéridos de leche. En la Tabla A-1, se recogen estos cálculos.

El peso molecular individual se obtuvo mediante la fórmula:

$$
P M_{C N}=[(N+3)(P M)]_{C}+[(2 N+2)(P M)]_{H}+[(6)(P M)]_{O}
$$

El número de carbonos $(\mathrm{N}+3)$ corresponde a "N" carbonos de los ácidos grasos más los tres del glicerol. El número de hidrógenos $(2 \mathrm{~N}+2)$ se obtiene de sumar los [2(N-3)+3] hidrógenos de los ácidos grasos y los 5 hidrógenos que aporta el glicerato. El valor " $2(\mathrm{~N}-3)+3$ ” resulta de considerar que cada carbono de ácido graso $(\mathrm{N})$ tiene dos (2) hidrógenos enlazados, excepto el carbono carbonílico (no aporta hidrógeno, de ahí que se reste 3) y el carbono final de cada ácido graso (aporta un hidrógeno más, de ahí que se sume 3).

En esta estimación se asume que los ácidos grasos presentes en la molécula de triglicérido son saturados, ya que la diferencia en el cálculo sería de dos hidrógenos menos por cada insaturación, un error que puede considerarse mínimo si se tiene en cuenta las variaciones en las proporciones de los triglicéridos en la leche y en el contenido de ácidos grasos insaturados. 
Tabla A-1. Estimación del peso molecular promedio de los triglicéridos en la leche

\begin{tabular}{|c|c|c|c|c|c|c|c|c|}
\hline \multicolumn{5}{|c|}{ Triglicéridos } & \multicolumn{2}{|c|}{$\begin{array}{l}\% \text { y Peso molecular relativo } \\
\text { en leche de oveja }^{5}\end{array}$} & \multicolumn{2}{|c|}{$\begin{array}{c}\% \text { y Peso molecular relativo } \\
\text { en leche de vaca }\end{array}$} \\
\hline$\left(C_{N}\right)^{1}$ & $\begin{array}{l}\mathbf{N}^{\circ} \text { de C } \\
(\mathrm{N}+3)^{2}\end{array}$ & $\begin{array}{l}N^{\circ} \text { de H } \\
(2 \mathrm{~N}+2)^{3} \\
\end{array}$ & $\mathrm{~N}^{\circ}$ de $\mathrm{O}$ & $\mathbf{P M}_{\text {Individual }}{ }^{4}$ & $(\%)$ & $\mathbf{P M}_{\text {Relativo }}$ & $(\%)$ & $\mathbf{P M}_{\text {Relativo }}$ \\
\hline $\mathrm{C}_{26}$ & 29 & 54 & 6 & 498,74 & 0,72 & 3,5909 & 0,22 & 1,0972 \\
\hline $\mathrm{C}_{28}$ & 31 & 58 & 6 & 526,79 & 1,78 & 9,3768 & 0,57 & 3,0027 \\
\hline $\mathrm{C}_{30}$ & 33 & 62 & 6 & 554,84 & 3,15 & 17,4775 & 1,13 & 6,2697 \\
\hline $\mathrm{C}_{32}$ & 35 & 66 & 6 & 582,89 & 5,13 & 29,9025 & 2,56 & 14,9221 \\
\hline $\mathrm{C}_{34}$ & 37 & 70 & 6 & 610,95 & 7,95 & 48,5704 & 5,95 & 36,3514 \\
\hline $\mathrm{C}_{36}$ & 39 & 74 & 6 & 639,00 & 11,24 & 71,8237 & 10,80 & 69,0121 \\
\hline $\mathrm{C}_{38}$ & 41 & 78 & 6 & 667,05 & 14,23 & 94,9218 & 12,50 & 83,3818 \\
\hline $\mathrm{C}_{40}$ & 43 & 82 & 6 & 695,11 & 12,50 & 86,8884 & 9,87 & 68,6071 \\
\hline $\mathrm{C}_{42}$ & 45 & 86 & 6 & 723,16 & 9,21 & 66,6031 & 6,87 & 49,6811 \\
\hline $\mathrm{C}_{44}$ & 47 & 90 & 6 & 751,21 & 7,67 & 57,6181 & 6,47 & 48,6035 \\
\hline $\mathrm{C}_{46}$ & 49 & 94 & 6 & 779,27 & 6,19 & 48,2366 & 7,32 & 57,0423 \\
\hline $\mathrm{C}_{48}$ & 51 & 98 & 6 & 807,32 & 5,69 & 45,9365 & 9,12 & 73,6276 \\
\hline $\mathrm{C}_{50}$ & 53 & 102 & 6 & 835,37 & 6,49 & 54,2157 & 11,30 & 94,3972 \\
\hline $\mathrm{C}_{52}$ & 55 & 106 & 6 & 863,43 & 6,41 & 55,3456 & 10,00 & 86,3427 \\
\hline $\mathrm{C}_{54}$ & 57 & 110 & 6 & 891,48 & 1,64 & 14,6203 & 4,99 & 44,4848 \\
\hline \multicolumn{5}{|c|}{ PESO MOLECULAR PROMEDIO ${ }^{7}$} & 705,128 & l (ovejas) & \multicolumn{2}{|c|}{ 736,8235 g/mol (vacas) } \\
\hline
\end{tabular}

(1) El subíndice "N" indica el número de carbonos en las tres moléculas de ácido graso unidas al triglicérido. ${ }^{(2)}$ Número de carbonos totales. ${ }^{(3)}$ Número de hidrógenos totales. ${ }^{(4)}$ Peso molecular individual (se asume que todos los ácidos grasos son saturados). ${ }^{(5)}$ Para calcular el peso molecular relativo de cada triglicérido en leche de oveja, se utilizaron los porcentajes publicados por Fontecha et al. (2005) y Goudjil et al. (2003). ${ }^{(6)}$ Cálculos para la leche de vaca, empleando los porcentajes recogidos por Park et al. (2007). ${ }^{(7)}$ Con la suma de todos los pesos moleculares relativos, se obtuvo el peso molecular promedio de triglicéridos.

\section{Conocer el peso molecular promedio de los ácidos grasos y de los FAME's}

Peso molecular promedio de ácidos grasos libres: Hay que restar al peso molecular final de triglicérido, el valor de peso molecular del glicerato; luego sumar 3 veces el peso molecular del grupo $-\mathrm{OH}$. Finalmente, se divide entre tres y se obtiene el peso molecular promedio para cada ácido graso.

$$
\begin{aligned}
& \left.\mathrm{PM}_{\mathrm{AGlibre}}=[705,1282-89,07 \text { (glicerato })+(51,0220)_{\mathrm{OH}}\right] / 3=\mathbf{2 2 2 , 3 6} \mathbf{g} / \mathbf{m o l} \text { (ovejas) } \\
& \left.\mathrm{PM}_{\mathrm{AGlibre}}=[736,8235-89,07 \text { (glicerato })+(51,0220)_{\mathrm{OH}}\right] / 3=\mathbf{2 3 2 , 9 2} \mathbf{~ g} / \mathbf{m o l} \text { (vacas) }
\end{aligned}
$$

Peso molecular promedio de FAME's: El cálculo se realizaría de la misma forma que en el caso anterior, pero teniendo en cuenta que $-\mathrm{OH}$ se sustituye por $-\mathrm{OCH}_{3}$, por lo que hay que cambiar "H” por " $\mathrm{CH}_{3}$ ” (PM = 15).

$$
\begin{gathered}
\mathrm{PM}_{\mathrm{FAME}}=\left[705,1282-89,07(\text { glicerato })+(93,1018)_{\mathrm{O}-\mathrm{CH} 3}\right] / 3=\mathbf{2 3 6}, \mathbf{3 9} \mathbf{~ g} / \mathbf{m o l} \text { (ovejas) } \\
\mathrm{PM}_{\mathrm{FAME}}=\left[736,8235-89,07(\text { glicerato })+(93,1018)_{\mathrm{O}-\mathrm{CH} 3}\right] / 3=\mathbf{2 4 6 , 9 5} \mathbf{g} / \mathbf{m o l}(\text { vacas })
\end{gathered}
$$

Fontecha et al. (2005) aporta datos porcentuales de los ácidos grasos presentes en leche de oveja (Tabla A-2). Con estos datos también se pudo obtener el peso molecular promedio de ácido graso en la leche de oveja; los resultados se aproximan bastante a los calculados anteriormente. 
Tabla A-2. Estimación del peso molecular promedio de los ácidos grasos (libres o FAME) presentes en la leche de oveja

\begin{tabular}{|c|c|c|c|c|c|}
\hline \multirow{2}{*}{ Ácido graso } & \multirow{2}{*}{$(\%)^{1}$} & \multicolumn{2}{|c|}{ Pesos moleculares como ácidos grasos libres } & \multicolumn{2}{|c|}{ Pesos moleculares como FAME } \\
\hline & & $\mathbf{P M}_{\text {Individual }}$ & $\mathbf{P M}_{\text {Relativo }}$ & $\mathbf{P M}_{\text {Individual }}$ & $\mathbf{P M}_{\text {Relativo }}$ \\
\hline $\mathrm{C}_{4: 0}$ & 8,81 & 88,11 & 7,7621 & 102,13 & 8,9978 \\
\hline $\mathrm{C}_{6: 0}$ & 5,52 & 116,16 & 6,4119 & 130,18 & 7,1862 \\
\hline $\mathrm{C}_{8: 0}$ & 4,05 & 144,21 & 5,8406 & 158,24 & 6,4086 \\
\hline $\mathrm{C}_{10: 0}$ & 10,06 & 172,26 & 17,3298 & 186,29 & 18,7409 \\
\hline $\mathrm{C}_{12: 0}$ & 4,84 & 200,32 & 9,6954 & 214,34 & 10,3743 \\
\hline $\mathrm{C}_{14: 0}$ & 10,28 & 228,37 & 23,4765 & 242,40 & 24,9185 \\
\hline $\mathrm{C}_{15: 0}$ & 1,64 & 242,40 & 3,9753 & 256,42 & 4,2054 \\
\hline $\mathrm{C}_{16: 0}$ & 22,58 & 256,42 & 57,9006 & 270,45 & 61,0678 \\
\hline $\mathrm{C}_{16: 1}$ & 0,90 & 254,41 & 2,2897 & 268,43 & 2,4159 \\
\hline $\mathrm{C}_{17: 0}$ & 1,19 & 270,45 & 3,2184 & 284,48 & 3,3853 \\
\hline $\mathrm{C}_{18: 0}$ & 7,44 & 284,48 & 21,1651 & 298,50 & 22,2087 \\
\hline $\mathrm{C}_{18: 1}$ & 16,50 & 282,46 & 46,6061 & 296,49 & 48,9205 \\
\hline $\mathrm{C}_{18: 2}$ & 3,12 & 280,45 & 8,7499 & 294,47 & 9,1875 \\
\hline Otros & 3,07 & 222,36 & 6,8265 & 236,39 & 7,2571 \\
\hline \multicolumn{2}{|c|}{ PESO MOLECULAR PROMEDIO $^{2}$} & \multicolumn{2}{|c|}{ 221,2478 g/mol (AG libres) } & \multicolumn{2}{|c|}{ 235,2744 g/mol (FAME) } \\
\hline
\end{tabular}

${ }^{(1)}$ Datos tomados de Fontecha et al. (2005). ${ }^{(2)}$ El peso molecular promedio de ácidos grasos (libre o FAME) se obtuvo de la suma de todos los pesos moleculares relativos.

\section{Establecer la relación numérica entre "gramos de grasa" y "ácidos grasos totales"}

Una vez conocidos los pesos moleculares promedio de ácidos grasos (libre o FAME) y triglicéridos, se procede a buscar la relación numérica que permita convertir los datos expresados como ácidos grasos (libre o FAME) en gramo de grasa. Teniendo en cuenta que en cada triglicérido hay 3 moléculas de ácido graso y asumiendo que el 100\% de la grasa de leche extraída se compone prácticamente de triglicéridos, se puede realizar el cálculo de dicho factor.

Para aquellos valores expresados como ácidos grasos libres $\left(\mathbf{A G}_{\text {libre }}\right)$, esta relación sería:

\section{$1,0 \mathrm{~g}$ de grasa $=0,9413 \mathrm{~g}$ de ácidos grasos libres totales}

$$
g_{\text {AGlibre }}=1,00 g_{\text {grasa }}\left(\frac{1,0 g_{\text {TAG }}}{1,0 g_{\text {grasa }}}\right)\left(\frac{1 \mathrm{~mol}_{\text {TAG }}}{705,1282 g_{\text {TAG }}}\right)\left(\frac{3 \mathrm{~mol}_{\text {AGlibre }}}{1 \mathrm{~mol}}\right)\left(\frac{221,2478 \mathrm{~g}_{\text {AAG }}}{1 \mathrm{~mol}}\right)\left(\frac{2 \mathrm{bre}}{}\right)=0,9413 \mathrm{~g}
$$

Para los contenidos expresados como FAME total, se calcula un factor que los relacione con los gramos de grasa; de hecho, se pudo calcular que:

\section{$1,0 \mathrm{~g}$ de grasa $=1,0010 \mathrm{~g}$ de FAME total}

$$
g_{\text {FAME }}=1,00 g_{\text {grasa }}\left(\frac{1,0 g_{\text {TAG }}}{1,0 g_{\text {grasa }}}\right)\left(\frac{1 \mathrm{~mol}_{\text {TAG }}}{705,1282 \mathrm{~g}_{\text {TAG }}}\right)\left(\frac{3 \mathrm{~mol}_{\text {FAME }}}{1 \mathrm{~mol}}\right)\left(\frac{235,2744 \mathrm{~g}_{\text {FAME }}}{1 \mathrm{~mol}}\right)=1,0010 \mathrm{~g}
$$


Sin embargo, hay que tener en cuenta que con este factor sólo se transformaría el contenido de FAME total (denominador) y no el contenido de CLA (numerador). Por lo que sería necesario introducir otro factor que transforme la cantidad de CLA $\mathrm{FAME}_{\mathrm{FA}}$ C $\mathrm{LA}_{\text {libre. }}$. Con los valores de peso

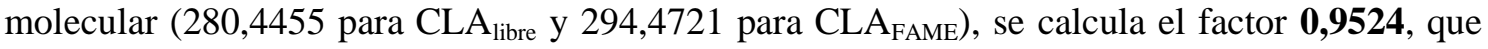
al multiplicarse por $\mathbf{1 , 0 0 1 0}$, se obtiene $\mathbf{0 , 9 5 3 3}$. Este último factor es el que se utilizaría para obtener el contenido de CLA (en miligramos por gramo de grasa).

En leche de vaca, se procedería de la misma forma, pero empleando los pesos moleculares promedio correspondientes a esta especie. En la Tabla A-3 se recogen los factores calculados para ambas especies; dichos factores se aproximan al factor $\mathbf{0 , 9 4 5}$, utilizado por otros autores (Moreiras et al., 2009; Mataix Verdú et al., 2009; Partidario et al., 2008; McCance y Widdowson's, 1992).

Tabla A-3. Factores para transformar el contenido de CLA, expresados en otras unidades, a mg/g de grasa

\begin{tabular}{|c|c|c|c|c|c|}
\hline \multirow{2}{*}{ Expresión inicial } & \multirow{2}{*}{ Factor } & \multirow{2}{*}{ Expresión intermedia } & \multirow{2}{*}{ Expresión final } & \multicolumn{2}{|c|}{ FACTORES } \\
\hline & & & & Ovejas & Vacas \\
\hline g CLA / 100 g ácidos grasos & 10 & mg CLA / g ácidos grasos & mg CLA / g Grasa & 0,9413 & 0,9483 \\
\hline $\mathrm{g} \mathrm{CLA}_{\text {FAME }} / 100 \mathrm{~g}$ FAME's & 10 & mg CLA FAME /g FAME's & mg CLA / g Grasa & 0,9533 & 0,9576 \\
\hline
\end{tabular}


Anexo 2: Familia, nombre científico y nombre común de algunas plantas utilizadas como pasto en la alimentación animal

\section{Familia: Gramineae o Poaceae - Gramíneas}

Avena sativa $\mathrm{L}$.

Avena

Dactylis glomerata L. Jopillo, jopillo de monte, japillo

Festuca arundinaceae Schreb. .Cañuela, lastón Festuca pratensis Huds. .Cañuela, cañuela de prados

Hordeum vulgare $\mathrm{L}$. Cebada

Lolium multiflorum Lam. Vallico o ballico

Lolium perenne $\mathrm{L}$. Vallico, hierba triguera

Lolium rigidium Gaudin Vallico, margal

Phleum pratense $\mathrm{L}$ Hierba macerguera, bohordillo

Poa pratensis $\mathrm{L}$ Poa común, grama de prado

Poa trivialis L. Poa común, gramilla, espiguilla

\section{Familia Leguminosae o Fabaceae - Leguminosas}

Hedysarum coronarium $\mathrm{L}$. Sulla, zulla, pipirigallo, esparceta roja

Lotus corniculatus L. .Cuernecillo, cornajuelos, trébol amarillo o de cuernos

Medicago sativa $\mathrm{L}$. Alfalfa, mielga, lucerna

Medicago polymorpha $\mathrm{L}$. Alfalfa de secano, carretón

Pisium sativum $L$. arveja, guisante, chícharo

Trifolium pratense $\mathrm{L}$. ..Trébol rojo o violeta

Trifolium repens $\mathrm{L}$. Trébol blanco

Trifolium subterraneum $\mathrm{L}$. Trébol subterráneo

\section{Familia Compositae o Asteraceae - Compuestas}

Chrysanthemum coronarium $\mathrm{L}$ Cristantemo silvestre, mojigato

Esta información se consultó en las siguientes bases de datos:

Flora Ibérica. Plantas vasculares de la Península Ibérica e Islas Baleares. Real Jardín Botánico (CSIC). http://www.floraiberica.es/index.php.

Herbario de la Universidad Pública de Navarra (UPNA). Departamento de Ciencias del Medio Natural (Universidad Pública de Navarra). http://www.unavarra.es/servicio/herbario/index.htm. 


\section{Anexo 3: Publicaciones}

García-Moreno, C., Peña-Egido, M. J., Rivas-Gonzalo, J. C., Rodríguez Castañedas, J .L. (2005). Informe nutricional sobre la leche de oveja. Encargado por Leche Gaza. Departamento Química Analítica, Nutrición y Bromatología. Diciembre 2005.

Rodríguez Castañedas, J. L., Peña-Egido, M. J., García Marino, M., García-Moreno, C. (2011). Quantitative determination of conjugated linoleic acid isomers by silver ion HPLC in ewe milk fat. Journal of Food Composition and Analysis 24: 1004-1008.

Rodríguez Castañedas, J. L., García-Moreno, C., Peña-Egido, M. J. Contenido de isómeros CLA en leche de oveja UHT semidesnatada. Influencia del proceso y variación estacional. En fase de redacción.

Rodríguez Castañedas, J. L., Peña-Egido, M. J., García-Moreno, C. Isómeros CLA en yogur y cuajada de leche de oveja. En fase de redacción. 